\title{
Transect HYD-01C
}

\author{
Expedition 325 Scientists $^{2}$
}

\section{Chapter contents}

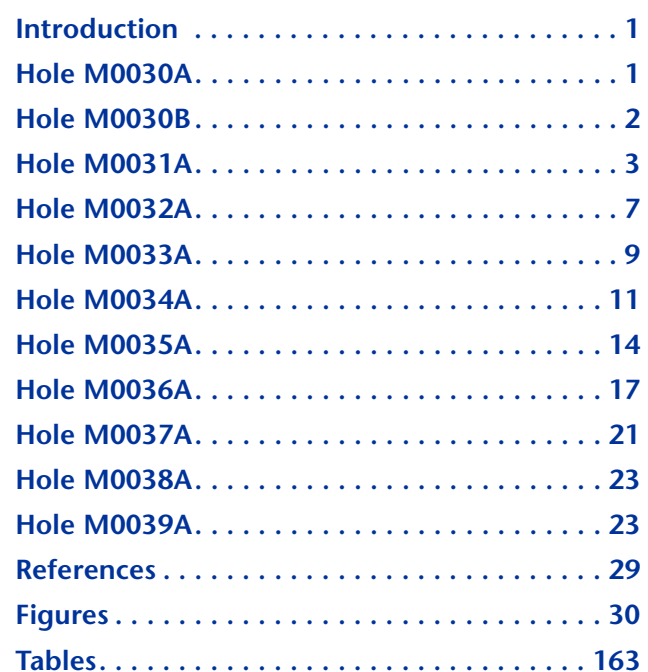

${ }^{1}$ Expedition 325 Scientists, 2011. Transect HYD01C. In Webster, J.M., Yokoyama, Y., Cotterill, C., and the Expedition 325 Scientists, Proc. IODP, 325: Tokyo (Integrated Ocean Drilling Program Management International, Inc.). doi:10.2204/iodp.proc.325.103.2011

'Expedition 325 Scientists' addresses.

\section{Introduction}

During Integrated Ocean Drilling Program (IODP) Expedition 325, cores were recovered from 11 holes (6 sites) at Hydrographer's Passage, comprising transect HYD-01C (Holes M0030AM0039A) (Fig. F1), with an average transect recovery of $27.05 \%$ of the drilled length. Water depths ranged from 51.0 to $122.29 \mathrm{~m}$ (lowest astronomical tide) and were taken from tidally corrected EM300 multibeam bathymetry data. Existing data sets were evaluated prior to arrival at each site, and drilling targets and their respective coordinates were chosen from within the agreed area approved by the IODP Environmental Protection and Safety Panel.

\section{Hole M0030A}

\section{Operations}

\section{Transit to transect HYD-01C}

The Greatship Maya departed for IODP Hole M0030A on transect HYD-01C at $2100 \mathrm{~h}$ on 11 February 2010 after spending $53 \mathrm{~h}$ in port. For the first $16 \mathrm{~h}$, transit speed was a maximum of $5 \mathrm{kt}$ because of water coming up through the moonpool door and ingressing into the engine room via a faulty hatch. Once the hatch was repaired, the transit speed was slowly increased to $12 \mathrm{kt}$ from $1300 \mathrm{~h}$ onward. There was also a problem with the vessel's air conditioning system for $24 \mathrm{~h}$ after departing Townsville, Australia, which was rectified by the engineering crew onboard.

\section{Site 5, Hole M0030A}

The Greatship Maya arrived on station over Hole M0030A at 2315 h on 12 February 2010 (Table T1) and proceeded to begin tests on the dynamic positioning system. The initial spin test revealed an offset of $12 \mathrm{~m}$, as the center of the vessel had not been correctly set to rotate around the drillstring in the moonpool. Corrections were made and further spin tests conducted until $0200 \mathrm{~h}$ on 13 February. The HiPap seabed transponder was deployed, and at $0223 \mathrm{~h}$ the bridge gave the go-ahead to commence coring operations. By 0520 h, the American Petroleum Institute (API) pipe had been run to $5 \mathrm{~m}$ above the seabed, and the downpipe camera was deployed for a precoring seabed survey to make sure the position was devoid of live coral. It was noted that there were very strong currents pushing the end of the API pipe. 
At $0610 \mathrm{~h}$, the camera became stuck on recovery when the cable wrapped around the camera frame inside the API pipe. By $0625 \mathrm{~h}$, the camera was at the top of the string but again caught, so the cable was cut and the camera recovered. By $0700 \mathrm{~h}$, API pipe was being run to tag the seabed, and the first core was on deck at $0945 \mathrm{~h}$. Runs 1 and 2 were conducted using the standard rotary corer (ALN) barrel and Run 3 using the extended nose corer. However, during the extended nose corer run the shoe became blocked with loose carbonate sand, so the coring strategy was altered, pumping the ALN barrel back down with seawater and coring with seawater flushing. However, at $1345 \mathrm{~h}$, the overshot wire became slack and entangled when deployed to recover the ALN barrel and had to be cut. By $1700 \mathrm{~h}$, the wireline had been recovered, but the overshot had been left inside the API pipe, as the shackle had broken. This required tripping of the string to recover the barrel and overshot, thereby terminating the hole at 6 meters below seafloor (mbsf) with an average recovery of $4 \%$. Recovery of the barrel and overshot was completed by $1730 \mathrm{~h}$, and the chaser on the overshot was found to have jammed in the first API pipe. Repairs were conducted on the overshot chaser and the wireline between 1730 and $2005 \mathrm{~h}$. It was decided to core the same location (Hole M0030B).

\section{Sedimentology and biological assemblages}

Hole M0030A had low recovery (4\%) and is divided into two distinct lithostratigraphic units.

\section{Unit 1: Section 325-M0030A-1R-CC: living coralline crusts}

The uppermost Unit 1, consisting of the $6 \mathrm{~cm}$ recovered in Section 325-M0030A-1R-CC, is composed largely of recently live coralline algae "bindstone" (Fig. F2). There are no visible corals.

\section{Unit 2: Section 325-M0030A-2R-CC: unconsolidated sediment}

The lowermost Unit 2, consisting of the $18 \mathrm{~cm}$ of Section 325-M0030A-2R-CC, is composed of fine to coarse lime sand containing bioclasts of mollusks, echinoids, and abundant larger foraminifera, including well-preserved specimens of Cycloclypeus and Operculina. There are no visible corals.

\section{Physical properties}

Because of limited recovery (4\%) from Hole M0030A ( $0.24 \mathrm{~m}$ total recovery from $6 \mathrm{~m}$ drilling depth below seafloor [DSF-A]), very few petrophysical measurements were taken (Table T2). This section summa- rizes the petrophysical data acquired both offshore and at the Onshore Science Party in Bremen.

\section{Digital line scans and color reflectance}

Two cores were measured from Hole M0030A using a digital line scan system with all data recorded at a resolution of $150 \mathrm{pixel} / \mathrm{cm}$ as both images and redgreen-blue (RGB) values. Both cores were also scanned for color reflectance (Fig. F3). Color reflectance $\mathrm{L}^{*}$ in Hole M0030A varies between $54.71 \%$ and $68.08 \%$. The shallowest core measured (Section 325M0030A-1R-1) is composed mainly of a coralline algae bindstone and has lower reflectance and higher $a^{*}$ and $b^{*}$ values than Section 325-M0030A-2X-1, which is composed of lime sand. Because of the low recovery in this hole, no obvious trends are observed with depth.

\section{Paleomagnetism}

Measurements of low-field and mass-specific magnetic susceptibility $(\chi)$ were performed on samples taken from the working half of the recovered core (Table T3). Low positive susceptibilities occur throughout the cores, ranging from $0.23 \times 10^{-8}$ to $1.72 \times 10^{-8} \mathrm{~m}^{3} / \mathrm{kg}$. A negative value of $-0.63 \times 10^{-8}$ $\mathrm{m}^{3} / \mathrm{kg}$ was recorded for the sample taken at 3.03 mbsf in Hole M0030B.

\section{Hole M0030B}

\section{Operations}

\section{Site 5, Hole M0030B}

By 2015 h on 13 February 2010, API pipe was being run, and the seabed was tagged at $2215 \mathrm{~h}$ (Table T1). The first standard rotary corer (ALN) core was recovered at $2240 \mathrm{~h}$. At $0030 \mathrm{~h}$ on 14 February, the vessel repositioned to compensate for the strong current, bringing the API pipe back to vertical. Two more ALN cores were run, but on recovering the third at $0100 \mathrm{~h}$, the barrel stuck and the wireline winch cable snapped. This again required tripping the API pipe, so Hole M0030B was terminated at 9 mbsf, with an average core recovery of $6.1 \%$. Between 0200 and $0250 \mathrm{~h}$, operations were suspended while repairs to the roughneck jaw grips were undertaken, and by $0520 \mathrm{~h}$ the bottom-hole assembly was at the drill floor. The barrel remained stuck until flushing with water finally released it at $0545 \mathrm{~h}$, when it was discovered that the ALN bit was split. The decision was made to transit slowly to Site 6, Hole M0031A, while repairs to the wireline winch were completed. The HiPap beacon was recovered, and the vessel departed for Site 6 at $0550 \mathrm{~h}$. 


\section{Sedimentology and biological assemblages}

Hole M0030B had low recovery (6\%) and is divided into three distinct lithostratigraphic units.

\section{Unit 1: interval 325-M0030B-1R-1, 0-8 cm: modern lime sand}

The uppermost Unit 1, consisting of interval 325M0030B-1R-1, $0-8 \mathrm{~cm}$, is composed of fine to medium lime sand. There are no visible corals.

\section{Unit 2: interval 325-M0030B-1R-1, 8-19 cm: modern lime pebbles}

Unit 2, consisting of interval 325-M0030B-1R-1, 18$19 \mathrm{~cm}$, is composed of lime granules and pebbles rich in larger foraminifera, including well-preserved specimens of Cycloclypeus, Elphidiidae, Operculina, and Sphaerogypsina. Coral fragments include Seriatopora and Porites.

\section{Unit 3: Sections 325-M0030B-2R-1 \\ through 3R-1: coralgal boundstone}

The lowermost Unit 3, spanning Sections 325M0030B-2R-1 through 3R-1, consists of fragments of massive corals co-occurring with coralline algae, fragmented larger foraminifera Cycloclypeus and Operculina, and mollusks and probably represents a coralgal boundstone facies.

The only large corals are massive Isopora (Fig. F4) with fragments of Porites, Seriatopora, Tubipora musica, and Stylasterinidae.

\section{Physical properties}

Similar to Hole M0030A, Hole M0030B has limited core recovery (three cores with a total of $\sim 57 \mathrm{~cm}$ ), and consequently there were very few petrophysical measurements taken (Table T2). Cores recovered reached a total depth of $\sim 9.00 \mathrm{~m}$ DSF-A, and recovery was $\sim 6 \%$.

\section{Density and porosity}

Bulk density (multisensor core logger) measurements vary from 1.04 to $1.89 \mathrm{~g} / \mathrm{cm}^{3}$ in cores from Hole M0030B (Fig. F5). The cores are characterized by underfilled sections of mostly unconsolidated pebbles. These core quality issues generally result in underestimation of bulk density values. Two density measurements were taken on discrete samples during the Onshore Science Party, giving values of 1.75 and $2.06 \mathrm{~g} / \mathrm{cm}^{3}$ (Fig. F6).

\section{$P$-wave velocity}

$P$-wave velocity measurements taken on whole cores offshore range from 1607.04 to $1613.83 \mathrm{~m} / \mathrm{s}$ (Fig.
F5). These velocities are very close to that of seawater $(\sim 1500 \mathrm{~m} / \mathrm{s})$ and are indicative of sediments such as silts and silty clays. The single $P$-wave Logger for Discrete Samples measurement taken during the Onshore Science Party on a $20 \mathrm{~mm}$ plug from $3.12 \mathrm{~m}$ core depth below seafloor (CSF-A) had a mean resaturated velocity of $2952 \mathrm{~m} / \mathrm{s}$. This velocity indicates more lithified sediment. The discrepancy between the measurements is likely a function of core quality, with the discrete sample yielding the more reliable data.

\section{Magnetic susceptibility}

Values measured using the multisensor core logger offshore on whole cores range between $-11.43 \times 10^{-5}$ and $2.90 \times 10^{-5} \mathrm{SI}$ (Fig. F5). This range is indicative of a mixture of diamagnetic materials and very weakly magnetic materials.

\section{Electrical resistivity}

Electrical resistivity values range from 0.87 to 18.71 $\Omega \mathrm{m}$ over this short interval (Fig. F5). Values are primarily affected by lithology, pore fluid, and salinity, as well as core liner saturation.

\section{Digital line scans and color reflectance}

All three cores from Hole M0030B were measured using a digital line scan system with all data recorded at a resolution of $150 \mathrm{pixel} / \mathrm{cm}$ as both images and RGB values. Cores were not appropriate for measurement with the color reflectance sensor.

\section{Paleomagnetism}

For a discussion of paleomagnetism results from Hole M0030B, see "Paleomagnetism" in "Hole M0030A."

\section{Hole M0031A}

\section{Operations}

\section{Site 6, Hole M0031A}

The Greatship Maya arrived on station at Site 6 at $0730 \mathrm{~h}$ on 14 February 2010 (Table T1). While the vessel established a dynamic positioning model, the overshot tools were tested. Running of the API pipe commenced at $0830 \mathrm{~h}$. The downpipe camera was deployed for the precoring survey at $1030 \mathrm{~h}$ but was not working; possibly due to a faulty light. The camera was recovered, repaired, and deployed again, but it stuck $\sim 1 \mathrm{~m}$ from the end of the bottom-hole assembly because of a bent lifter loop jamming in the narrowest section of the bottom-hole assembly. The 
problem was rectified, and the precoring survey was completed by $1755 \mathrm{~h}$.

The first standard rotary corer core was recovered at $1825 \mathrm{~h}$ on 14 February, and coring operations continued until $0140 \mathrm{~h}$ on 16 February. However, problems occurred throughout the operation, including

- Strong currents requiring vessel repositioning five times (each move between 2 and $5 \mathrm{~m}$ );

- Hole collapse requiring reaming and flushing after Run 5 and during deployment of the barrel during Run 6 (9-12 mbsf);

- The inner barrel being stuck inside the outer barrel because of compacted sediment after Runs 6, 11, and 12;

- A 2 h downtime between 0530 and $0730 \mathrm{~h}$ to fix the mud pump;

- The barrel becoming stuck after Run 9, requiring three attempts to free it and retermination of the overshot wire (1015 and $1155 \mathrm{~h}$ ) and reaming prior to Run 10;

- Further reaming following a hole collapse after Run 15; and

- High pressure indicating a blocked bit during Run 16 , resulting in very limited recovery.

The hole was terminated after 17 runs at 43 mbsf with an average recovery of $13.2 \%$, and preparations were made to begin downhole through-pipe gamma logging. The through-pipe gamma sonde was deployed at $0230 \mathrm{~h}$ and was recovered back onto deck at $0755 \mathrm{~h}$. The API pipe was then tripped to $7 \mathrm{~m}$ above the seabed by $0855 \mathrm{~h}$, and a postcoring downpipe camera survey was conducted. The camera was left inside the API pipe for the transit. The Greatship Maya departed Hole M0031A at 0945 h on to transit slowly (under dynamic positioning) to Hole M0032A, $15 \mathrm{~m}$ away.

\section{Sedimentology and biological assemblages}

Hole M0031A is divided into five lithostratigraphic units.

\section{Unit 1: Sections 325-M0031A-2R-1 through 3R-1: coralgal boundstone}

The uppermost Unit 1, spanning Sections 325M0031A-2R-1 through 3R-1, consists of coralgal boundstone fragments with internal sediment and minor stromatolitic microbialite. Bryozoans cooccur with Halimeda in the internal sediment of the boundstone. Coralline algae form complex crusts of contorted plants. Most corals and coralline algae are bioeroded. A distinctive surface in the boundstone at
$17 \mathrm{~cm}$ in Section 325-M0031A-2R-1 is stained brown and is interpreted as a hardground (Fig. F7).

The dominant corals are massive Isopora (Fig. F8) associated with branching Pocilloporidae. Loose fragments include small pieces of Montipora, Acropora, and Pectiniidae.

\section{Unit 2: Sections 325-M0031A-3R-CC through 8R-CC: coralgal-microbialite boundstone}

Unit 2, spanning Sections 325-M0031A-3R-CC through 8R-CC, consists of poorly recovered, coralgal-microbialite boundstone that was highly disturbed during drilling. Fragments contain coral encrusted by thick coralline algae and microbialite, plus a few bryozoans. Internal bioclastic sediment with Halimeda is also visible. Gravel-sized sediment contains a few specimens of the foraminifera Alveolinella and Amphistegina. The boundstone is bioeroded locally by bivalves and sponges.

The coral assemblage is dominated by massive Isopora and medium-thickness, branching (corymbose?) Acropora (Figs. F9, F10). Other corals include Paulastrea and fragments of branching Pocilloporidae, Seriatopora, and possibly Millepora(?).

\section{Unit 3: Sections 325-M0031A-9R-1 to $15 \mathrm{R}-1,16 \mathrm{~cm}$ : unconsolidated sediment}

Unit 3, spanning Sections 325-M0031A-9R-1 to 15R$1,16 \mathrm{~cm}$, consists of unconsolidated lime sand, granules, and pebbles. Major components include fragments of corals, Halimeda, mollusks, and echinoid spines. The larger foraminifera Amphistegina, Baculogypsina, and Marginopora are sparsely represented in very coarse grained sediments from interval 325M0031A-13R-1, 45-50 cm, whereas Alveolinella, Amphistegina, Baculogypsina, Planorbulinella, and Sphaerogypsina are common in coarse-grained sediments from interval 13R-1, 115-120 cm.

Some rock fragments probably come from the overlying boundstones. It is difficult to determine whether all loose rock fragments are the result of downhole contamination or whether some of the unconsolidated sand and gravel represent the original in situ sediment within this interval. Section 325-M0031A-11R-1 includes larger fragments of coralgal framestone.

The few large corals in this unit are medium thickness, branching (corymbose?) Acropora or massive Poritidae. Fragments of other corals include Seriatopora, Pocillopora, Montastrea, Pavona turbinaria(?), Tubipora, Montipora(?), and Palauastrea(?). 
Unit 4: interval 325-M0031A-15R-1, 16-23 cm: grainstone

Unit 4, consisting of interval 325-M0031A-15R-1, $16-23 \mathrm{~cm}$, is composed of a grainstone of larger foraminifera, coralline algae, and mollusks (Fig. F11). Coral fragments include Turbinaria, Poritidae, Faviidae, and Coscinaraea(?).

\section{Unit 5: Sections 325-M0031A-16R-1 through 17R-CC: unconsolidated sediment}

The lowermost Unit 5, spanning Sections 325M0031A-16R-1 through 17R-CC, consists of unconsolidated coarse lime sand, granules, and pebbles. The coarse sand sediment has horizontal laminae. Major components are fragments of coral, Halimeda, mollusks, larger foraminifera (black-stained specimens of Rotallidae [Amphistegina or Elphidiidae]), and echinoids. The uppermost part of Unit 5 contains a large fragment of Tridacna (Fig. F12). Because some of these fragments are clearly derived from the overlying boundstones, coarser particles in this unit can be interpreted partly as downhole contamination.

There are no large corals, but coral fragments include parts of branching colonies of Seriatopora, Acropora, and unidentified Acroporidae and Pocillporidae.

\section{Physical properties}

Hole M0031A was drilled to $43 \mathrm{~m}$ DSF-A with a total of $5.68 \mathrm{~m}$ of core recovered equating to $13.21 \%$ recovery. Physical property data acquired in this hole are summarized in Table T2.

\section{Density and porosity}

Bulk density values from whole-core multisensor core logger (MSCL) measurements range from 1.03 to $2.37 \mathrm{~g} / \mathrm{cm}^{3}$ (Fig. F13). Bulk density from discrete samples varies between 1.79 and $2.40 \mathrm{~g} / \mathrm{cm}^{3}$, and porosity varies between $23 \%$ and $55 \%$ (Fig. F14). Grain density is higher (as much as $2.83 \mathrm{~g} / \mathrm{cm}^{3}$ ) in the bottom of the borehole (20-40 m CSF-A) than in the top (as much as $2.73 \mathrm{~g} / \mathrm{cm}^{3} ; 0-20 \mathrm{~m}$ CSF-A). These measurements are difficult to compare with the MSCL bulk density measurements because of core quality (see "Quality assurance and quality control" in the "Methods" chapter). However, discrete density measurements are, overall, higher than whole-core measurements, as might be expected. Rocks recovered from the borehole are very heterogeneous, with many lithologies changing rapidly with depth (for example, lime pebbles, coral, boundstone, lime granules, framestone, lime sand, etc.). It is therefore diffi- cult to relate porosity directly with observed lithology.

\section{$\boldsymbol{P}$-wave velocity}

$P$-wave velocity measurements taken on whole cores offshore ranged from 1675.08 to $1736.35 \mathrm{~m} / \mathrm{s}$ (Fig. F13). These velocities are very close to that of seawater $(1500 \mathrm{~m} / \mathrm{s})$ and are therefore indicative of unconsolidated sediments. Discrete samples from this hole were not available for $P$-wave analysis.

\section{Magnetic susceptibility}

For Hole M0031A cores, MSCL magnetic susceptibility was measured using a $1 \mathrm{~cm}$ sampling interval with the $80 \mathrm{~mm}$ loop (Fig. F13). Values range from $-1.28 \times 10^{-5}$ to $49.67 \times 10^{-5} \mathrm{SI}$, with the majority of values falling within the 0 to $10 \times 10^{-5}$ SI range. Owing to core recovery, it is difficult to comment on downhole trends. However, it is clear that in Section 325-M0031A-10R-1 at 20.56 m CSF-A, magnetic susceptibility is elevated relative to the cores above and below. In this section, magnetic susceptibility decreases downsection from a high of $49.67 \times 10^{-5}$ to $11.82 \times 10^{-5}$ SI at the section base.

\section{Electrical resistivity}

Electrical resistivity is primarily affected by lithology, pore fluid, and salinity, as well as core liner saturation. Resistivity is highly variable from low values of $0.74 \Omega \mathrm{m}$ to high values of $37.51 \Omega \mathrm{m}$ (Fig. F13). Notable intervals of high resistivity occur in Sections 325M0031A-2R-1, 7R-1, and 11R-1 ( 3, 12, and 23.6 $\mathrm{m}$ CSF-A, respectively). The lowest resistivity is registered at 28-29.60 m CSF-A.

\section{Digital line scans and color reflectance}

All cores from Hole M0031A were measured using a digital line scan system with all data recorded at a resolution of $150 \mathrm{pixel} / \mathrm{cm}$ as both images and RGB values. Color reflectance $L^{*}$ varies between $30.81 \%$ and $82.37 \%$ (Fig. F15). In general, reflectance values of coral framework were higher than those for carbonate sediments. Lime pebbles and fragments of microbialite and coral were common in this hole, and where sections were composed only of these fragments, no color reflectance measurements were taken because of the lack of flat surfaces (see "Physical properties" in the "Methods" chapter). The variation in the color of the microbialites is not due to measurements being taken on an uneven surface but rather to the frequent natural changes in color of this type of material. Deeper samples showed lower values for $\mathrm{a}^{*}$ entering the negative range of green 
color and also lower values of $b^{*}$, close to zero in some cases and very close to the blue color scale. The presence of a slight change in the colors is more easily observed in the ratio $\mathrm{a}^{*} / \mathrm{b}^{*}$, which is a better indicator of cyclic variations (Blum, 1997).

\section{Paleomagnetism}

Measurements of low-field and mass-specific magnetic susceptibility $(\chi)$ were performed on samples taken from the working half of the recovered core (Fig. F16). Low positive susceptibility values occur throughout the core, with an arithmetic mean of $0.84 \times 10^{-8} \mathrm{~m}^{3} / \mathrm{kg}$. Two peaks were also recorded, at 8.70 and 20.64 mbsf, with maximum values of 4.82 $\times 10^{-8}$ and $5.38 \times 10^{-8} \mathrm{~m}^{3} / \mathrm{kg}$, respectively. At 18.16 and $31.06 \mathrm{mbsf}$, two samples recorded low negative susceptibility values of $-1.09 \times 10^{-8}$ and $-0.17 \times 10^{-8}$ $\mathrm{m}^{3} / \mathrm{kg}$.

\section{Chronology}

Two calibrated radiocarbon ages (13 calibrated years before present [cal y BP; years before $1950 \mathrm{AD}$ ], Core 325-M0031A-2R; 17 cal y BP, Core 8R) (Fig. F17) and one U-Th age (25 cal y BP, Core 16R) (Table T10 in the "Methods" chapter) are consistent with their stratigraphic positions. The U-Th age is unaffected by corrections for initial ${ }^{230} \mathrm{Th}$, adding to the confidence in this age interpretation. This hole has recovered material from the Last Glacial Maximum interval and has captured the early stage of the deglaciation to $\sim 13$ cal y BP.

\section{Downhole measurements}

Geophysical wireline operations were completed in Hole M0031A to a depth of $36.37 \mathrm{~m}$ wireline matched depth below seafloor (WMSF) (seafloor picked from the log data) with the ANTARES Spectral Natural Gamma Probe (ASGR), one of the slimhole tools from the available logging tool suite (see "Downhole logging" in the "Methods" chapter). Recovery in Hole M0031A was just over 13\%. Therefore, wireline logging was performed to identify main boundaries in the borehole sequence and provide a continuous dataset. The ASGR log was acquired through the API pipe. In carbonate lithologies, where counts are normally very low, data were further attenuated by the presence of the drill pipe. Ideally, following logging through pipe the ASGR probe would be run in open-hole conditions and the signals compared and depth-matched for quality assurance/quality control. However, because of poor hole stability, this was not possible at this site.
Total natural gamma radiation (TGR) is very low ( 12.2 cps) despite logging speeds of $1 \mathrm{~m} / \mathrm{min}$ (Fig. F18). Although there is no clear differentiation between contributions of the different elements, changes in the concentration of uranium appear to coincide with the majority of variations in TGR. In order to identify statistically accurate results, negative component values (i.e., negative concentrations of potassium, uranium, and thorium) were removed from the dataset. When interpolated (assuming a gap between data points no greater than $10 \mathrm{~m}$ ), both the original and cleaned datasets exhibit similar trends.

Three (or four) logging units can be identified in Hole M0031A (Fig. F18):

1. Unit I/Unit II (0-14.48 m WMSF; Cores 325M0031A-2R through 7R) is characterized by TGR counts as high as $8 \mathrm{cps}$. The number of counts fluctuates throughout and reaches a low of $\sim 3$ cps at $5.25 \mathrm{~m}$ WMSF. The minimum TGR (cps) is where a tentative divide has been made between Unit I and Unit II; however, it is more logical that these units are grouped as one. The TGR low may reflect the change from a coralgal boundstone unit to a coralgal-microbialite boundstone unit. These two logging units fit well with the described lithostratigraphic units and hence link a relatively high TGR signal with both coralgal and coralgal-microbialite boundstones.

2. Unit III (14.48-25.31 m WMSF; Cores 325M0031A-8R through 11R) represents a zone of consistently low (relatively) TGR counts ranging from $\sim 2.3$ to $5.28 \mathrm{cps}$. This relates to a large zone described as unconsolidated sediments. Recovered core material comprises lime sand, granules, and pebbles. It is difficult to be certain whether all the observed loose fragments are a result of downhole contamination or if some of this material is in situ. Some areas of larger fragments are possibly derived from the coralgal boundstone units.

3. Unit IV (25.31-36.37 m WMSF; Cores 325M0031A-12R through 17R) is characterized by a zone of increasing TGR counts with depth. Values range from $\sim 2.9$ to $\sim 10 \mathrm{cps}$. The lithology in this zone is typified by a very thin grainstone unit at $\sim 31$ m CSF-A surrounded by unconsolidated sediments. The bottom portion of this hole comprises some coarser sand sediment with horizontal laminae. The sediment consists of benthic foraminifera, coral fragments, and echinoids. There is uncertainty regarding 
whether some of the larger particles/fragments in these sediments represent contamination from higher in the borehole.

Note that the total hole depth for Hole M0031A from the logging data is $\sim 4 \mathrm{~m}$ shallower than that from the drilling depth below seafloor. Downhole logging represents a method of continuous data acquisition uphole. The location/depth of the seafloor is picked from a spike/positive shift in the gamma ray curve (as done here for Hole M0031A). Often there are small differences in core and wireline depth. In this instance, it is noted that there is a discrepancy of $-3 \mathrm{~m}$ between the lithostratigraphic unit boundary depths identified in the TGR data. Further work may be able to refine the core-log depth relationship, resulting in a closer correlation between an area of consistently relatively high TGR counts with the boundstone units.

\section{Hole M0032A}

\section{Operations}

\section{Site 6, Hole M0032A}

At 0952 h on 16 February 2010, the Greatship Maya was settled on station over Hole M0032A and a downpipe camera survey was conducted (Table T1). At $1050 \mathrm{~h}$, an additional API pipe was added, and coring operations commenced at $1115 \mathrm{~h}$ using metal splits. The string overpressurized on the first run, and the standard rotary corer was tripped to free it. There was also evidence of hole caving and overpressurizing on the second run. However, coring then progressed steadily until $2355 \mathrm{~h}$, when the bit became blocked with sediment during Run 12 (liner tubes were used for Runs 5-15 instead of the metal splits). Runs 14-16 (metal splits used for Run 16) took from 0155 to $0515 \mathrm{~h}$ on 17 February to complete. Between 0515 and $0555 \mathrm{~h}$ there was a delay in operations for refueling the hydraulic power packs. Coring then continued to the end of the hole at $0925 \mathrm{~h}$ at $36.7 \mathrm{mbsf}$ (average recovery $=16.3 \%$ ).

The API pipe was tripped to $5 \mathrm{~m}$ above the seabed, and at $1015 \mathrm{~h}$ the downpipe camera was deployed for a seabed survey. Once this was completed and the camera was recovered at $1110 \mathrm{~h}$, the hydraulic power packs were shut down for maintenance until $1330 \mathrm{~h}$, when the vessel departed for Site 6, Hole M0033A.

\section{Sedimentology and biological assemblages}

Hole M0032A is divided into four distinct lithostratigraphic units.

\section{Unit 1: Section 325-M0032A-1R-1: coralgal boundstone}

The uppermost Unit 1, consisting only of Section $325-\mathrm{M} 0032 \mathrm{~A}-1 \mathrm{R}-1$, is composed of fragments of coralline algae and coral bindstone with serpulid worm tubes, bivalves, gastropods, and Halimeda. Recently living coralline algae, now dead, are present at the very top of the section. Reddish staining is common within the bindstone.

The dominant corals are submassive to massive colonies of Montipora (Fig. F19) plus fragments of Montipora and some foliaceous coral fragments.

\section{Unit 2: Sections 325-M0032A-1R-CC through 14R-CC: coralgal-microbialite boundstone}

The thick Unit 2, spanning Sections 325-M0032A1R-CC through 14R-CC, consists of coralgal-microbialite boundstone (Fig. F20). The boundstone is composed mainly of massive corals covered with crusts of nongeniculate coralline algae, which, in turn, are covered by thick microbialites. In some cases, coralline algae alternate with microbialite crusts (Fig. F21). Microbialites are dark colored and generally weakly to clearly laminated, with alternating darker and lighter laminae (Fig. F20). Bioclasts (Halimeda segments, molluscan shell fragments, and foraminifera) are imbedded in the microbialites. Some internal bioclastic sediment is also visible. Reddish-stained cavities are scattered through Section 325-M0032A-11R-1 (Fig. F22).

The dominant corals are massive Isopora (Fig. F23) and Faviidae, followed by branching Pocillopora, Acropora, and Seriatopora (Fig. F24). Associated corals include submassive Porites, Faviidae, Tubipora musica, Leptoseris(?), and Montipora(?). The same taxa are also abundant as small fragments. Corals are bioeroded locally.

\section{Unit 3: Sections 325-M0032A-15R-1 through 16R-CC: unconsolidated sediment}

Unit 3, spanning Sections 325-M0032A-15R-1 through 16R-CC, consists mostly of unconsolidated lime sand with lime granules and pebbles. Major components are fragments of coral, some with coralline algal crusts. The larger foraminifera Baculogypsina, Calcarina, Gypsina, and Sphaerogypsina are common in sandy gravel sediments from interval 325M0032A-16R-1, 0-5 cm. Mollusks, Halimeda, and echinoid spines also occur. Some of these components may represent downhole contamination during the coring operation. 
Corals are present only as fragments and include $\mathrm{Se}$ riatopora, Pocillopora, Acropora, Leptoseris, Tubipora musica, and Pachyseris(?).

\section{Unit 4: Sections 325-M0032A-18R-1 through 19R-CC: packstone/grainstone}

The lowermost Unit 4, spanning Sections 325M0032A-18R-1 through 19R-CC, consists mainly of packstone/grainstone to rudstone with mollusks, coral, Halimeda, echinoderms, and bryozoans. Gravelly sand sediments from interval 325-M0032A-18RCC, $0-5 \mathrm{~cm}$, contain abundant well-preserved specimens of the larger foraminifer Amphistegina. However, Amphistegina specimens became scarce in the muddy sand from interval 325-M0032A-19R-1, 12$17 \mathrm{~cm}$. An interval in Section 325-M0032A-19R-1 is composed of fragments of corals encrusted by coralline algae and is intercalated with the packstone/ grainstone.

Larger corals are Isopora and Faviidae, associated with fragments of Acropora, Isopora, Montipora, Seriatopora, Faviidae, Tubipora musica, and Stylasterinidae(?).

\section{Physical properties}

Hole M0032A was drilled to $36.70 \mathrm{~m}$ DSF-A. A total of $5.99 \mathrm{~m}$ was recovered (16.32\% recovery). Table T2 summarizes the physical property measurements taken on this core.

\section{Density and porosity}

Bulk density values from whole-core multisensor core logger measurements range from 1.04 to 2.54 $\mathrm{g} / \mathrm{cm}^{3}$ (Fig. F25). The bulk density of discrete samples varies between 2.04 and $2.41 \mathrm{~g} / \mathrm{cm}^{3}$, and porosity varies between $20 \%$ and $41 \%$ (Fig. F26). Grain density is relatively constant with a range of 2.74 to 2.79 $\mathrm{g} / \mathrm{cm}^{3}$. The heterogeneity downhole is significant and is similar to the previous hole (M0031A). However, the density and porosity parameters have lower variability in this borehole.

\section{P-wave velocity}

$P$-wave velocity measurements taken on whole cores offshore ranged from 1780.70 to $1937.94 \mathrm{~m} / \mathrm{s}$ (Fig. F25). Only one discrete $P$-wave velocity measurement was possible in Hole M0032A, sampled at 16.38 to $16.40 \mathrm{~m}$ CSF-A. The drilled plug is a mixture of coral and coralline algae and has a mean resaturated velocity of $5037 \mathrm{~m} / \mathrm{s}$.

\section{Magnetic susceptibility}

In Hole M0032A, multisensor core logger magnetic susceptibility values range from $-1.90 \times 10^{-5}$ to 12.07 $\times 10^{-5} \mathrm{SI}$, with most values being close to zero. There are two clear exceptions to this where there are magnetic susceptibility highs. The first of these is encountered in Section 325-M0032A-4R-1 (7.95 m CSFA), where values climb to $5.69 \times 10^{-5} \mathrm{SI}$. The second is deeper in the hole (17.61 m CSF-A) in Section 325M0032A-10R-1, where the maximum magnetic susceptibility value for the hole is reached $\left(12.07 \times 10^{-5}\right.$ SI).

\section{Electrical resistivity}

Electrical resistivity is affected by pore fluid and salinity, as well as core liner saturation and core quality. In Hole M0032A, resistivity ranges from low values of $0.59 \Omega \mathrm{m}$ to higher values of $12.10 \Omega \mathrm{m}$ (Fig. F25). The highest resistivity occurs in Sections 325M0032A-1R-1 and 8R-2. The lowest resistivity is registered at $\sim 12-13 \mathrm{~m}$ CSF-A.

\section{Digital line scans and color reflectance}

All cores from Hole M0032A were measured using the digital line scan system with all data recorded at a resolution of $150 \mathrm{pixel} / \mathrm{cm}$ as both images and RGB values. All appropriate cores were also scanned for color reflectance. Color reflectance $\mathrm{L}^{*}$ in Hole M0032A varies between $45.03 \%$ and $82.69 \%$ (Fig. F27). Variations in color reflectance parameters slightly decrease in reflectance with depth. The first unit (0-5 m CSF-A), which presented a heterogeneous lithology, showed a wider spectrum of values in the color reflectance spectrophotometry. Lithologies in the deepest part of Hole M0032A (18-33 m CSF-A) were very homogeneous in color reflectance characteristics, despite the occurrence of several different lithostratigraphic units (e.g., coralgal-microbialites, unconsolidated sediments, and packstones). The presence of a slight change in color is clearer in the ratio $a^{*} / b^{*}$, which is a better indicator of cyclic variations (Blum, 1997).

\section{Paleomagnetism}

Measurements of low-field and mass-specific magnetic susceptibility $(\chi)$ were performed on samples taken from the working half of the recovered core (Fig. F28). Low positive magnetic susceptibilities occur throughout the core, ranging from $0.019 \times 10^{-8}$ to $0.68 \times 10^{-8} \mathrm{~m}^{3} / \mathrm{kg}$. The measured arithmetic mean 
was $0.27 \times 10^{-8} \mathrm{~m}^{3} / \mathrm{kg}$. Four negative susceptibilities occur at 5.06, 17.62, 23.90, and 32.81 mbsf with susceptibility values of $-0.34 \times 10^{-8},-0.44 \times 10^{-8},-0.02$ $\times 10^{-8}$, and $-0.15 \times 10^{-8} \mathrm{~m}^{3} / \mathrm{kg}$, respectively.

\section{Chronology}

Two calibrated radiocarbon ages (13 cal y BP, Core 325-M0032A-1R; 15 cal y BP, Core 3R) (Fig. F29) and two U-Th ages (20 cal y BP, Core 8R; 61 cal y BP, Core 18R) (Table T10 in the "Methods" chapter) are consistent with their stratigraphic positions. The older U-Th age is unaffected by corrections for initial ${ }^{230} \mathrm{Th}$, adding to the confidence in this age interpretation. However, the younger age of $20 \mathrm{cal} \mathrm{y} \mathrm{BP} \mathrm{from}$ Core $325-\mathrm{M} 0031 \mathrm{~A}-8 \mathrm{R}$ is made significantly younger by these corrections. This hole recovered material from the Last Glacial Maximum interval and captured the early portion of the deglaciation to $\sim 13 \mathrm{cal}$ y BP. The deeper portions of this hole recovered older Pleistocene material.

\section{Hole M0033A}

\section{Operations}

\section{Site 6, Hole M0033A}

The vessel was on station at $1353 \mathrm{~h}, 17$ February 2010 (Table T1), after an additional $2 \mathrm{~m}$ move northeast from the original location to avoid the presence of live coral, observed during the precoring downpipe camera survey. At $1445 \mathrm{~h}$, the standard rotary corer core barrel and additional API pipe were run. Run 1 commenced at $1510 \mathrm{~h}$ after a slight delay due to a Differential Global Positioning System dropout. Coring operations continued until $0000 \mathrm{~h}$, and then the compressors and power packs were refueled until $0025 \mathrm{~h}$ on 18 February. Coring then restarted until $0530 \mathrm{~h}$, when the barrel stuck on Run 16. It was recovered after 30 min but had a broken latch lug on recovery. Run 17 was recovered at $0745 \mathrm{~h}$ after the water pressure spiked. The liner tube was crushed and stuck inside the barrel, with an extruded lug halfway down the barrel, reducing operations to one fully functional core barrel while the liner was removed. Coring continued for another six runs before the hole was terminated at $1335 \mathrm{~h}$ at $32.8 \mathrm{mbsf}$, with an average recovery of $40.9 \%$.

API pipe was tripped to just above the seabed before the downpipe camera was deployed at $1435 \mathrm{~h}$. However, the camera would not pass through the final 3$4 \mathrm{~m}$ of the bottom-hole assembly, and the wireline became twisted. The wireline was quickly untwisted from the top of the derrick, but the camera would still not pass through the bottom-hole assembly, so the camera survey was aborted at $1540 \mathrm{~h}$ without running a postcoring survey. The camera was recovered to deck by $1600 \mathrm{~h}$. By $1725 \mathrm{~h}$, the remainder of the API pipe was tripped, and the vessel began a slow $(1 \mathrm{kt})$ transit to Site 3 in order to allow for repairs to the roughneck slips.

\section{Sedimentology and biological assemblages}

Hole M0033A is divided into five lithostratigraphic units.

\section{Unit 1: Sections 325-M0033A-1R-1 through 1R-CC: coralgal boundstone}

The uppermost Unit 1, spanning Sections 325M0033A-1R-1 through 1R-CC, consists of fragments of coralgal boundstone. The uppermost interval 325M0033A-1R-1, 0-45 cm, consists of heavily bored, brown-stained boundstone with coral and internal sediment. Coralline algae form an open framework of thin plants on corals (Porites), which, in turn, overlie or are surrounded by packstone with coral, Halimeda, mollusk, benthic foraminiferal, and coralline algal fragments. These deposits are bioeroded with brown stains.

This unit is dominated by a massive Porites colony with associated pieces of massive Montipora(?) and Goniopora(?).

\section{Unit 2: Sections 325-M0033A-2R-1 \\ to $11 \mathrm{R}-1,19 \mathrm{~cm}$ : coralgal-microbialite boundstone}

Unit 2, spanning Sections 325-M0033A-2R-1 to 11R$1,19 \mathrm{~cm}$ (Fig. F30), consists of coralgal-microbialite boundstone (Fig. F31). Relative proportions of corals (Fig. F32), coralline algae, and microbialites in the boundstone vary considerably throughout the unit. Coralline algae alternate with microbialite crusts containing trapped bioclasts. Vermetids intergrown with coralline algae are common (Fig. F33). Bryozoans and serpulids are visible locally. Coralline algae occur as thick crusts overgrowing corals or as irregular, contorted structures intergrown with microbialites. Microbialites are usually dark colored with poorly defined laminae or alternating darker and lighter laminae. Some internal bioclastic sediment with Halimeda occurs throughout this unit. The boundstone is bioeroded locally by bivalves and sponges. The larger foraminifera Amphistegina and Operculina are present, but scarce, in muddy gravels from interval 325-M0033A-3R-1, 11-16 cm.

The dominant corals are massive Isopora colonies associated with medium-thickness branching (digitate) Acropora (Figs. F31, F34) and fine-branching Pocilloporidae. Coral fragments include Isopora, Pocillopora, Tubipora musica, and Fungiidae. 
Unit 3: Sections 325-M0033A-11R-1, $19 \mathrm{~cm}$, through 19R-CC: coralgal-microbialite boundstone with geopetal fabrics

Unit 3, spanning Sections 325-M0033A-11R-1, 19 $\mathrm{cm}$, through 19R-CC, also consists of coralgal-microbialite boundstone. Although the components and main features of this boundstone are similar to those of Unit 2, Unit 3 has a higher proportion of internal sediment and also contains geopetal fabrics in borings, intraskeletal voids, and small cavities (Fig. F35). The internal sediment consists of wackestone/packstone to floatstone rich in mollusks, Halimeda, bryozoans, echinoids, larger foraminifera, and coralline algae that locally form small rhodoliths. As in Unit 2 , relative proportions of corals, coralline algae, and microbialites vary substantially, but the three components seem to cycle repeatedly throughout the unit. Microbialites are mainly stromatolitic and commonly contain trapped bioclasts (Fig. F36). Bioerosion tends to be concentrated in the outer parts of corals but also affects some other components of the boundstone.

The coral assemblage is diverse and dominated by Faviidae (mainly Favia) (Figs. F37, F38), branching Acropora, fine-branched Seriatopora, and thicker Pocillopora branches (Fig. F39). Other common corals are Montipora, Porites, Tubipora musica (Fig. F40), Fungiidae, Psammocora(?), and Agariciidae(?). Fragments include all of the above corals plus Cyphastrea and Siderastreidae.

\section{Unit 4: Core 325-M0033A-20R through Section 22R-1: unconsolidated sediment}

Unit 4, spanning Core 325-M0033A-20R through Section 22R-1, consists of unconsolidated lime granules and pebbles with minor quantities of sand. Major components include coral fragments, Halimeda, and mollusks (Fig. F41). Larger foraminifera (Alveolinella, Amphistegina, and Soritinae) are common in interval 325-M0033A-22R-1, 40-45 cm, and echinoid spines also occur throughout this interval. Some fragments of the overlying boundstones were identified and are clearly the result of downhole contamination.

There are no large corals, but identifiable fragments include Seriatopora, Porites, and possibly Montipora.

\section{Unit 5: Sections 325-M0033A-22R-CC through 23R-CC: packstone/grainstone}

The lowermost Unit 5, spanning Sections 325M0033A-22R-CC through 325-M0033A-23R-CC, is composed mainly of a dark gray packstone/grainstone. The major components are benthic foraminifera, gastropods, bivalves, coral, Halimeda, larger for- aminifera, echinoderms, and bryozoans. It also includes local occurrences of worm tubes and possible calcareous sponges (Fig. F42). The top of the cemented interval is heavily bored by worm tubes and sponges. The uppermost interval of Section 325M0033A-23R-1, from 0 to $25 \mathrm{~cm}$, contains lime granules to pebbles, similar in composition to the overlying interval, intercalated with the packstone/ grainstone, and probably represents downhole contamination during coring.

There are no large corals, but identifiable fragments include Seriatopora, Porites, and possibly Montipora.

\section{Physical properties}

Hole M0033A was drilled to $32.80 \mathrm{~m}$ DSF-A. A total of $13.41 \mathrm{~m}$ of core was recovered (40.88\% recovery). Petrophysical data acquired from this core are compiled in Table T2.

\section{Density and porosity}

Gamma density values from whole-core multisensor core logger (MSCL) measurements range from 1.00 to $2.53 \mathrm{~g} / \mathrm{cm}^{3}$ (Fig. F43). The bulk density of discrete samples varies between 1.84 and $2.45 \mathrm{~g} / \mathrm{cm}^{3}$, and porosity varies between $18 \%$ and $54 \%$ (Fig. F44). As expected, discrete measurements resulted in values at the higher end of the range exhibited by MSCL measurements. Grain density is nearly constant with a range of 2.76 to $2.84 \mathrm{~g} / \mathrm{cm}^{3}$. Petrophysical properties on the discrete plug samples do show fluctuations. However, it is difficult to compare these values with the MSCL data and/or lithostratigraphic results because of the heterogeneity and/or disturbed nature of the recovered core material.

\section{$\boldsymbol{P}$-wave velocity}

$P$-wave velocity offshore MSCL measurements on whole cores were unsuccessful owing to poor acoustic coupling (function of poor core quality). However, eight discrete samples were collected from Hole M0033A and measured onshore (Fig. F45A). P-wave velocity values from discrete samples range from 3340 to $4712 \mathrm{~m} / \mathrm{s}$ (resaturated). There are two main trends downhole. Between 3.24 and $12.90 \mathrm{~m}$ CSF-A velocity decreases from $4080 \mathrm{~m} / \mathrm{s}$ to the minimum measured here. Velocity then increases to the maximum value $(4712 \mathrm{~m} / \mathrm{s})$ at $14.61 \mathrm{~m} \mathrm{CSF}-\mathrm{A}$ and with depth decreases to $3865 \mathrm{~m} / \mathrm{s}$ (base measurement at $23.91 \mathrm{~m}$ CSF-A). Neither of these packages of decreasing velocity appear to coincide with lithologic changes downhole. Bulk density and $P$-wave velocity measured on discrete samples show similar trends: as bulk density increases, $P$-wave velocity also increases (Fig. F45B). 


\section{Magnetic susceptibility}

The majority of the MSCL magnetic susceptibility data for Hole M0033A is in the range of $-1 \times 10^{-5}$ to 0 SI (Fig. F43). The overall range is $-1.29 \times 10^{-5}$ to 7.17 $\times 10^{-5}$ SI. Two core sections yielded high values of magnetic susceptibility relative to the rest of the hole. These were Sections 325-M0033A-5R-2 (highest value at $7.61 \mathrm{~m} \mathrm{CSF-A)}$ and 8R-1 (highest value at $9.89 \mathrm{~m}$ CSF-A), and in both cases, values were highest at the top of the section, decreasing downsection.

\section{Electrical resistivity}

Electrical resistivity for Hole M0033A cores ranges from low values of $0.77 \Omega \mathrm{m}$ to higher values of 28.86 $\Omega \mathrm{m}$ (Fig. F43). The highest resistivity occurs in Sections 325-M0033A-6R-1 and 9R-1. The lowest resistivity is recorded at $\sim 20 \mathrm{~m}$ CSF-A.

\section{Digital line scans and color reflectance}

All cores from Hole M0033A were measured using the digital line scan system, with all data recorded at a resolution of $150 \mathrm{pixel} / \mathrm{cm}$ as both images and RGB values. All appropriate cores were also scanned for color reflectance. Color reflectance in Hole M0033A varies between $30.86 \%$ and $83.96 \% \mathrm{~L}^{*}$ units (Fig. F46). Variations in color reflectance parameters slightly decrease (6.4\%) in reflectance with depth. The alternation of coralgal-microbialite boundstones and unconsolidated carbonate sediments from 3.3 to $7.2 \mathrm{~m}$ CSF-A produces a greater fluctuation in the values of the three color reflectance parameters $\left(\mathrm{L}^{*}\right.$, $\mathrm{a}^{*}$, and $\mathrm{b}^{*}$ ). A more homogeneous area of carbonate sediment from 25.3 to $29.2 \mathrm{~m}$ CSF-A reflects a slight decrease in reflectance values. In the bottom few meters of Hole M0033A, the presence of a packstone with worm tubes is visible in the $\mathrm{a}^{*} / \mathrm{b}^{*}$ values.

\section{Paleomagnetism}

Measurements of low-field and mass-specific magnetic susceptibility $(\chi)$ were performed on samples taken from the working half of the recovered core (Fig. F47). Four low negative (diamagnetic) susceptibilities were recorded at $0.01,6.03,15.86$, and 16.04 mbsf, with susceptibility values of $-0.39 \times 10^{-8},-0.06$ $\times 10^{-8},-0.16 \times 10^{-8}$, and $-0.01 \times 10^{-8} \mathrm{~m}^{3} / \mathrm{kg}$, respectively. Measured positive core susceptibilities range from $0.07 \times 10^{-8}$ to $1.90 \times 10^{-8} \mathrm{~m}^{3} / \mathrm{kg}$ (with a salient peak at $7.53 \mathrm{mbsf}$ ). The arithmetic mean susceptibility for M0033A cores was $0.38 \times 10^{-8} \mathrm{~m}^{3} / \mathrm{kg}$.

\section{Chronology}

Two calibrated radiocarbon ages (14 cal y BP, Core 325-M0033A-3; 15 cal y BP, Core 7R) (Fig. F48) and one U-Th age (31 cal y BP, Core 15R) (Table T10 in the "Methods" chapter) are consistent with their stratigraphic positions. The U-Th age is made significantly younger by corrections for initial ${ }^{230} \mathrm{Th}$ and is thus less reliable. It is therefore unlikely that Core 325-M0033A-15R has a true age older than the Last Glacial Maximum. This hole recovered material from the Last Glacial Maximum interval and captured the early portion of the deglaciation to $\sim 14$ cal y BP.

\section{Hole M0034A}

\section{Operations}

\section{Site 3, Hole M0034A}

The Greatship Maya was on station and settled on dynamic positioning (DP) at $1825 \mathrm{~h}$ on 18 February 2010 (Table T1). Repairs to the roughneck slips continued while discussions about the best way to hang the HQ pipe were conducted. Between 1925 and $2100 \mathrm{~h}$, the moonpool door was closed. This process took longer than anticipated because of damage sustained during the initial transit from Townsville. At $1900 \mathrm{~h}$, API pipe started being run to just above the seabed. A downpipe camera survey was conducted, and by $2305 \mathrm{~h}$, preparations to run the first core barrel were made. The first standard rotary corer (ALN) core was recovered at $0020 \mathrm{~h}$ on 19 February, and coring continued for another six runs until $0515 \mathrm{~h}$, when preparations began to change to $\mathrm{HQ}$ coring. Running the HQ rods took from 0900 to $1047 \mathrm{~h}$ using the API pipe as an outer casing. Flushing the hole began and continued for $25 \mathrm{~min}$.

The first HQ core (Run 8) was recovered at $1150 \mathrm{~h}$, and HQ coring continued for another four runs until $1500 \mathrm{~h}$, reaching a depth of $18.6 \mathrm{mbsf}$. The bit became blocked during Run 12 and it took 25 min to free it. Flushing then continued until 1525 h. However, the currents had been increasing along with wind speed over the course of coring, and at $1525 \mathrm{~h}$ the HQ rods twisted off $\sim 2 \mathrm{~m}$ below the drill deck. At $1530 \mathrm{~h}$, the vessel was moved to straighten the API pipe, and fishing for the end of the broken HQ pipe began using a casing recovery tap. The recovery tool broke off the rod at $1710 \mathrm{~h}$ and was manually recovered using a pup joint. At $1915 \mathrm{~h}$, an attempt was made to hammer a tap into the broken joint. At $2235 \mathrm{~h}$, an additional API pipe was added, connecting to the joint above the moonpool door, and was pulled back to the slips. Flushing and reaming continued in an attempt to lower the API pipe slightly in the hole, but the hole was by this point caving and periodically forcing the API pipe upward. By $0235 \mathrm{~h}$ on 20 February, the fishing operation could restart, as the top of the API pipe was safely set in the slips at the drill floor. However, another API pipe was added 
at $0310 \mathrm{~h}$, as the pipe was sinking in a softer lithology.

The HQ pipe was tagged at $0345 \mathrm{~h}$, and recovery began. This was completed at $0734 \mathrm{~h}$, when preparations began to change back to API coring using the ALN core barrel. The hole was open-holed with the API pipe back down to 18.6 mbsf. When the ALN barrel was initially deployed, mud pressure spiked and the barrel was recovered without advancing. Two washers were removed from the inner barrel bearing head to increase the shoe/bit air gap, and the barrel was redeployed, with the first core being recovered at $1005 \mathrm{~h}$. Run 15 had poor recovery, so a washer was added to the inner barrel bearing head again to reduce the effect of flushing. However, this caused the pressure to spike again, so the barrel was tripped and a new impregnated bit was put on. Between 1235 and $1310 \mathrm{~h}$, operations halted because repairs were being made on the mud pumps. Four further attempts were then made to core, all of which resulted in no advance and overpressurizing of the drill string. An infill sample from an unknown depth was recovered on one occasion and was curated as Run 16.

At 1518 h, the Greatship Maya lost Differential Global Positioning System (DGPS) corrections and the vessel moved $23 \mathrm{~m}$ off station in $56 \mathrm{~m}$ water depth. The GPS was restored at $1520 \mathrm{~h}$ and DPGS at $1524 \mathrm{~h}$. Although the vessel was manually moved back onto station within $10 \mathrm{~min}$, the API pipe was bent, requiring a full trip. Once the API pipe was on deck (1810 $\mathrm{h})$, three pipes were found to be bent and unusable. Checks were run with the ALN and bottom-hole assembly in the slips, using both liners and metal splits, and no overpressurizing was noted.

Discussions took place between the Master of the Greatship Maya, Chief Engineer, Bluestone Party Chief, European Consortium for Ocean Research Drilling (ECORD) Science Operator (ESO) Operations Superintendant, European Geological Survey Surveyor, Chief Mate, and Chief Electrical Engineer as to why the GPS and DGPS signal had been lost. The Master contacted shore-based GC Rieber personnel for advice and stated that no further drilling operations were to take place until the problem had been rectified, thereby terminating Hole M0034A at 23.1 mbsf with an average recovery of $29.1 \%$. Another GPS drop-out occurred at $2000 \mathrm{~h}$ for $10 \mathrm{~min}$. A passing vessel was contacted, and they had not suffered any loss of signal.

During the early morning of 21 February, the Greatship Maya suffered three power failures due to the bow thrusters ramping up to $100 \%$ without warning and tripping the generator because of overdemand. At 0945 h, it was decided that a secondary, indepen- dent positioning system was required before further drilling could take place. This would hold the vessel on DP should a further GPS/DGPS signal drop-out occur. Permission was sought from the Great Barrier Reef Marine Park Authority (GBRMPA) to use the $3 \mathrm{~m}$ $\times 3 \mathrm{~m}$ seabed template with a HiPap beacon installed on it. The Environmental Management Plan had previously only allowed a $1 \mathrm{~m} \times 1 \mathrm{~m}$ template to be used, which was being pushed off location in the strong currents experienced at Hydrographer's Passage. Notice of permission granted was received from GBRMPA by $1005 \mathrm{~h}$.

It was decided, however, that no coring operations could take place until the secondary power failure issue was rectified. Engine and DP data were downloaded and sent to GC Rieber Singapore, who passed the information onto ConverTeam, who were responsible for the electrical and DP installation. By $2300 \mathrm{~h}$, the vessel crew had identified the problem, run a simulation to ascertain that this was a correct identification, and rectified the issue. At $2330 \mathrm{~h}$, the Master informed the drill floor operations team that he was satisfied that changes to the thruster settings had rectified the problem and that the vessel could move to Site 11, Hole M0035A.

\section{Sedimentology and biological assemblages}

Hole M0034A is divided into four lithostratigraphic units.

\section{Unit 1: interval 325-M0034A-1R-1, 0-20 cm: modern coralgal boundstone}

The uppermost Unit 1, consisting only of interval 325-M0034A-1R-1, 0-20 cm, is a modern sediment composed of lime coralgal boundstone pebbles associated with fine-grained lime sand. Some pebbles have brown staining. Pebble-sized bioclasts of mollusk shell and bryozoans are present. Well-preserved specimens of the larger foraminifera Amphistegina, Heterostegina, Operculina, and fragments of Homotrema are common in interval 325-M0034A-1R-1, 6$11 \mathrm{~cm}$. Only one, possibly hermatypic (zooxanthellate), coral in this unit was identifiable.

\section{Unit 2: Sections 325-M0034A-1R-1, $20 \mathrm{~cm}$, to $12 \mathrm{R}-1,14 \mathrm{~cm}$ : coralgal-microbialite boundstone}

Unit 2, spanning Sections 325-M0034A-1R-1, $20 \mathrm{~cm}$, to $12 \mathrm{R}-1,14 \mathrm{~cm}$, consists of coralgal-microbialite boundstone. Microbialites are almost absent from the upper part of this unit, from Sections 325M0034A-1R-1, $20 \mathrm{~cm}$, to 4R-1, $20 \mathrm{~cm}$, but they become common to abundant in the lower Sections $4 \mathrm{R}-1,20 \mathrm{~cm}$, to $12 \mathrm{R}-2,14 \mathrm{~cm}$. The boundstone con- 
sists mainly of massive corals (Fig. F49) covered with thin (and, much less commonly, thick) crusts of nongeniculate coralline algae that, in turn, are encrusted by thick microbialite envelopes (Figs. F50, F51). Growth forms of nongeniculate coralline algae are exclusively encrusting. Microbialites are buff colored and generally weakly laminated. Bioclasts of Halimeda segments and, less commonly, molluscan shell fragments are enclosed in the microbialites (Fig. F52). Corals are slightly bioeroded, with borings partly to completely filled with fine sand to silt-sized calcareous internal sediment (Fig. F53).

The uppermost part of Unit 2 consists of a large massive Porites colony (Fig. F54); below this colony, the dominant corals are massive to robustly branching Isopora colonies (Figs. F52, F55). Associated corals are Goniopora(?) (Fig. F56), Acropora with medium-thickness branches, massive Faviidae (Fig. F57), branching Pocilloporidae, and encrusting Porites and Montipora. Most fragments are Isopora but they also include Montipora, Porites, Acropora, Seriatopora, Pocillopora(?), Goniopora(?), and Faviidae. Many fragments are both bioeroded and abraded, suggesting some postdepositional transport.

\section{Unit 3: Sections 325-M0034A-13R-1 through 14R-CC: packstone}

Unit 3, spanning Sections 325-M0034A-13R-1 through 14R-CC, consists mainly of massive clasts and, less commonly, branching corals. There are no nongeniculate coralline algae, but there are small (as large as pebble-sized) lithoclasts of gray packstone.

The most common coral is Isopora with fragments of Isopora, Seriatopora, and Acropora(?).

\section{Unit 4: Section 325-M0034A-16W-CC: unconsolidated sediments}

The lowermost Unit 4, consisting only of Section 325-M0034A-16W-CC, is composed of gravelly sediment. This sediment appears to be derived from the seafloor and borehole wall, and it contains abundant bioclasts of Halimeda, fragmented specimens of the benthic foraminifer Heterostegina (scarce), mollusks, and corals, as well as undifferentiated limestone clasts. There are no visible corals or fragments.

\section{Physical properties}

Hole M0034A was drilled to 23.10 m DSF-A, with a total of $6.71 \mathrm{~m}$ of core recovered (29.05\% recovery). Table T2 summarizes all physical property data acquired from this transect, including means and standard deviations for each data type in each borehole.

\section{Density and porosity}

Gamma density values from whole-core multisensor core logger measurements range from 1.01 to 2.57 $\mathrm{g} / \mathrm{cm}^{3}$ (Fig. F58). Bulk density was also measured on 10 discrete samples. Between 2 and 20 m CSF-A, the bulk density of discrete samples presents an increasing trend with depth from 1.96 to $2.48 \mathrm{~g} / \mathrm{cm}^{3}$ and porosity values present a decreasing trend from $46 \%$ to $17 \%$ downsection (Fig. F59). This is the only borehole where we find a quasimonotonic variation in porosity and density versus depth. However, it is difficult to relate this finding to the described lithostratigraphy.

\section{$\boldsymbol{P}$-wave velocity}

MSCL $P$-wave measurements on whole cores offshore were not successful. However, three discrete samples were collected and measured from Hole M0034A onshore (Fig. F60A). $P$-wave values from discrete samples range from 3508 to $4471 \mathrm{~m} / \mathrm{s}$ (mean resaturated $P$-wave). From these three measurements, one can infer an increase in $P$-wave with depth. However, because of the gap in recovery, there is a large section of unknown values (Fig. F60A). Bulk density and $P$ wave values show similar trends when measured on discrete samples. However, it is different from Hole M0033A in that as bulk density decreases, $P$-wave increases. (Fig. F60B).

\section{Magnetic susceptibility}

Magnetic susceptibility values in Hole M0034A range from $-2.23 \times 10^{-5}$ to $1.35 \times 10^{-5}$ SI (Fig. F58). Note that Section 325-M0034A-11R-1 was remeasured as part of the quality assurance/quality control plan (see "Physical properties" in the "Methods" chapter). The remeasured value indicates that the apparently higher magnetic susceptibility of this core was an artifact of an error with the $80 \mathrm{~mm}$ loop, meaning that the trend is true but the absolute values are overestimated in the original measurement. There are no downhole trends evident from the dataset.

\section{Electrical resistivity}

Resistivity ranges from low values of $1.50 \Omega \mathrm{m}$ to higher values of $34.92 \Omega \mathrm{m}$ (Fig. F58). Resistivity values are highly spread over most of this range from Sections 325-M0034A-8R-1 through 12R-1.

\section{Digital line scans and color reflectance}

All cores from Hole M0034A were measured using the digital line scan system with all data recorded at a resolution of $150 \mathrm{pixel} / \mathrm{cm}$ as both images and RGB values. All appropriate cores were scanned for color 
reflectance. Color reflectance in Hole M0034A L* values vary between $41.82 \%$ and $82.77 \%$ but over a shorter range $(50 \%-80 \%)$ if the outliers are removed (Fig. F61). Measurements of color reflectance parameters $a^{*}$ and $b^{*}$ had small variations in the average value per section. The ratio $a^{*} / b^{*}$ clearly separates two outliers with higher values in the red color scale, which is likely due to the presence of red fine branching Tubipora musica.

\section{Paleomagnetism}

Measurements of low-field and mass-specific magnetic susceptibility $(\chi)$ were performed on samples taken from the working half of the recovered core (Fig. F62). Positive low susceptibility values were recorded uniformly throughout the samples, from the top of the core to the total depth. Positive values ranged from $0.30 \times 10^{-8}$ to $1.98 \times 10^{-8} \mathrm{~m}^{3} / \mathrm{kg}$ with a mean value of $0.53 \times 10^{-8} \mathrm{~m}^{3} / \mathrm{kg}$. There are also three samples characterized by negative (diamagnetic) susceptibilities located at 17.12, 18.64, and $20.14 \mathrm{mbsf}$ with values of $-0.16 \times 10^{-8},-0.81 \times 10^{-8}$, and $-0.76 \times$ $10^{-8} \mathrm{~m}^{3} / \mathrm{kg}$, respectively.

\section{Chronology}

Two calibrated radiocarbon ages (10 cal y BP, Core 325-M0034A-1R; 11 cal y BP, Core 7R) (Fig. F63) and one U-Th age (11 cal y BP, Core 13R) (Table T10 in the "Methods" chapter) are consistent with their stratigraphic positions. The U-Th age is unaffected by corrections for initial ${ }^{230} \mathrm{Th}$, adding to the confidence in this age interpretation. This hole recovered material from the middle portion of the deglaciation.

\section{Hole M0035A}

\section{Operations}

\section{Site 11, Hole M0035A}

The Greatship Maya arrived at Site 11 over Hole M0035A at 2345 h on 21 February 2010 and settled on dynamic positioning (DP) (Table T1). At $0045 \mathrm{~h}$, the moonpool door was opened, and running of API pipe commenced at $0100 \mathrm{~h}$ on 22 February. Operations halted between 0200 and $0250 \mathrm{~h}$ for repairs to the roughneck hydraulics. Once the API pipe was just above the seabed, the seabed template was lowered $20 \mathrm{~m}$ below the sea surface to test the HiPap transponder and was then recovered back to the moonpool. At $0355 \mathrm{~h}$, the API pipe was lowered further, and the downpipe camera was deployed for a precoring survey. The camera was recovered by 0550 $h$. The API pipe was then run to tag the seabed and pulled back $0.5-1 \mathrm{~m}$, with the aim to have the end of the pipe rest inside the seabed template when deployed but free to move where the template guided it. The template was lowered onto the seabed at 0635 h. However, because of the template settling into the sediment, the first attempt at standard rotary corer (ALN) coring showed that the API pipe and ALN core barrel were now outside the template entry cone. At $0730 \mathrm{~h}$, the ALN barrel and API pipe were tripped, and at $1015 \mathrm{~h}$, the seabed template was recovered. The ALN bit was smashed, and the API bit was cracked in three places. Both were repaired, and the API pipe was rerun starting at $1100 \mathrm{~h}$. The API pipe was in position just above the seabed by $1410 \mathrm{~h}$, and the downpipe camera was deployed. However, at $1445 \mathrm{~h}$, the vessel again lost position with the camera still inside the API pipe. As the HiPap transponder was attached to the seabed template, which had not been deployed yet, the vessel started to drift.

At $1451 \mathrm{~h}$, the API pipe was raised by $2 \mathrm{~m}$ to avoid any obstacles on the seabed while the vessel regained station, and the camera was recovered. The GPS came back online at $1513 \mathrm{~h}$. The Master of the Greatship Maya and Dynamic-Positioning Officer stated that they were happy with the DP model at $1555 \mathrm{~h}$ and were ready to restart operations, but the ESO Operations Superintendant required that a secondary positioning system be established, henceforth known as the seabed transponder. This transponder was to be deployed over the side of the vessel prior to operations beginning at any site from this point on to prevent further positioning problems occurring during setup and running of coring operations. At $2030 \mathrm{~h}$, the decision was made to abandon Hole M0035A and return to Townsville, where engineers for both the GPS and DP systems would be waiting. The remainder of the API pipe was tripped, and the drill floor secured for transit.

\section{Port call at Townsville}

The Greatship Maya departed Site 11 (Hole M0035A) on transect HYD-01C at 2240 h on 22 February 2010 and arrived alongside in Townsville at $2050 \mathrm{~h}$ on 23 February. Engineers from Veripos (GPS) and ConverTeam (DP) boarded the vessel. Work to identify and rectify problems with both the DP and GPS systems continued overnight. The Greatship Maya departed Townsville at $1010 \mathrm{~h}$ on 24 February to begin sea trials of the DP and GPS systems. At $2350 \mathrm{~h}$, a supply boat arrived alongside the Greatship Maya. Additional core liner tubes and a new seabed frame for the HiPap seabed transponder were taken onboard, and one Veripos surveyor and the ConverTeam engineer departed. One Veripos engineer remained onboard. 


\section{Transit to transect HYD-01C}

The Greatship Maya departed for Site 11 on transect HYD-01C at $0020 \mathrm{~h}$ on 25 February 2010 and arrived at the location of Hole M0035A at $0100 \mathrm{~h}$ on $26 \mathrm{Feb}-$ ruary, where she remained waiting on weather until 0405 h on 27 February.

\section{Hole M0035A}

At 0330 h on 27 February 2010, the HiPap transponder was attached to the seabed frame in readiness for improvement in the weather conditions. Permission was given to begin operations, and at $0430 \mathrm{~h}$ the vessel moved $10 \mathrm{~m}$ starboard of Site 11, Hole M0035A, under DP to deploy the seabed transponder. The vessel was back on station over Hole M0035A at $0530 \mathrm{~h}$. The bridge confirmed that drilling operations could begin at $0605 \mathrm{~h}$, and work began changing the API bit to a new stepped impregnated bit. Running API pipe commenced at $0715 \mathrm{~h}$, pausing at $0735 \mathrm{~h}$ while the seabed template was suspended in the moonpool before continuing until $0930 \mathrm{~h}$. Between 0930 and $1010 \mathrm{~h}$, a downpipe camera survey was conducted. Additional API pipe was then run, and ALN coring commenced at $1110 \mathrm{~h}$.

At $1250 \mathrm{~h}$, the second core was recovered to deck. However, there were problems with hole collapse, and operations had to cease, as power was lost to the drillers' consol. Coring operations restarted at 1600 $\mathrm{h}$, with the power problem now restricted to mud pump number 1 . The roughneck control box was also found to be leaking hydraulic oil. At $1740 \mathrm{~h}$, the bit became blocked. Pumping and reaming did not free the bit, so at $1915 \mathrm{~h}$ the hammer sampler was deployed, freeing the bit at $2215 \mathrm{~h}$.

At $2325 \mathrm{~h}$, the decision was made to switch to HQ coring. Preparations for this continued until $0205 \mathrm{~h}$ on 28 February, including fitting a collar to the API pipe above the seabed template suspended in the moonpool. It was observed that the API pipe and seabed template were very unstable within the moonpool. This was attributed to strong currents pushing the API pipe and the API pipe not reacting against the hole. At $0335 \mathrm{~h}$, the decision was made to return to API coring. Repairs were made to the winch cable at $0425 \mathrm{~h}$, damaged during setting up for HQ coring, with coring operations restarting at $0440 \mathrm{~h}$. Between 0800 and $1025 \mathrm{~h}$, operations were halted because of a problem with the mud pumps caused by air entering the suction valve in the moonpool. Between 1200 and 1235 h, and again between 1600 and $1620 \mathrm{~h}$, operations halted as repairs were made to the compressor because of overheat- ing. At $1625 \mathrm{~h}$, the bit became blocked during Run 14 , but it was freed by pumping water.

The bit became blocked again, accompanied by high pressure at 0240 and $0415 \mathrm{~h}$ on 1 March. The ALN barrel was recovered on both occasions. Sand had jammed the inner and outer barrel. The barrel was stripped down, fully cleaned, and reassembled. Coring continued until $0740 \mathrm{~h}$ when Hole M0035A was terminated at $29.9 \mathrm{mbsf}$, with an average recovery of $40.9 \%$. The API pipe was tripped to $5 \mathrm{~m}$ above the seabed, and a downpipe camera survey was conducted, finishing at $0850 \mathrm{~h}$. The camera was left inside the API pipe for the move to the next coring location. The seabed transponder was recovered and a fully charged beacon attached to the frame.

\section{Sedimentology and biological assemblages}

Hole M0035A is divided into four lithostratigraphic units.

\section{Unit 1: Core 325-M0035A-1R through Section 2R-CC: modern coralgal boundstone}

The uppermost Unit 1, consisting of the interval from Core 325-M0035A-1R through Section 2R-CC, consists of modern reef deposits in which major constituents are coral fragments encrusted by coralline algae and bioclastic lime sands with coral, coralline algae, Halimeda, and larger foraminifera (abundant and well-preserved or stained specimens of Alveolinella, Amphistegina, Cycloclypeus, Elphidiidae, Heterostegina, and Lenticulina). There are no hermatypic (zooxanthellate) corals.

\section{Unit 2: Sections 325-M0035A-3R-1 to 7R-1, $16 \mathrm{~cm}$ : coralgal boundstone}

Unit 2, spanning Sections 325-M0035A-3R-1, to 7R$1,16 \mathrm{~cm}$, is a coral boundstone composed largely of massive corals, with bioclastic lime sands containing shells and coral fragments, Halimeda, coralline algae, and rare fragmented foraminifera Amphistegina, Heterostegina, and Sphaerogypsina. The benthic foraminifera Amphistegina and Operculina (fragmented and scarce) are present in interval 325-M0035A-1R-1, 20$25 \mathrm{~cm}$, and in sandy gravel sediments from interval $5 \mathrm{R}-1,25-30 \mathrm{~cm}$.

There are a few unidentified ahermatypic (nonzooxanthellate) corals at the top of the unit. The dominant coral is massive Isopora (Fig. F64), with some Pocillopora and Montipora(?). Coral fragments are diverse, including Isopora, Tubipora musica, Seriatopora, Acropora, Montipora, Agariciidae, Faviidae, and Fungiidae. 
Unit 3: Sections 325-M0035A-7R-1, $16 \mathrm{~cm}$, to $23 \mathrm{R}-1,6 \mathrm{~cm}$ : coralgal-microbialite boundstone

Unit 3, spanning Sections 325-M0035A-7R-1, $16 \mathrm{~cm}$, to $23 \mathrm{R}-1,6 \mathrm{~cm}$, is a coralgal-microbialite boundstone (Fig. F65) that contains massive and branching corals and coralline algal crusts up to several centimeters thick. The algal crusts contain vermetid gastropods and, less often, the encrusting foraminifer Homotrema rubrum. Microbialites are usually dark gray and weakly laminated; in rare cases, they are columnar. The succession in this unit, from bottom to top, is: coral, coralline algae, microbialite. The lower part of this unit contains bioclastic rudstone associated with the microbialite (Fig. F66).

Stained and fragmented specimens of Amphistegina, Elphidiidae, and Heterostegina are scarce in interval $325-\mathrm{M} 0035 \mathrm{~A}-12 \mathrm{R}-1,20-25 \mathrm{~cm}$, whereas the very coarse sand from interval 13R-1, 20-25 cm, contains fragmented specimens (scarce) of Amphistegina, Elphidiidae, and Gypsina. Very coarse sediments from interval 325-M0035A-21R-1, 40-45 cm, contain abundant well-preserved specimens of Cycloclypeus, Operculina, Alveolinella, Homotrema, Sphaerogypsina, and Textulariida.

The uppermost part of Unit 3 (Cores 325-M0035A-7R through $14 \mathrm{R}$ ) is dominated by massive Isopora (Fig. F67) and branching colonies of Seriatopora (Fig. F68), Acropora, and Pocillopora. The main associated corals are Montipora, Goniopora(?), branching Acropora (Fig. F69), and Tubipora musica. Lower in the hole, downward from Core 325-M0035A-15R, Unit 3 is dominated by branching Acropora, massive Faviidae (including Favia pallida and Cyphastrea) (Fig. F70), Agariciidae, and Tubipora musica (Fig. F71). Associated corals include branching Acropora (Fig. F72), Montipora, Seriatopora, Porites, and Pectiniidae(?). Fragments are similar to the dominant and associated corals in each section.

In Core 325-M0035A-21R, there are $90 \mathrm{~cm}$ of coarse to very coarse lime sand with Halimeda, benthic foraminifera, coral (including Seriatopora), and mollusks, as well as microbialite clasts. This sand, which occurs between the coralgal-microbialite boundstones, appears to be downhole contamination and, therefore, an artifact of drilling.

\section{Unit 4: Section 325-M0035A-23R-1, $6 \mathrm{~cm}$, to the base of Hole M0035A: packstone to grainstone}

The lowermost Unit 4, spanning Section 325M0035A-23R-1, $6 \mathrm{~cm}$, to the base of Hole M0035A, is composed of a dark gray bioclastic packstone to grainstone (Figs. F73, F74) that contains fragments of coral (including Porites, Faviidae, and Pocillopori- dae), coralline algae, Halimeda, mollusk shells, and benthic foraminifer tests.

\section{Physical properties}

A total of $12.23 \mathrm{~m}$ of core was recovered from Hole M0035A, which was drilled to 29.90 m DSF-A. This equates to $40.90 \%$ recovery. Physical property data for this hole are summarized in Table T2.

\section{Density and porosity}

Bulk density values from whole-core multisensor core logger (MSCL) measurements range from 1.00 to $2.50 \mathrm{~g} / \mathrm{cm}^{3}$ (Fig. F75). Bulk density was also measured on 15 discrete samples and ranges from 1.92 to $2.43 \mathrm{~g} / \mathrm{cm}^{3}$ (Fig. F76). Porosity ranges from 19\% to $49 \%$. Grain densities in Hole M0035A are similar to those found in Hole M0033A (ranging from 2.74 to $2.80 \mathrm{~g} / \mathrm{cm}^{3}$ ). Because of the heterogeneity in the formations and/or the disturbed nature of the core material, it is difficult to compare it with the MSCL data and/or stratigraphy.

\section{$P$-wave velocity}

Whole-core MSCL $P$-wave measurements were unsuccessful because of underfilled core liners (no acoustic coupling). However, seven discrete samples from Hole M0035A were measured (Fig. F77A) using the discrete $P$-wave logger. $P$-wave values (resaturated) from discrete samples range from 3207 to $4321 \mathrm{~m} / \mathrm{s}$ (mean resaturated $P$-wave). There is no evidence from these seven measurements for any downhole trend in $P$-wave data. However, bulk density and $P$-wave measured on discrete samples show similar trends (Fig. F77B).

\section{Magnetic susceptibility}

Hole M0035A cores yielded magnetic susceptibility values ranging from $-3.90 \times 10^{-5}$ to $248.66 \times 10^{-5} \mathrm{SI}$ (Fig. F75). The majority of the data falls within the $-1 \times 10^{-5}$ to $5 \times 10^{-5}$ SI range. There is no clear downhole trend; however, there is one significant magnetic susceptibility high at the top of Section 325M0035A-12R-1 (15.65 m CSF-A) that decreases to "normal" hole values downcore. There is no indication in the core description for this high magnetic susceptibility coinciding with a particular lithology.

\section{Electrical resistivity}

Noncontact resistivity measurements taken on whole cores yielded values ranging from 0.45 to $11.06 \Omega \mathrm{m}$ (Fig. F75). There appear to be potentially three intervals of higher resistivity $(\sim 12.5-13, \sim 17-$ 18.2 , and $\sim 23.8-24.2 \mathrm{~m}$ CSF-A). However, owing to the often poor core quality (see "Physical proper- 
ties" in the "Methods" chapter) in Hole M0035A, resistivity data should be treated with a degree of caution.

\section{Digital line scans and color reflectance}

Similar to the other holes in this transect, all cores from Hole M0035A were digitally scanned, and, where appropriate, cores were measured for color reflectance. Color reflectance $L^{*}$ in Hole M0035A varies between $47.18 \%$ and $82.84 \%$. Variations in the measurements of color reflectance parameters show a slight decrease in reflectance with depth (Fig. F78). Values in the scale of blue to yellow $\left(b^{\star}\right)$ get closer to zero with depth. This trend is more clear in the $a^{*} / b^{*}$ ratio, which changes from positive to negative values downhole. Coral fragments of massive Acropora sp. show consistent repetitive values for the parameters $L^{*}, a^{*}$, and $b^{*}$. Increases in the dispersion of the data in each core section, mainly represented by $\mathrm{L}^{*}$ and $b^{*}$ values, likely result from the complex nature of the lithologies that includes coralgal and coralgalmicrobialite boundstone, broken fragments, and unlithified sediments. In this borehole, there is again a clear relationship between the presence of Tubipora musica and the increase in the red parameter $\left(\mathrm{a}^{*}\right)$ to positive numbers.

\section{Paleomagnetism}

Measurements of low-field and mass-specific magnetic susceptibility $(\chi)$ were performed on samples taken from the working half of the recovered core (Fig. F79). Positive low susceptibilities occur throughout the core, with an arithmetic mean value of $0.46 \times 10^{-8} \mathrm{~m}^{3} / \mathrm{kg}$. There is also a peak located at $15.93 \mathrm{mbsf}$ with a relatively high susceptibility value of $1.80 \times 10^{-8} \mathrm{~m}^{3} / \mathrm{kg}$, indicating the possible presence of ferromagnetic and/or paramagnetic minerals. The record also shows four negative (diamagnetic) susceptibilities at $12.75,21.08,22.77$, and $28.04 \mathrm{mbsf}$ with values of $-0.09 \times 10^{-8},-0.06 \times 10^{-8},-0.10 \times 10^{-8}$, and $-0.20 \times 10^{-8} \mathrm{~m}^{3} / \mathrm{kg}$, respectively.

\section{Chronology}

Two calibrated radiocarbon ages (15 cal y BP, Core 325-M0035A-3R; 18 cal y BP, Core 12R) (Fig. F80) and one U-Th age (21 cal y BP, Core 20R) (Table T10 in the "Methods" chapter) are consistent with their stratigraphic positions. The U-Th age is unaffected by corrections for initial ${ }^{230} \mathrm{Th}$, adding to the confidence in this age interpretation. This hole recovered material from the Last Glacial Maximum and cap- tured the early portion of the deglaciation to $\sim 15 \mathrm{cal}$ y BP.

\section{Hole M0036A}

\section{Operations}

\section{Site 11, Hole M0036A}

At $0940 \mathrm{~h}$ on 1 March 2010, the seabed transponder was redeployed, and the vessel maneuvered under dynamic positioning to Site 1, Hole M0036A (Table T1). Between 0940 and $1055 \mathrm{~h}$, the vessel undertook a series of small moves $(<5 \mathrm{~m})$ to target the top of a coral high and position the API pipe over an area devoid of live coral using the downpipe camera system to image the seabed. By $1100 \mathrm{~h}$, the downpipe camera was recovered and API pipe was being run, tagging the seafloor at $1135 \mathrm{~h}$. The first core (standard rotary corer) was recovered at $1150 \mathrm{~h}$, and operations continued until $0600 \mathrm{~h}$ on 2 March, with a total of 22 runs reaching $34 \mathrm{mbsf}$, with an average recovery of $26.2 \%$. On the penultimate run at $0445 \mathrm{~h}$, the barrel became blocked with sand, requiring the hammer sampler to free it.

At $0600 \mathrm{~h}$, preparations for downhole logging began. Between 0855 and $1115 \mathrm{~h}$, the through-pipe gamma sonde was deployed, logging an interval of $33.26 \mathrm{~m}$ WMSF. At $1115 \mathrm{~h}$, circulation and conditioning of the hole commenced prior to three API pipes being tripped, bringing the pipe to 10 mbsf. At $1255 \mathrm{~h}$, lowering of the seabed template began, with the template on the seabed at $1400 \mathrm{~h}$. Progress was slow because of strong currents pushing the electrical umbilical around the underside of the template. At 1510, 1630, 1900, and $2050 \mathrm{~h}$ the resistivity, sonic, open-hole gamma, and magnetic susceptibility sondes, respectively, were deployed downhole, logging the intervals 7.5-25.87, 7.45-16.50, 7.45-10.66, and 7.45-7.47 m WMSF, respectively. A gradual collapse of the hole during this period was noted, with each successive tool penetrating to increasingly shallower depths. At $2145 \mathrm{~h}$, the caliper tool was deployed downhole. However, communication problems with the tool meant that at $2330 \mathrm{~h}$ a second caliper was tried downhole. Again, communication problems prevented logging using this instrument, and logging operations were terminated at $2340 \mathrm{~h}$ on 2 March. Demobilization of the logging equipment continued until $0040 \mathrm{~h}$ on 3 March, when the seabed template began to be raised. At $0130 \mathrm{~h}$, two API pipes were tripped and a downpipe camera survey was conducted. Tripping of the API pipe continued from $0220 \mathrm{~h}$ and was completed by $0400 \mathrm{~h}$, 
when the vessel moved to recover the seabed transponder. The Greatship Maya then moved slowly to Site 9, Hole M0037A, while maintenance of the drill floor hydraulics was carried out.

\section{Sedimentology and biological assemblages}

Hole M0036A is divided into seven lithostratigraphic units.

\section{Unit 1: Section 325-M0036A-2R-1: coralgal boundstone}

The uppermost Unit 1, consisting of Section 325M0036A-2R-1, is composed of fragments of coralline algae and coral boundstone with serpulid worm tubes, encrusting foraminifers, and bivalves, plus loose particles of gastropods, Halimeda, and larger foraminifera. The boundstone has reddish staining throughout this unit.

This boundstone contains one colonial ahermatypic coral colony and some highly altered coral fragments that are unidentifiable, including one possible solitary Fungiidae.

\section{Unit 2: Sections 325-M0036A-3W-1 through 6R-CC: unconsolidated sediments}

Unit 2, consisting of Sections 325-M0036A-3W-1 through 6R-CC, is composed of unconsolidated lime granules and pebbles (in the uppermost $20 \mathrm{~cm}$ of the unit) with medium to coarse lime sand that includes granules and pebbles. Major components are fragments of corals, Halimeda, bivalves, gastropods, and bryozoans (Fig. F81). Larger foraminifera are also a major component, with layers of abundant, well-preserved specimens of Alveolinella, Amphistegina, Cycloclypeus, Homotrema, Operculina, and Textulariida in very coarse sand sediments from interval 325M0036A-3W-1, 30-35 cm, in gravelly very coarse sand sediments from interval 4R-1, 50-55 cm, and in muddy very coarse sand sediments from interval 4R$1,140-145 \mathrm{~cm}$. Some fragments are clearly derived from the overlying boundstone, and others consist of microbialites. Some mollusk fragments appear fresh and may come from the modern seafloor, so some components may be attributed to downhole contamination during coring.

There are no large corals, but coral fragments are abundant. Although most are too small for identification, they include Seriatopora, Stylophora(?), branching Acropora, foliaceous Leptoseris, small solitary Fungiidae, and possibly Poritidae.
Unit 3: Sections 325-M0036A-7R-1 through 9R-CC: coralgal boundstone

Unit 3, spanning Sections 325-M0036A-7R-1 through 9R-CC, consists of large fragments of coralgal boundstone with minor microbialite. The boundstone is composed mainly of massive corals covered with crusts of nongeniculate coralline algae intergrown with vermetids. The microbialites are thin, digitated crusts lining voids in the boundstone. There is some fine-grained internal sediment, plus fragments of mollusks and bryozoans.

Although there are no large corals in the upper part of Unit 3, massive Isopora (Fig. F82) and thickbranching Acropora dominate the lowest section (Core 325-M0036A-9R). Fragments include (often rounded) pieces of Pocillopora, Isopora, Acropora, Seriatopora, Leptoseris, and Fungiidae. Corals are bioeroded locally.

\section{Unit 4: Sections 325-M0036A-10R-1 to 19R-1,} $8 \mathrm{~cm}$ : coralgal-microbialite boundstone

Unit 4, spanning Sections 325-M0036A-10R-1 to 19R-1, $8 \mathrm{~cm}$, consists of coralgal-microbialite boundstone with varying proportions of coral, coralline algae, and microbialite arranged in an alternating pattern (Fig. F83). Microbialites are mainly stromatolitic (laminated), with alternating darker and lighter laminae that include trapped bioclasts. Vermetids commonly intergrown with coralline algae occur as thick crusts on top of the corals or as irregular, contorted structures intergrown with microbialites. Internal bioclastic sediments that include larger foraminifera and Halimeda are rare in this unit. There is a large fragment of Tridacna at the top of Section 325M0036A-13R-1. The boundstone is bioeroded locally by bivalves and sponges. Microbialite crusts are poorly developed in the interval from Sections 325M0036A-12R-1, $24 \mathrm{~cm}$, through 14R-1.

The coral assemblage is dominated by medium to robustly branching Acropora (Fig. F84), massive Isopora, and fine-branching Seriatopora (Fig. F83). Other common corals are massive Faviidae, Goniopora, and Tubipora. Fragments include all of these taxa, plus Stylophora.

\section{Unit 5: Sections 325-M0036A-19R-1, $8 \mathrm{~cm}$, through 20R-1: dark-colored worm-tube coralgal boundstone}

Unit 5, spanning Sections 325-M0036A-19R-1, $8 \mathrm{~cm}$, through 20R-1, consists of a dark-colored boundstone of encrusting coral and thin coralline algae in 
its upper part and a boundstone of coral, thin foliose coralline algae, and worm tubes in the lowermost 10 $\mathrm{cm}$. The boundstone is intensely bioeroded and "blackened."

The dominant coral is massive Goniopora, with fragments of massive Faviidae and fine-branching Seriatopora.

\section{Unit 6: Section 325-M0036A-20R-CC: packstone}

Unit 6, consisting only of Section 325-M0036A-20RCC, is composed of dark gray packstone with larger foraminifera, mollusks, and Halimeda (Fig. F85). There are no visible corals.

\section{Unit 7: Sections 325-M0036A-21R-1 through 21R-CC: unconsolidated sediment}

The lowermost Unit 7, spanning Sections 325M0036A-21R-1 through 21R-CC, is composed of unconsolidated coarse lime sand and pebbles in drilling mud. Visible components include larger foraminifera, mollusks, and Halimeda. Well-preserved larger foraminifera Alveolinella, Amphistegina, Elphidiidae, and Operculina are common in muddy, very coarse sand from interval 325-M0036A-21-1R, 0-5 cm. Sandy mud from interval 325-M0036A-21R-1, 20-25 $\mathrm{cm}$, contains fragmented specimens of Elphidiidae, Gypsina, and Operculina, whereas moderately preserved specimens of Amphistegina and Operculina are present (but scarce) in fine-grained sands from interval 325-M0036A-21R-CC, $0-5 \mathrm{~cm}$. There are no visible corals.

\section{Physical properties}

Petrophysical data from Hole M0036A are summarized in Table T2. The hole was drilled to $34.00 \mathrm{~m}$ DSF-A, and a total of $8.91 \mathrm{~m}$ of core was recovered (26.21\% recovery).

\section{Density and porosity}

Bulk density values from whole-core multisensor core logger (MSCL) measurements range from 1.01 to $2.28 \mathrm{~g} / \mathrm{cm}^{3}$ (Fig. F86). Bulk density was also measured on 17 discrete samples with values ranging from 1.75 to $2.37 \mathrm{~g} / \mathrm{cm}^{3}$ (Fig. F87). Porosity values range from $23 \%$ to $58 \%$, whereas grain density fluctuates between 2.74 and $2.82 \mathrm{~g} / \mathrm{cm}^{3}$. There are no clear downhole trends in the moisture and density dataset for Hole M0036A. Bulk density from discrete measurements generally falls at the higher end of the range given by the MSCL, which is as expected (the MSCL tends to underestimate gamma density where core quality is poor) (see "Physical properties" in the "Methods" chapter).

\section{$P$-wave velocity}

Whole-core MSCL measurements yielded some $P$ wave velocity data for Hole M0036A cores (Fig. F86). Values range from 1556.38 to $1657.35 \mathrm{~m} / \mathrm{s}$, which are very low values considering the lithology. $P$-wave measurement on four discrete samples from these cores were also conducted, yielding data in the range of 3520 to $3919 \mathrm{~m} / \mathrm{s}$ (mean resaturated $P$-wave) (Fig. F88A). There is no evidence for a systematic change in values downhole. It is difficult to comment on the relationship between bulk density and $P$-wave velocity owing to the very few data points available (Fig. F88B).

\section{Magnetic susceptibility}

There is no downhole trend in the magnetic susceptibility data for Hole M0036A, which may be owing to a combination of core quality and core recovery, as is the case with many of the holes in this transect. However, there is good recovery from Cores 325M0036A-4R and 5R (3.5-5.23 m CSF-A), which show some variation in magnetic susceptibility values (Fig. F86). Overall, data ranges from diamagnetic $-5.78 \times$ $10^{-5}$ SI to magnetic $8.09 \times 10^{-5}$ SI.

\section{Electrical resistivity}

Whole-core noncontact resistivity measurements in Hole M0036A yielded data ranging from 0.55 to $26.54 \Omega \mathrm{m}$ (Fig. F86). Resistivity values are highly variable downhole. However, from $\sim 3.6$ to $5.2 \mathrm{~m}$ CSF-A in a zone of good recovery resistivity increases downhole from $\sim 0.5$ to $1.1 \Omega \mathrm{m}$.

\section{Digital line scans and color reflectance}

All cores from Hole M0036A were digitally scanned and, where appropriate, cores were measured for color reflectance. Color reflectance in Hole M0036A varies between $43.55 \%$ and $84.54 \% \mathrm{~L}^{*}$ units (Fig. F89). Variations in color reflectance parameters show a slight decrease in reflectance with depth. Values in the scale of blue to yellow ( $\left.b^{*}\right)$ approach to zero with depth, with a total variation of $20 \%$. This trend is more evident in the $a^{*} / b^{*}$ ratio, which changes from positive to negative values. The slope in the three parameters $\left(L^{*}, a^{*}\right.$, and $\left.b^{*}\right)$ follows a similar trend. In locations dominated by massive Acropora sp. colonies, color characteristics remain constant throughout.

\section{Thermal conductivity}

For Hole M0036A, only one measurement was made at $5.15 \mathrm{~m} \mathrm{CSF-A,} \mathrm{showing} \mathrm{a} \mathrm{thermal} \mathrm{conductivity} \mathrm{of}$ $0.826 \mathrm{~W} /(\mathrm{m} \cdot \mathrm{K})$. The general lack of thermal conductivity measurements in this hole, as well as across 
transect HYD-01C, is due to the nature of the recovered cores being inappropriate for measurement (see "Physical properties" in the "Methods" chapter).

\section{Paleomagnetism}

Measurements of low-field and mass-specific magnetic susceptibility $(\chi)$ were performed on samples taken from the working half of the recovered core (Fig. F90). Positive low susceptibilities were recorded throughout the core, with an arithmetic mean value of $0.55 \times 10^{-8} \mathrm{~m}^{3} / \mathrm{kg}$. In addition, a cluster of susceptibility measurements located between 3.56 and 5.13 mbsf is characterized by positive values ranging from $0.84 \times 10^{-8}$ to $1.9 \times 10^{-8} \mathrm{~m}^{3} / \mathrm{kg}$. A peak was measured at $18.68 \mathrm{mbsf}$ with a susceptibility value of $1.49 \times 10^{-8}$ $\mathrm{m}^{3} / \mathrm{kg}$, indicating the possible presence of ferromagnetic and/or paramagnetic minerals. The record also shows negative susceptibility recordings at 11.01 , 20.58 , and $25.03 \mathrm{mbsf}$ with susceptibility values of $-2.61 \times 10^{-8},-0.33 \times 10^{-8}$, and $-0.28 \times 10^{-8} \mathrm{~m}^{3} / \mathrm{kg}$, respectively.

\section{Chronology}

Two calibrated radiocarbon ages (17 cal y BP, Core 325-M0036A-8R; 17 cal y BP, Core 11) (Fig. F91) and one U-Th age (21 cal y BP, Core 18R) (Table T10 in the "Methods" chapter) are consistent with their stratigraphic positions. The two calibrated radiocarbon dates are the same age, when rounded to $1 \mathrm{cal} \mathrm{y}$ $\mathrm{BP}$, but the individual age ranges are still consistent with the stratigraphic order. The U-Th age is only slightly affected by corrections for initial ${ }^{230} \mathrm{Th}$, the seawater correction making the age $0.7 \mathrm{k} . \mathrm{y}$. younger, thus adding confidence to the interpretation that this hole includes material of Last Glacial Maximum age. Therefore, this hole recovered material from the Last Glacial Maximum and captured the early portion of the deglaciation to $\sim 17 \mathrm{cal} \mathrm{y} \mathrm{BP.}$

\section{Downhole measurements}

Geophysical wireline operations were completed in Hole M0036A to a total depth of $33.26 \mathrm{~m}$ WMSF (seafloor picked from the ANTARES Spectral Natural Gamma Probe [ASGR] log) with the ASGR sonde. Recovery in Hole M0036A was just over 26\%; therefore, downhole measurements can be used to fill gaps in the core recovery. Downhole logging was conducted through an Advanced Petroleum Institute (API) hole, the diameter of which is beyond the maximum working size for the acoustic and optical tools (acoustic borehole televiewer [ABI40] and optical borehole viewer [OBI40]). Therefore, a reduced logging suite was run. Chronologically, the tools run were as follows:
1. ASGR 512 (through API pipe) (the tool experienced a power surge on returning to the surface following logging and was no longer functional),

2. ALT Induction Conductivity Probe (DIL45) (in open hole),

3. Sonic (centralizers were undersized so the tool would fit through the API bit; therefore, the tool was not optimally centralized in the hole; hence, errors were introduced into the measurements),

4. ASGR 256 (back-up Spectral Gamma Ray tool),

5. Magnetic susceptibility probe (EM51), and

6. Caliper (attempted deployment).

(See "Downhole logging" in the "Methods" chapter for detailed tool specifications). Following tripping of the pipe to facilitate logging in open hole, the environment downhole became unstable and the drilled hole began to infill, and over the duration of downhole logging the hole continued to infill. The deepest open hole measurement (DIL45) reached 25.72 m WMSF, with Hole M0036A becoming totally infilled by deployment of the caliper (the final tool deployed).

From the logging data, three main logging units were identified in Hole M0036A (Fig. F92):

1. Unit I (0-11.59 m WMSF; Cores 325-M0036A-2R through 9R) is characterized by (relatively) consistently high total gamma ray (TGR) counts. Values generally range from $\sim 6$ to $9.3 \mathrm{cps}$ (through pipe) and 8.7 to $10.3 \mathrm{cps}$ (in open hole); however, at $2.10 \mathrm{~m} \mathrm{WMSF}$, counts drop to 3.2 cps. Open-hole data from the DIL45 shows values ranging between 157 and 190 mmho (induction electrical conductivity of greater investigation depth (ILD); deep conductivity measurement). Velocity measurements range from values near to seawater $(1500 \mathrm{~m} / \mathrm{s})$ to 1893.30 $\mathrm{m} / \mathrm{s}$, and magnetic susceptibility hovers around 1.6 mSI. Logging Unit I corresponds to an upper thin unit of coralgal boundstone followed by a $3 \mathrm{~m}$ unconsolidated material and a lower $3.35 \mathrm{~m}$ unit of coralgal boundstone.

2. Unit II (11.59-25.31 m WMSF; Cores 325M0036A-10R through 18R) represents a zone of relatively low gamma ray counts with values ranging between 3.43 and 4.69 cps (through pipe). Within Unit II, conductivity does vary, with two main zones of slightly elevated values. Conductivity ranges from 226 to $343 \mathrm{mmho}$ (ILD; deep conductivity measurement). Higher DIL45 values are found in the depth ranges 12.5-15.66 and 17.98-25.31 m WMSF. Sonic velocity values obtained are not particularly robust, with measured values ranging from values 
below the $P$-wave velocity of seawater $(1500$ $\mathrm{m} / \mathrm{s}$ ) to $\sim 1900 \mathrm{~m} / \mathrm{s}$. In this depth range, the associated lithology is a coralgal-microbialite boundstone unit characterized by alternating corals, coralline algae, and microbialites. Areas of higher conductivity are likely to relate to zones of greater rugosity in the formation.

3. Unit III (25.31-33.26 m WMSF; Cores 325M0036A-19R through 21R) was solely differentiated on trends in the TGR measured through API pipe. It is characterized by increasing TGR counts, with values starting at $2.73 \mathrm{cps}$ at the top of the logging unit and increasing to 7.54 cps at the base of the hole. The different lithostratigraphic units observed throughout this logging unit are not apparent in the TGR data. The top of the unit is represented by a dark-colored, bioeroded boundstone followed by packstone comprising benthic foraminifers (no corals). The base of the hole comprises unconsolidated coarse lime sand and pebbles containing no corals.

\section{Hole M0037A}

\section{Operations}

\section{Site 9, Hole M0037A}

The seabed transponder was deployed at $0640 \mathrm{~h}$ on 2 March 2010, and by $0700 \mathrm{~h}$, the vessel was in position above Site 9, Hole M0037A (Table T1). Running of API pipe commenced at $0745 \mathrm{~h}$, but repairs to a hydraulic hose on the elevator after a collision with the roughneck halted operations between 0820 and $0950 \mathrm{~h}$. Running of the API pipe restarted at $0950 \mathrm{~h}$, and by $1100 \mathrm{~h}$, the pipe was situated $10 \mathrm{~m}$ above the seabed and the downpipe camera was being deployed. The camera survey was completed by 1140 $\mathrm{h}$, and preparations to core began. The first standard rotary corer core was recovered at $1330 \mathrm{~h}$, and coring continued successfully until $0055 \mathrm{~h}$ on 4 March, when the hole was terminated at 21 mbsf with an average recovery of $35.8 \%$.

The API pipe was tripped to $10 \mathrm{~m}$ above the seabed between 0055 and $0230 \mathrm{~h}$, when the vessel moved to recover the seabed transponder. At $0250 \mathrm{~h}$, the Greatship Maya began to move slowly, under dynamic positioning, to Site 8, Hole M0038A.

\section{Sedimentology and biological assemblages}

Hole M0037A is divided into three lithostratigraphic intervals.
Unit 1: Sections 325-M0037A-1R-1 to 8R-1, $60 \mathrm{~cm}$ : unconsolidated sediment

The uppermost Unit 1, spanning Sections 325M0037A-1R-1 to 8R-1, $60 \mathrm{~cm}$, consists of unconsolidated lime granules and pebbles with minor amounts of sand. Major components include fragments of Halimeda, mollusks, corals, and bryozoans, with minor coralline algae and echinoids. Fragmented specimens of the larger foraminifera Alveolinella, Amphistegina, Elphidiidae, Heterostegina, Operculina, and Soritinae are common in muddy gravel from interval 325-M0037A-1R-1, 70-75 cm, whereas the muddy gravel from interval 11R-2, $10-15 \mathrm{~cm}$, commonly contains well-preserved specimens of Amphistegina, Alveolinella, Elphidiidae, and Soritinae. Some grains appear to be microbialite boundstone and packstone. The boundstone fragments are typical of the present-day seafloor samples recovered in Section 325-M0037A-6R-1 and are indicative of some downhole contamination.

Coral fragments of Seriatopora are abundant in most sections. Other fragments include Acropora, Isopora, Tubipora, and Pocillopora(?).

\section{Unit 2: interval 325-M0037A-8R-1, 60-70 cm: grainstone}

Unit 2, consisting only of interval 325-M0037A-8R$1,60-70 \mathrm{~cm}$, is composed of gray grainstone (Fig. F93) with well-sorted grains of larger foraminifera, mollusks, and corals. Coral fragments include Seriatopora, Acropora, and Pocilloporidae.

\section{Unit 3: Sections 325-M0037A-8R-CC through 13R-1: lime sand and pebbles}

The lowermost Unit 3, spanning Sections 325M0037A-8R-CC through 13R-1, consists of lime pebbles and granules in a fine to coarse sand matrix. Major components are larger foraminifera. Well-preserved and stained specimens of Alveolinella, Amphistegina, Baculogypsina, and Operculina are common in interval 325-M0037A-9R-1, 30-35 cm, and well-preserved and stained specimens of Alveolinella, Amphistegina, Elphidiidae, Miliolida, and Operculina are common in interval 10R-1, 70-75 cm. Specimens of Alveolinella, Elphidiidae, and Operculina are rare in the medium to very coarse sand-sized sediments from interval 325-M0037A-13R-1, 25-30 cm.

Bivalve/gastropod shells and Halimeda were also major components of Unit 3. Echinoid fragments are minor elements, and black grains, probably microbialite, are also present. Foraminiferal tests and bivalve shells have a distinct subhorizontal orientation 
in undisturbed portions of the cores (Fig. F94). Accumulations of pebbles of diverse composition at the top of all cores in this unit clearly indicate downhole contamination (see Fig. F9 in the "Methods" chapter).

Seriatopora fragments are present throughout Unit 3, with some Pocilloporidae near the top.

\section{Physical properties}

Hole M0037A was drilled to 21.00 m DSF-A with a total of $7.52 \mathrm{~m}$ of core recovered (35.81\% recovery). Petrophysical data are compiled in Table T2.

\section{Density and porosity}

In Hole M0037A, bulk density values from wholecore multisensor core logger (MSCL) measurements range from 1.17 to $2.54 \mathrm{~g} / \mathrm{cm}^{3}$ (Fig. F95). Owing to reasonable core recovery and better core quality in this hole, the dataset is much more complete than for many of the holes in this transect. Bulk density was also measured on 12 discrete samples with values ranging from 1.94 to $2.40 \mathrm{~g} / \mathrm{cm}^{3}$ and porosity values ranging from $23 \%$ to $48 \%$ (Fig. F96). Grain density fluctuates between 2.73 and $2.81 \mathrm{~g} / \mathrm{cm}^{3}$. MSCL density data correspond well with the discrete density measurements.

\section{$P$-wave velocity}

Whole-core MSCL measurements give $P$-wave velocity data for Hole M0037A ranging from 1500.34 to $1872.03 \mathrm{~m} / \mathrm{s}$ (Fig. F95). The minimum values obtained indicate unrealistic values for sediment (1500 $\mathrm{m} / \mathrm{s}$ is the velocity of seawater) (see "Physical properties" in the "Methods" chapter). The $P$-wave record in Hole M0037A is incomplete, with data only available from the top of the hole (0-1.2 m CSF-A) and from 11.2 to $15.6 \mathrm{~m}$ CSF-A. It is therefore difficult to identify any downhole trends in the dataset. No $P$-wave measurements were taken on discrete samples from Hole M0037A.

\section{Magnetic susceptibility}

Similar to other holes in this transect, the majority of magnetic susceptibility measurements for Hole M0037A are close to zero (Fig. F95). There are three distinct highs in the bottom half of this hole that show smooth curves peaking at $55.97 \times 10^{-5}$ SI (Section 325-M0037A-9R-1; $12.69 \mathrm{~m}$ CSF-A), $38.27 \times 10^{-5}$ SI (Section 10R-1; $14.15 \mathrm{~m}$ CSF-A), and $46.56 \times 10^{-5}$ SI (Section 11R-1; $15.66 \mathrm{~m} \mathrm{CSF-A).} \mathrm{The} \mathrm{data} \mathrm{range} \mathrm{for}$ this hole is $-1.31 \times 10^{-5}$ to $55.97 \times 10^{-5} \mathrm{SI}$.

\section{Electrical resistivity}

Noncontact resistivity measurements on whole cores from Hole M0037A generate data ranging from 0.65 to $2.54 \Omega \mathrm{m}$ (Fig. F95). Although the dataset is patchy (a consequence of core recovery), there are some zones of better recovery where there are intervals that have clear trends of increasing resistivity with depth. Most notably, these trends occur in the intervals $0-1.8 \mathrm{~m}$ CSF-A (from 0.9 to $1.8 \Omega \mathrm{m}$ ) and 14-15.4 m CSF-A (0.6 to $1.4 \Omega \mathrm{m})$.

\section{Digital line scans and color reflectance}

All cores from Hole M0037A were digitally scanned, and, where appropriate, cores were measured for color reflectance. Color reflectance $L^{*}$ in Hole M0037A varies between $35.12 \%$ and $73.35 \%$ (Fig. F97). The cores were more homogeneous than those from other boreholes in this transect. Several areas were identified by visual description as being disturbed by drilling and, as such, contained a higher quantity of loose broken fragments. In general, these intervals were not measured for color reflectance because of the lack of flat, smooth surfaces in the core. Toward the top of Hole M0037A, a wide distribution of color reflectance values is coincident with the coarser, fragmented intervals. In core sections deeper in the hole where fragmentation is less prevalent, the deviation from the mean is generally less.

\section{Paleomagnetism}

Measurements of low-field and mass-specific magnetic susceptibility $(\chi)$ were performed on samples taken from the working half of the recovered core (Fig. F98). Low positive susceptibilities were measured throughout the core, with an arithmetic mean value of $0.33 \times 10^{-8} \mathrm{~m}^{3} / \mathrm{kg}$. At the top of the core, four positive susceptibilities were recorded between 0.1 and 1.39 mbsf. A higher susceptibility value of $1.83 \times 10^{-8} \mathrm{~m}^{3} / \mathrm{kg}$, recorded at $7.57 \mathrm{mbsf}$, indicates the possible presence of ferromagnetic and/or paramagnetic minerals.

\section{Chronology}

Two calibrated radiocarbon ages $(8 \mathrm{cal}$ y $\mathrm{BP}$, Core 325-M0037A-4R; 16 cal y BP, Core 6R) (Fig. F99) and one U-Th age (13 cal y BP, Core 7R) (Table T10 in the "Methods" chapter) are inconsistent with the stratigraphic order of the samples. This may indicate that the material dated represents a reworked deposit, disturbance by drilling, or inaccuracy in dating. The true age of the U-Th dated coral is unlikely to be older (the initial ${ }^{230} \mathrm{Th}$ seawater correction actually 
makes the ages younger by 1.2 k.y.). This hole appears to consist of deposits of deglacial age but may include reworked material.

\section{Hole M0038A}

\section{Operations}

\section{Site 8, Hole M0038A}

The seabed transponder was deployed at $0320 \mathrm{~h}$ on 4 March 2010 prior to moving onto station by $0340 \mathrm{~h}$ (Table T1). However, a mud pump suction failure at $0330 \mathrm{~h}$ prevented operations commencing until $1400 \mathrm{~h}$. API pipe was run to just above the seabed by $1430 \mathrm{~h}$. A downpipe camera survey was completed by $1510 \mathrm{~h}$, and the API pipe tagged the seabed at $1535 \mathrm{~h}$. However, on recovery of the first standard rotary corer core at $1540 \mathrm{~h}$, the bit was found to have been completely destroyed. The decision was made to lift the drillstring, move $2 \mathrm{~m}$, and begin a new hole to avoid coring any remnants of the bit. As this area was within the field of view of the camera survey for Hole M0038A, no new survey was required prior to coring operations at the hole.

\section{Sedimentology and biological assemblages}

Hole M0038A contains a single lithostratigraphic unit.

\section{Unit 1: Sections 325-M0038A-1R-1 through 1R-CC: modern seafloor sediment}

Unit 1, spanning Sections 325-M0038A-1R-1 through 1R-CC, contains all sedimentary material from Hole M0038A. The section is composed of pebble-sized fragments of corals, coralline algae, and bryozoans in addition to coral rudstone with a bioclastic packstone matrix, all of which have brown staining. These may be derived from the modern seafloor. Cavities, possibly formed by dissolution, occur in the rudstone and are partly to fully filled with gray, well-consolidated lime mud.

There were no identifiable corals in Section 325M0038A-1R-1, but Section 1R-CC consists exclusively of coral fragments with brown staining, including large pieces of massive Porites that were part of a single in situ colony until fractured during drilling.

\section{Physical properties}

A total of $0.18 \mathrm{~m}$ of core was recovered from Hole M0038A, which was drilled to $1.5 \mathrm{~m}$ DSF-A (12\% recovery). Owing to the very short hole and the low recovery, it was not possible to carry out the full suite of petrophysical measurements (Table T2) on the recovered core.

\section{Density and porosity}

In Hole M0038A, whole-core multisensor core logger measurements were not taken because of low core recovery, and only one sample was taken for discrete measurement. Bulk density for this sample is $2.33 \mathrm{~g} / \mathrm{cm}^{3}$, grain density is $2.75 \mathrm{~g} / \mathrm{cm}^{3}$, and porosity is $24 \%$.

\section{Digital line scans and color reflectance}

Cores from Hole M0038A were digitally scanned and, where appropriate, measured for color reflectance. Only three color reflectance spectrophotometry measurements in Hole M0038A were possible because of the lack of recovery. $\mathrm{L}^{*}$ values had a minimum of $72 \%$ and a maximum of $74.69 \%$. The graph is not shown for this borehole because of the lack of measurements.

\section{Paleomagnetism}

Measurements of low-field and mass-specific magnetic susceptibility $(\chi)$ were performed on one sample taken from the working half of the recovered core. Very low negative (diamagnetic) susceptibility was measured in this sample, taken at $0.03 \mathrm{mbsf}$, with a value of $-0.23 \times 10^{-8} \mathrm{~m}^{3} / \mathrm{kg}$.

\section{Chronology}

This hole has only one calibrated radiocarbon age of 13 cal y BP from Core 325-M0038A-1R (Fig. F100). This age is from the top of the hole, indicating that it may have captured part of the early deglaciation.

\section{Hole M0039A}

\section{Operations}

\section{Site 8, Hole M0039A}

Hole M0039A tagged seabed at $1625 \mathrm{~h}$ on 4 March 2010, and the first standard rotary corer core was on deck at $1700 \mathrm{~h}$ (Table T1). Coring continued until $2340 \mathrm{~h}$, when the driller noted high mud pressure, suggesting the barrel was blocked. On recovery, the latch head assembly was found to be blocked with sediment. This occurred on three consecutive deployments, resulting in no advance in the drilled depth. At $0300 \mathrm{~h}$ on $5 \mathrm{March}$, the barrel advanced slowly during Run 10, and coring continued until $1400 \mathrm{~h}$ (with a break between 1130 and $1220 \mathrm{~h}$ for repairs to the latch head dog), when the hole was terminated at $28.4 \mathrm{mbsf}$ with an average recovery of $36.6 \%$. By $1420 \mathrm{~h}$, the API pipe was tripped to just above the seabed in order to run a downpipe camera 
survey. Tripping the API pipe then continued from 1455 to $1650 \mathrm{~h}$, when the seabed transponder was recovered.

\section{Sedimentology and biological assemblages}

Hole M0039A is divided into five lithostratigraphic units.

\section{Unit 1: interval 325-M0039A-1R-1, 0-18 cm: modern sediments}

The uppermost Unit 1, consisting of interval 325M0039A-1R-1, 0-18 cm, is modern sediment composed of mainly of unconsolidated, predominantly pebble sized coral clasts (some with brown staining) associated with calcareous gravelly sand. Some coral clasts are covered with nongeniculate coralline algae. Well-preserved specimens of Textulariida are present but scarce in muddy gravels from interval 325M0039A-1R-1, 5-10 cm.

The top of Unit 1 contains pieces of massive Faviidae above colonial ahermatypic corals, whereas an unidentified, medium thickness, branching coral is common below $15 \mathrm{~cm}$.

\section{Unit 2: interval 325-M0039A-1R-1, 18-38 cm: floatstone}

Unit 2, consisting of the short interval 325-M0039A$1 \mathrm{R}-1,18-38 \mathrm{~cm}$, is composed of bioclastic floatstone (Fig. F101) containing gravel-sized bioclasts of bryozoans, mollusks, gastropods, and smaller proportions of bivalves. The matrix of this floatstone has a packstone fabric in which some cavities, of uncertain origin, are partly filled with well-lithified lime mud. There are no visible corals in Unit 2.

\section{Unit 3: Sections 325-M0039A-1R-1, $38 \mathrm{~cm}$, to $4 \mathrm{R}-1,52 \mathrm{~cm}$ : coralgal boundstone}

Unit 3, spanning Sections 325-M0039A-1R-1, $38 \mathrm{~cm}$, to $4 \mathrm{R}-1,52 \mathrm{~cm}$, is a coralgal boundstone (Fig. F102). Massive corals are common throughout this unit. Nongeniculate coralline algae are usually a minor component of the sediment, but thick crusts of nongeniculate coralline algae occur in interval 325M0039A-3R-1, 26-31 cm. There is a thin $(\sim 5 \mathrm{~mm})$ layer of microbialite covering a massive coral at Section 325-M0039A-4R-1, $32 \mathrm{~cm}$. Two intervals of bioclastic packstones are intercalated at 325-M0039A4R-1, 9-16 cm, and 4R-1, 20-40 cm (Fig. F103). These packstones are composed mainly of mollusk bioclasts, fragments of corals (encrusted by nongeniculate coralline algae), and nongeniculate coralline algae. Halimeda segments are abundant in interval 325-M0039A-4R-1, 20-40 cm.

Massive, probably in situ, Porites colonies (Fig. F104) dominate Unit 3, and associated corals include massive Isopora (Fig. F105), medium-thickness branching Acropora (Fig. F106), submassive Goniopora, and branching Pocilloporidae. Fragments include Porites, Isopora, Seriatopora, Pocillopora(?), and some ahermatypic corals.

\section{Unit 4: Sections 325-M0039A-4R-CC to 21R-1, $11 \mathrm{~cm}$ : coralgal-microbialite boundstone}

Unit 4, spanning Sections 325-M0039A-4R-CC through 21R-1, $11 \mathrm{~cm}$, is composed of coralgal-microbialite boundstone associated with bioclastic packstone (Fig. F107). The boundstone consists of corals thinly covered with nongeniculate coralline algae and capped by thick microbialite envelopes. Massive corals dominate, with some associated branching forms. Nongeniculate coralline algae are not as important volumetrically as corals and microbialites. The microbialites are gray and weakly to clearly laminated (Fig. F108). Depressions and layers of bioclasts such as Halimeda segments, molluscan shell fragments, and coral clasts occur within the microbialites, and these portions have a packstone fabric (Fig. F109). Cavities of uncertain origin are common, and some are partly filled with unconsolidated and/or consolidated internal sediments (calcareous silt). Some coral clasts in the lowermost part of interval 325-M0039A-21R-1 0-11 cm, are stained dark gray. Fragments of Homotrema were found in gravelly coarse sands from interval 325-M0039A-12R-CC, $5-10 \mathrm{~cm}$, whereas well-preserved or abraded specimens of Amphistegina, Baculogypsina, Calcarina, Marginopora, and Miliolida are common in medium to coarse sands from interval 21R-1, 15-20 cm.

There are two intervals of sand with pebbles and common to abundant bioclasts of Halimeda, benthic foraminifera, and mollusks in addition to corals and limestone clasts: intervals 325-M0039A-20R-1, 0-73 $\mathrm{cm}$, and 21R-1, 11-22 cm (Fig. F110). These intervals probably formed during coring, and, therefore, indicate downhole contamination.

A diverse coral assemblage is dominated by massive Porites (Fig. F111), submassive to massive Faviidae (Fig. F112), massive Isopora (Fig. F113), and branching Acropora (including tabular colonies) (Fig. F114). Associated corals include massive Astreopora (Fig. F115), Cyphastrea, Montipora, Pocillopora, Echinopora (Fig. F116), Goniopora, and Tubipora. One section contains an apparently alcyonarian spiculite (Fig. F117). 


\section{Unit 5: Section 325-M0039A-21R-CC: grainstone}

Unit 5, the lowermost unit in Hole M0039A, consists of material from Section 325-M0039A-21R-CC and contains a grainstone with well-sorted bioclasts of corals, benthic foraminifers, Halimeda, and mollusks (Fig. F118). All coral fragments are tiny; only one Acropora fragment was identified.

\section{Physical properties}

A total of $10.39 \mathrm{~m}$ of core was recovered from Hole M0039A, which was drilled to 28.4 m DSF-A (36.58\% recovery). The corresponding petrophysical data are summarized in Table T2.

\section{Density and porosity}

In Hole M0039A, whole-core multisensor core logger (MSCL) measurements range from 1.02 to $2.45 \mathrm{~g} / \mathrm{cm}^{3}$ (Fig. F119). The nature of the core quality and the short core lengths mean that the data quality is compromised (see "Physical properties" in the "Methods" chapter). However, eight discrete samples were analyzed for moisture and density, giving bulk density values in the range of 2.02 to $2.39 \mathrm{~g} / \mathrm{cm}^{3}$. Porosity values for the same samples range from $20 \%$ to $43 \%$ (Fig. F120), and grain density fluctuates between 2.75 and $2.81 \mathrm{~g} / \mathrm{cm}^{3}$. There are no clear downhole trends in the density and porosity datasets and equally no clear relationship between the two bulk density measurements (MSCL and discrete).

\section{P-wave velocity}

$P$-wave velocity MSCL measurement of Hole M0039A cores yielded a solitary data point $(6.23 \mathrm{~m}$ CSF-A) with a value of $1636.52 \mathrm{~m} / \mathrm{s}$ (Fig. F119). Two samples were measured using the discrete $P$-wave logger. Mean resaturated measurement values were 3131 and $4701 \mathrm{~m} / \mathrm{s}$ (Fig. F121). Owing to the limited $P$-wave data points available in Hole M0039A, it is impossible to comment on downhole trends.

\section{Magnetic susceptibility}

The magnetic susceptibility data range for this hole is $-4.13 \times 10^{-5}$ to $9.79 \times 10^{-5} \mathrm{SI}$ (Fig. F119). However, the majority of magnetic susceptibility values fall between $-1 \times 10^{-5}$ and $1 \times 10^{-5}$ SI. Core recovery impacts the ability to ascertain any downhole trends in Hole M0039A.

\section{Electrical resistivity}

Whole-core noncontact resistivity measurements on Hole M0039A cores yielded data ranging from 0.59 to $12.97 \Omega \mathrm{m}$ (Fig. F119). Similar to the other datasets for this hole, it is difficult to comment on trends or notable features with respect to the resistivity dataset owing to short core length, core quality, and recovery.

\section{Digital line scans and color reflectance}

All cores from Hole M0039A were digitally scanned, and, where appropriate, cores were measured for color reflectance. Color reflectance $L^{*}$ in Hole M0039A varies between $51.59 \%$ and $84.24 \%$ (Fig. F122). Variations in color reflectance parameters show a slight decrease in reflectance with depth, as well as a decrease in the dispersion of the measurements. This can be attributed to the alternation between coralgal and coralgal-microbialite boundstone, broken fragments, and unlithified sediment lithologies in the higher and medium parts of the borehole. With the exception of the basal packstone unit, the lowermost $6 \mathrm{~m}$ of the borehole presented a more homogeneous composition that corresponds to the less dispersed measurements of color spectroscopy. The outliers in the red wavelength, high $\mathrm{a}^{*}$ value, were due to Tubipora sp.

\section{Paleomagnetism}

Measurements of low-field and mass-specific magnetic susceptibility $(\chi)$ were performed on samples taken from the working half of the recovered core (Fig. F123). Very low positive susceptibilities occur throughout the core, with five negative peaks at $0.08,7.69,13.47,14.12$, and 15.55 mbsf characterized by susceptibilities of $-0.22 \times 10^{-8},-0.38 \times 10^{-8}$, $-0.12 \times 10^{-8},-0.08 \times 10^{-8}$, and $-0.53 \times 10^{-8} \mathrm{~m}^{3} / \mathrm{kg}$. An arithmetic mean value of $0.20 \times 10^{-8} \mathrm{~m}^{3} / \mathrm{kg}$ was calculated for the positive values recorded in this core.

\section{Chronology}

Two calibrated radiocarbon ages (14 cal y BP, Core 325-M0039A-1R; 17 cal y BP, Core 9R) (Fig. F124) and one U-Th age (19 cal y BP, Core 16R) (Table T10 in the "Methods" chapter) are consistent with their stratigraphic positions. The U-Th age is unaffected by corrections for initial ${ }^{230} \mathrm{Th}$ (the seawater correction makes the age only $0.5 \mathrm{k}$.y. younger), adding to the confidence in this age interpretation. This hole 
recovered material from the early portion of the deglaciation to $14 \mathrm{cal} \mathrm{y} \mathrm{BP}$, and because there are five cores below the 19 cal y BP dated sample, the hole may also contain older material.

\section{Transect HYD-01C summary}

\section{Sedimentology and biological assemblages}

Coralgal and coralgal-microbialite boundstones are the dominant lithologies recovered along transect HYD-01C (Fig. F125). Just below the modern seafloor between one and three coralgal boundstone and coralgal-microbialite boundstone units occur in most transect HYD-01C holes, except for Holes M0030A and $\mathrm{M} 0030 \mathrm{~B}$, in which recovery was extremely low, and Hole M0037A, the most distal and deepest site on the transect (at 122 meters below sea level [mbsl]).

The coralgal lithologies, spanning one or two sections depending on the hole, contain little or no microbialite and range from $<1 \mathrm{~m}$ thickness in Hole M0032A to $8 \mathrm{~m}$ in Hole M0031A. These coralgal lithologies consistently overlie coralgal-microbialite units in Holes M0031A-M0033A, M0035A, M0036A, M0038A, and M0039A. In Hole M0034A, a 2 m thick coral boundstone underlies an $18 \mathrm{~m}$ thick coralgalmicrobialite unit, whereas in Hole M0036A, the coralgal boundstone is interbedded with $6 \mathrm{~m}$ of unconsolidated sediment units. The main corals in the coralgal units are massive Isopora with lesser amounts of massive Porites, submassive to massive Montipora, and branching Acropora.

The coralgal-microbialite units are dominated volumetrically by microbialites, and these boundstones are the thickest lithologies in every hole except Hole M0037A. They range from $10 \mathrm{~m}$ thick in Hole M0031A to $\sim 30 \mathrm{~m}$ thick in Hole M0033A. They contain diverse coral assemblages dominated by massive Isopora, branching Acropora, and Seriatopora, but also locally abundant massive Porites and Faviidae.

In six of the nine holes along transect HYD-01C, unconsolidated sediment from $<1$ to $19 \mathrm{~m}$ thick underlies the upper coralgal-microbialite boundstone units and is composed of bioclastic lime sand to pebbles containing mollusks, larger foraminifera, Halimeda, fragments of corals and red algae, bryozoans, echinoderms, and sea urchin spines. In Hole M0034A, the unconsolidated unit is overlain by a coralgal lithology, whereas in Hole M0036A, the unconsolidated unit is bracketed by coralgal units. These unconsolidated sediments were probably partly disturbed by coring operations.

A thin $(<3 \mathrm{~m})$ skeletal packstone to grainstone unit rich in larger foraminifera, calcareous algae, and/or a dark coralgal worm tube boundstone is interbedded with, or underlies, the unconsolidated sediment unit in Holes M0031A-M0033A, M0035A, M0036A, M0038A, and M0039A. A similar unconsolidated unit also forms the base of the recovered sequences in Holes M0031A and M0036A.

Hole M0037A, the most distal and deepest site at 122 mbsl along transect HYD-01C, has a different lithologic composition and succession, with almost uninterrupted unconsolidated sediments extending from the seafloor to the base of the hole. The uppermost $12 \mathrm{~m}$ of unconsolidated lime sands to pebbles overlie a thin $(10 \mathrm{~cm})$ interval of grainstone rich in foraminifera, coralline algae, and coral fragments that in turn overlies $8 \mathrm{~m}$ of lime sand rich in larger foraminifera and mollusks. Although there is clear evidence of downhole contamination in the upper part of each section, these deposits appear to be undisturbed and, therefore, are probably in situ, with minimal disturbance from downhole contamination.

Table T4 documents all larger foraminifera described in this transect in association with hole, run, and depth (below seafloor).

\section{Physical properties}

Partial recovery was achieved at holes drilled on transect HYD-01C. With regard to physical property measurements (summarized in Table T2), cores were only partially saturated and often underfilled, impacting on the data coverage and quality. Borehole depths are as follows:

- Hole M0031A = 90.05 mbsl, 40 m DSF-A.

- Hole M0032A = 90.87 mbsl, 33 m DSF-A.

- Hole M0033A = 91.30 mbsl, 31 m DSF-A.

- Hole M0034A = 51 mbsl, 23.5 m DSF-A.

- Hole M0035A = 100 mbsl, 28 m DSF-A

- Hole M0036A = 98.89 mbsl, 30 m DSF-A.

- Hole M0037A = 122.29 mbsl, 19.5 m DSF-A.

- Hole M0039A = 107.04 mbsl. 26.6 m DSF-A.

In general, recovery was low and recovered intervals were often disturbed by drilling or partially unsaturated because of the unlithified to semilithified nature of the cored formations.

\section{Density and porosity}

Density and porosity vary similarly in all of the boreholes drilled across transect HYD-01C. Discrete sample porosity ranges from $20 \%$ to $58 \%$ because of significant variability in the pore systems (e.g., moldic, vuggy growth framework and intergranular) (Fig. F126). Bulk densities of discrete samples vary between 1.75 and $2.48 \mathrm{~g} / \mathrm{cm}^{3}$. Densities measured on 
whole cores with the multisensor core logger (MSCL) are sometimes $<2 \mathrm{~g} / \mathrm{cm}^{3}$. This is likely owing to the partial saturation of the cores and also to the fact that the majority of the core comprises unconsolidated fragments. There is a classic linear relationship between the porosity $(\phi)$ and bulk density $\left(\rho=\rho_{s}[1-\right.$ $\left.\phi]+\rho_{w} \phi\right)$ of discrete samples (Fig. F127). Grain density varies between 2.71 and $2.85 \mathrm{~g} / \mathrm{cm}^{3}$ and may correspond to a value between the density of calcite $\left(2.71 \mathrm{~g} / \mathrm{cm}^{3}\right)$ and aragonite $\left(2.93 \mathrm{~g} / \mathrm{cm}^{3}\right)$.

\section{$\boldsymbol{P}$-wave velocity}

A plot of velocity (from discrete samples) versus porosity (from discrete samples) for all samples from this transect shows an inverse relationship (Fig. F128) between $P$-wave velocity and porosity. MSCL data range from 1500.34 to $1937.94 \mathrm{~m} / \mathrm{s}$, much lower values than discrete measurements on core plugs. The scale dependency of petrophysical measurements, along with the (inevitable) difference in "selective" sampling of core as opposed to bulk MSCL measurements, is evident: for a given density value, discrete measurements have higher $P$-wave velocity values than MSCL measurements. At the high end of the range in velocity for a given porosity, these differences can be interpreted as the added effect of pore characteristics like pore shape and connectivity and textural properties of the coral and microbialite units. Differences on the low end of the range in velocity for a given porosity may originate from lack of burial compaction and/or pronounced diagenesis.

\section{Magnetic susceptibility}

Magnetic susceptibility data collected at this transect are difficult to interpret because of gaps in the dataset as a result of core recovery issues. However, the majority of data falls between $-5 \times 10^{-5}$ and $5 \times 10^{-5}$ SI across all of the holes, with occasional clear magnetic susceptibility highs defined by smooth curves.

\section{Electrical resistivity}

Reliable resistivity measurements were difficult to obtain using the MSCL because of the presence of loose sediments or partially saturated cores. When resistivity was measured on unconsolidated or sandy sediments, low values were found (Hole M0037A, 1$2 \mathrm{~m}$ CSF-A, where resistivity is between 1 and $2 \Omega \mathrm{m}$ ). Relatively high resistivities were found when measuring more consolidated sediments (Hole M0034A, 12-14 m CSF-A, where resistivity is between 10 and $30 \Omega \mathrm{m}$ [coral framework and microbialite]). A more detailed study of electrical properties of the cores would require measurements with fully saturated discrete samples.

\section{Color reflectance}

The values of color reflectance spectrophotometry were calculated for each borehole as discrete measurements. The main parameters measured are the total reflectance $\left(\mathrm{L}^{*}\right)$ and the color indexes $\mathrm{a}^{*}$ (green to red, green being negative and red positive) and $b^{*}$ (blue to yellow, blue being negative and yellow positive). The $a^{*} / b^{*}$ ratio was also calculated for all boreholes, as it can be used as a better proxy to identify changes in characteristics of the sediment than the independent values of $\mathrm{a}^{*}$ and $\mathrm{b}^{*}$.

Measurements were taken in the most uniform zones in a unit. This is shown by the data, in the sense that massive corals sampled at several points present a consistent pattern of color. In these situations, the data obtained show a main value with a small deviation for the three parameters $\left(\mathrm{L}^{*}, \mathrm{a}^{*}\right.$, and $\left.\mathrm{b}^{*}\right)$. In the locations where Tubipora sp. was found, a strong signal in the red spectrum $\left(\mathrm{a}^{*}\right)$ was found. In most of the boreholes, slightly higher values of reflectance are present just below the seafloor where modern reef sediment was recovered.

In transect HYD-01C, Holes M0031A-M0033A are located in similar water depths and can be correlated. No relevant trends were found in these cores, but the reflectance for all of these boreholes shows similar values. This is also true of Holes M0035A and M0036A, which are also in comparable water depths. As the final sea level data are not yet available, the cores were all presented as meters core depth below seafloor (m CSF-A). Discrete measurements of reflectance values for all boreholes in transect HYD-01C are represented in Figure F129. Boreholes are represented in order from coast (shallow) to offshore (deep).

\section{Paleomagnetism}

Transect HYD-01C comprises 11 holes, collected from 6 sites, located on the northern side of Hydrographer's Passage. Materials recovered were dominated by corals and calcareous sediments. The materials show mainly low and/or negative values of lowfield and mass-normalized magnetic susceptibility. The arithmetic mean of the values from these sites appears to indicate that they are primarily related to diamagnetic materials.

The lower peaks recorded in the magnetic susceptibility results (diamagnetic material) are difficult to correlate to a common geological or paleomagnetic feature. However, the majority of the positive peaks 
in magnetic susceptibility, which indicate the presence of ferromagnetic and/or paramagnetic material, are located at particular depths: $3-4,7-8,17-20$, and 27-30 mbsf. This feature appears to be associated with lithological variations, in particular the occurrence of sandy layers, which indicate an important variation in the growth regime of the Great Barrier Reef and potentially mark significant paleoclimatic changes.

Further rock magnetic studies on these layers may provide information relating to the nature and processes that produce these lithological variations, whereas environmental magnetic studies could reinforce the climatic origin of these layers and provide information on the amount, composition, and grain size of the magnetic component retained in the sediments.

\section{Geochemistry}

A total of 16 interstitial water samples from transect HYD-01C were obtained from Holes M0031A (1), M0033A (2), M0035A (1), M0036A (3), M0037A (6), and M0039A (3). Samples were analyzed for cation and anion concentrations (Table T5). Parameters including $\mathrm{pH}$, alkalinity, and concentrations of ammonium were measured during the offshore phase of the expedition, whereas the major cation and anion measurements were undertaken during the Onshore Science Party. All geochemical constituents were determined to be within the normal ranges for marine sediments. Because of the scarcity of interstitial water samples in this transect, interpretations relating to vertical variations could not be made.

\section{Chronology}

At transect HYD-01C (Fig. F125), the $50 \mathrm{~m}$ reef target was drilled in Hole M0034A (Site 3) and has been dated to $10 \mathrm{cal}$ y BP at the top of the hole (Core 325M0034A-2R; $52 \mathrm{mbsl}$ ) and $11 \mathrm{cal} \mathrm{y} \mathrm{BP}$ at $68 \mathrm{mbsl}$. Therefore, this site seems to contain a record of the middle of the last deglaciation. Holes M0031AM0033A (Site 6) drilled into a feature at $90 \mathrm{mbsl}$ and returned ages of 13-14 cal y BP near the tops of the cores (325-M0031A-2R, 325-M0032A-1R, and 325M0033A-3R). These three holes all penetrate to greater depths where older ages were returned $(25 \mathrm{cal}$ y BP, Core 325-M0031A-16R; 20 cal y BP, Core 325M0032A-8R; 31 cal y BP, Core 325-M0033A-15R) from depths between 106 and 127 mbsl. Hole M0032A also returned a pre-Last Glacial Maximum (LGM) age of $61 \mathrm{cal} \mathrm{y} \mathrm{BP} \mathrm{from} \mathrm{a} \mathrm{depth} \mathrm{of} 121 \mathrm{mbsl}$ (Core 325-M0032A-18R). Therefore, holes at Site 6 recovered material from the LGM interval (and also earlier), as well as captured part of the last deglaciation. Holes M0035A and M0036A (Site 11), farther offshore, drilled a feature at $100 \mathrm{mbsl}$ and returned an age of $15 \mathrm{cal}$ y BP from near the top of one of the cores (325-M0035A-3R, $103 \mathrm{mbsl})$ and ages of 18-17 cal y BP from deeper in the holes (18 cal y BP, Core 325-M0035A-12R; 17 cal y BP, Core 325-M0036A-8R; 17 cal y BP, Core 325-M0036A-11R) between 109 and $116 \mathrm{mbsl}$. The bases of the holes at Site 11 returned ages of $21 \mathrm{cal}$ y BP from 124 to 127 mbsl (Cores 325M0036A-18R and 325-M0035A-20R). Therefore, Site 11 appears to record the end of the LGM as well as the early portion of the deglaciation. Holes M0038A and M0039A (Site 8) recovered material of similar age, $13-19$ cal y BP, to that at Site 11 but from a feature at 107 mbsl. Here, the tops of the holes (Cores 325-M0038A-1R and 325-M0039A-2R) at 107 and 108 mbsl produced ages of 14-13 cal y BP, and the bottom of Hole M0039A recovered material dating to $19 \mathrm{cal} \mathrm{y} \mathrm{BP}$. Therefore, Site 8 also recorded the end of the LGM as well as the early portion of the last deglaciation. Hole M0037A, at the deepest site on transect HYD-01C (Site 9), produced ages of 8, 16, and 13 cal y BP (Cores 325-M0037A-2R, 4R, and 7R, respectively), but these are not in stratigraphic order. Therefore, this site probably accumulated material during the last deglaciation, and the sequence is likely to be composed of reworked material.

\section{Downhole measurements}

Downhole geophysical logs provide continuous information on physical, chemical, textural, and structural properties of geological formations penetrated by a borehole. In intervals of low or disturbed core recovery, downhole geophysical logs provide the only way to characterize the borehole section. This is especially true when recovery is poor and when comparable measurements or observations cannot be obtained from core, as downhole geophysical logging allows precise depth positioning of core pieces by visual (borehole images) and/or petrophysical correlation.

\section{Borehole geophysical instruments}

The suite of slimline logging tools deployed at transect HYD-01C is as follows:

- The ANTARES Spectral Natural Gamma Probe (ASGR) allows identification of the individual elements that emit gamma rays (potassium, uranium, and thorium).

- The Induction Conductivity Probe (DIL45) provides measurements of electrical conductivity. The output of the tool comprises two logs: induction electrical conductivity of medium investigation depth $(0.57 \mathrm{~m})$ and induction electrical conductivity of greater investigation depth $(0.83 \mathrm{~m})$. 
- The Full Waveform Sonic Probe (2PSA-1000; SONIC) measures compressional wave velocities of the formation. In addition, analysis of surface waves in the borehole (i.e., Stoneley waves) can be indicative of formation permeability.

- The magnetic susceptibility probe (EM51) provides measurements of magnetic susceptibility and electrical conductivity. The output of the tool comprises two logs: magnetic susceptibility and electrical conductivity.

Two boreholes were logged at this transect (Holes M0031A and M0036A). However, both holes were API diameter, and hence approximately double the diameter of an ideal HQ ("logging") hole. Following completion of coring in Hole M0031A, the ASGR through-pipe measurement was run as standard, thus guaranteeing at least one continuous measurement unrelated to open-hole borehole conditions. All the above-mentioned downhole tools were deployed in Hole M0036A. However, because of rapid hole infill as borehole conditions became increasingly hostile, the measurable depth for open-hole logging in Hole M0036A diminished throughout the logging operation. In order to record ultra-high-resolution geophysical downhole logging data, the acquisition was done from the rooster box, which was heave compensated.

\section{Preliminary results}

Wireline logging operations on transect HYD-01C provided two sets of comparable through-pipe gamma ray data. Very little open-hole data were acquired in Hole M0036A because of hole instability. However, it is possible to discern three major logging units at these two sites solely considering the gamma ray data collected through API pipe (Fig. F130).

- The uppermost unit has elevated values of natural radioactivity and is associated with a coralgal boundstone unit.
- The middle unit is characterized by low values of natural radioactivity and is associated with an unconsolidated unit (lime sand and pebbles) in Hole M0031A and a coralgal-microbialite boundstone unit in Hole in M0036A.

- The basal unit has a trend of increasing natural radioactivity to the bottom of the hole. This manifests as unconsolidated material in Hole M0031A, whereas in Hole M0036A, a dark-colored, bioeroded boundstone followed by a packstone unit comprising benthic foraminifers (no corals) is observed. The base of Hole M0036A comprises unconsolidated coarse lime sand and pebbles.

\section{References}

Blum, P., 1997. Physical properties handbook: a guide to the shipboard measurement of physical properties of deep-sea cores. ODP Tech. Note, 26. doi:10.2973/ odp.tn.26.1997

Bronk Ramsey, C., 2009. Bayesian analysis of radiocarbon dates. Radiocarbon, 51(1):337-360. http://digitalcommons.arizona.edu/restrictedobjectviewer?o=http:// radiocarbon.library.arizona.edu/Volume51/ Number1/0b094122-5128-4777-9edd-b4dad8f3864d

Reimer, P.J., Baillie, M.G.L., Bard, E., Bayliss, A., Beck, J.W., Blackwell, P.G., Bronk, R.C., Buck, C.E., Burr, G.S., Edwards, R.L., Friedrich, M., Grootes, P.M., Guilderson, T.P., Hajdas, I., Heaton, T.J., Hogg, A.G., Hughen, K.A., Kaiser, K.F., Kromer, B., McCormac, F.G., Manning, S.W., Reimer, R.W., Richards, D.A., Southon, J.R., Talamo, S., Turney, C.S.M., van der Plicht, J., and Weyhenmeyer, C.E., 2009. Intcal09 and Marine09 radiocarbon age calibration curves, 0-50,000 years cal BP. Radiocarbon, 51(4):1111-1150. http://digitalcommons.arizona.edu/restrictedobjectviewer?o=http://radiocarbon.library.arizona.edu/Volume51/Number4/ 49691745-6a68-4e2c-a26f-08f0a16c1a53

Publication: 16 July 2011

MS 325-103 
Figure F1. Contour plot showing transect HYD-01C (Hydrographer's Passage), Expedition 325. Sites 1-11 and Holes M0030A-M0039A are indicated. See Figure F2 in the "Expedition 325 summary" chapter for general location. EPSP = Environmental Protection and Safety Panel, GBRMPA = Great Barrier Reef Marine Park Authority.

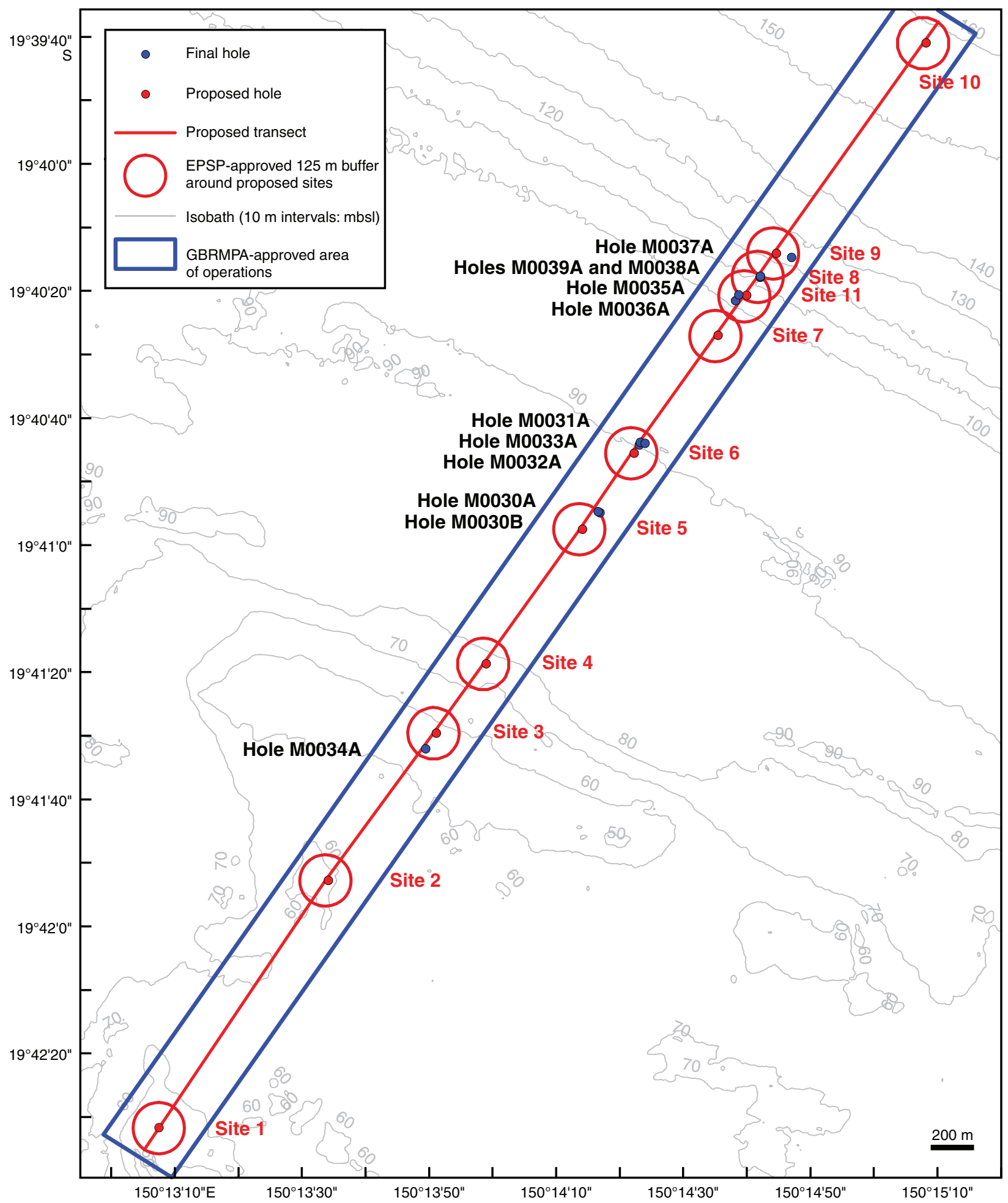


Figure F2. High-resolution line scan image of a bioeroded coralgal bindstone (interval 325-M0030A-1R-CC, 1$7 \mathrm{~cm})$.

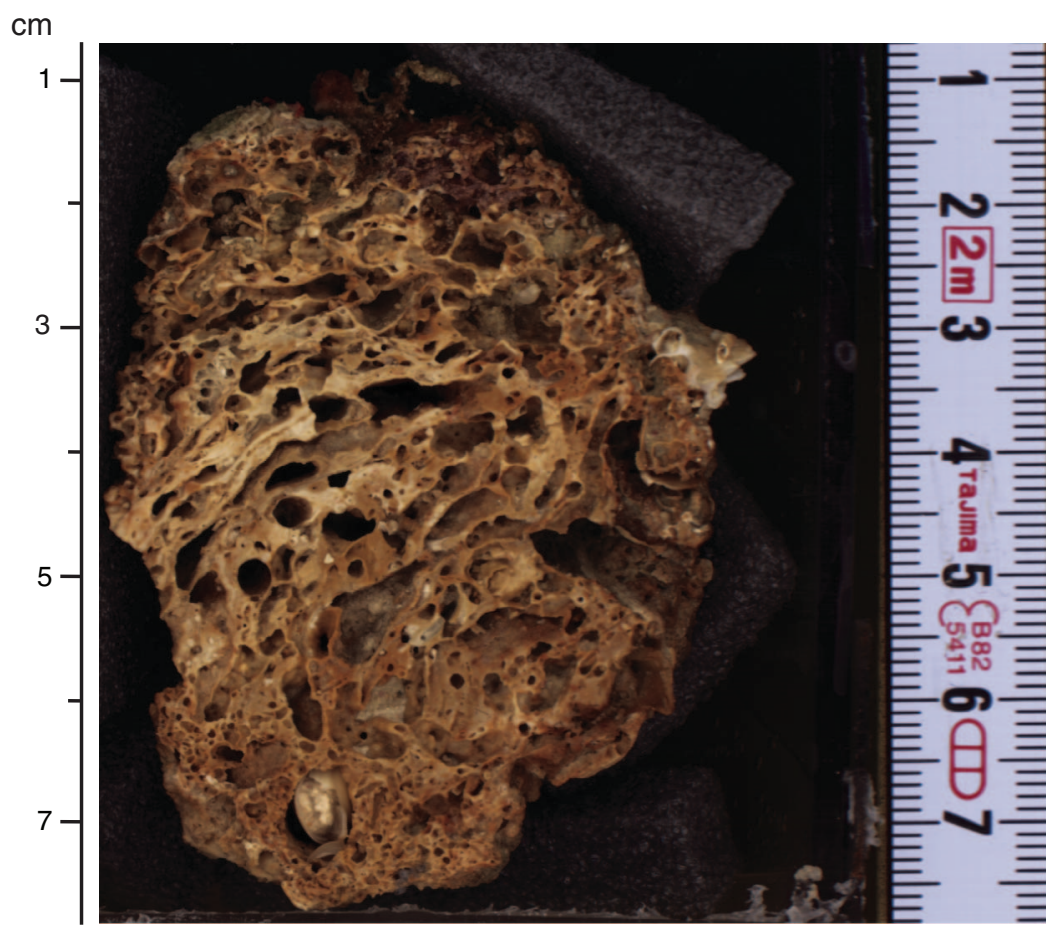


Figure F3. Values of reflectance $\left(\mathrm{L}^{*}\right)$, green to red $\left(\mathrm{a}^{*}\right)$, and blue to yellow $\left(\mathrm{b}^{*}\right)$ indexes, along with ratio $\mathrm{a}^{*} / \mathrm{b}^{*}$ for Hole M0030A.

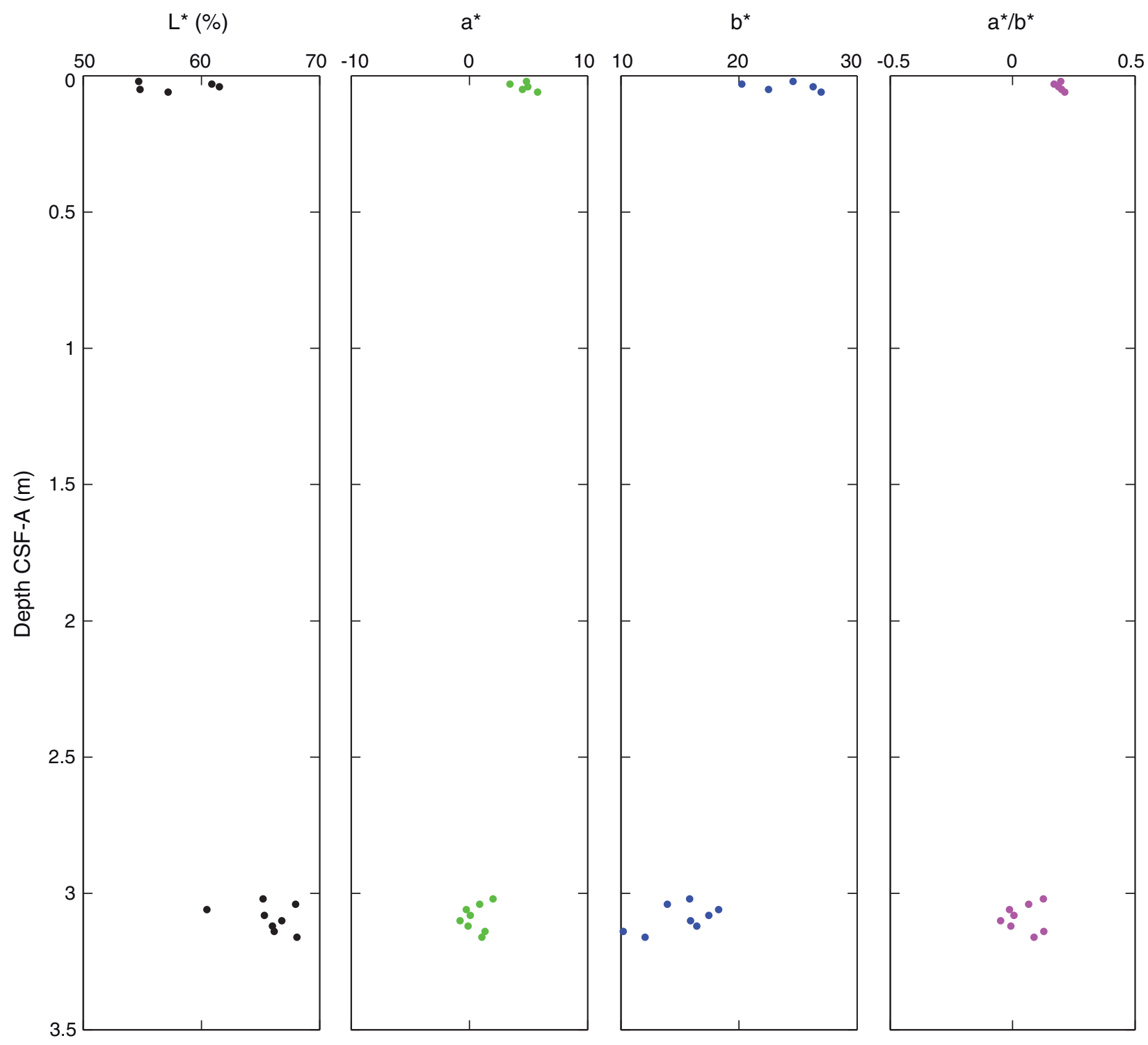


Figure F4. High-resolution line scan image of a massive Isopora colony (interval 325-M0030B-3R-1, 12-16 cm).

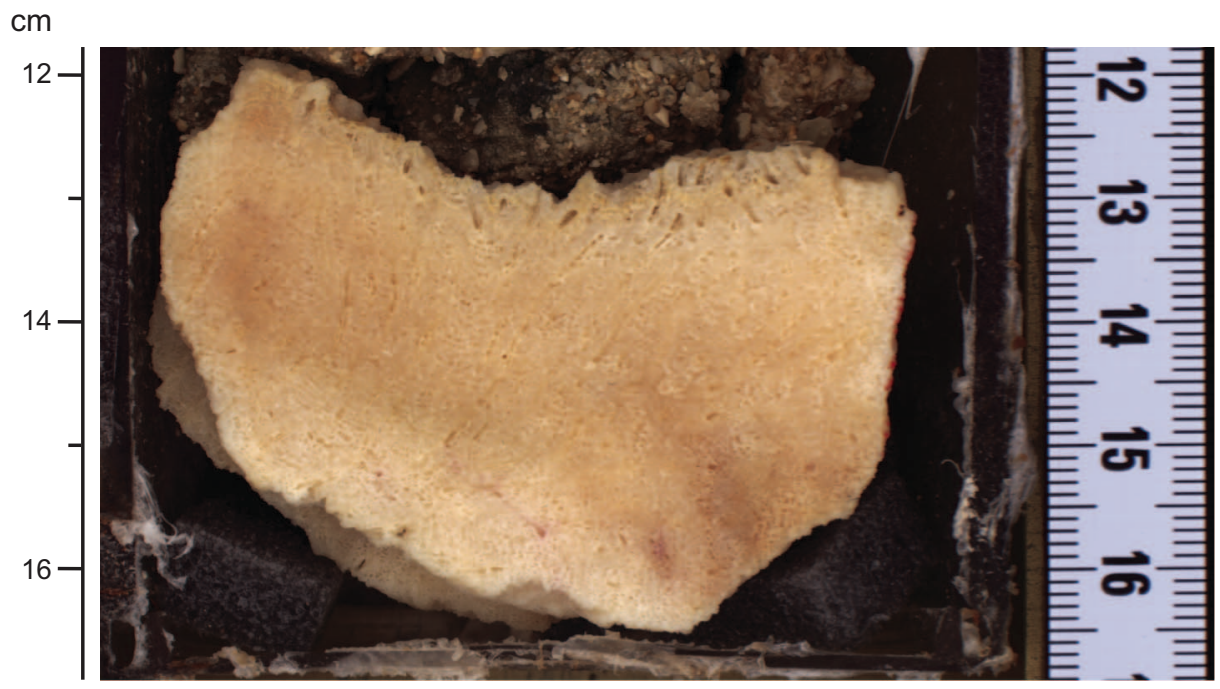


Figure F5. Summary diagram showing data collected on whole cores using the MSCL, Hole M0030B.

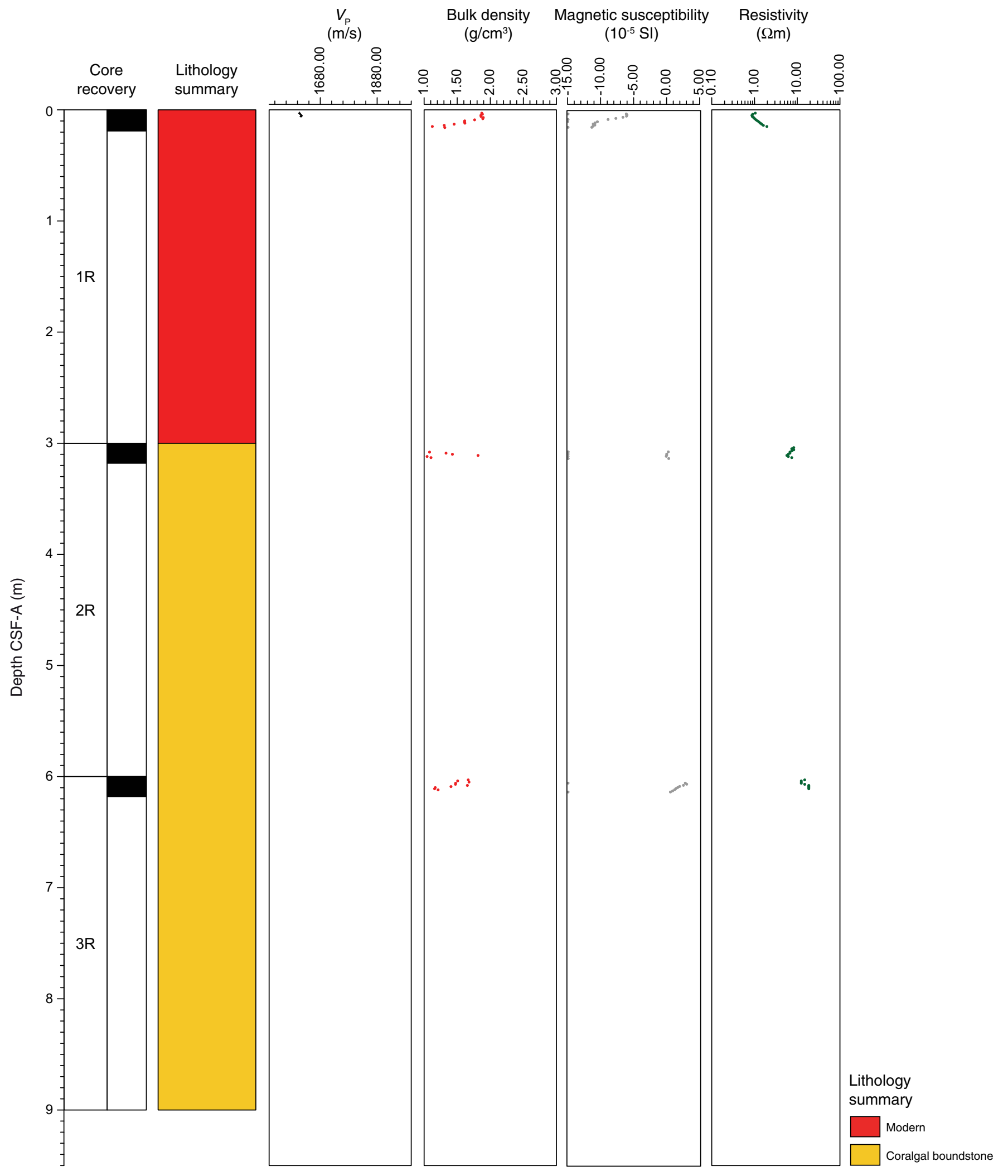


Figure F6. Petrophysical measurements obtained from discrete samples with a pycnometer, Hole M0030B. Bulk density measured on whole cores with the MSCL is shown in red on the bulk density plot.

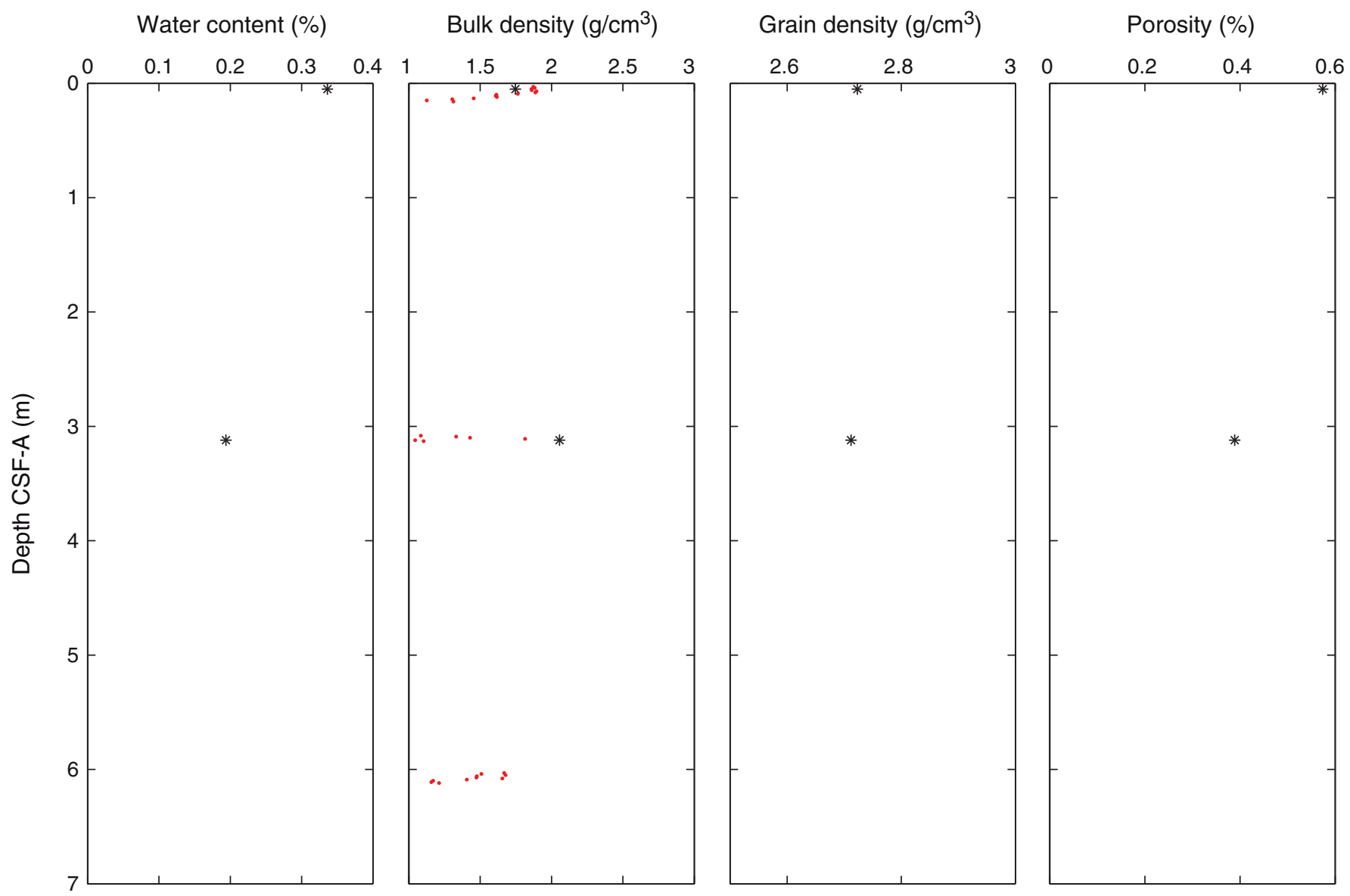


Figure F7. High-resolution line scan image showing orange-stained, highly bioeroded coralgal boundstone (corals are Pocilloporidae) with thin microbialite crust (interval 325-M0031A-2R-1, 10-21 cm).

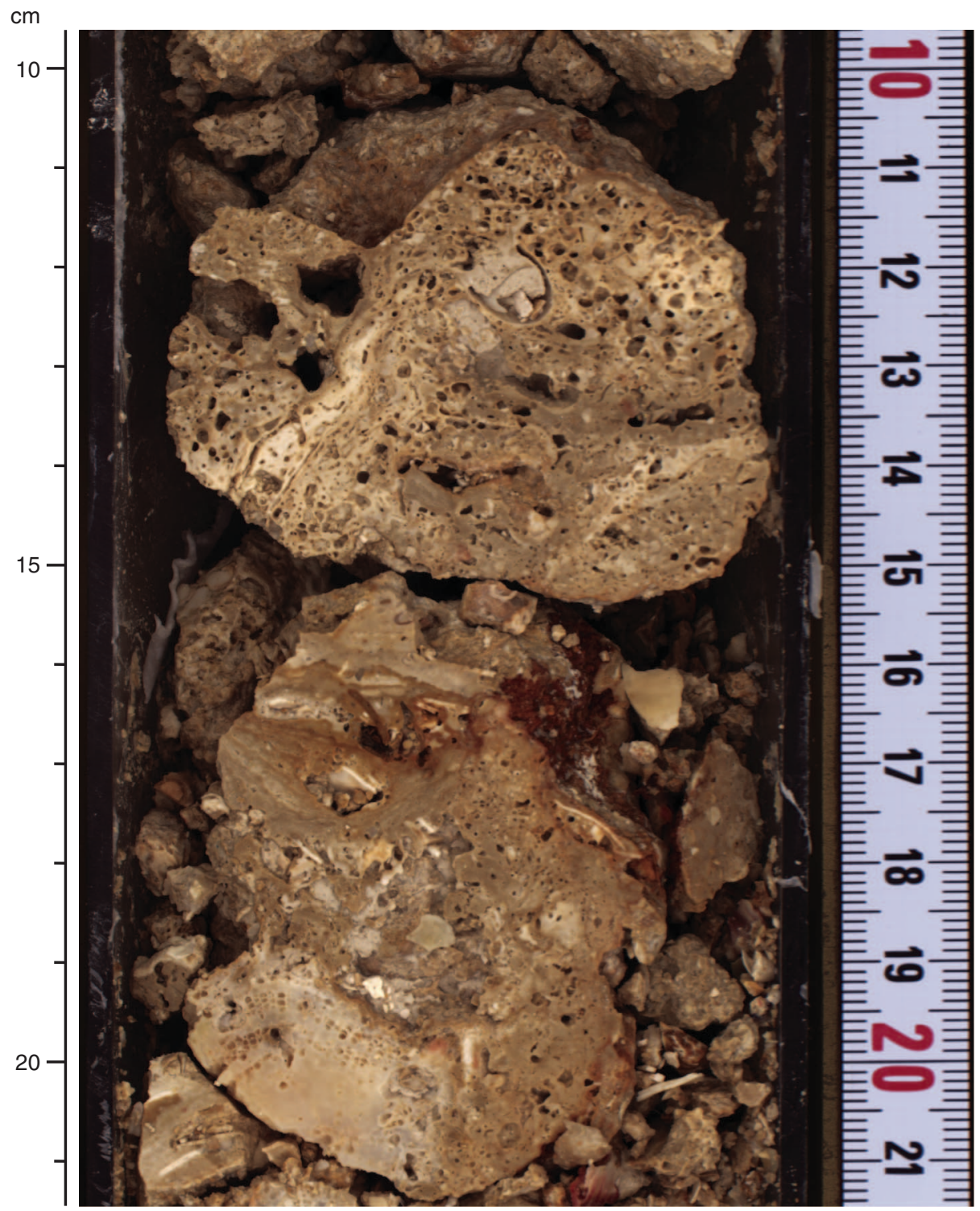


Figure F8. High-resolution line scan image of a massive Isopora colony (interval 325-M0031A-2R-1, 26-32 cm).

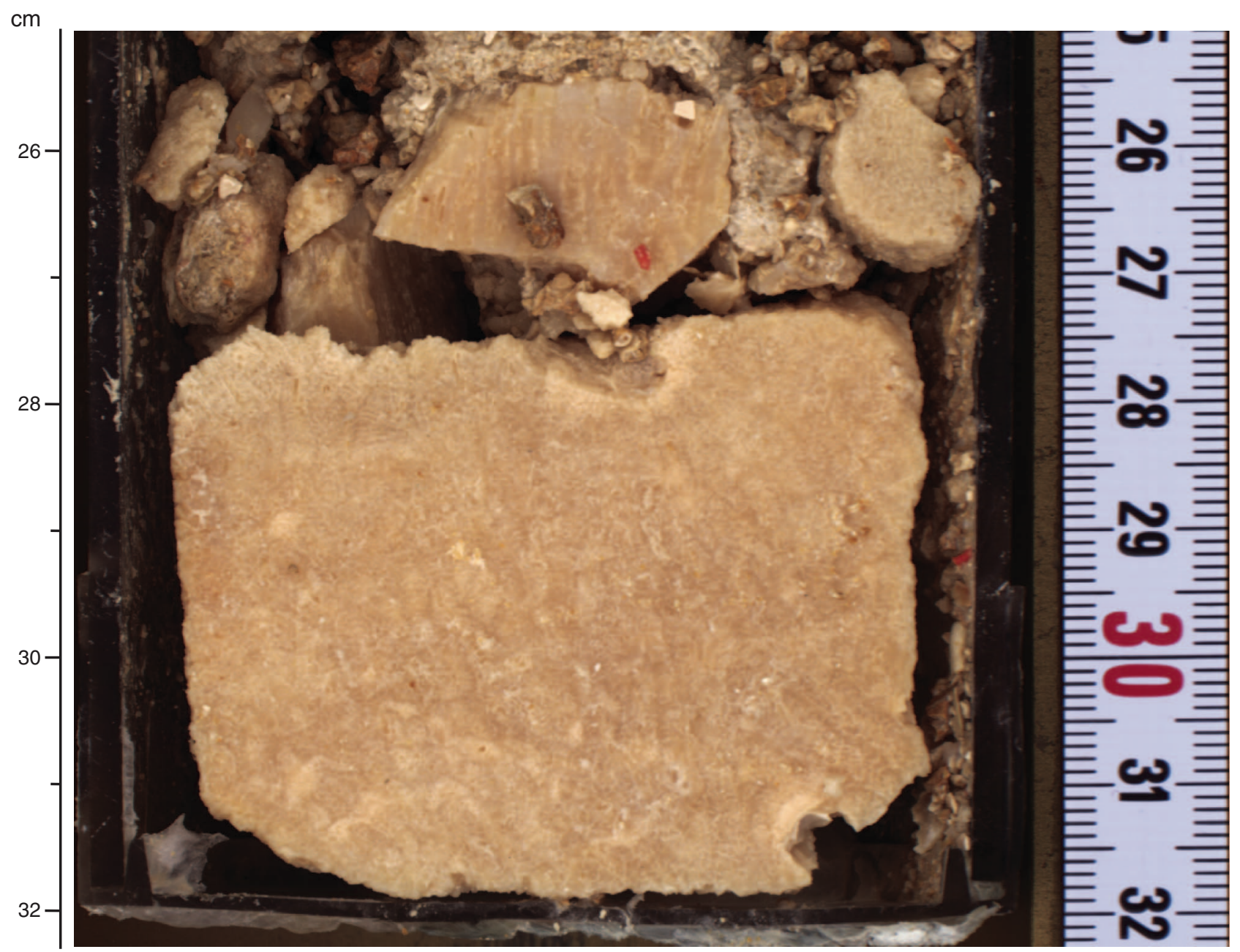


Figure F9. High-resolution line scan image of a medium branching corymbose(?) Acropora (in situ?) (interval 325-M0031A-8R-1, 30-40 cm).

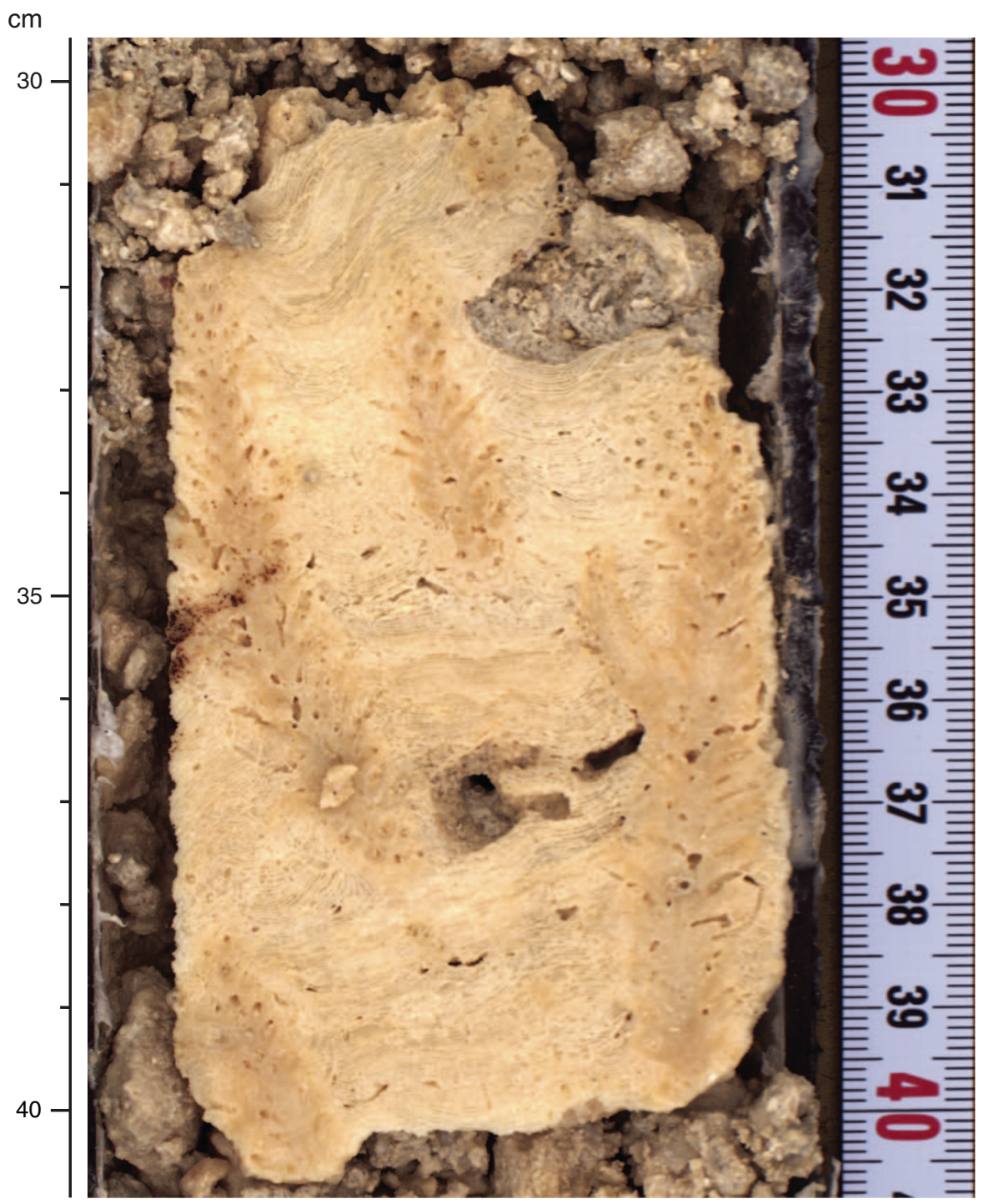


Figure F10. High-resolution line scan image of a medium branching corymbose(?) Acropora colony (in situ?) (interval 325-M0031A-8R-CC, 1-7 cm).

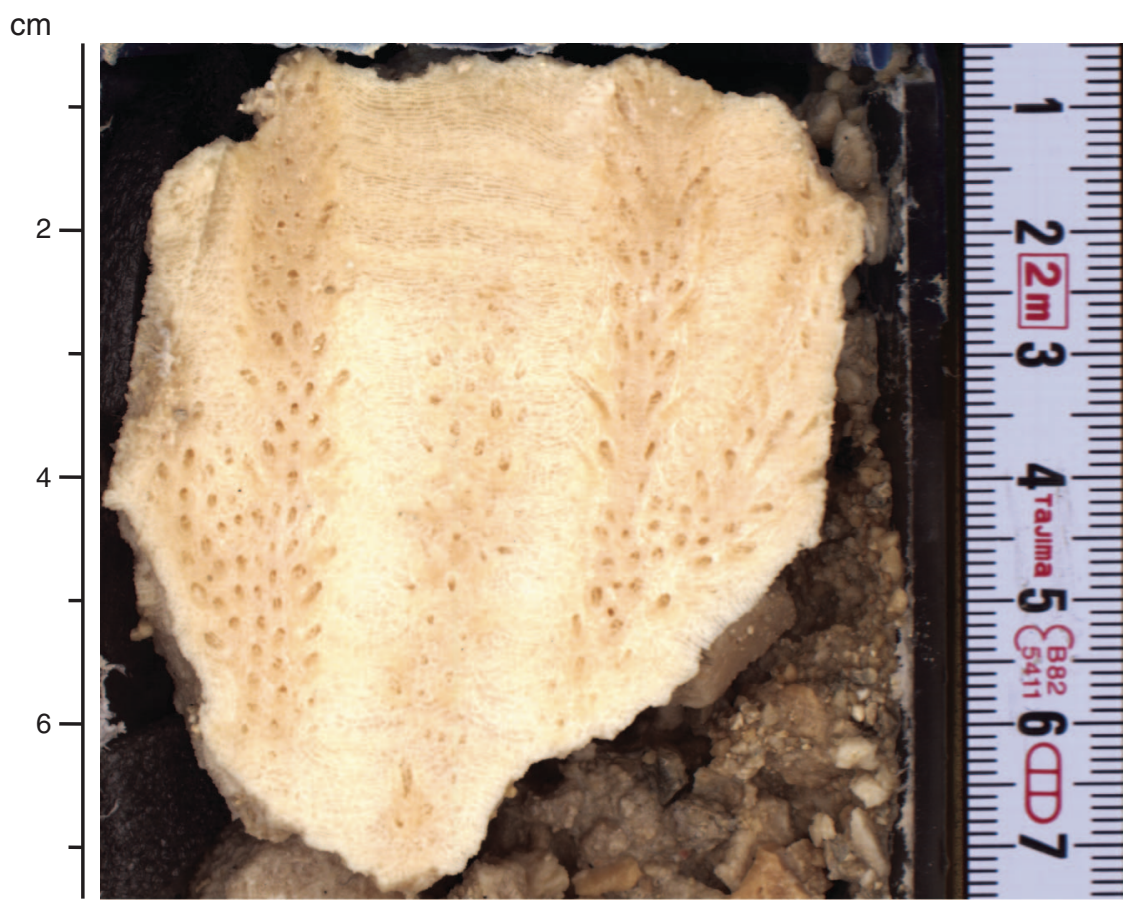


Figure F11. High-resolution line scan image of grainstone with benthic foraminifers, coralline algae, and mollusks (interval 325-M0031A-15R-1, 16-22 cm).

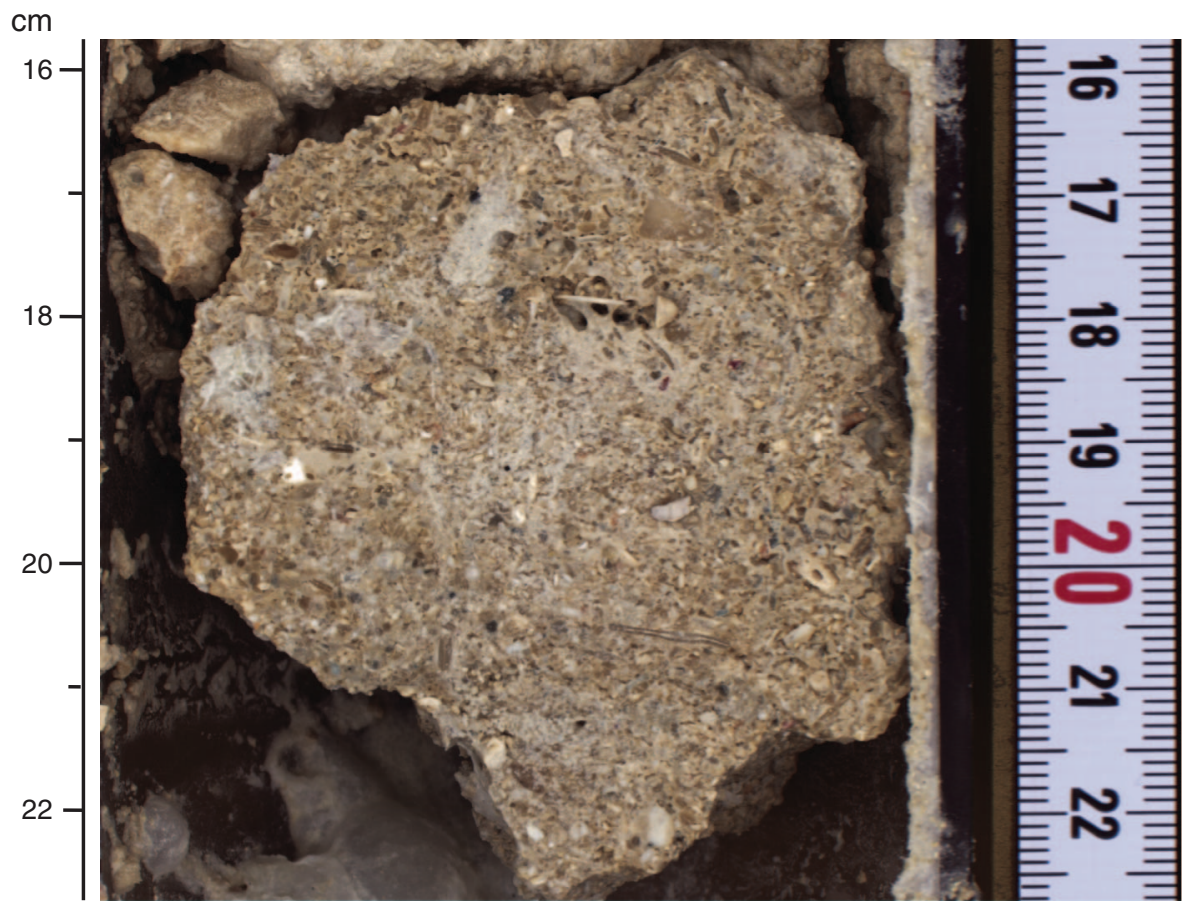


Figure F12. High-resolution line scan image of a large Tridacna fragment (interval 325-M0031A-16R-1, 1-5 cm).

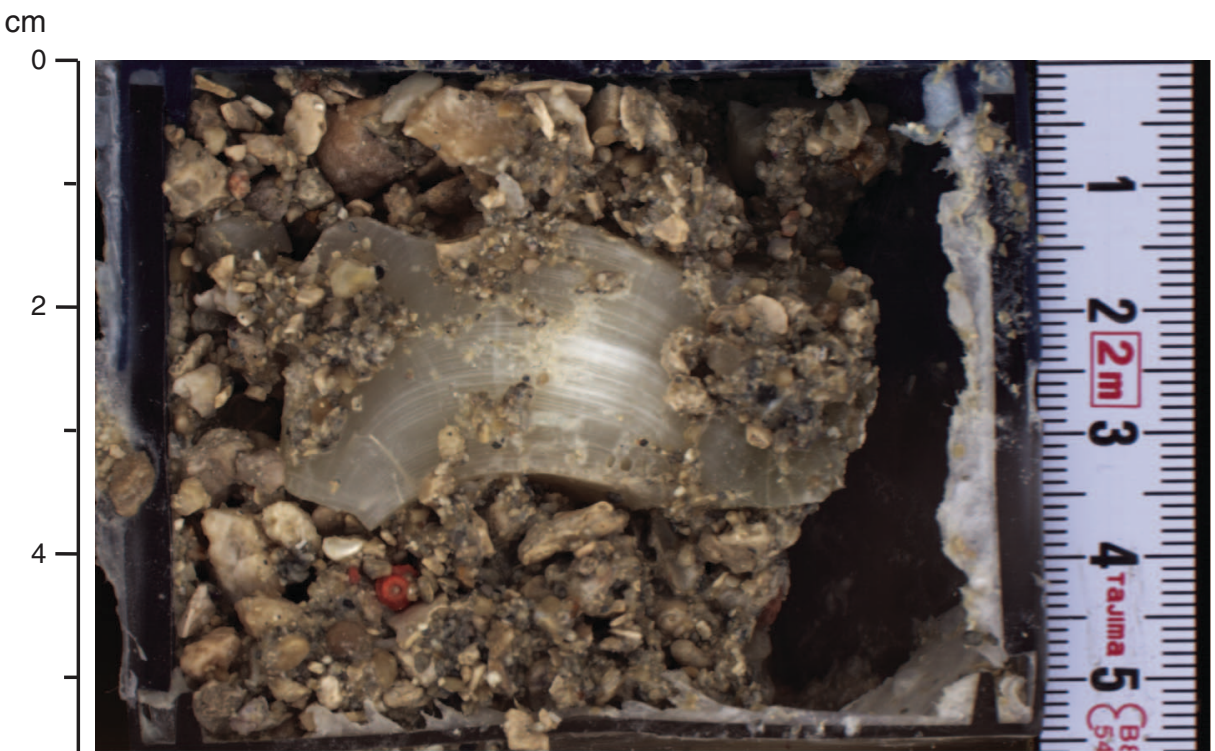


Figure F13. Summary diagram showing data collected on whole cores using the MSCL, Hole M0031A.

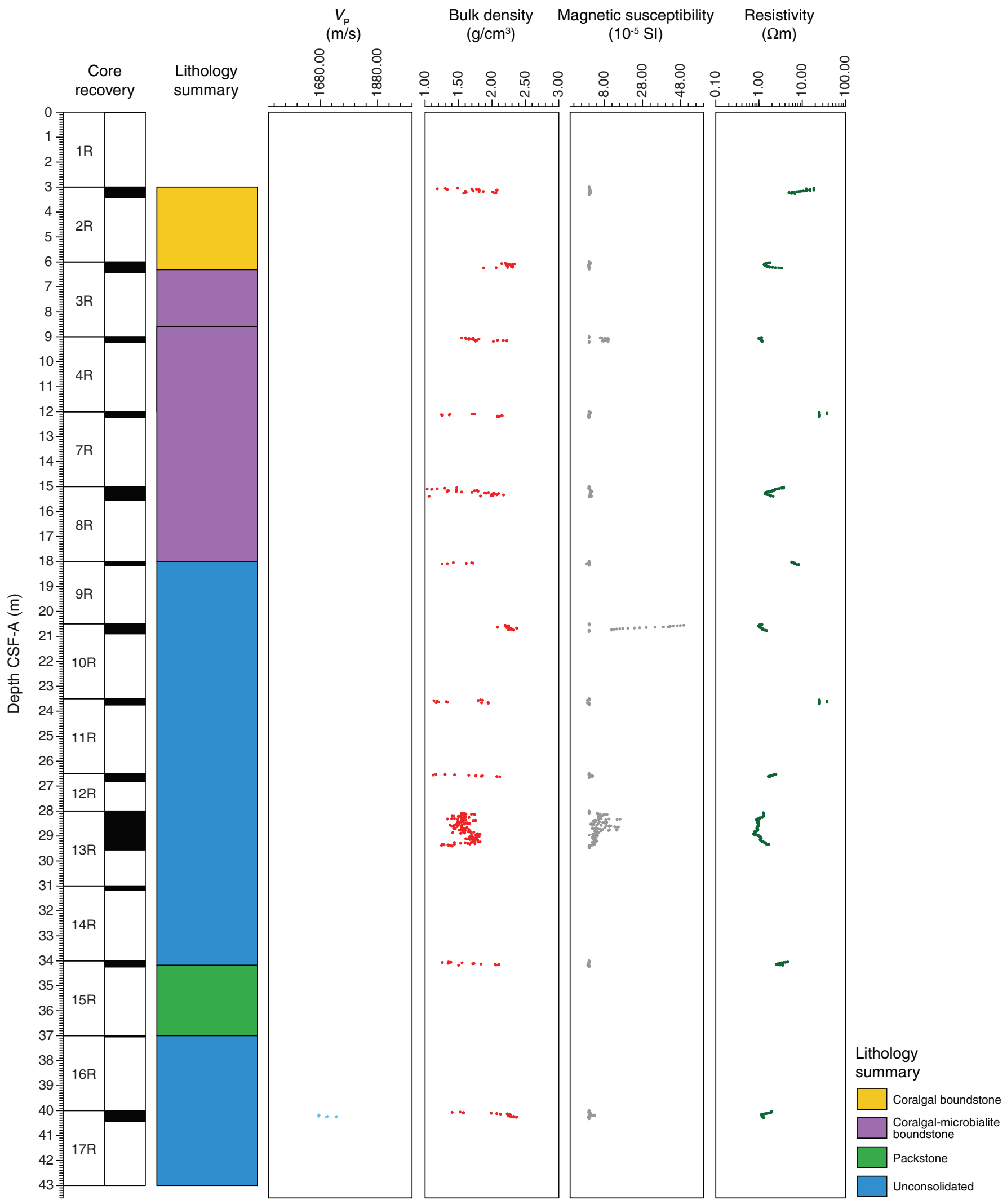


Figure F14. Petrophysical measurements obtained from discrete samples with a pycnometer, Hole M0031A. Bulk density measured on whole cores with the MSCL is shown in red on the bulk density plot.

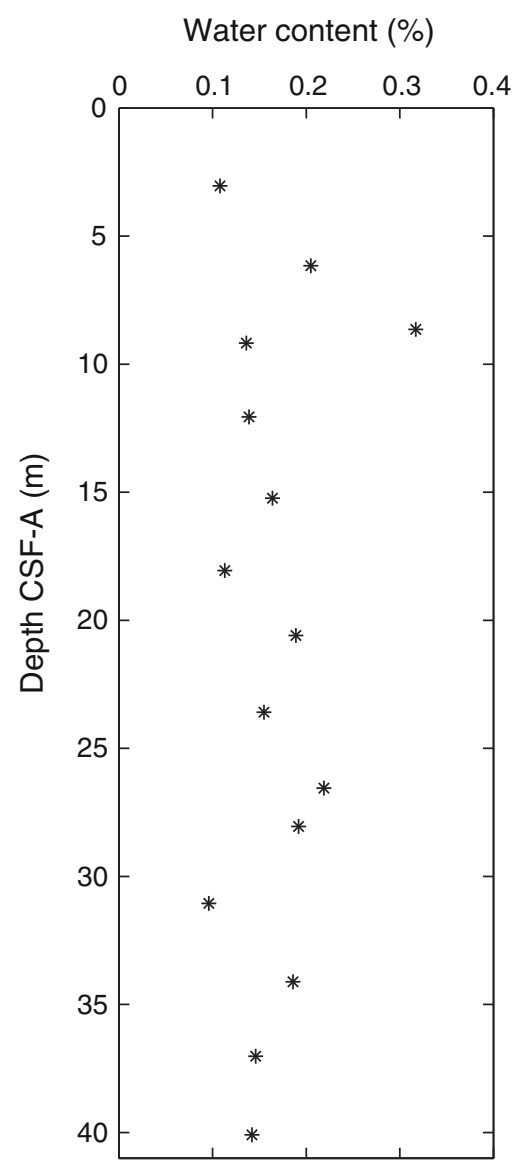

\section{Bulk density $\left(\mathrm{g} / \mathrm{cm}^{3}\right)$}

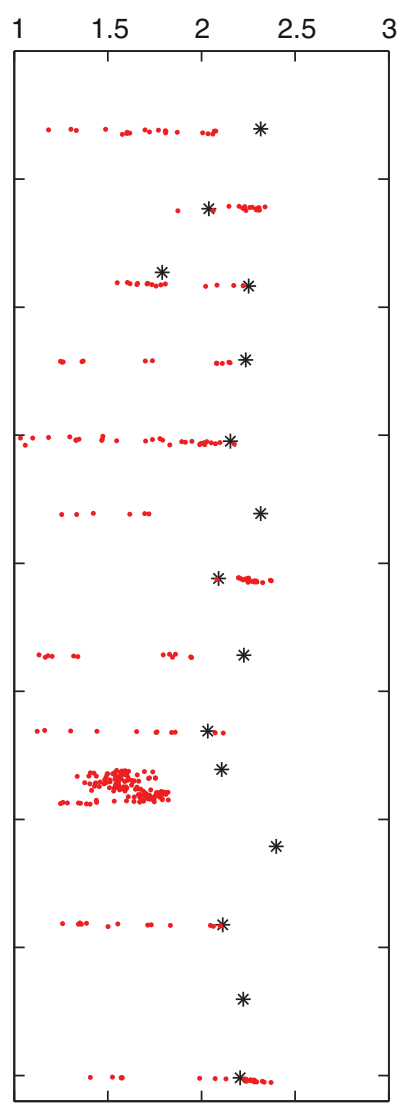

Grain density $\left(\mathrm{g} / \mathrm{cm}^{3}\right)$

Porosity (\%)

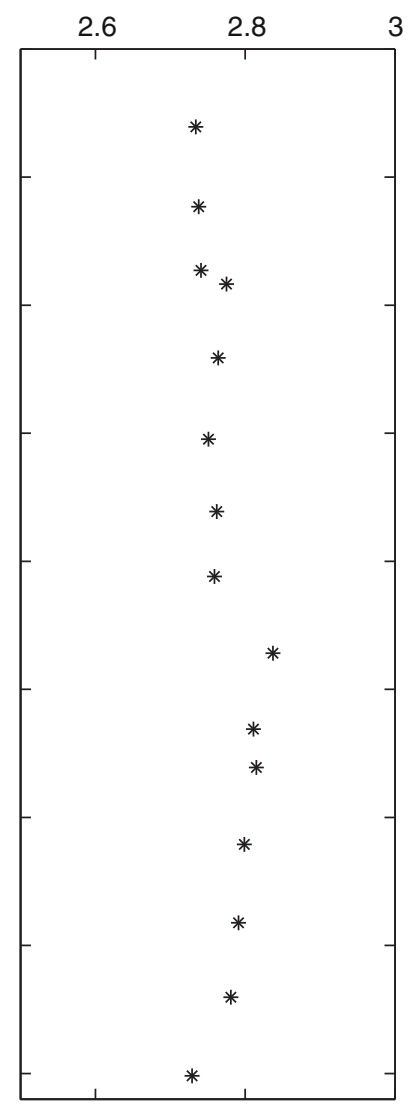

30

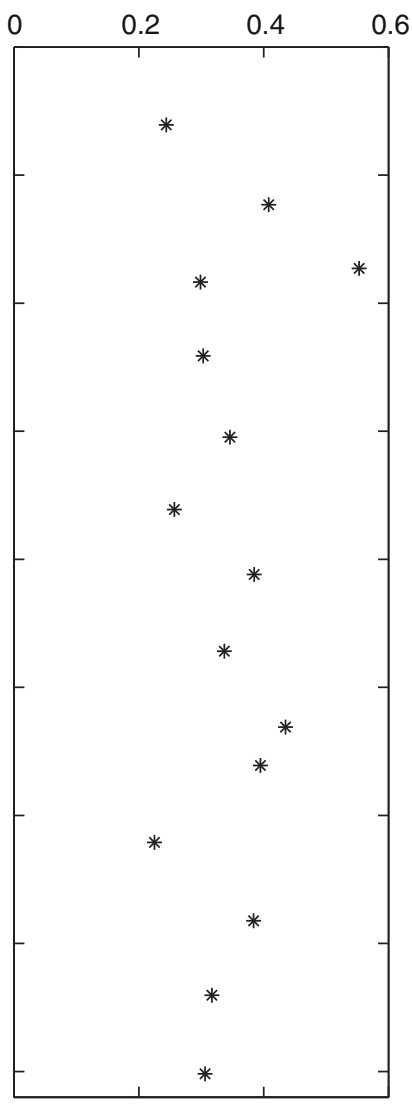


Figure F15. Values of reflectance $\left(\mathrm{L}^{*}\right)$, green to red $\left(\mathrm{a}^{*}\right)$, and blue to yellow $\left(\mathrm{b}^{\star}\right)$ indexes, along with ratio $\mathrm{a}^{*} / \mathrm{b}^{*}$ for Hole M0031A.

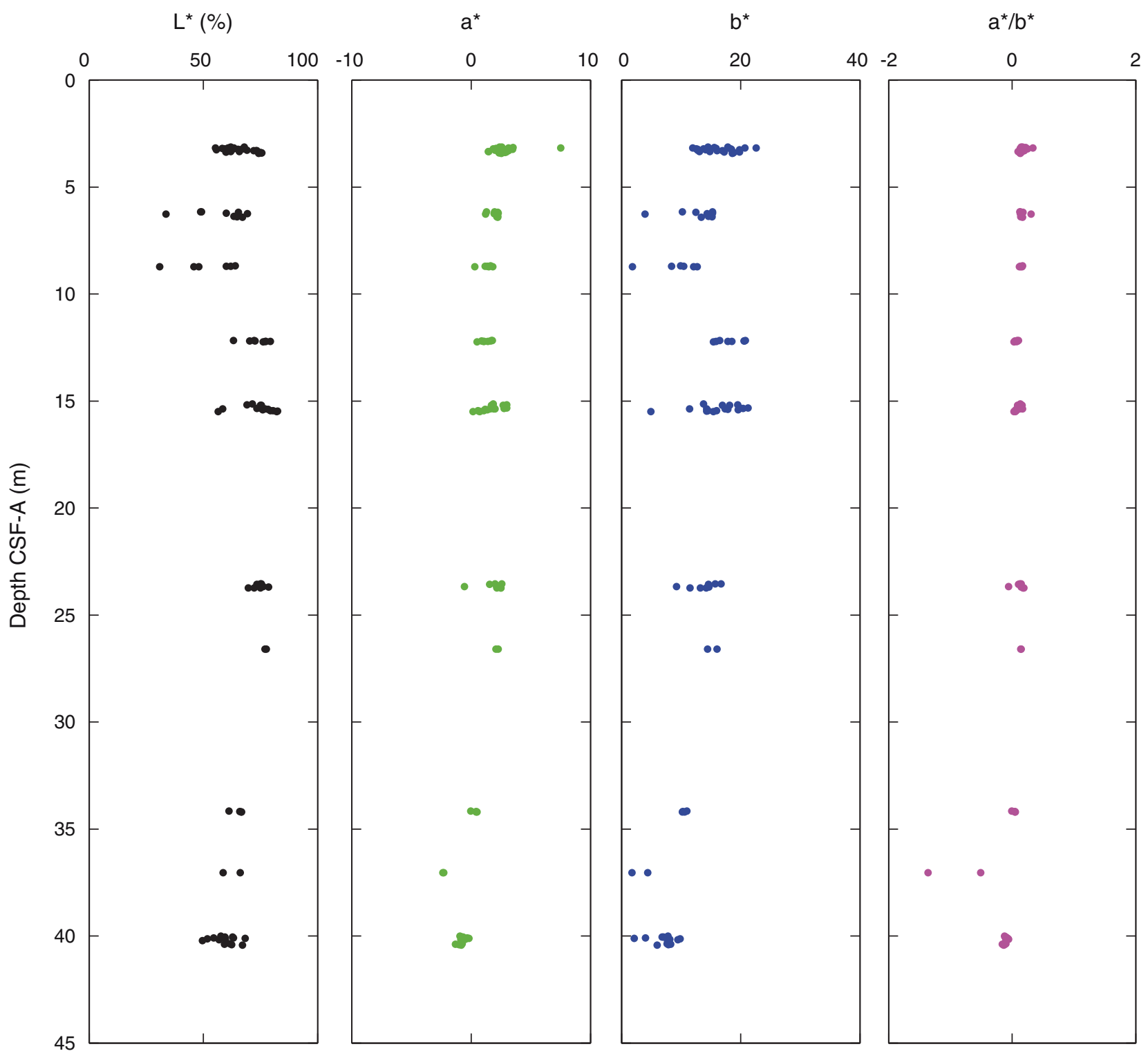


Figure F16. Magnetic susceptibility record for Hole M0031A. Water depth $=90.05 \mathrm{~m}$ (lowest astronomical tide). Magnetic susceptibility $\left(10^{-8} \mathrm{~m}^{3} / \mathrm{kg}\right)$

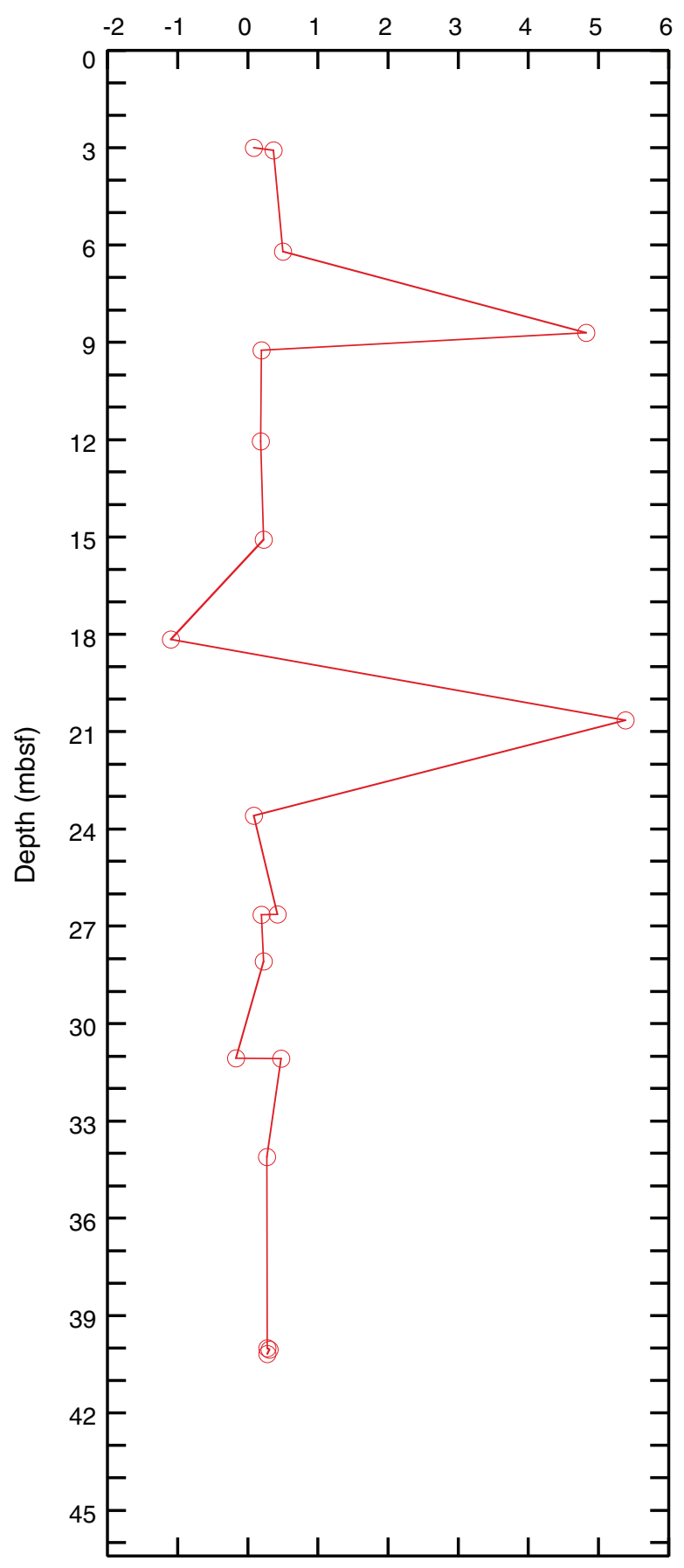


Figure F17. Preliminary chronology for Hole M0031A. Radiocarbon data are presented as graphs with the uncalibrated radiocarbon age and uncertainty shown as the red normal distribution on the ordinate axis and the probability distribution of the calibrated age shown in gray on the abscissa. The marine09 calibration curve is shown in blue. Horizontal bars indicate portions of the age distribution that are significant at the $95.4 \%$ confidence interval and the mean age (white circle \pm 1 standard deviation) used for the purposes of the preliminary dating. All ages are presented as thousands of calendar years BP (1950 AD). See Table T10 in the "Methods" chapter. (See Bronk Ramsey [2009], as well as Bronk Ramsey [2010] at c14.arch.ox.ac.uk/oxcal.html.)
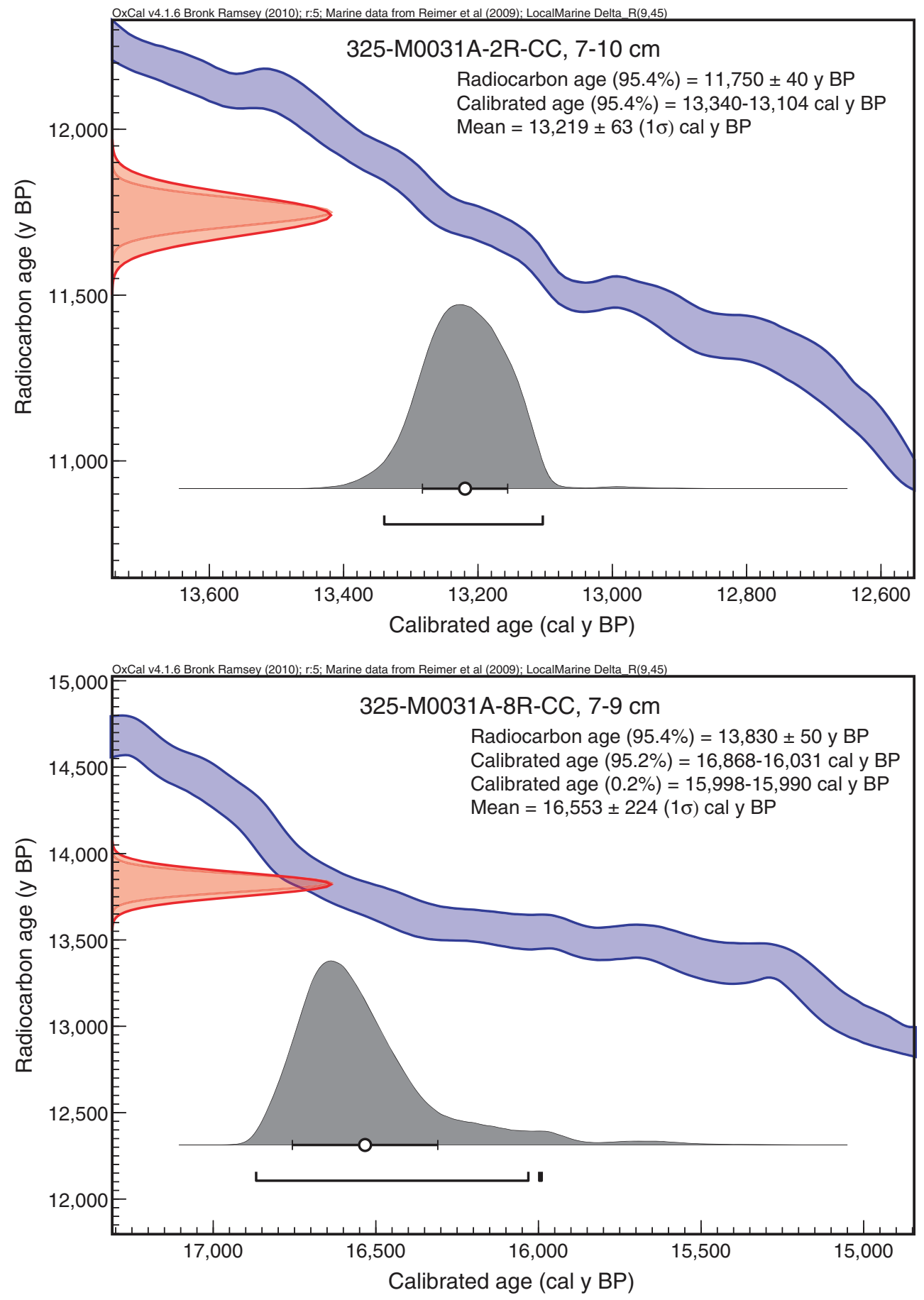
Figure F18. Composite showing all logging data collected in Hole M0031A. TGR $=$ total gamma ray (raw), $\mathrm{TP}=$ through pipe. ${ }^{*}=$ negative values removed. (This figure is also available in an oversized format.)

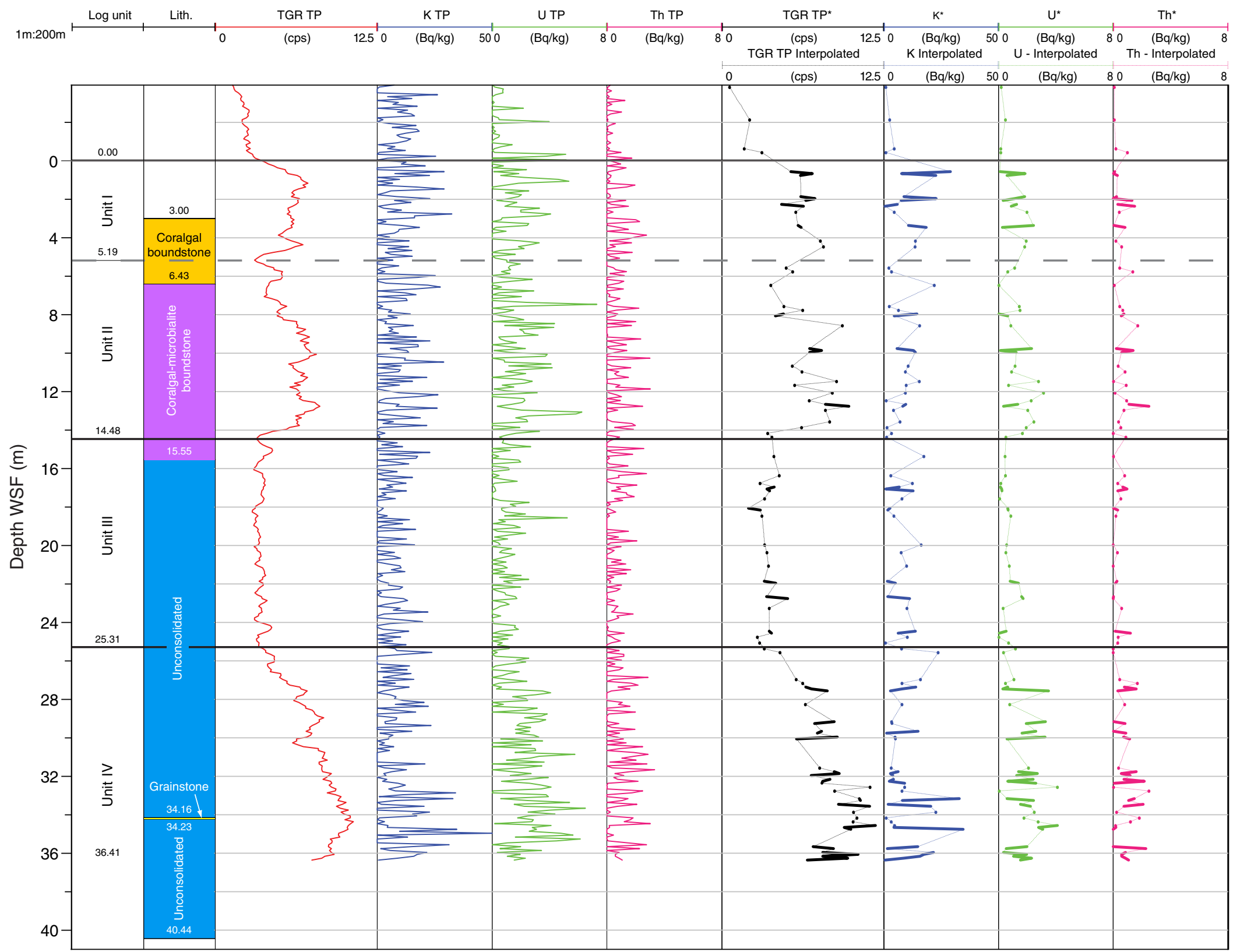


Figure F19. High-resolution line scan image of a massive Montipora colony (interval 325-M0032A-1R-1, 27-35 $\mathrm{cm})$.

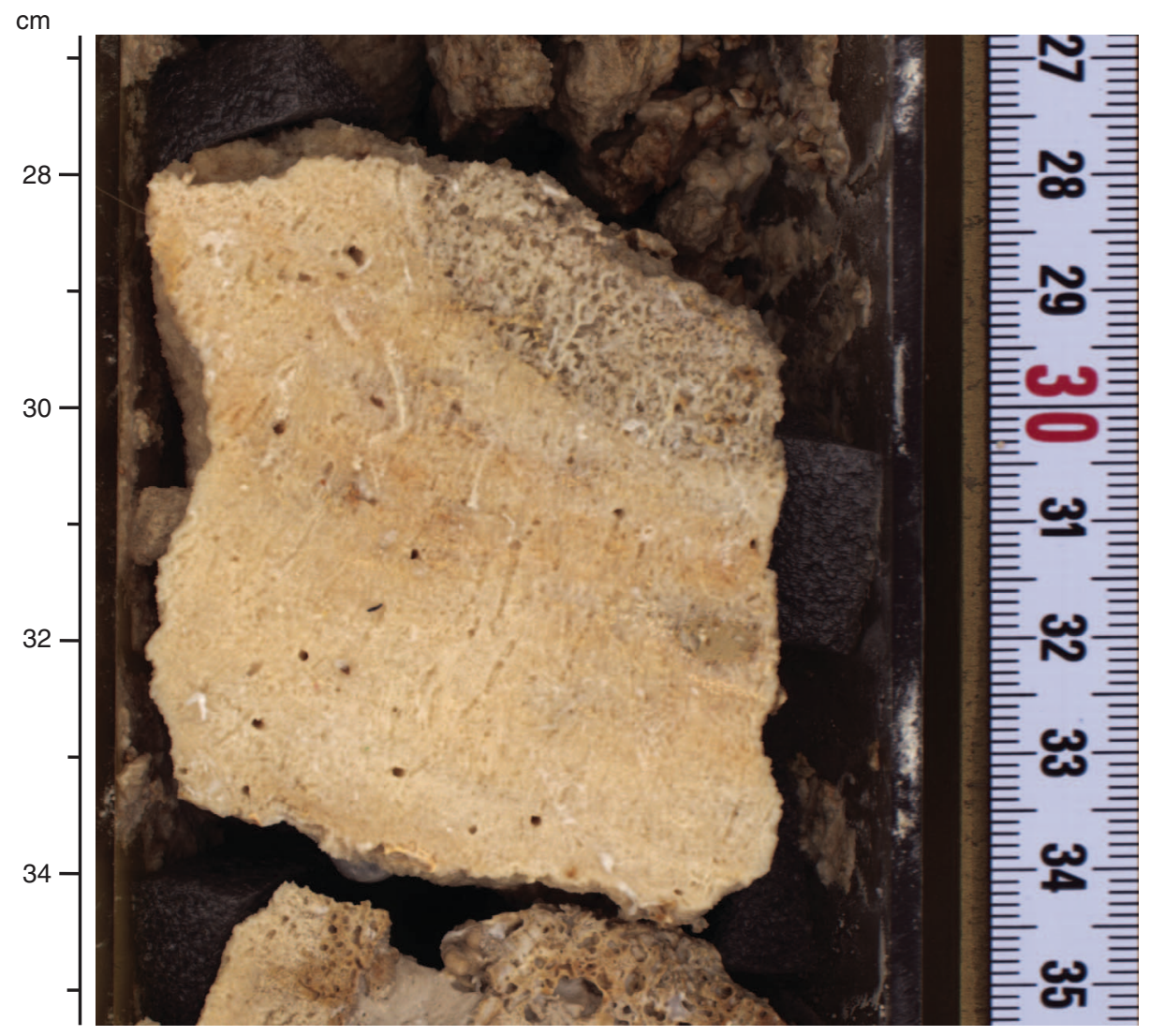


Figure F20. High-resolution line scan image of laminated microbialite (interval 325-M0032A-3R-CC, 10-14 $\mathrm{cm})$.

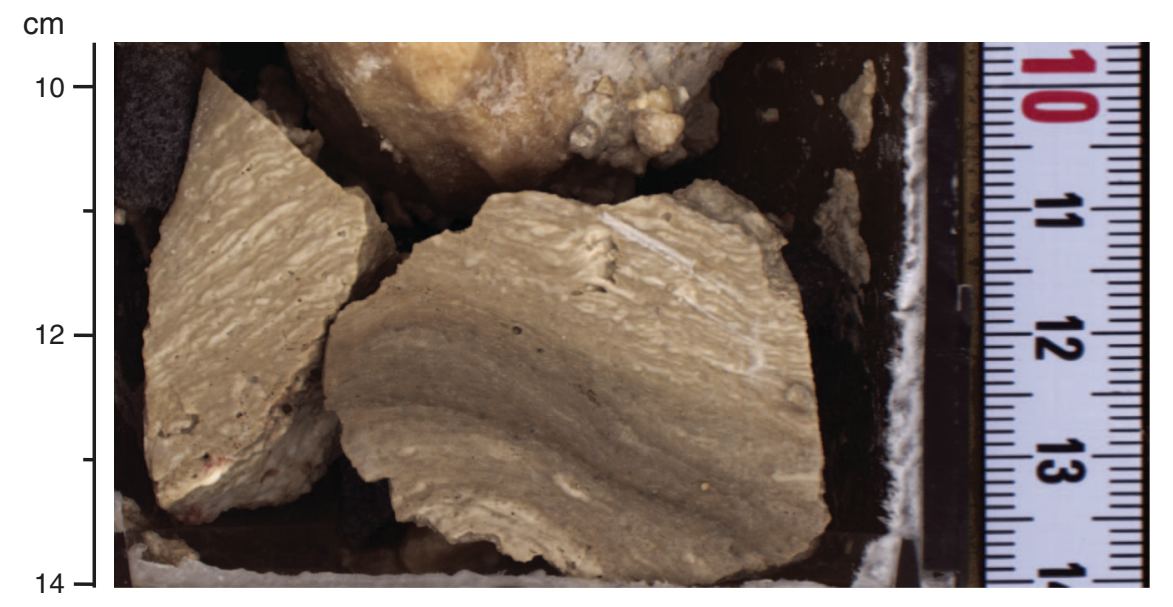


Figure F21. High-resolution line scan image of mixed corals, including Faviidae and Porites(?), with thick coralline algal crusts and thin microbialite crusts (interval 325-M0032A-11R-1, 30-38 cm).

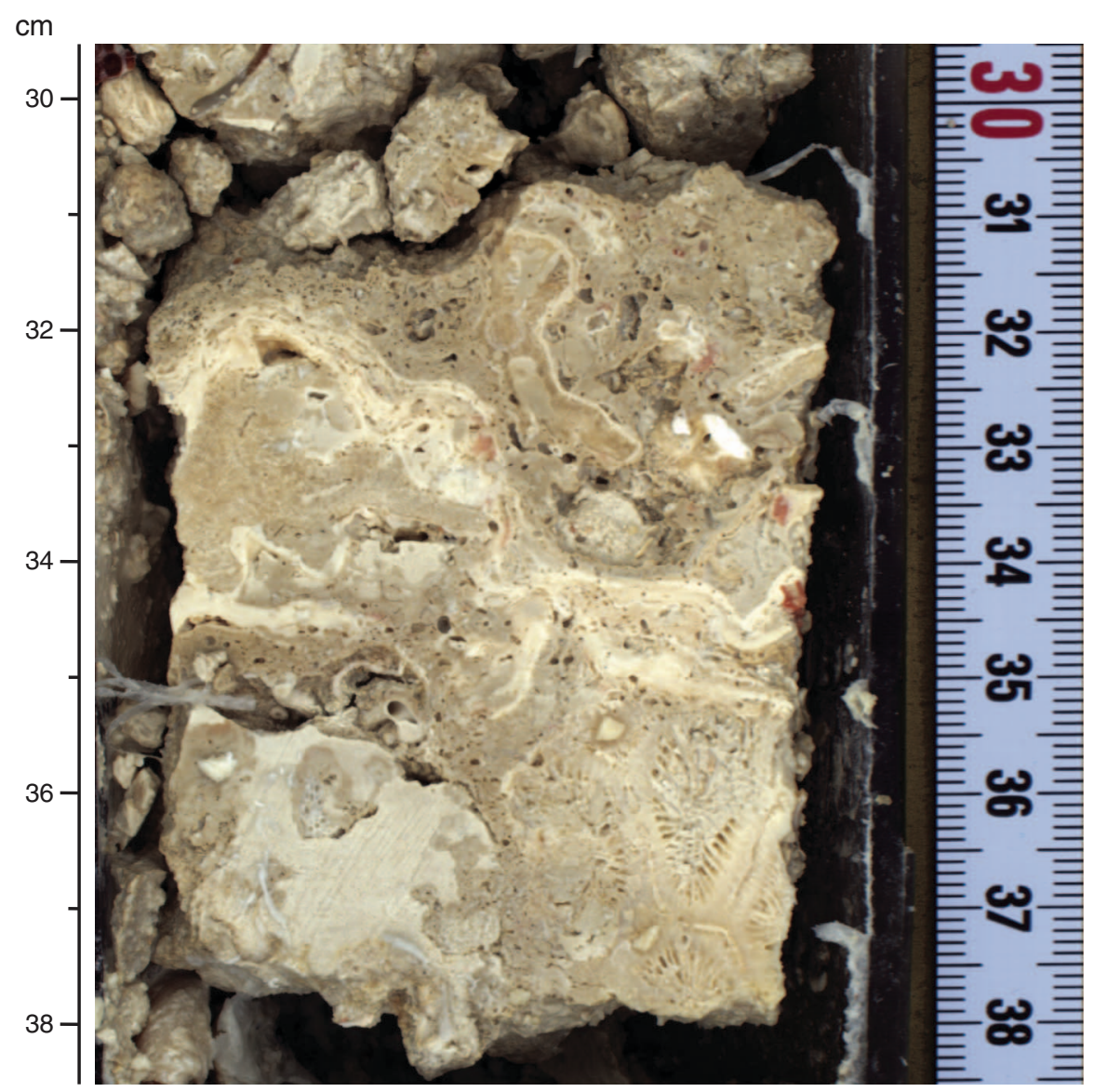


Figure F22. High-resolution line scan image of coralgal boundstone with staining on the cavity (interval 325M0032A-11R-1, 22-28 cm).

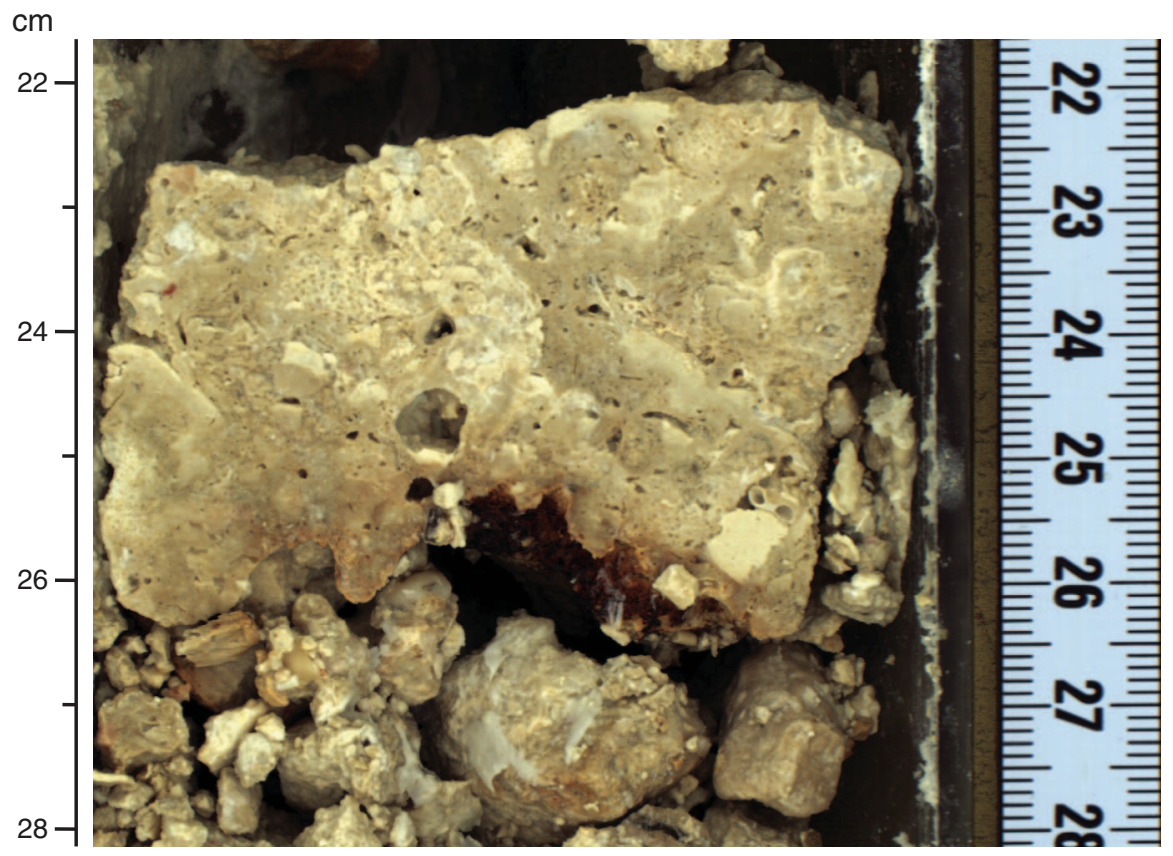


Figure F23. High-resolution line scan image of a massive in situ Isopora colony (interval 325-M0032A-8R-2, 1$27 \mathrm{~cm})$.

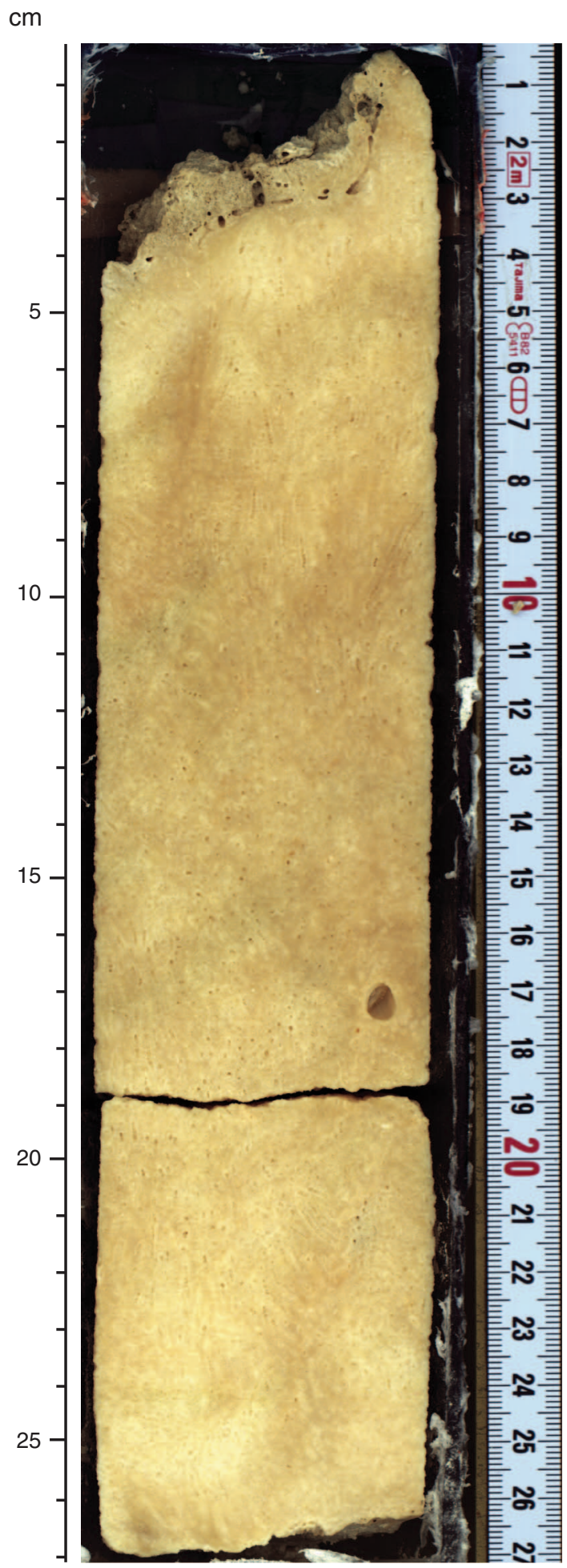


Figure F24. High-resolution line scan image of a medium branching Pocillopora (?) with thick coralline crust (interval 325-M0032A-7R-CC, 5-10 cm).

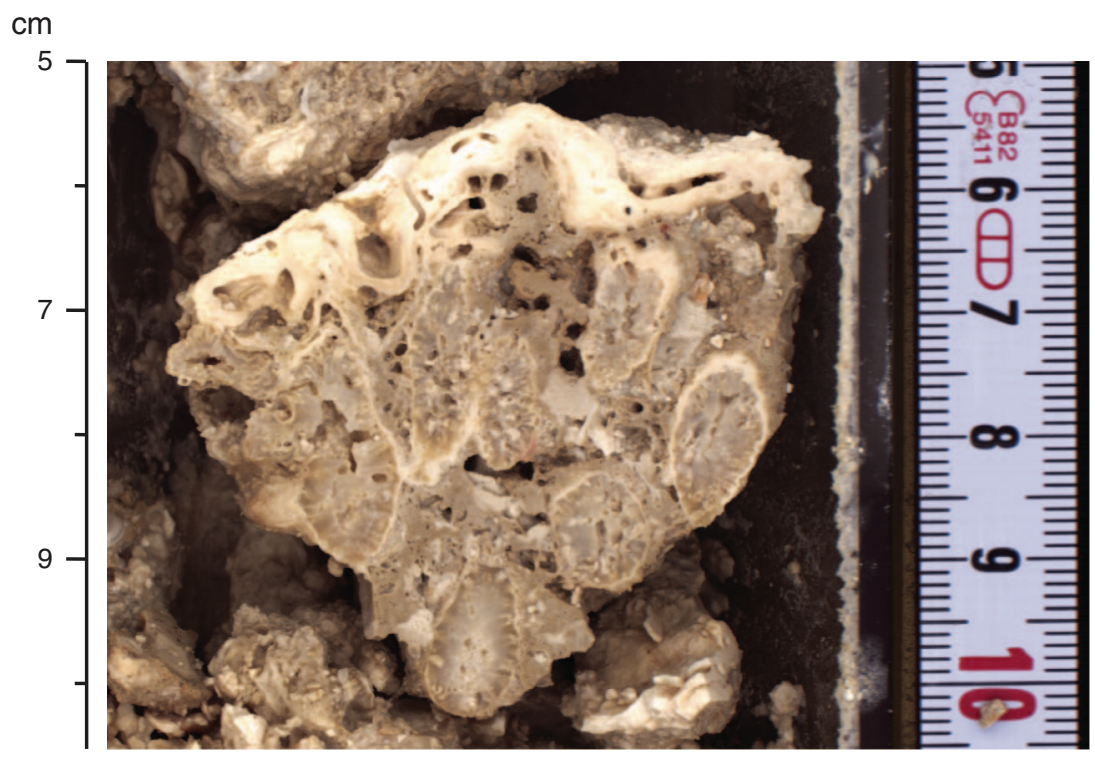


Figure F25. Summary diagram showing data collected on whole cores using the MSCL, Hole M0032A.

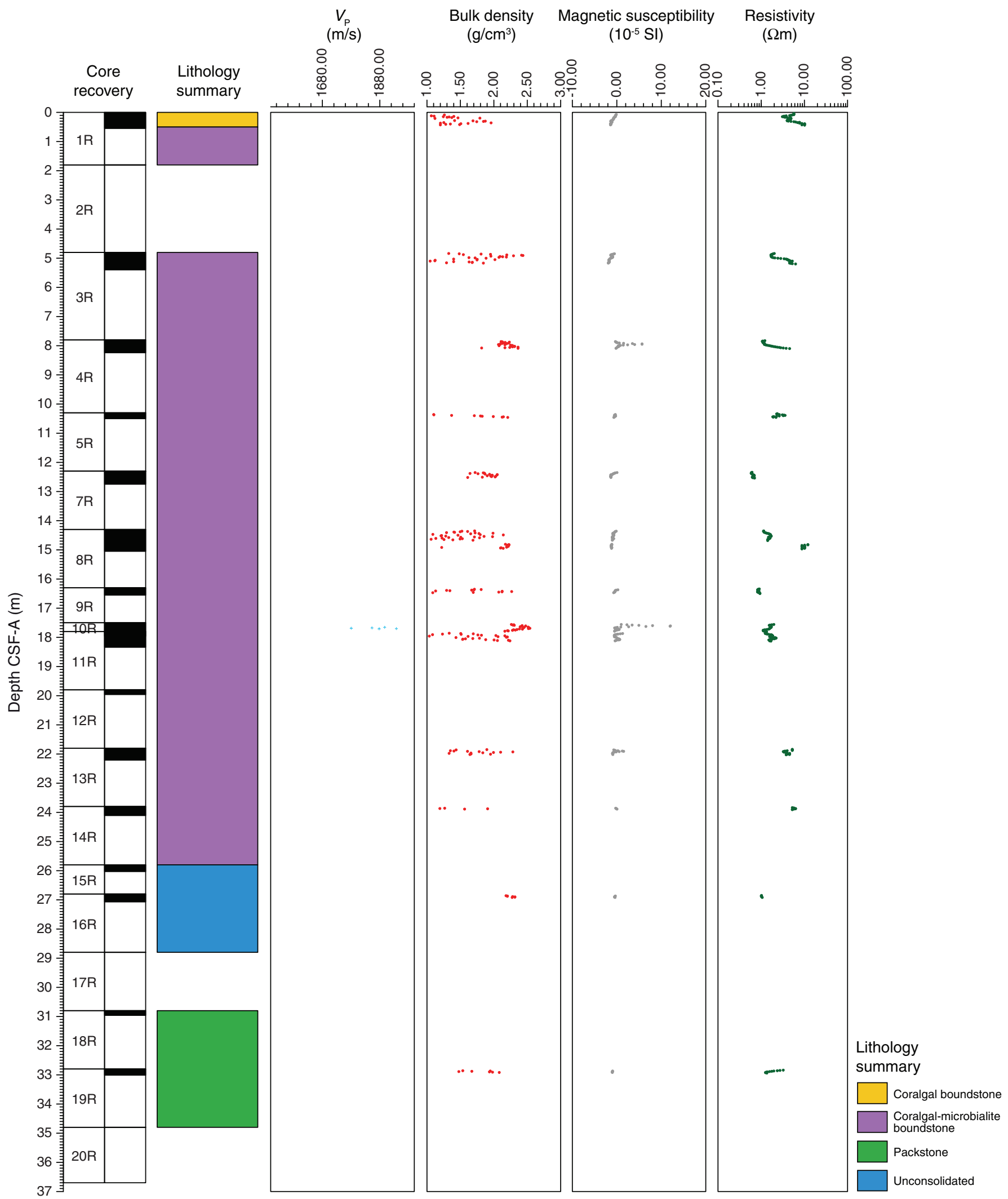


Figure F26. Petrophysical measurements obtained from discrete samples with a pycnometer, Hole M0032A. Bulk density measured on whole cores with the MSCL is shown in red on the bulk density plot.

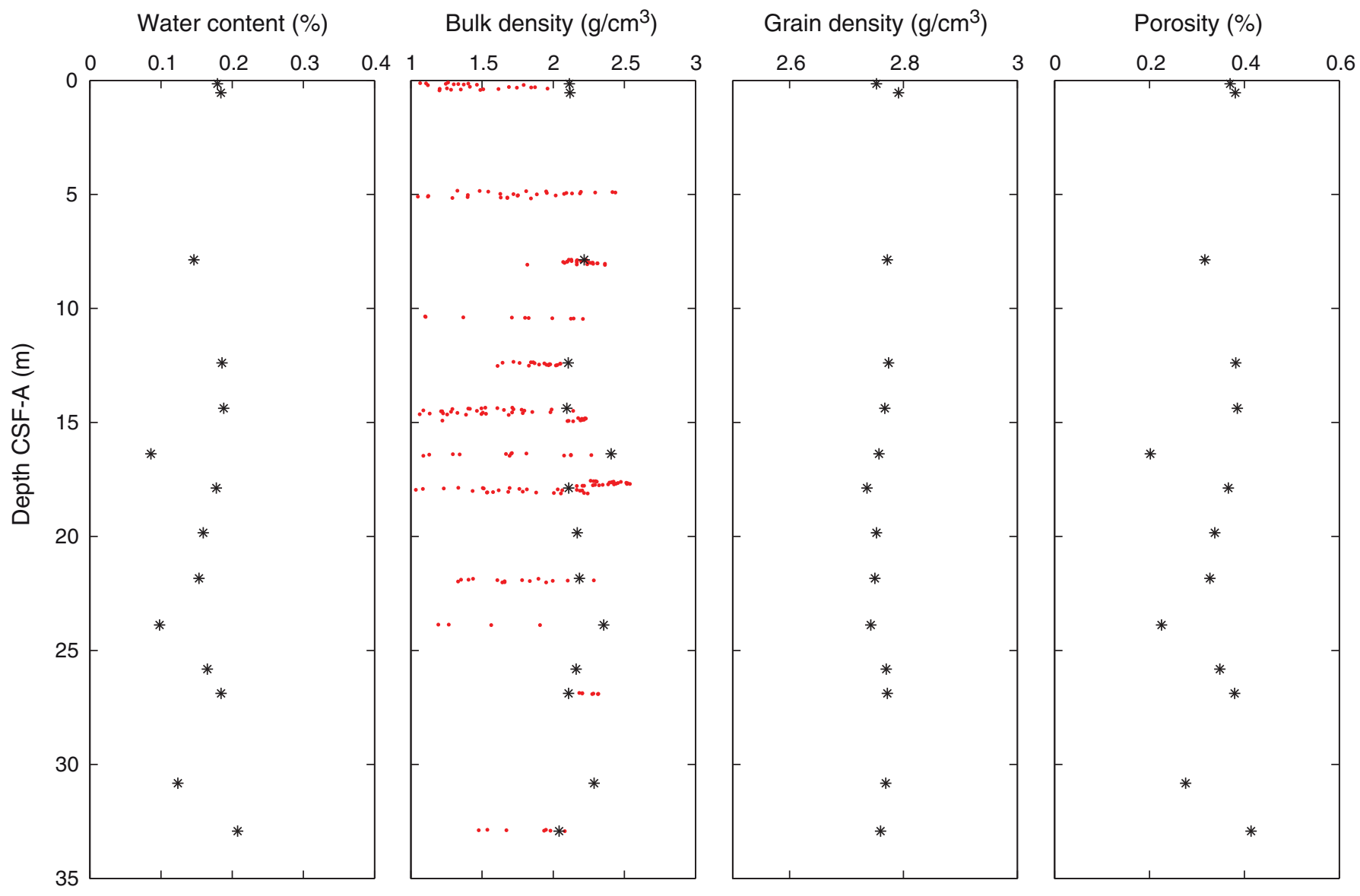


Figure F27. Values of reflectance $\left(\mathrm{L}^{*}\right)$, green to red $\left(\mathrm{a}^{*}\right)$, and blue to yellow $\left(\mathrm{b}^{*}\right)$ indexes, along with ratio $\mathrm{a}^{*} / \mathrm{b}^{*}$ for Hole M0032A.

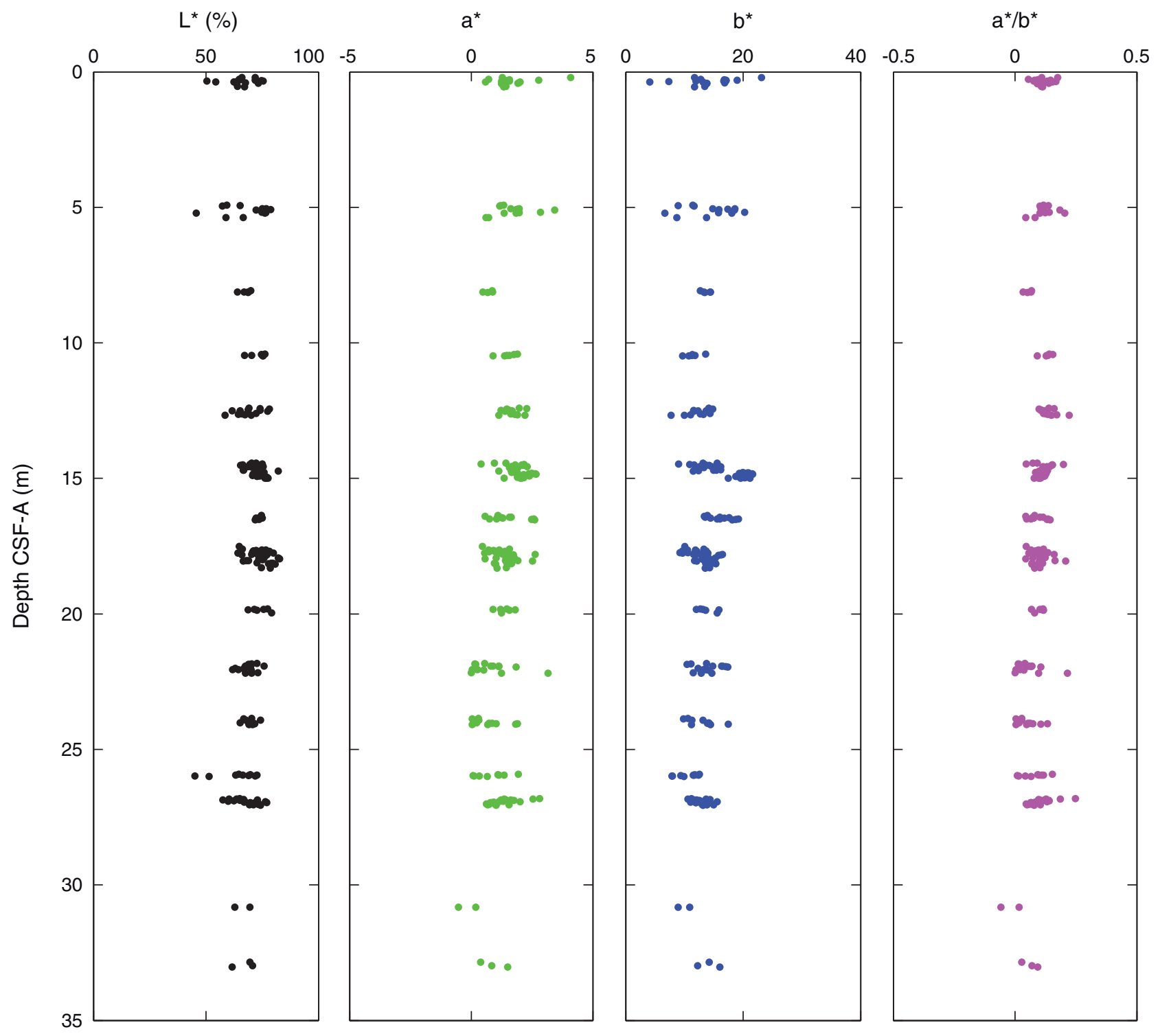


Figure F28. Magnetic susceptibility record for Hole M0032A. Water depth $=91.58 \mathrm{~m}$ (lowest astronomical tide).

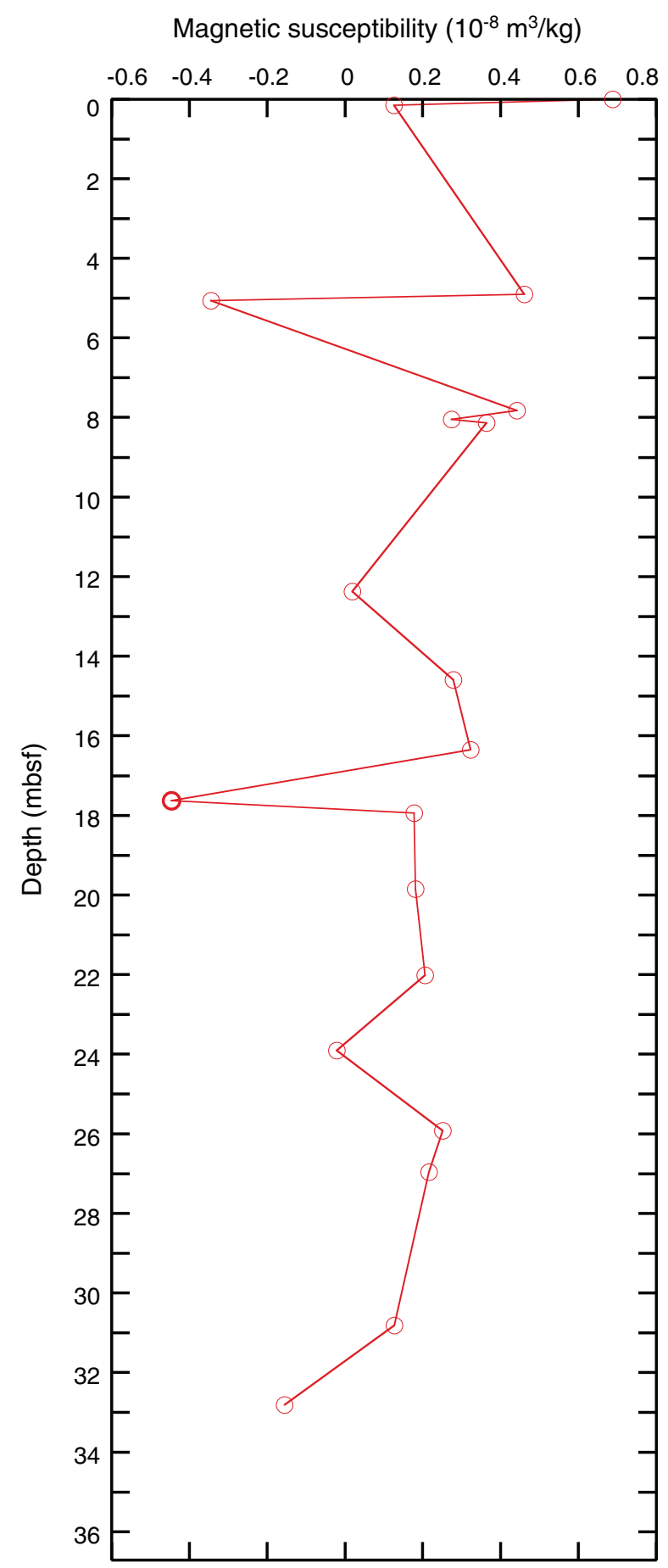


Figure F29. Preliminary chronology for Hole M0032A. Radiocarbon data are presented as graphs with the uncalibrated radiocarbon age and uncertainty shown as the red normal distribution on the ordinate axis and the probability distribution of the calibrated age shown in gray on the abscissa. The marine09 calibration curve is shown in blue. Horizontal bars indicate portions of the age distribution that are significant at the $95.4 \%$ confidence interval and the mean age (white circle \pm 1 standard deviation) used for the purposes of the preliminary dating. All ages are presented as thousands of calendar years BP (1950 AD). See Table T10 in the "Methods" chapter. (See Bronk Ramsey [2009], as well as Bronk Ramsey [2010] at c14.arch.ox.ac.uk/oxcal.html.)
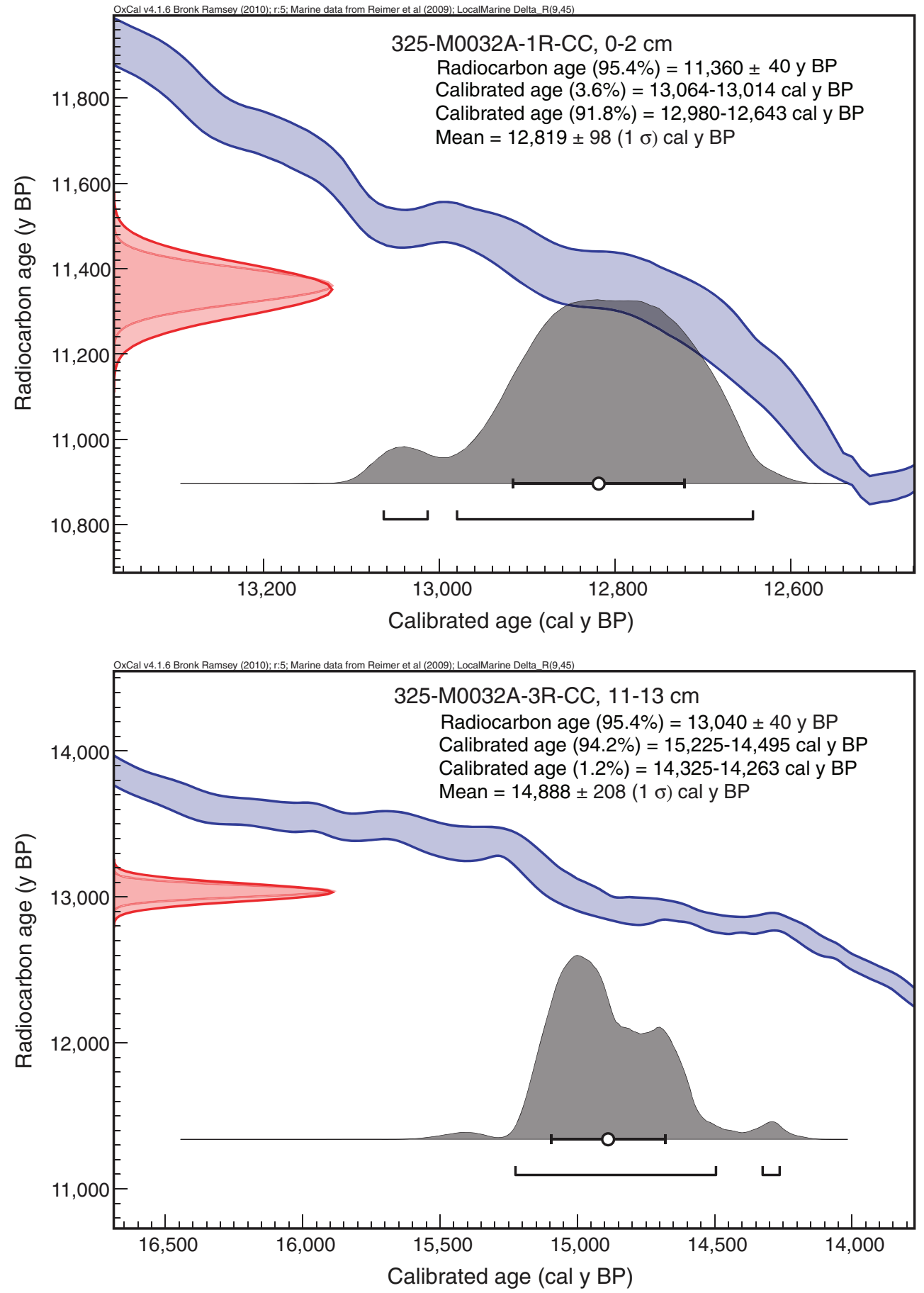
Figure F30. High-resolution line scan image showing a major lithologic boundary between packstone with bioclasts and thick coralline algae with vermetids and bryozoans (interval 325-M0033A-11R-1, 10-29 cm).

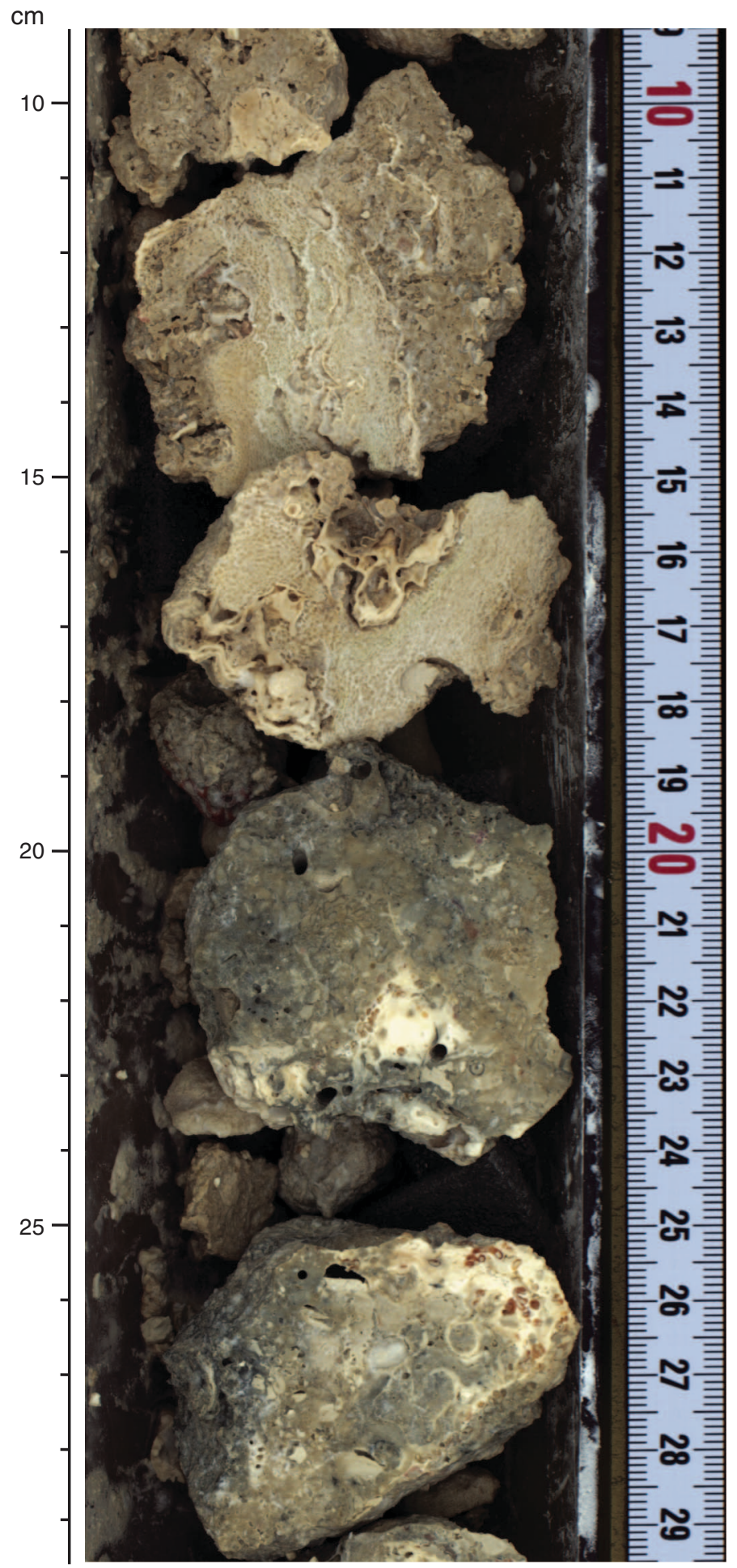


Figure F31. High-resolution line scan image of a medium branching Acropora encrusted by coralline algae and microbialites (interval 325-M0033A-5R-1, 99-124 cm) and (at top) a massive Isopora colony and some columnar microbialite.

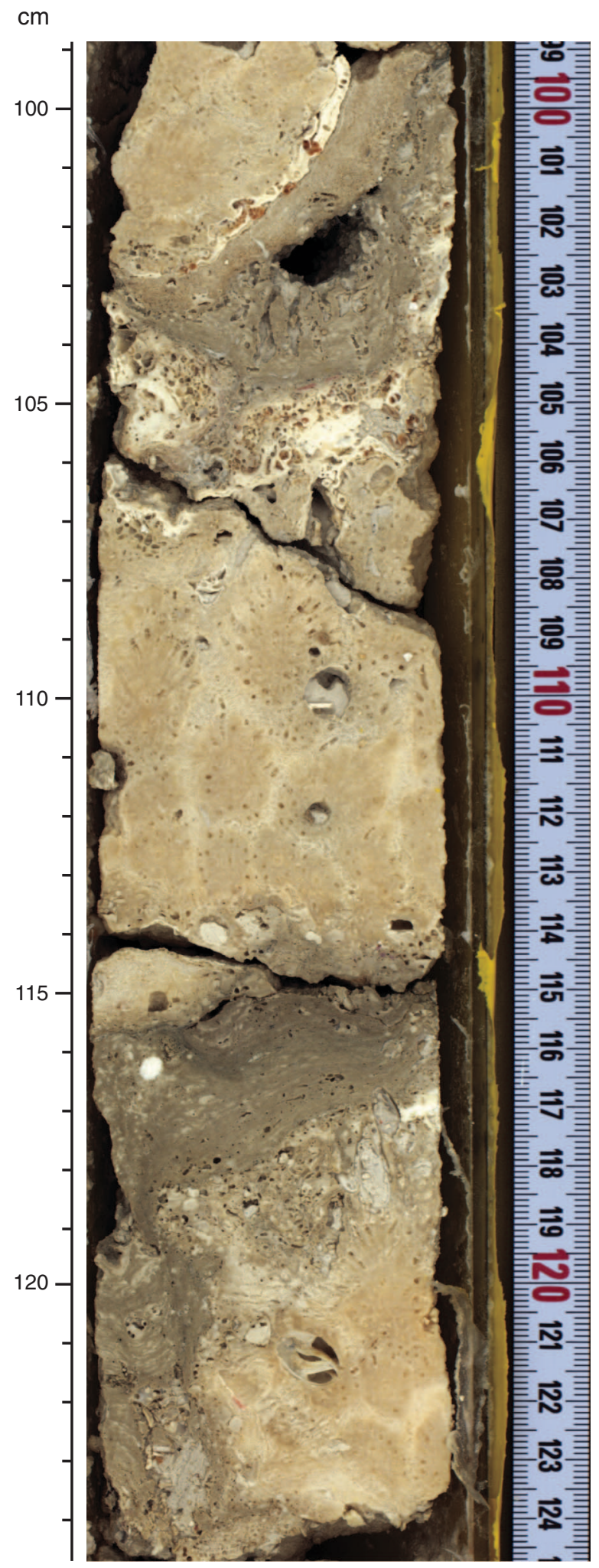


Figure F32. High-resolution line scan image of a branching Acropora (with massive base; in situ?) and a thick coralline algal crust (interval 325-M0033A-3R-CC, 0-6 cm).

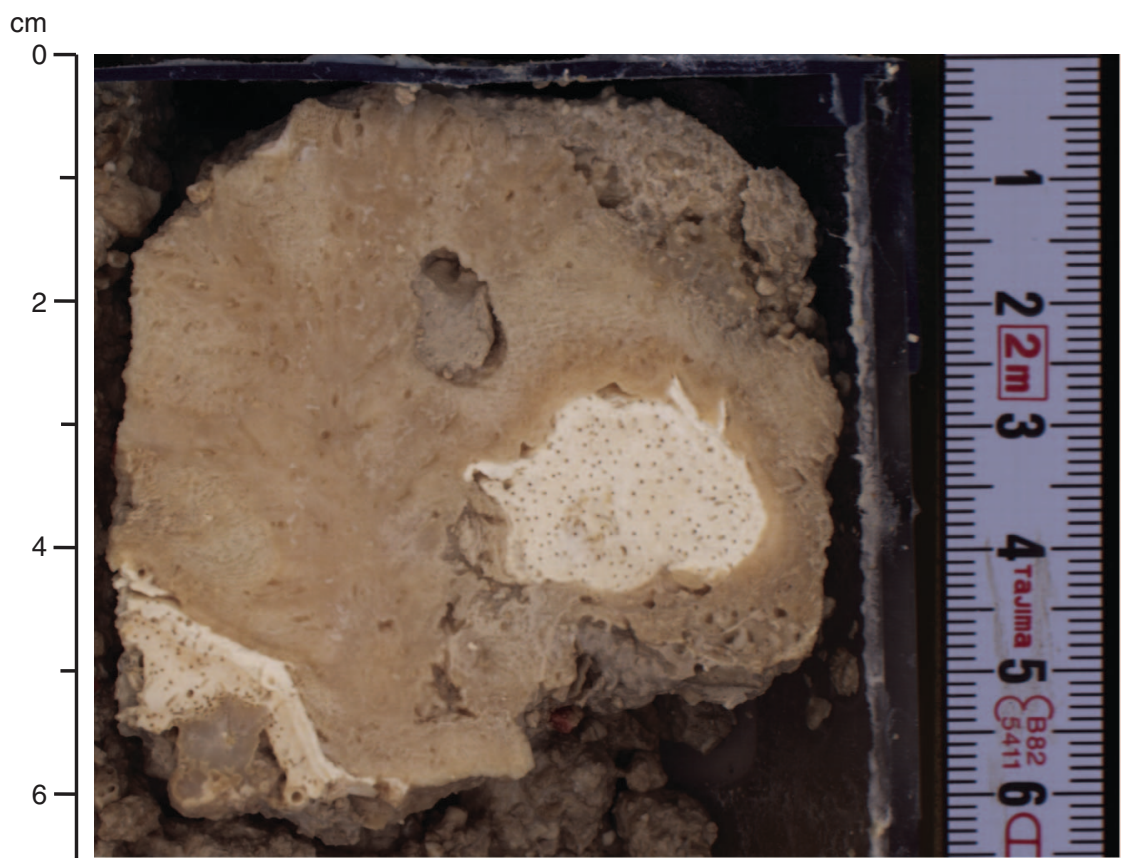


Figure F33. High-resolution line scan image of a massive Isopora colony (in situ?) encrusted by thick coralline algae and thick laminated microbialite crusts containing vermetids (interval 325-M0033A-5R-1, 76-99 cm).

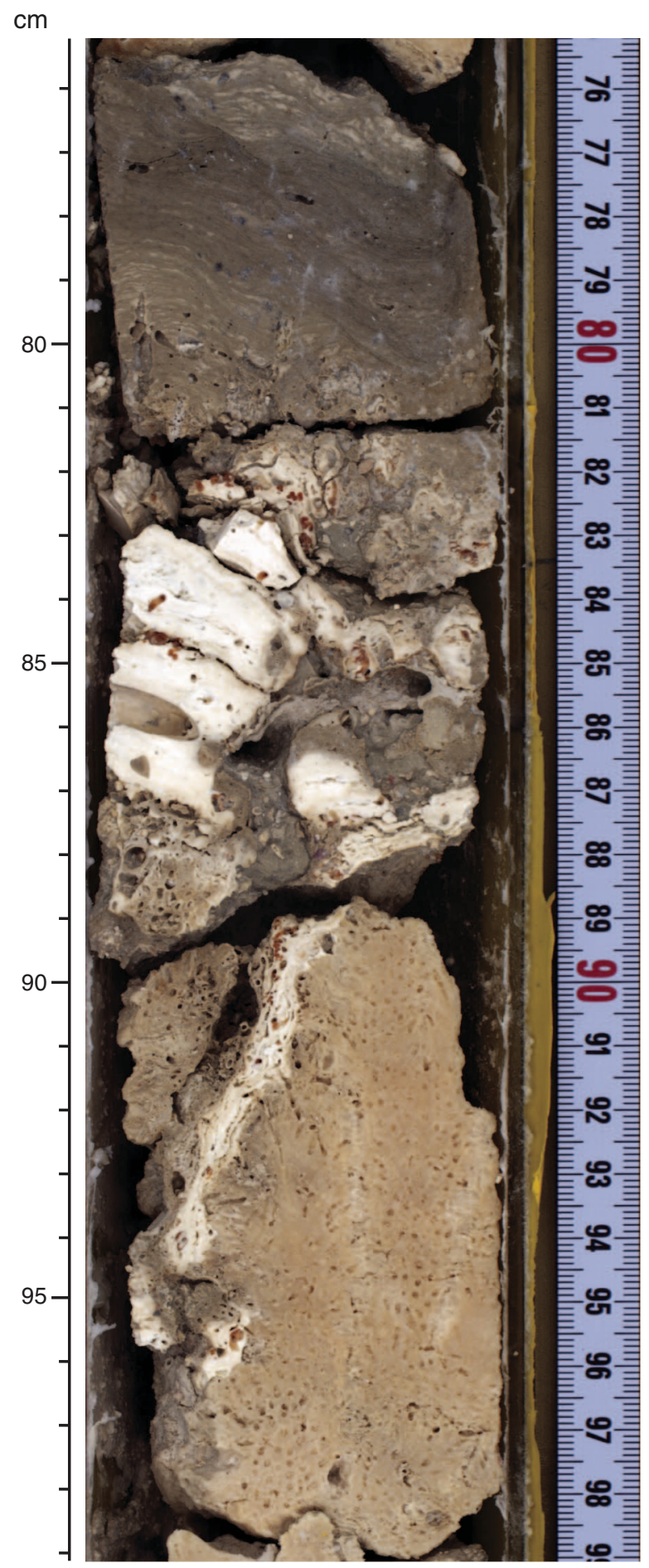


Figure F34. High-resolution line scan image of a fine to medium branching Acropora (in situ?) (interval 325M0033A-10R-1, 15-29 cm).

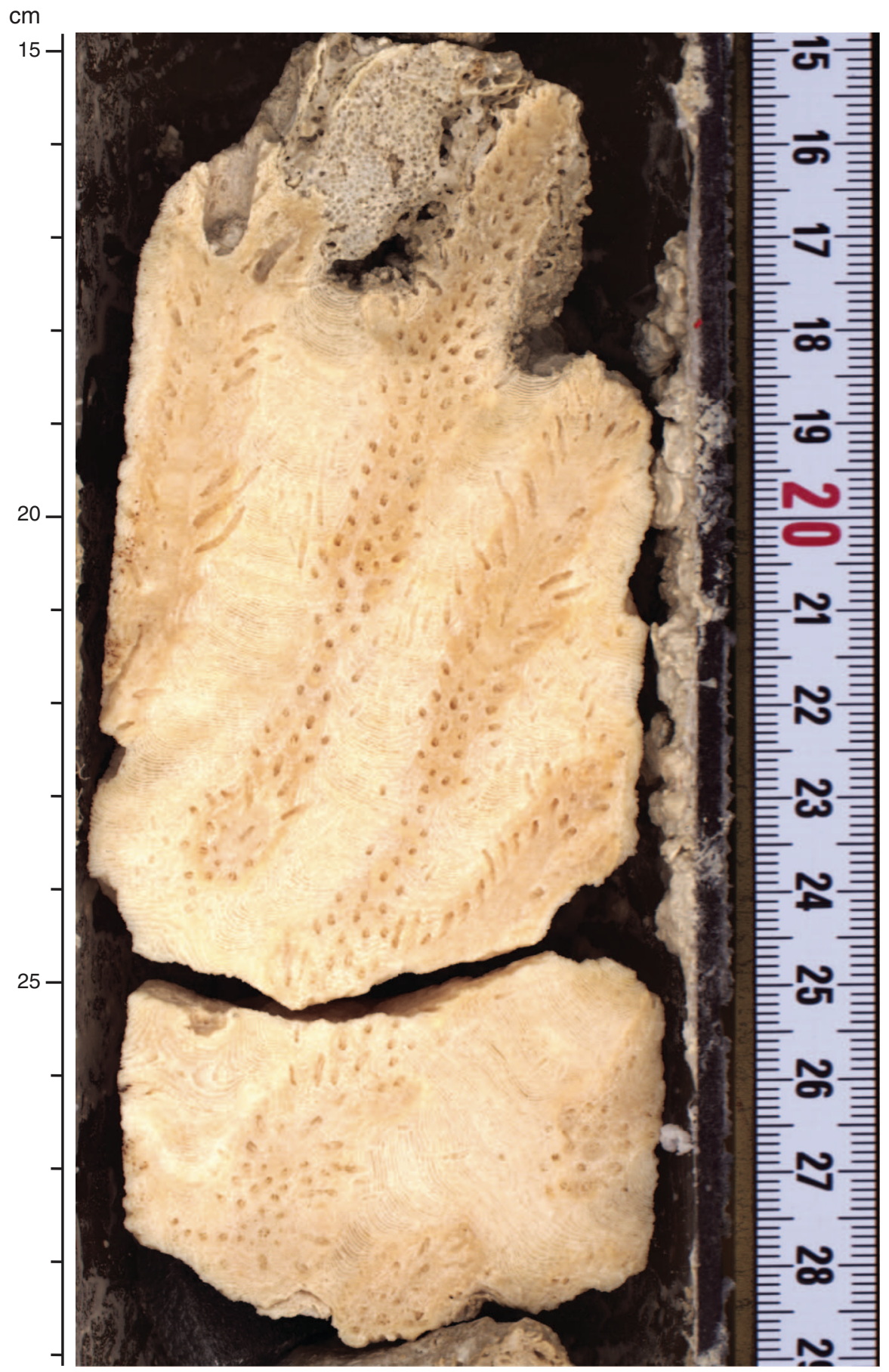


Figure F35. High-resolution line scan image of packstone with bioclasts and thick coralline algae with vermitids. There are numerous geopetal fabrics throughout (interval 325-M0033A-11R-1, 25-44 cm).

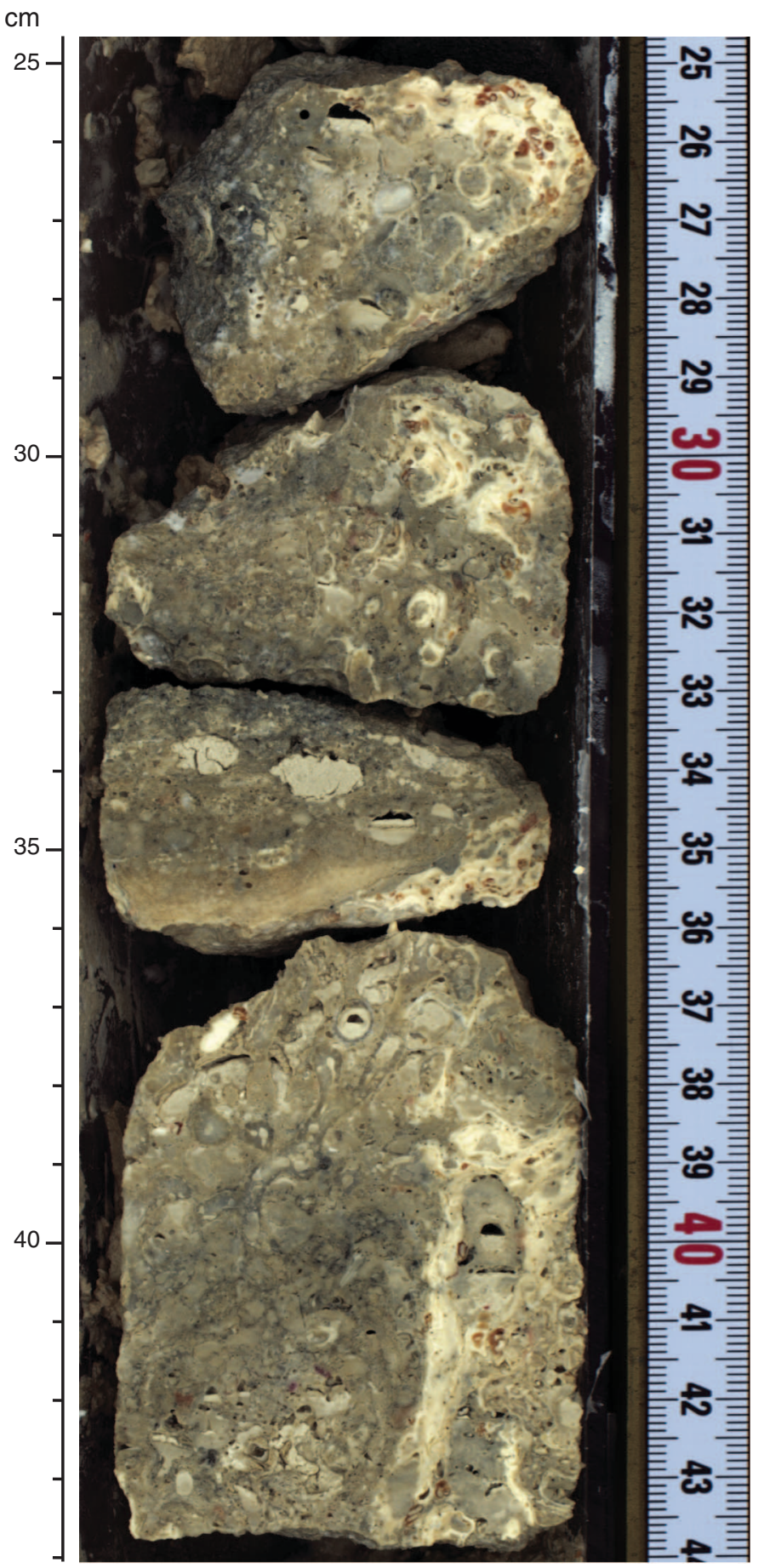


Figure F36. High-resolution line scan image of laminated microbialite (interval 325-M0033A-18R-1, 33-37 $\mathrm{cm})$.

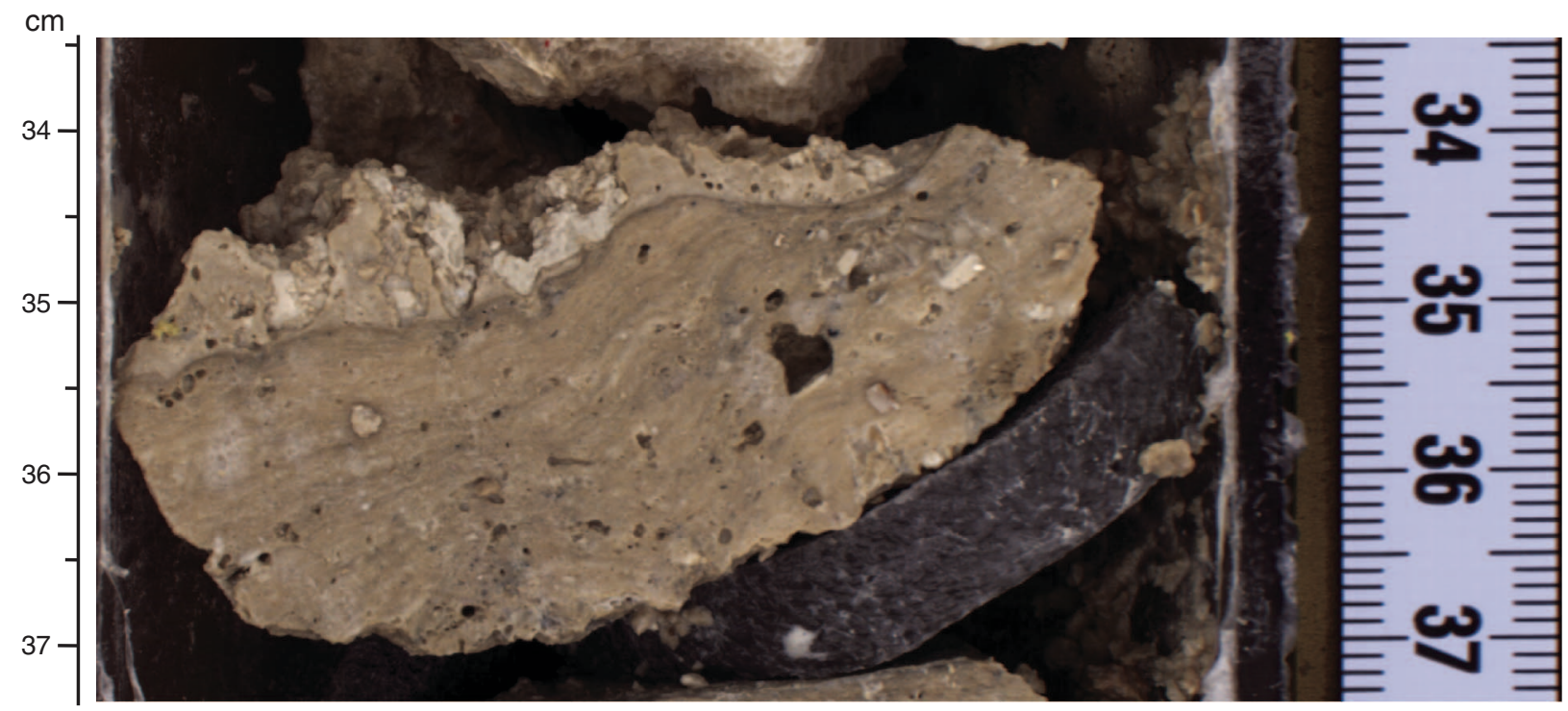


Figure F37. High-resolution line scan image of a massive Favites (in situ?) encrusted by thick laminated microbialite (interval 325-M0033A-16R-1, 71-80 cm).

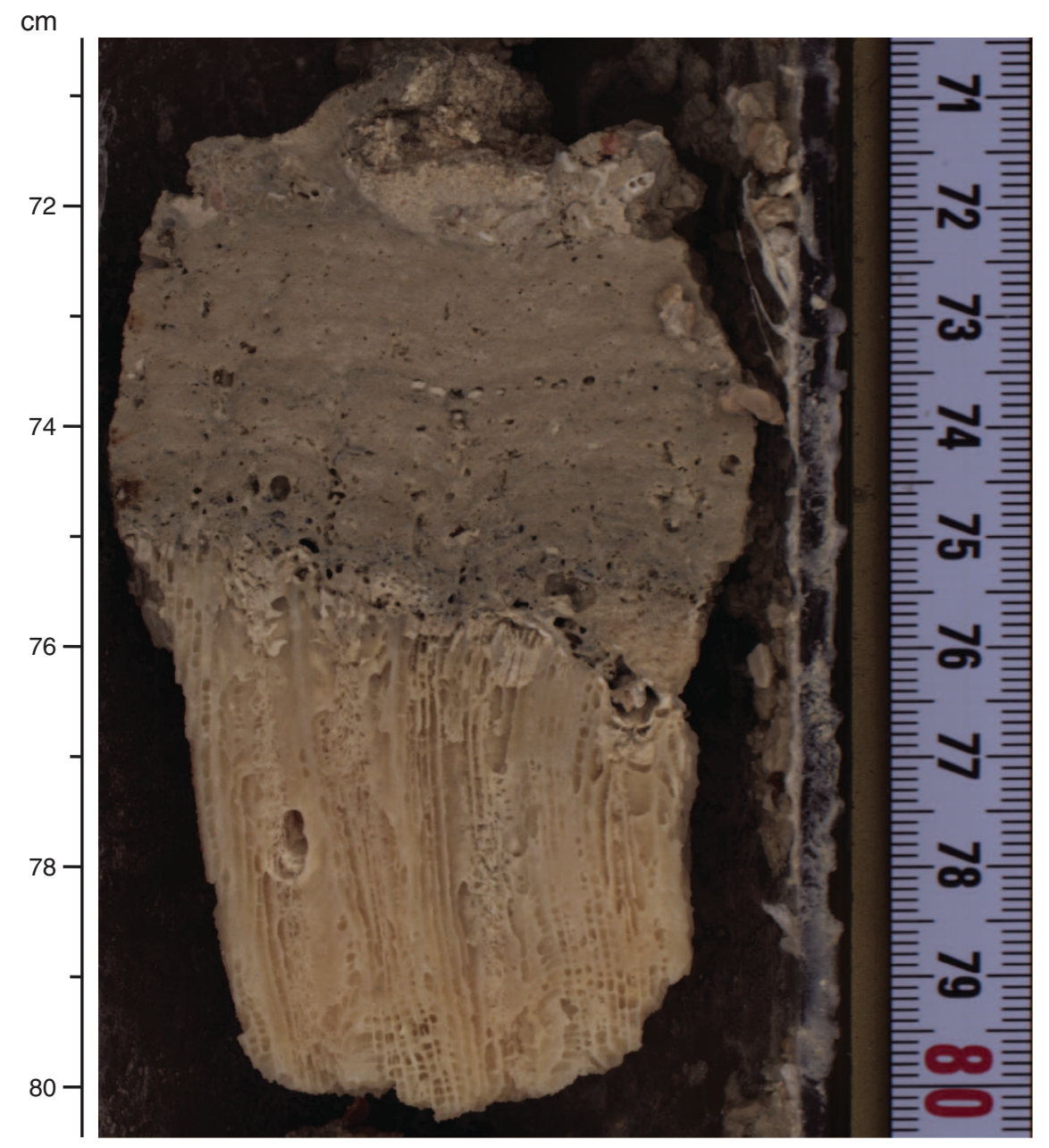


Figure F38. High-resolution line scan image of a submassive/massive Favia (in situ?) (interval 325-M0033A$16 \mathrm{R}-1,12-26 \mathrm{~cm})$.

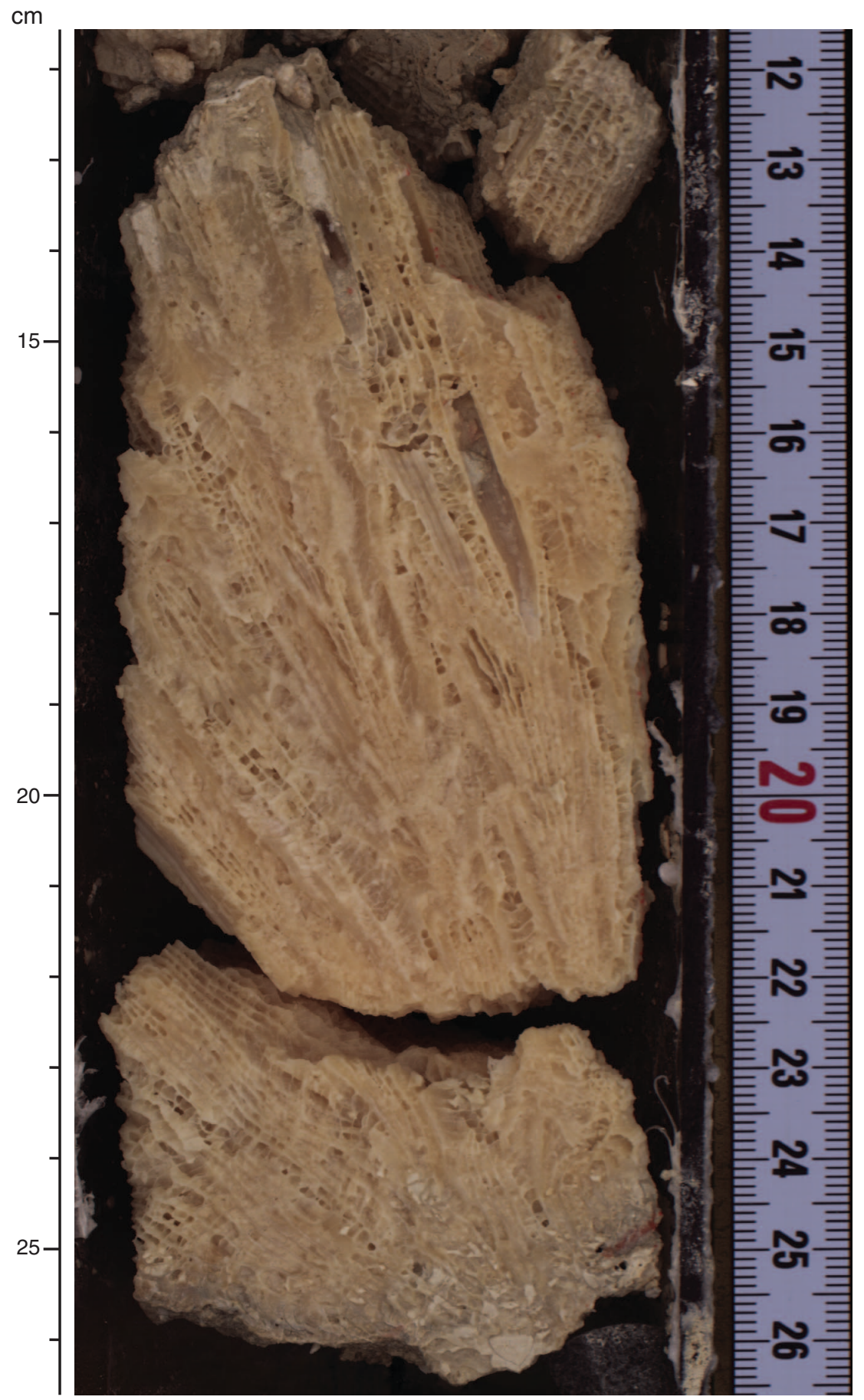


Figure F39. High-resolution line scan image of thick Pocillopora branches (interval 325-M0033A-18R-1, 27-33 $\mathrm{cm})$.

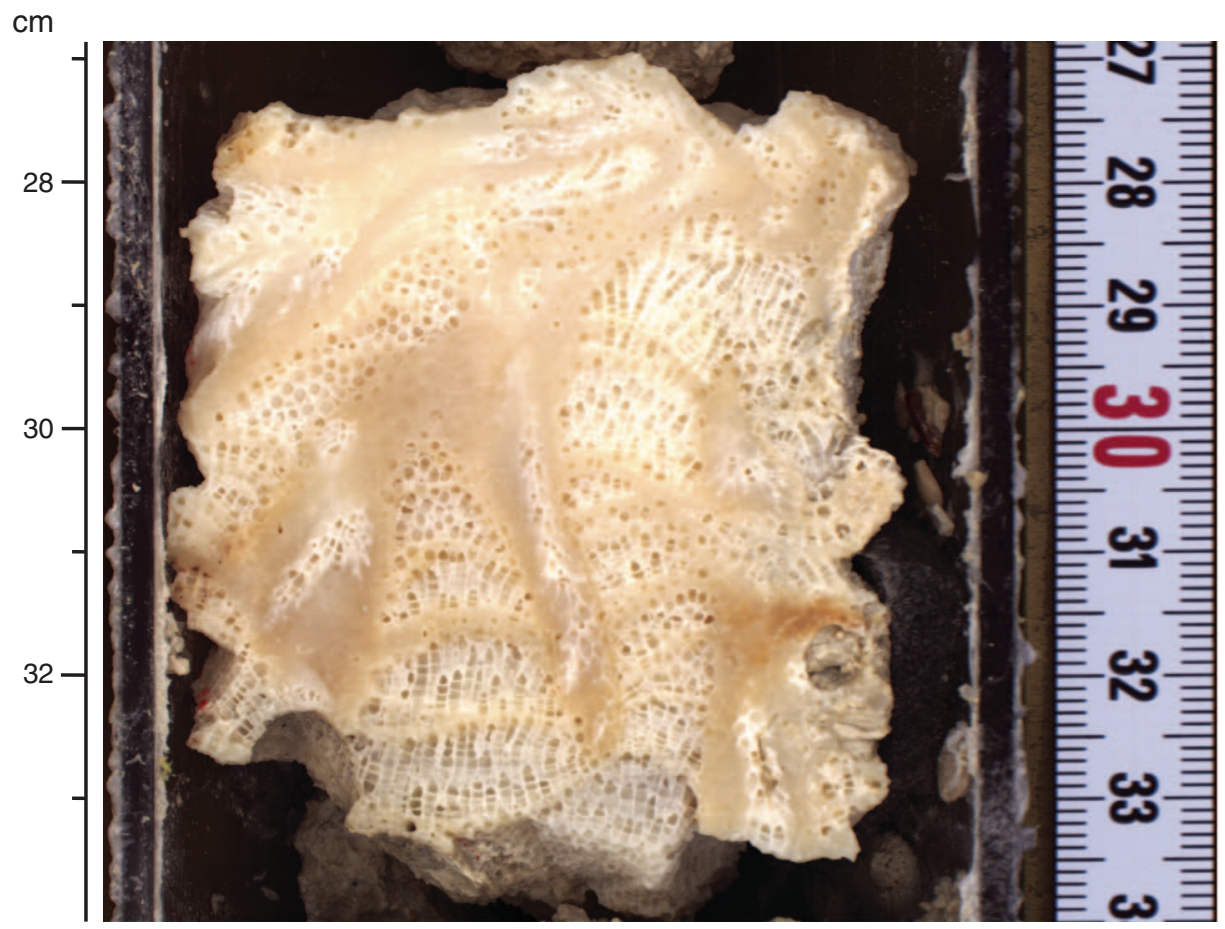


Figure F40. High-resolution line scan image of a massive Tubipora musica encrusted by coralline algae (interval 325-M0033A-15R-1, 17-26 cm).

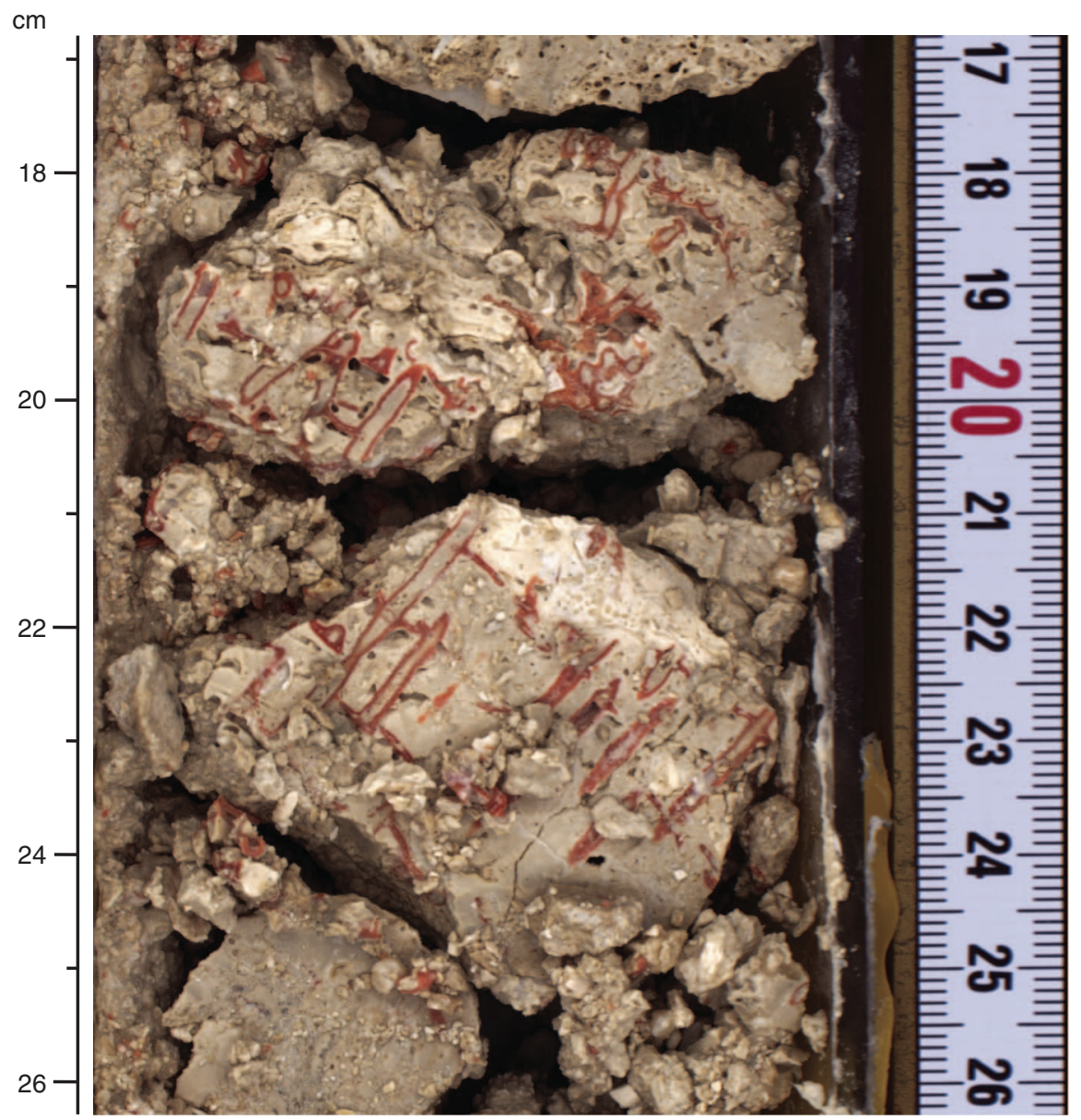


Figure F41. High-resolution line scan image of lime granules and sand with bivalve shells, including Anadara (interval 325-M0033A-21R-1, 57-69 cm).

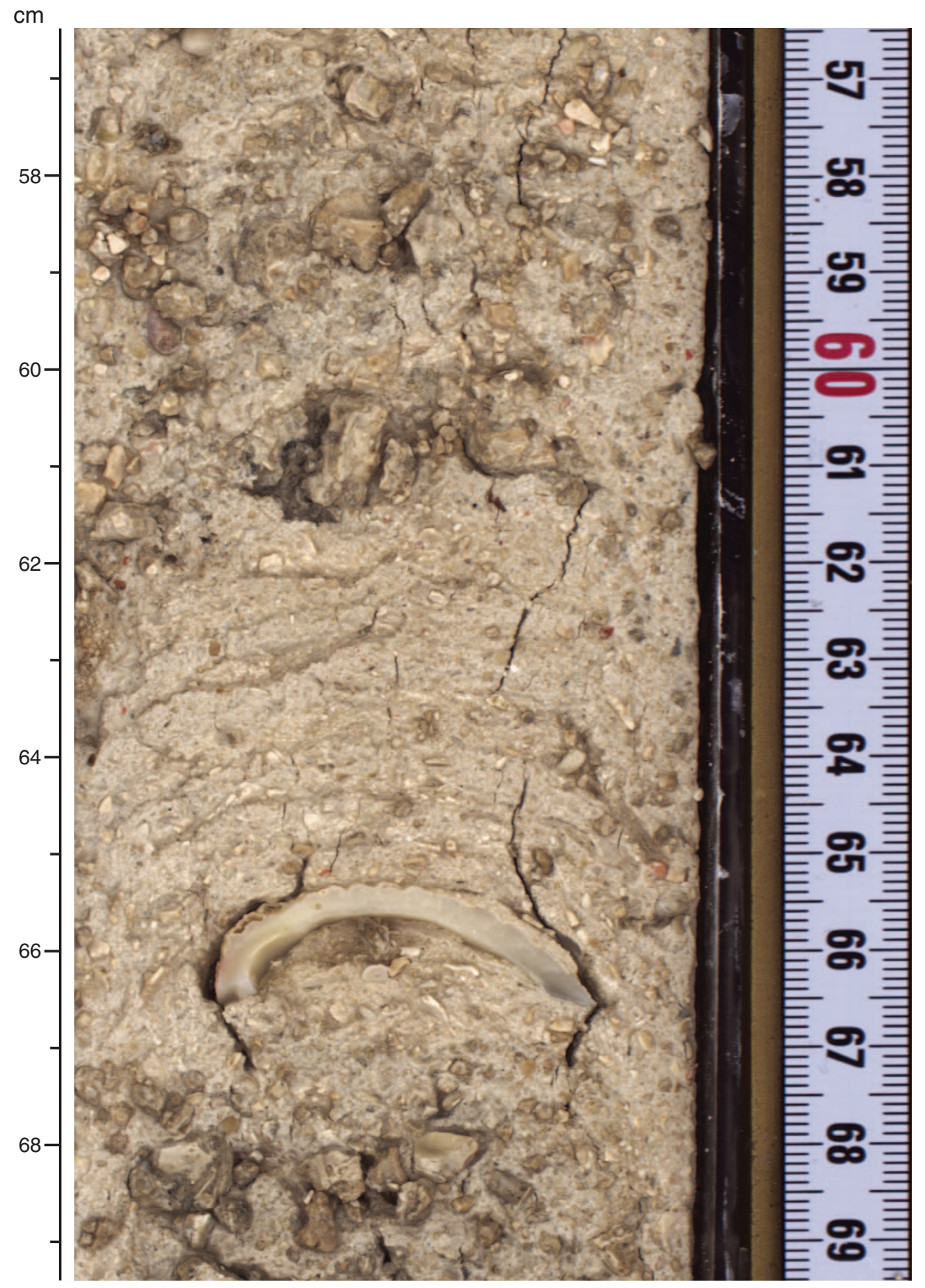


Figure F42. High-resolution line scan image of packstone with worm tubes, Halimeda, and diverse bioclasts (interval 325-M0033A-23R-1, 25-34 cm).

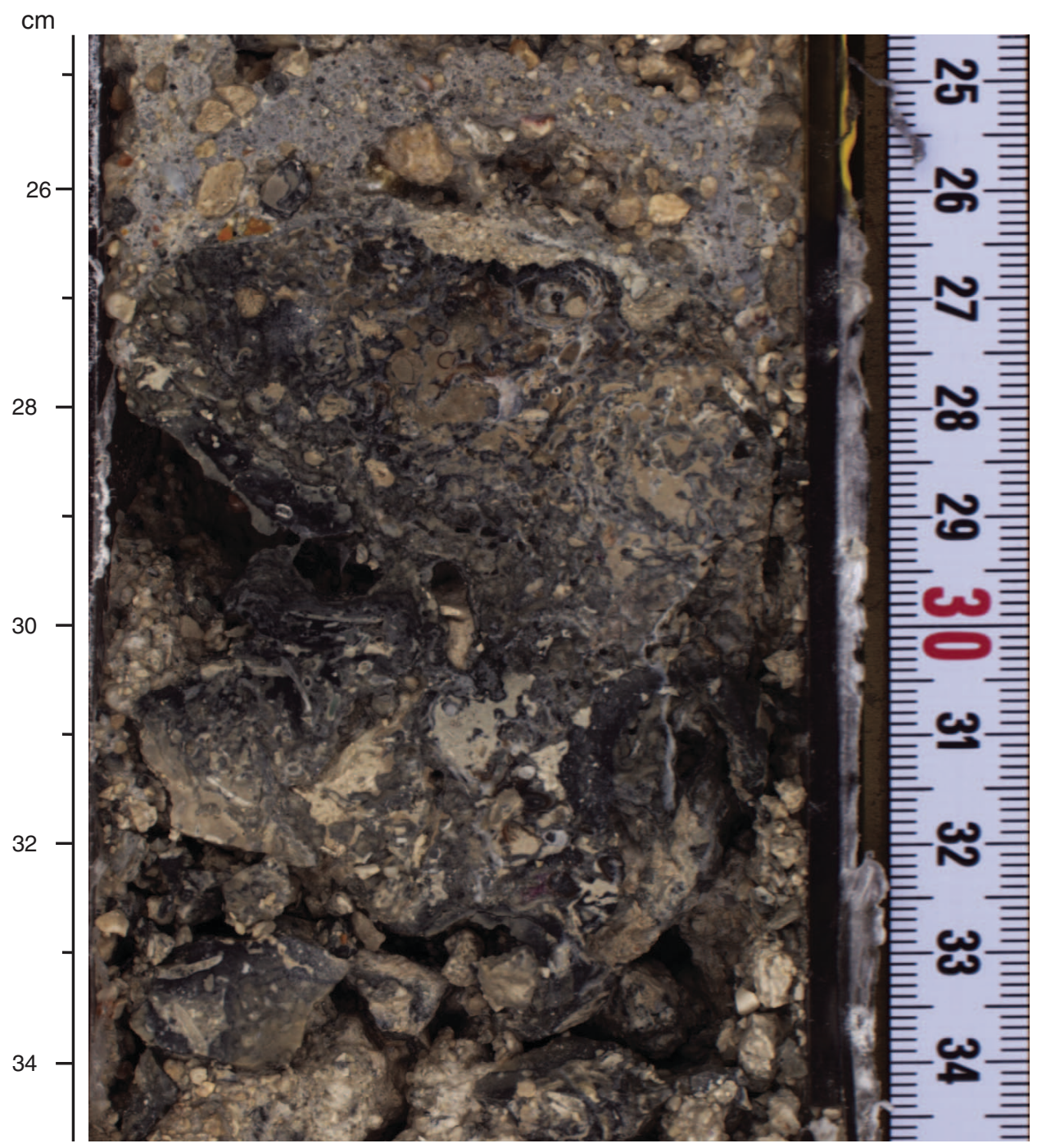


Figure F43. Summary diagram showing data collected on whole cores using the MSCL, Hole M0033A.

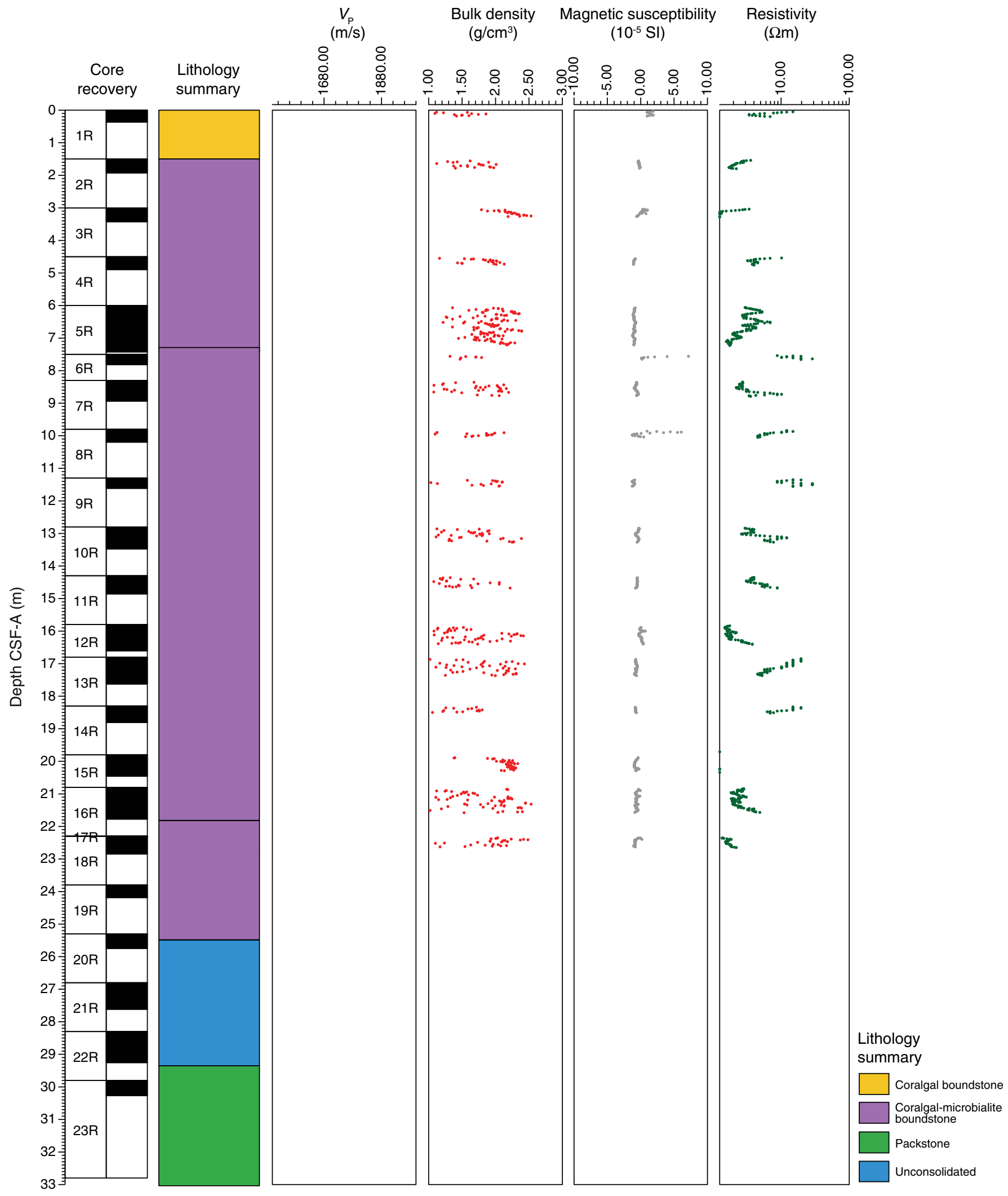


Figure F44. Petrophysical measurements obtained from discrete samples with a pycnometer, Hole M0033A. Bulk density measured on whole cores with the MSCL is shown in red on the bulk density plot.

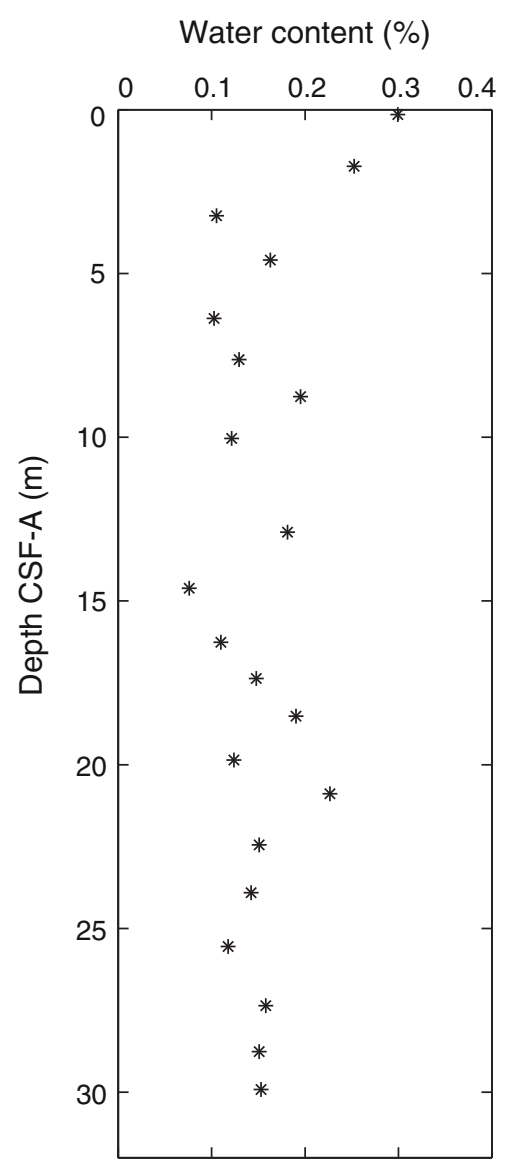

Bulk density $\left(\mathrm{g} / \mathrm{cm}^{3}\right)$

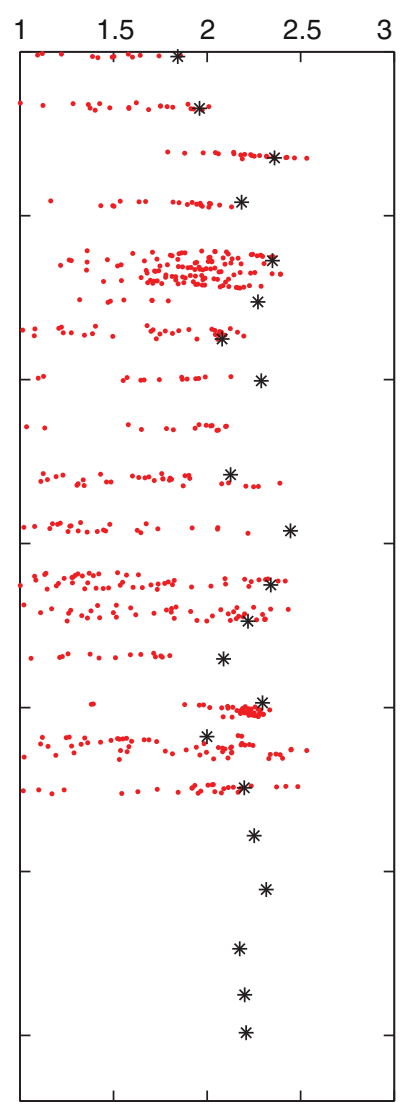

Grain density $\left(\mathrm{g} / \mathrm{cm}^{3}\right)$

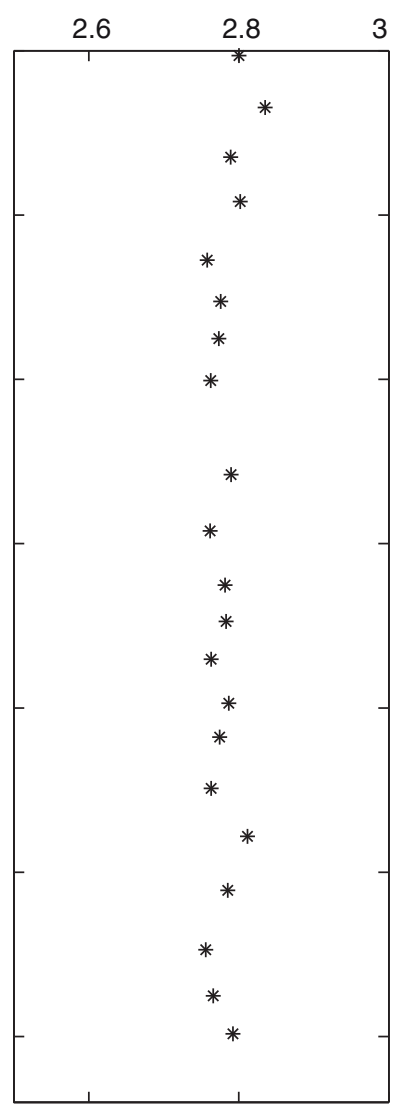

Porosity (\%)

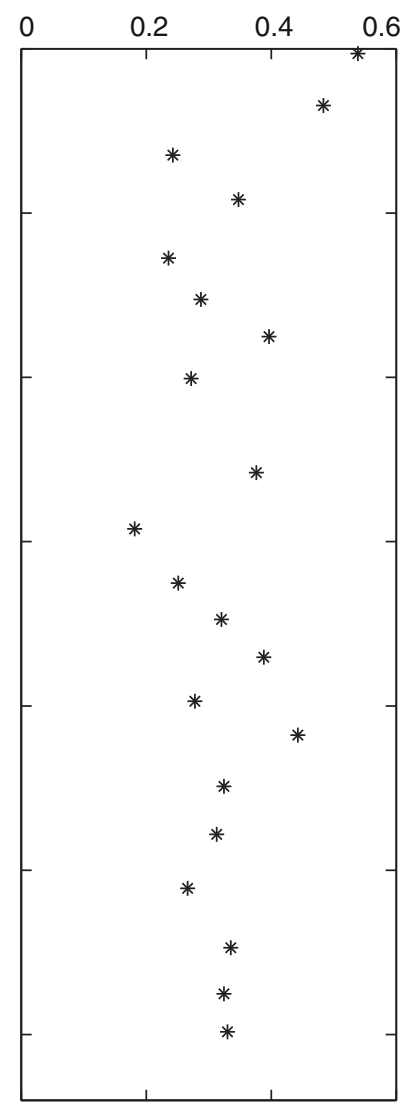


Figure F45. $P$-wave velocity data, Hole M0033A. A. Plot of initial, dry, and resaturated $P$-wave velocity measurements on discrete samples vs. depth. Three measurements were taken at each depth and are denoted by a dot. Average values are plotted as an open triangle. B. Plot showing discrete $P$-wave velocity vs. discrete bulk density.
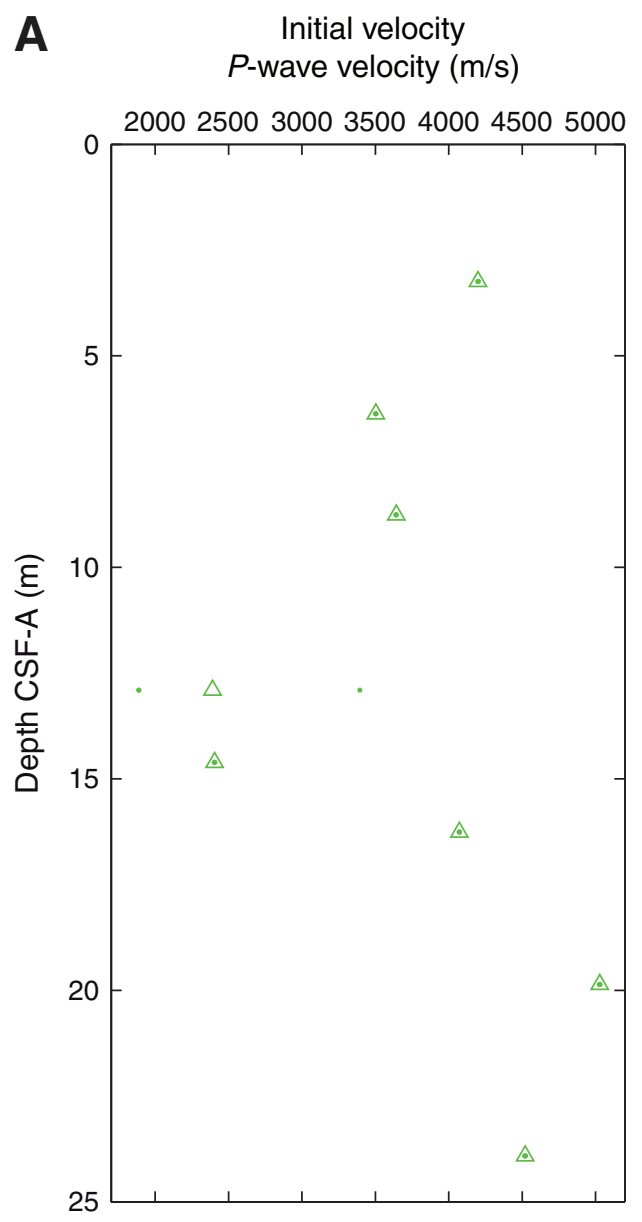

Dry velocity

$P$-wave velocity $(\mathrm{m} / \mathrm{s})$

2000250030003500400045005000

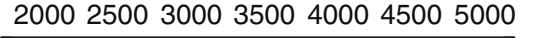

$\Delta$

$\triangle$

$\Delta$

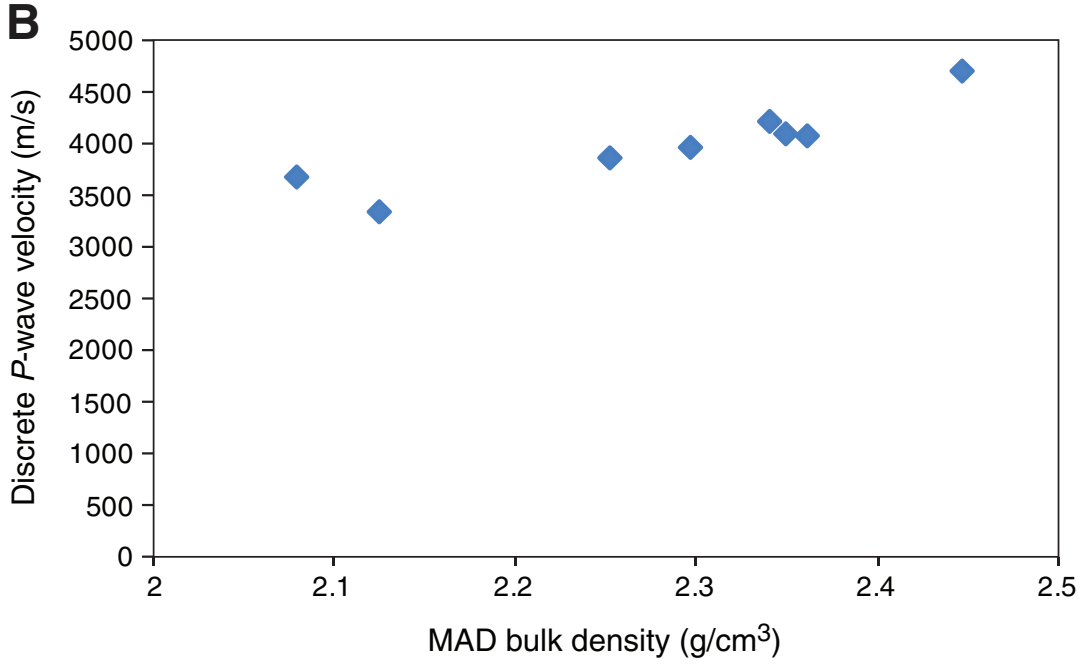

2000250030003500400045005000

Resaturated velocity

$P$-wave velocity $(\mathrm{m} / \mathrm{s})$

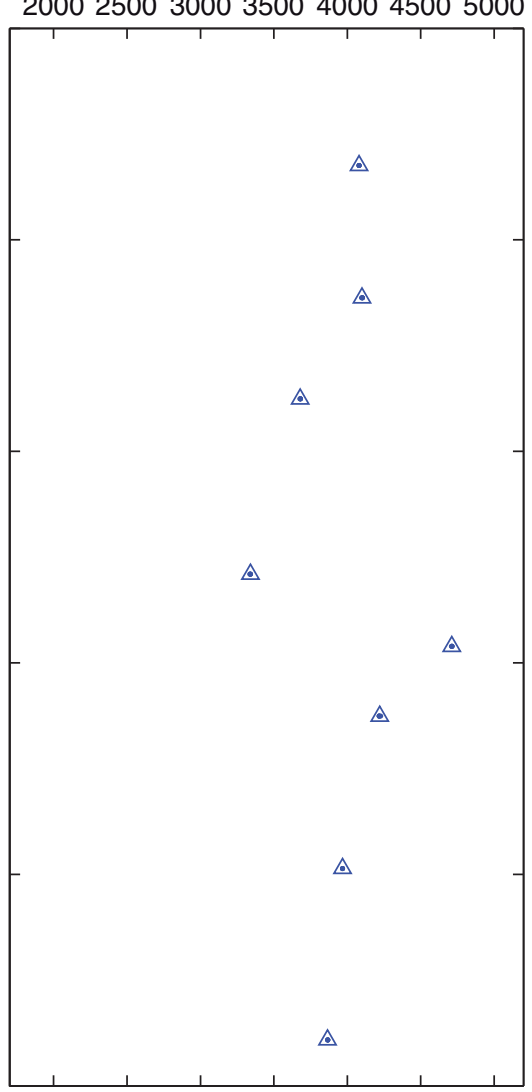


Figure F46. Values of reflectance $\left(\mathrm{L}^{*}\right)$, green to red $\left(\mathrm{a}^{*}\right)$, and blue to yellow $\left(\mathrm{b}^{\star}\right)$ indexes, along with ratio $\mathrm{a}^{*} / \mathrm{b}^{*}$ for Hole M0033A.

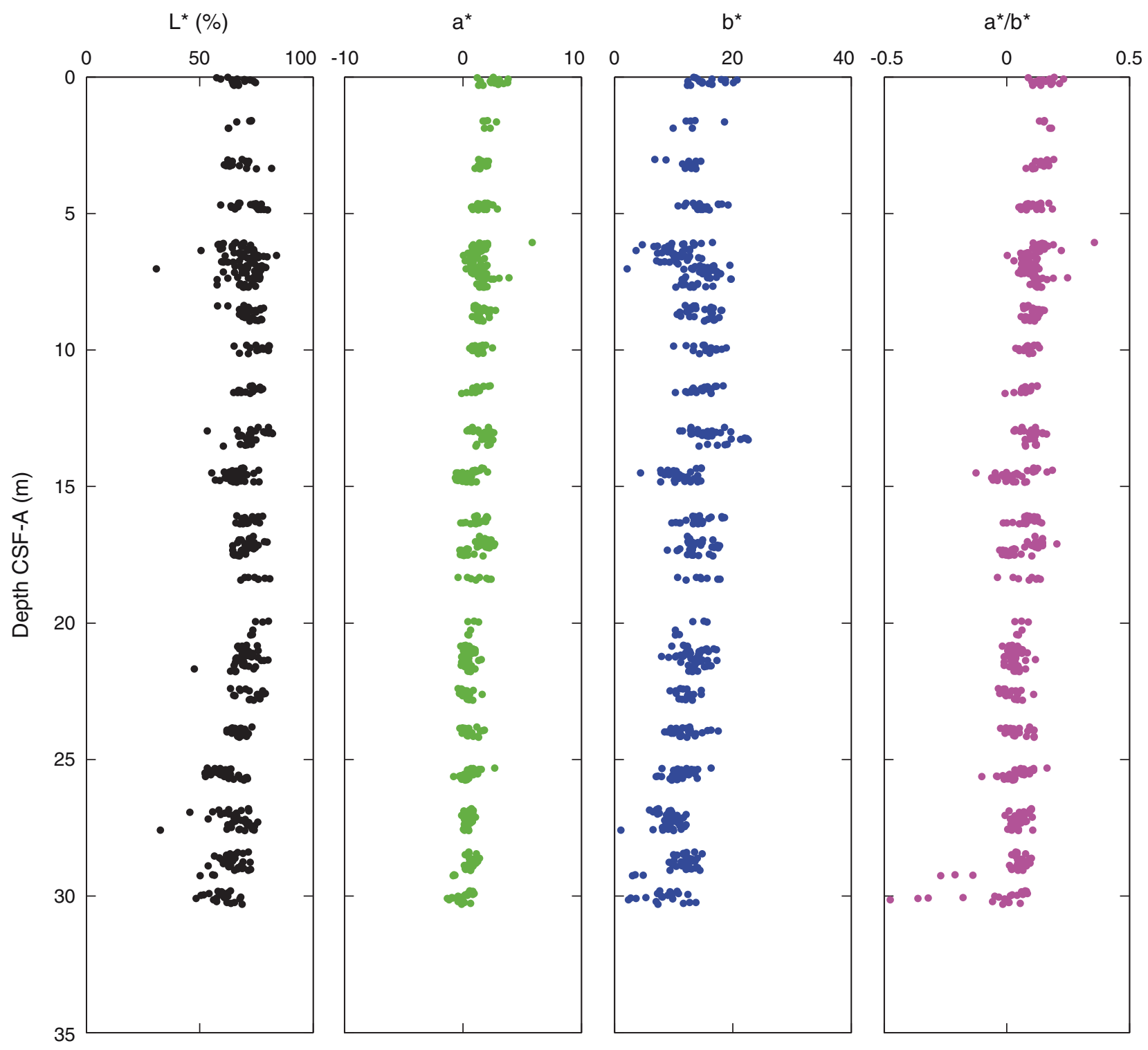


Figure F47. Magnetic susceptibility record for Hole M0033A. Water depth $=91.32 \mathrm{~m}$ (lowest astronomical tide). Magnetic susceptibility $\left(10^{-8} \mathrm{~m}^{3} / \mathrm{kg}\right)$

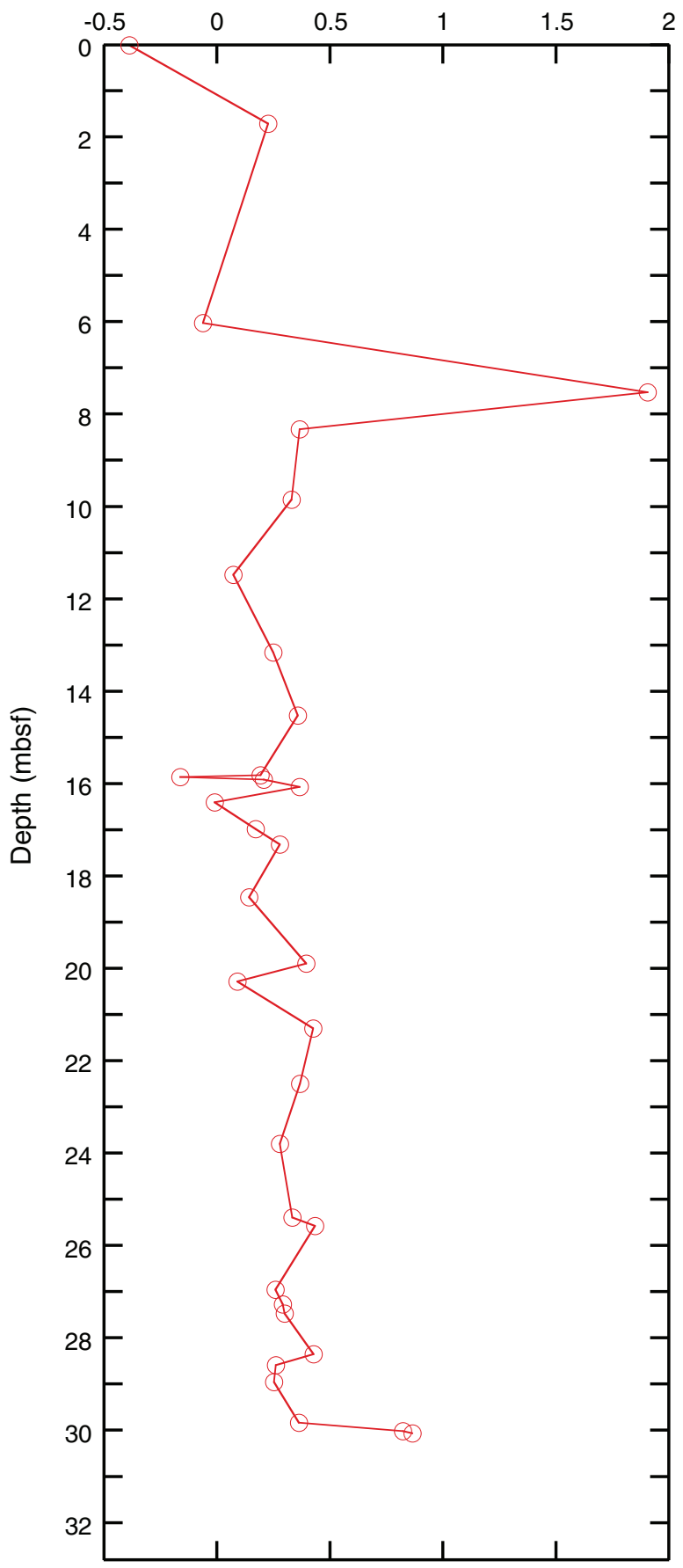


Figure F48. Preliminary chronology for Hole M0033A. Radiocarbon data are presented as graphs with the uncalibrated radiocarbon age and uncertainty shown as the red normal distribution on the ordinate axis and the probability distribution of the calibrated age shown in gray on the abscissa. The marine09 calibration curve is shown in blue. Horizontal bars indicate portions of the age distribution that are significant at the $95.4 \%$ confidence interval and the mean age (white circle \pm 1 standard deviation) used for the purposes of the preliminary dating. All ages are presented as thousands of calendar years BP (1950 AD). See Table T10 in the "Methods" chapter. (See Bronk Ramsey [2009], as well as Bronk Ramsey [2010] at c14.arch.ox.ac.uk/oxcal.html.)
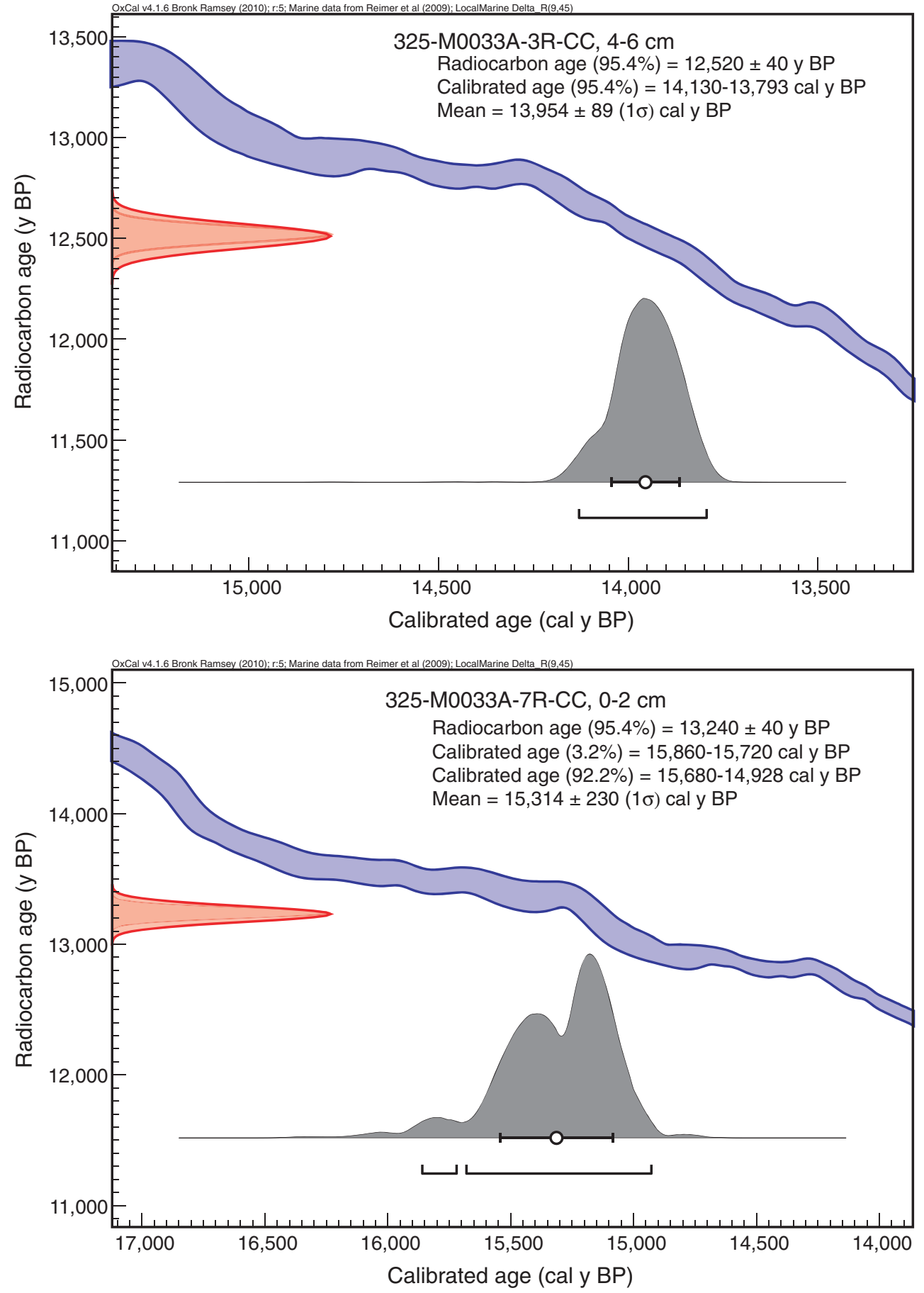
Figure F49. High-resolution line scan image of bioerosion by sponge, worm tube, and bivalves in a massive Porites (in situ) and a highly eroded foliaceous coral. (interval 325-M0034A-1R-1, 20-30 cm).

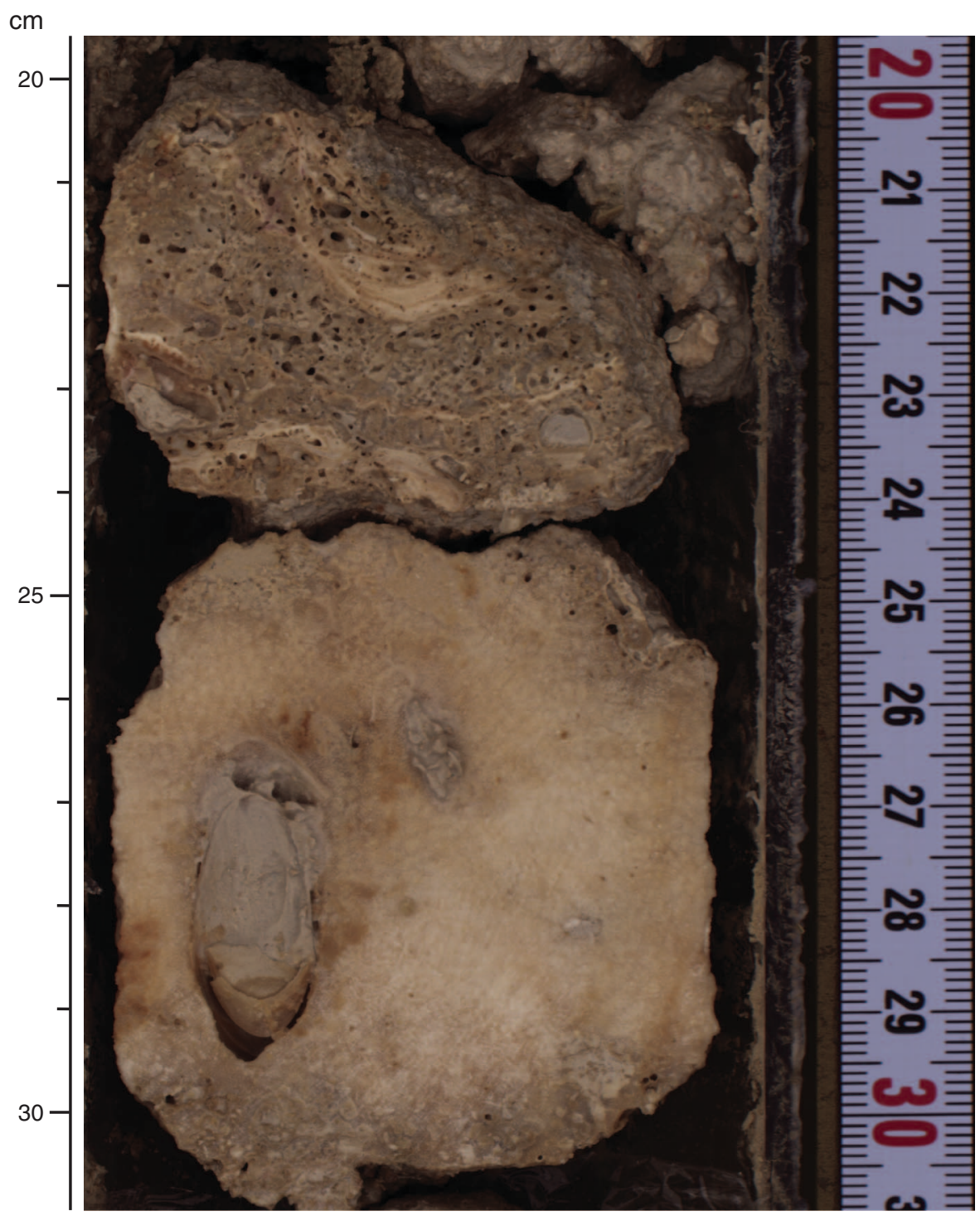


Figure F50. High-resolution line scan image of a fine branching Pocilloporidae, massive Isopora (not in situ), and Goniopora(?) encrusted by thin coralline algae and laminated microbialites (interval 325-M0034A-8R-1, 30$38 \mathrm{~cm})$.

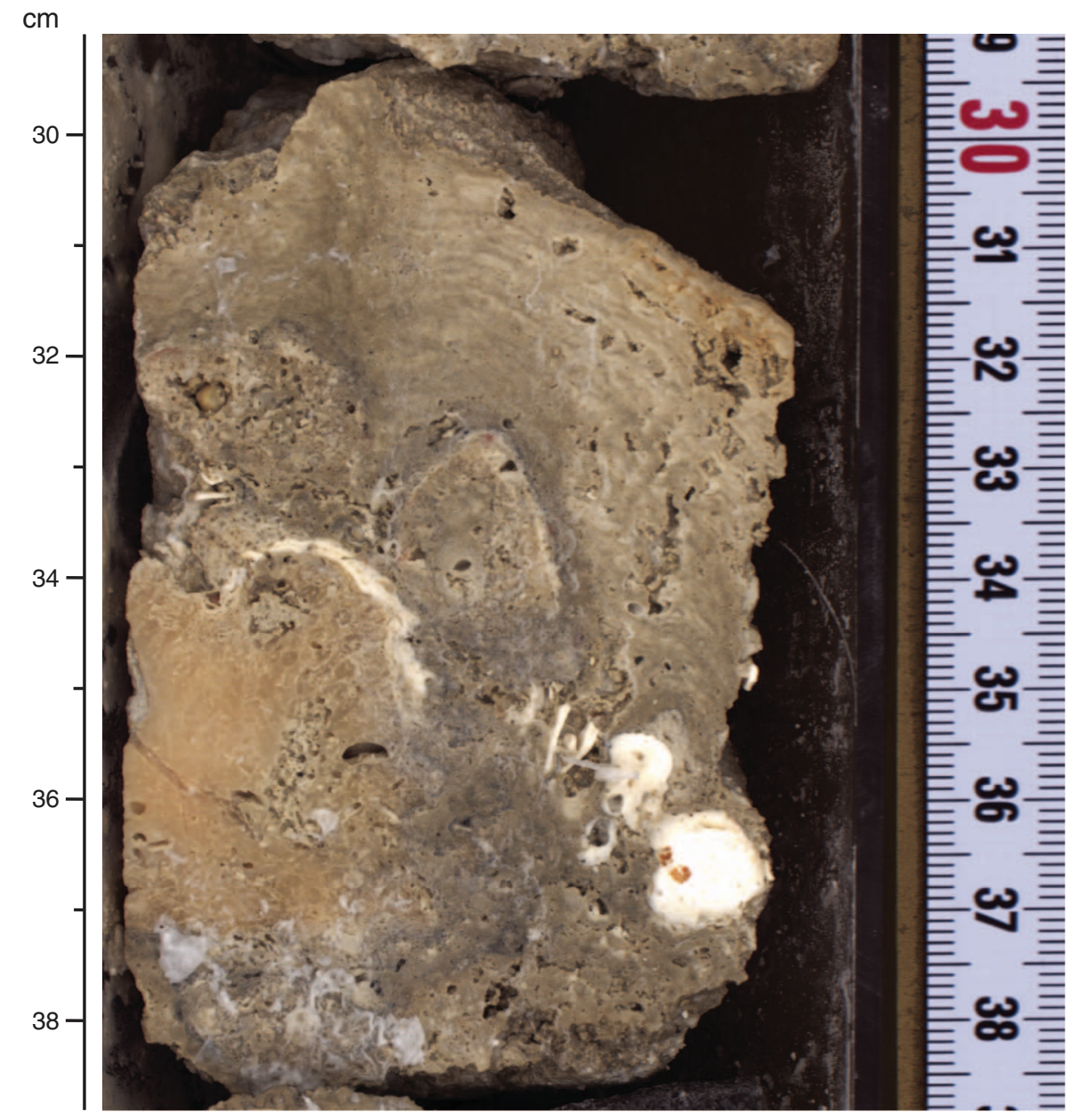


Figure F51. High-resolution line scan image of a robustly branching Isopora(?) (not in situ) encrusted by thick coralline algae and laminated microbialites (interval 325-M0034A-9R-1, 11-20 cm).

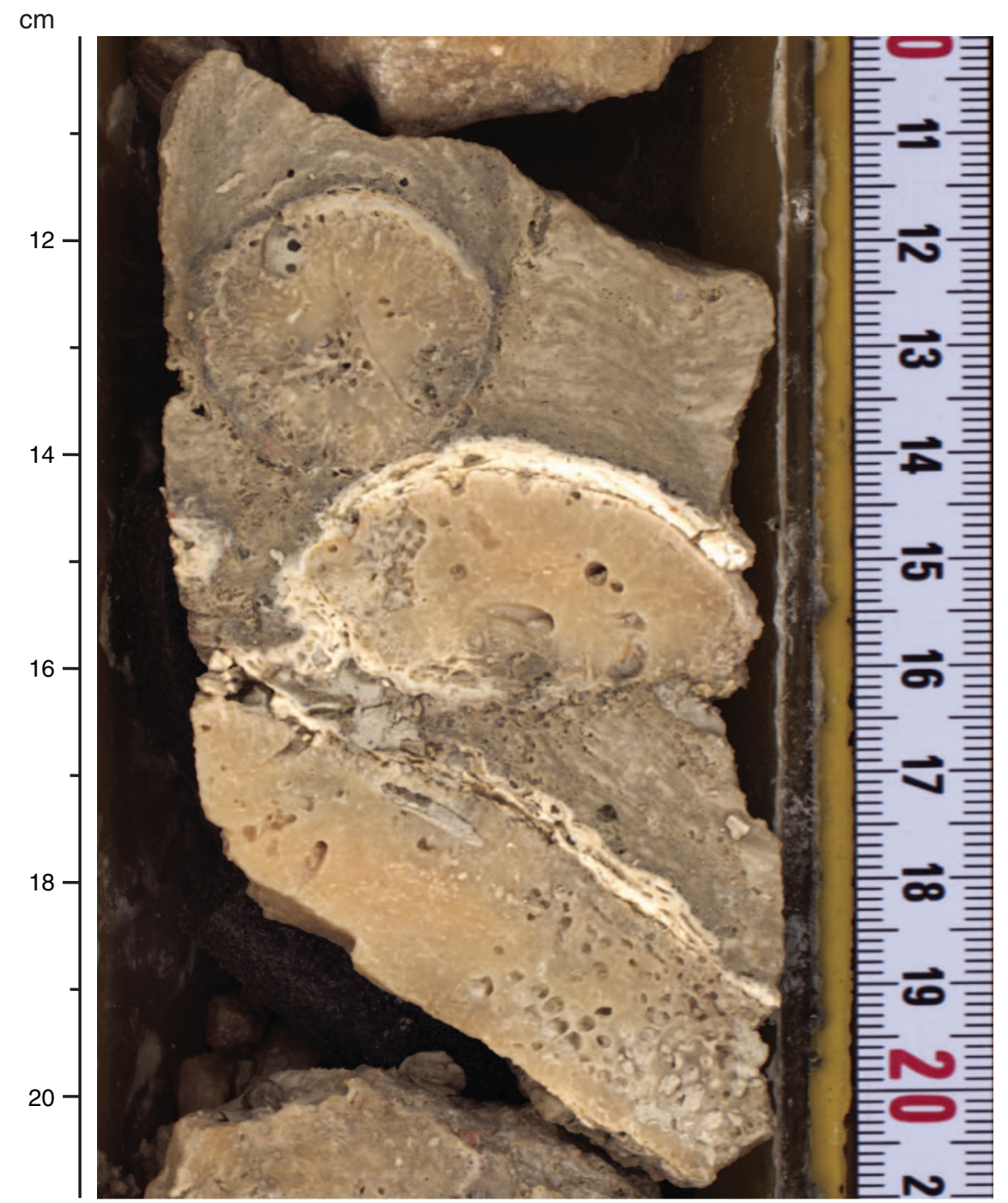


Figure F52. High-resolution line scan image of a massive Isopora, robustly branching Isopora, and encrusting Montipora (interval 325-M0034A-9R-1, 53-70 cm). Columnar microbialites are present, with internal sediments containing Halimeda.

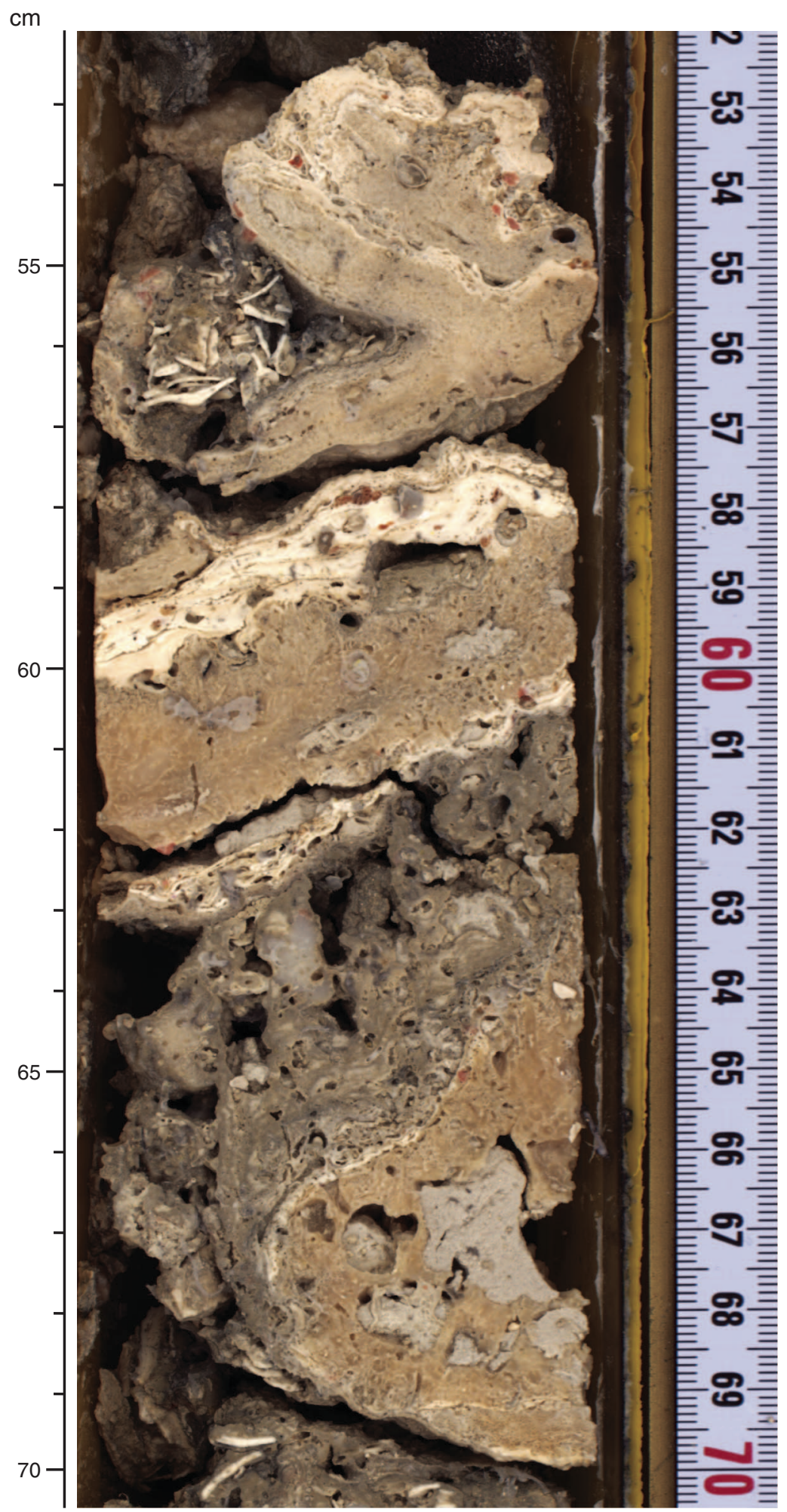


Figure F53. High-resolution line scan image of bioeroded corals with cavities partially infilled with sediment (interval 325-M0034A-1R-1, 23-29 cm).

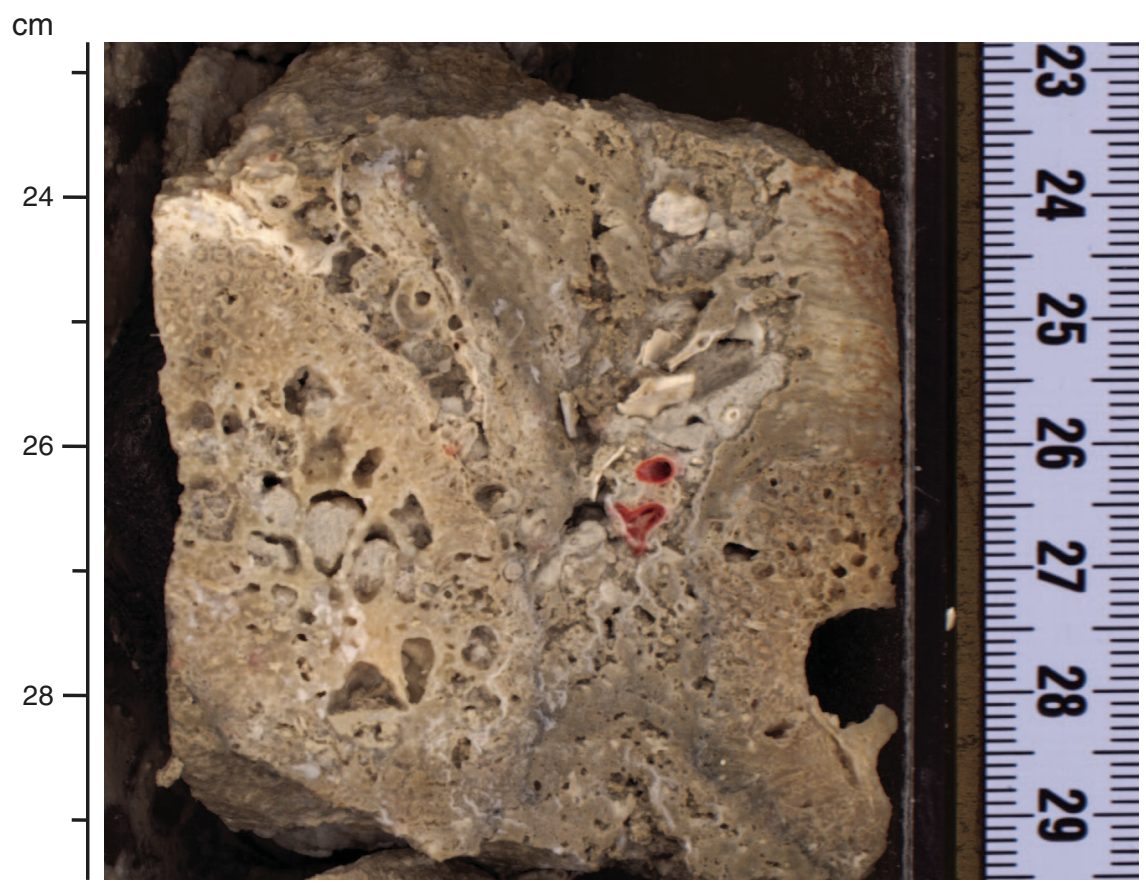


Figure F54. High-resolution line scan image of a massive Porites colony (in situ) (interval 325-M0034A-1R-1, $31-53 \mathrm{~cm})$.

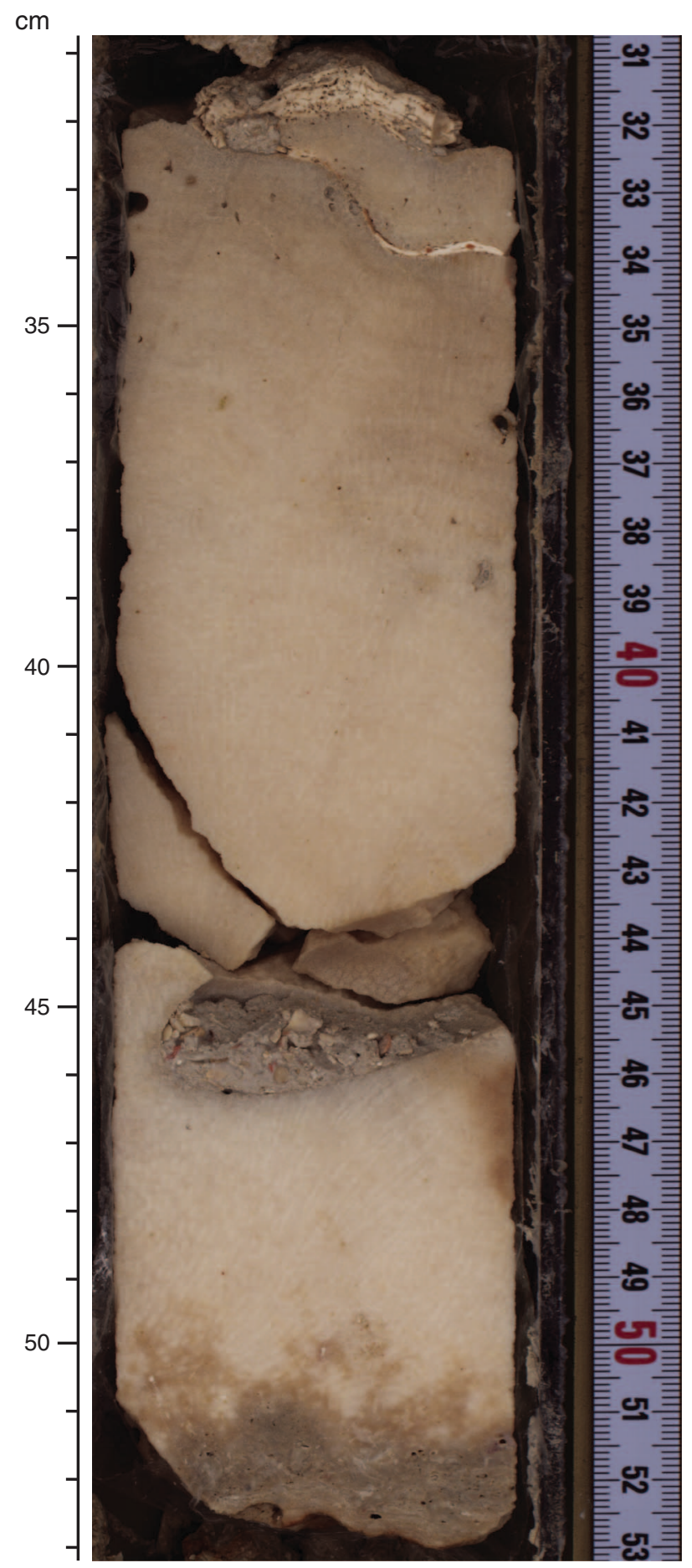


Figure F55. High-resolution line scan image of a massive Isopora colony (in situ) encrusted by coralline algae (interval 325-M0034A-4R-1, 23-33 cm). Internal sediments contain Halimeda.

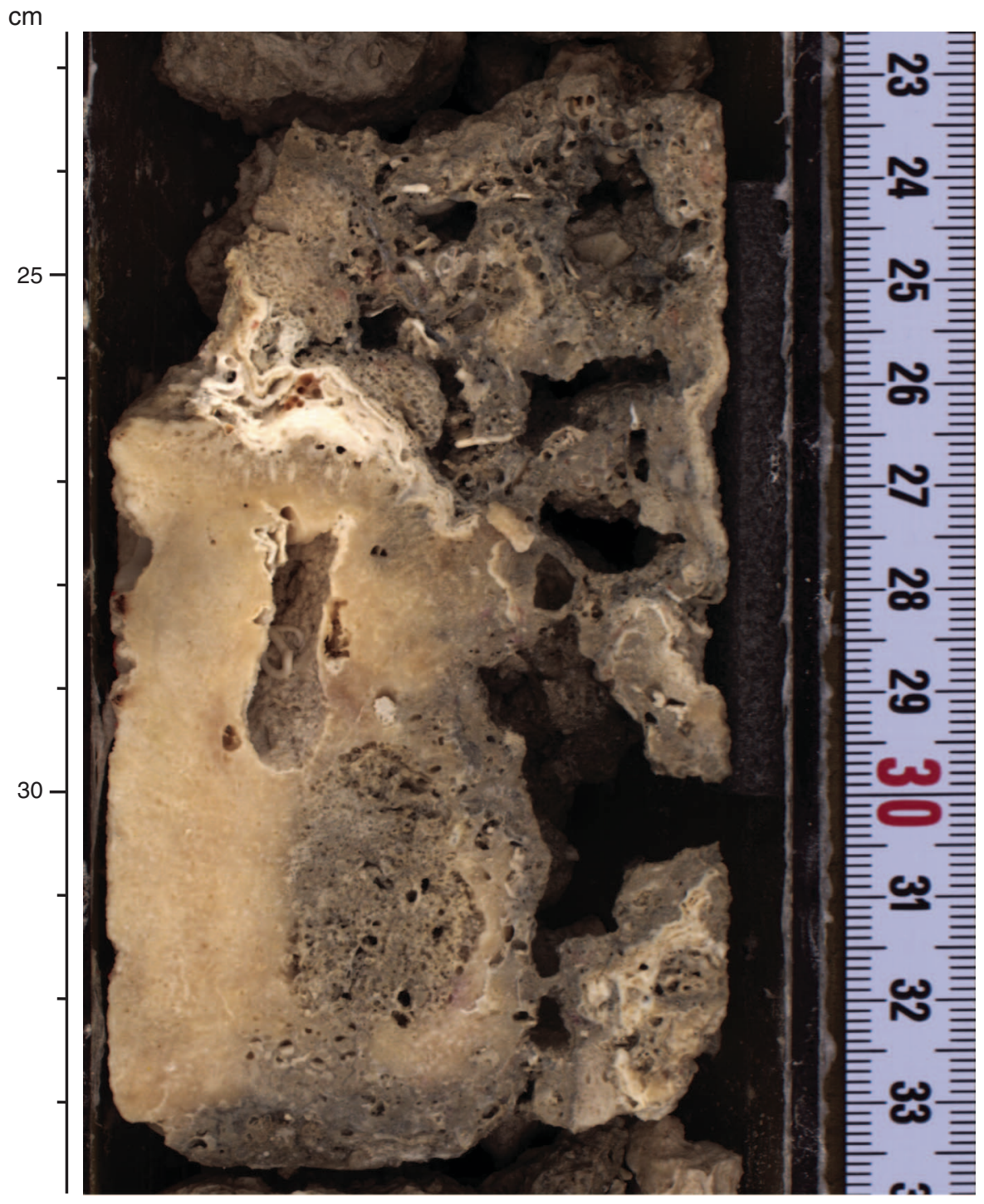


Figure F56. High-resolution line scan image of a massive Goniopora(?) colony (in situ) encrusted by thick coralline algae (interval 325-M0034A-11R-1, 20-73 cm). Thin encrusting Montipora(?) and unconsolidated internal sediments are present.

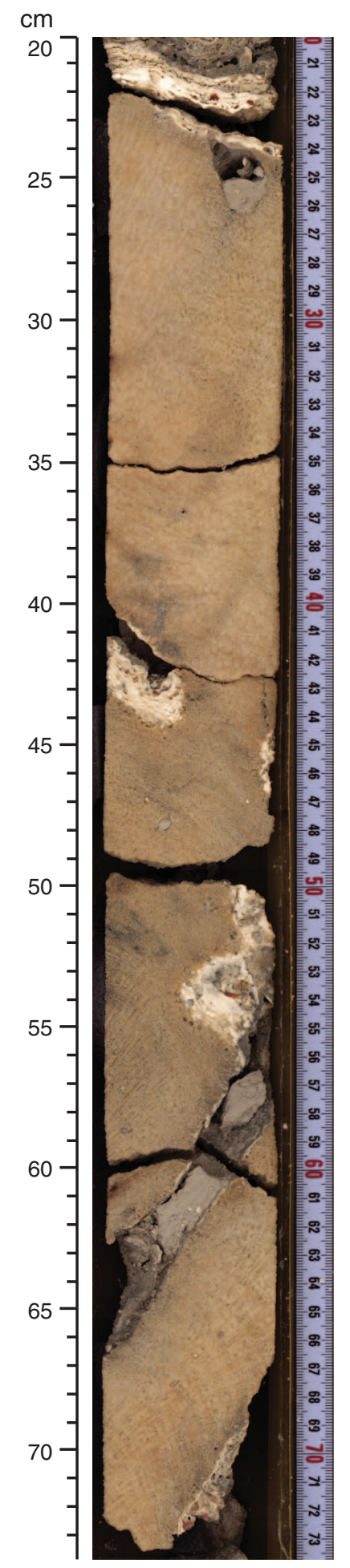


Figure F57. High-resolution line scan image of a massive Faviidae colony (in situ) and thick coralline crust (interval 325-M0034A-2R-CC, 1-10 cm).

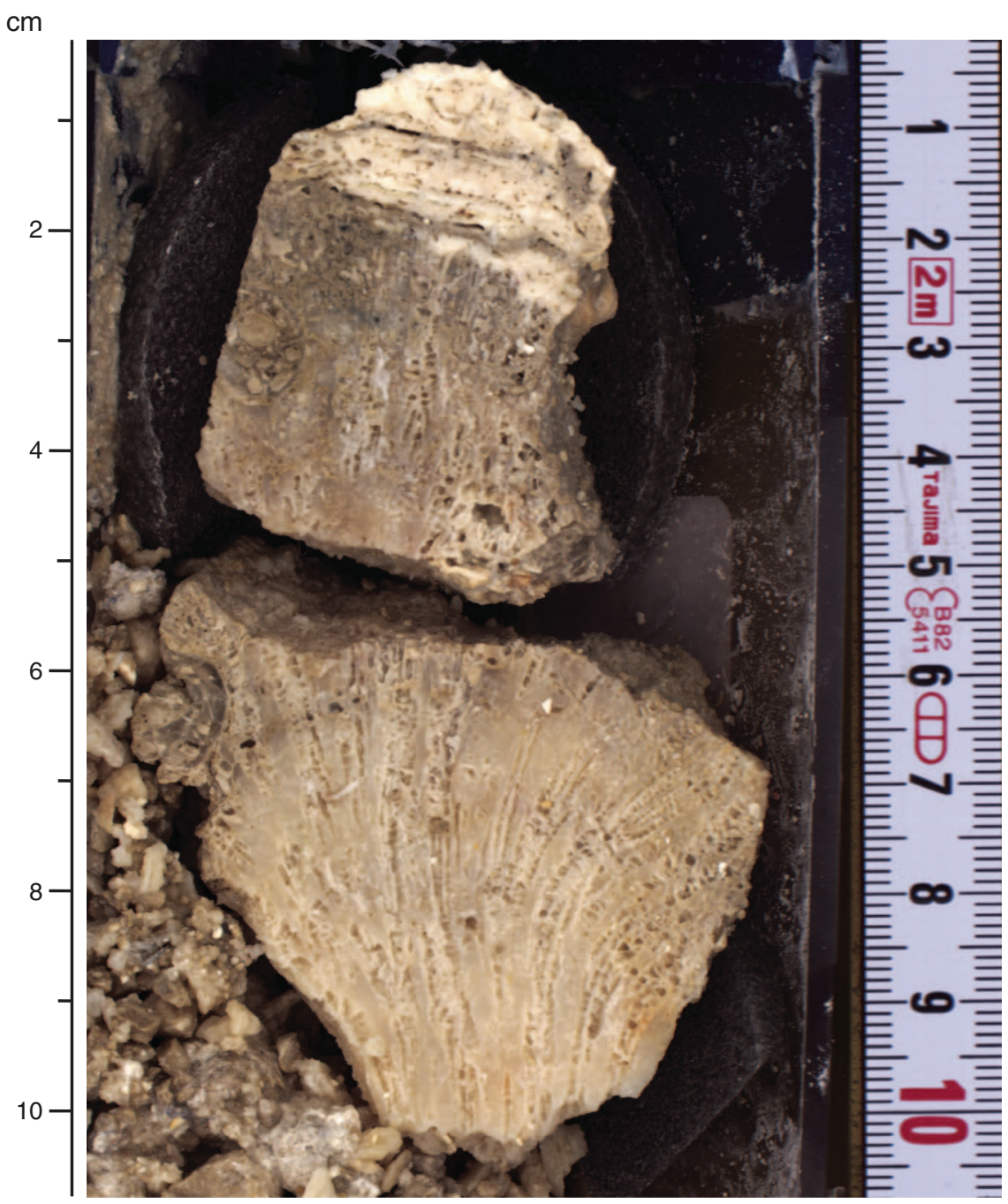


Figure F58. Summary diagram showing data collected on whole cores using the MSCL, Hole M0034A.

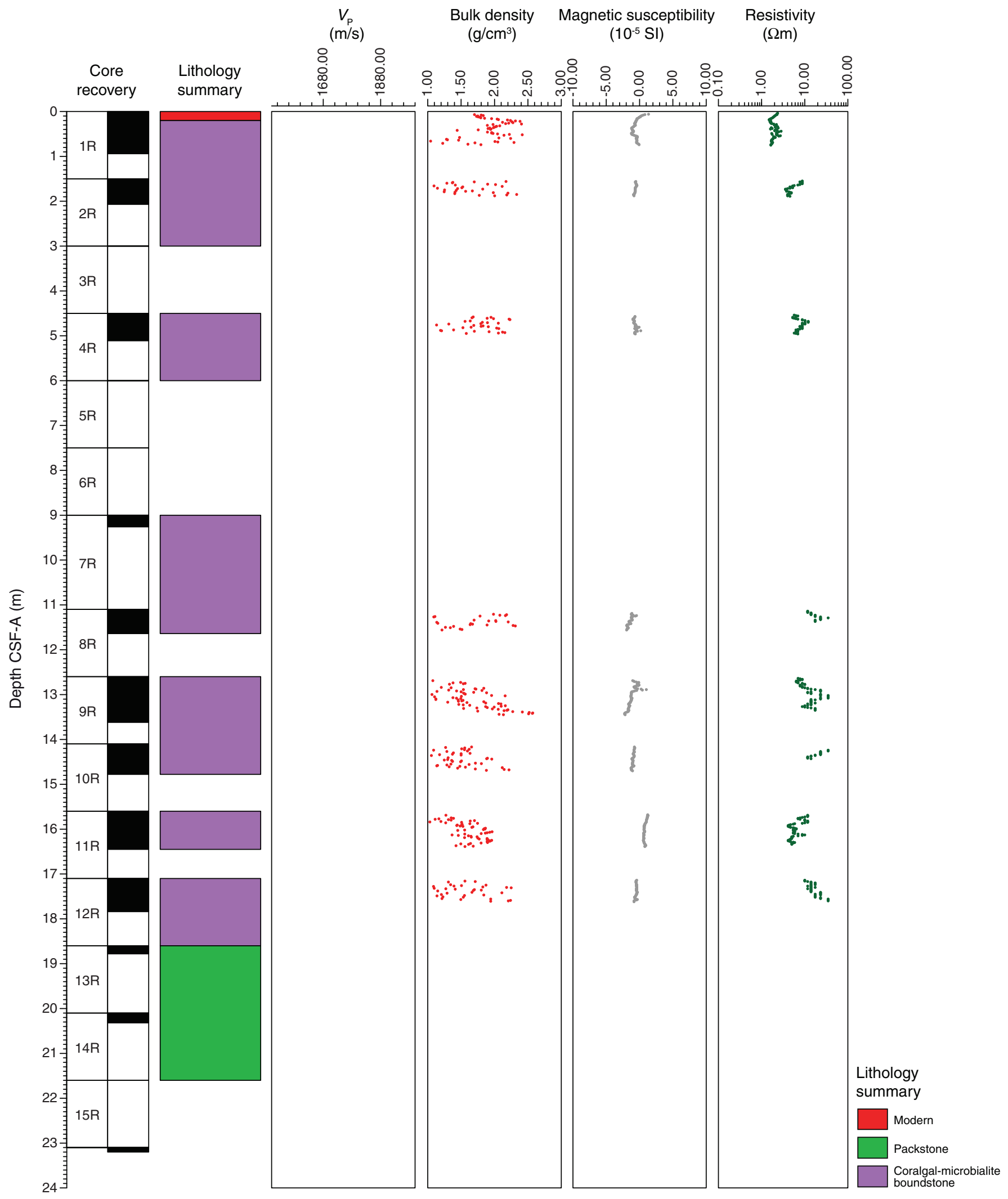


Figure F59. Petrophysical measurements obtained from discrete samples with a pycnometer, Hole M0034A. Bulk density measured on whole cores with the MSCL is shown in red on the bulk density plot.

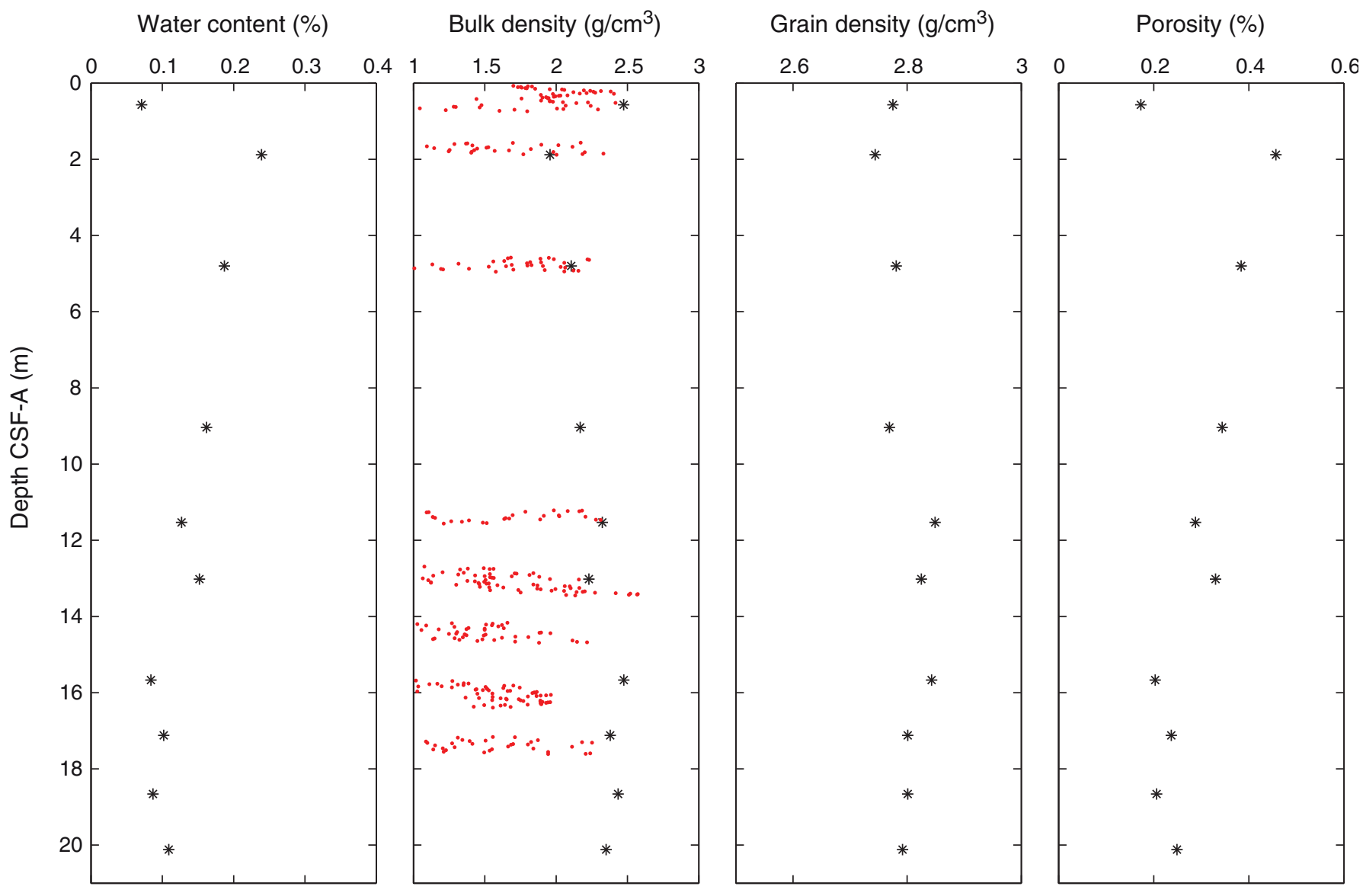


Figure F60. $P$-wave velocity data, Hole M0034A. A. Plot of initial, dry, and resaturated $P$-wave velocity measurements on discrete samples vs. depth. Three measurements were taken at each depth and are denoted by a dot. Average values are plotted as an open triangle. B. Plot showing discrete $P$-wave velocity vs. discrete bulk density.

A

Initial velocity

$P$-wave velocity $(\mathrm{m} / \mathrm{s})$

Resaturated velocity

$P$-wave velocity $(\mathrm{m} / \mathrm{s})$
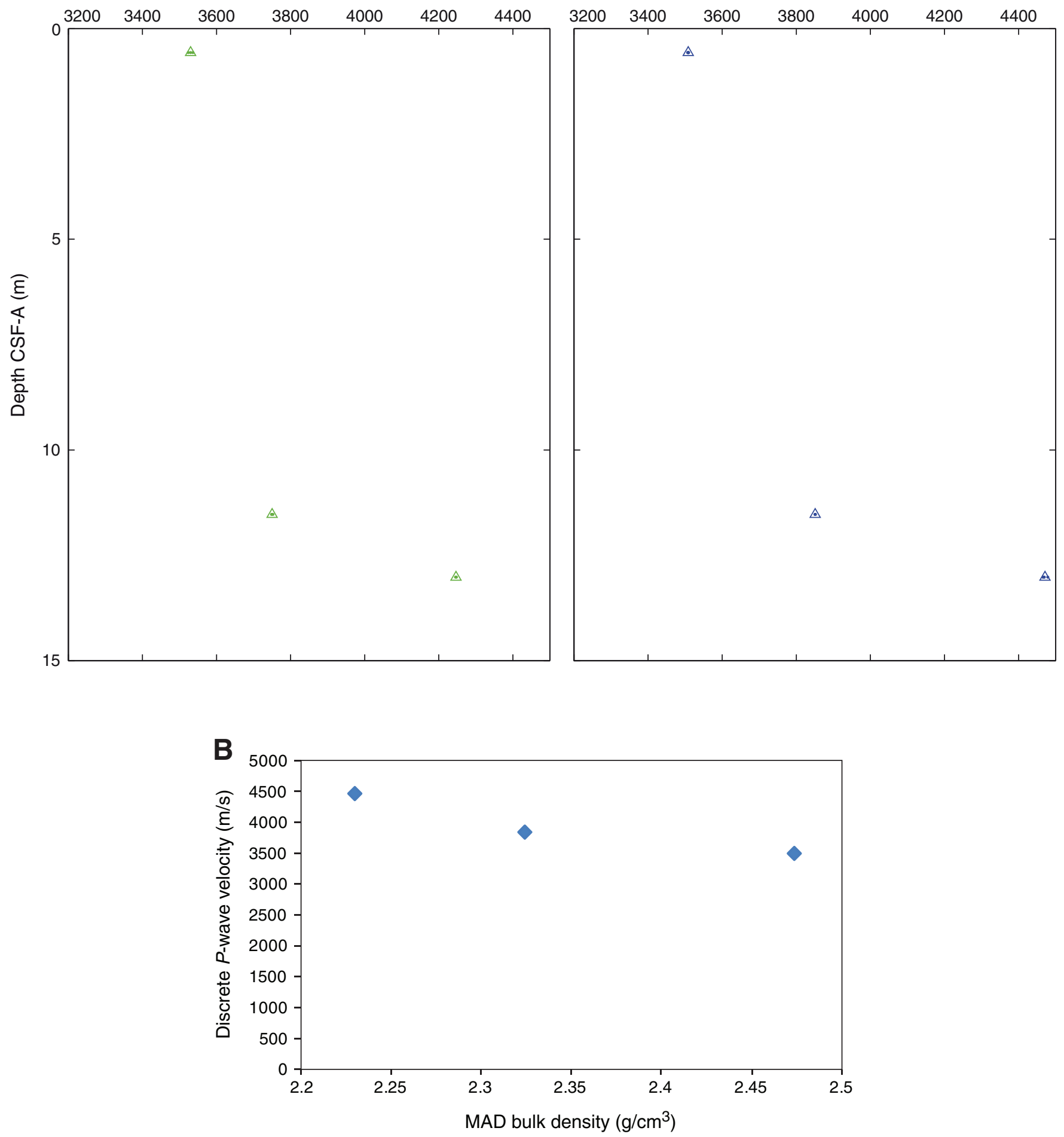
Figure F61. Values of reflectance $\left(\mathrm{L}^{*}\right)$, green to red $\left(\mathrm{a}^{*}\right)$, and blue to yellow $\left(\mathrm{b}^{*}\right)$ indexes, along with ratio $\mathrm{a}^{*} / \mathrm{b}^{*}$ for Hole M0034A.

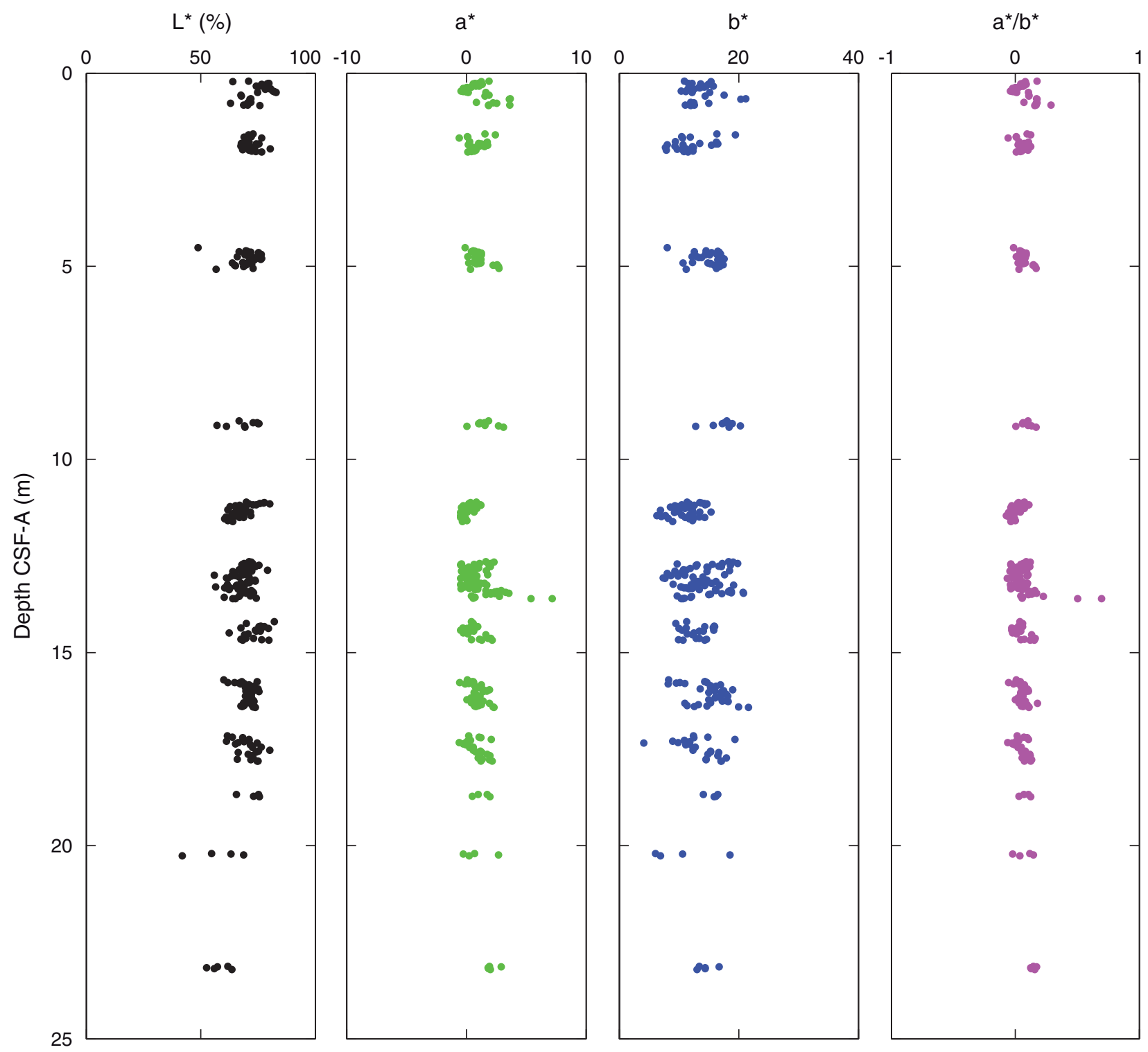


Figure F62. Magnetic susceptibility record for Hole M0034A. Water depth $=51 \mathrm{~m}$ (lowest astronomical tide).

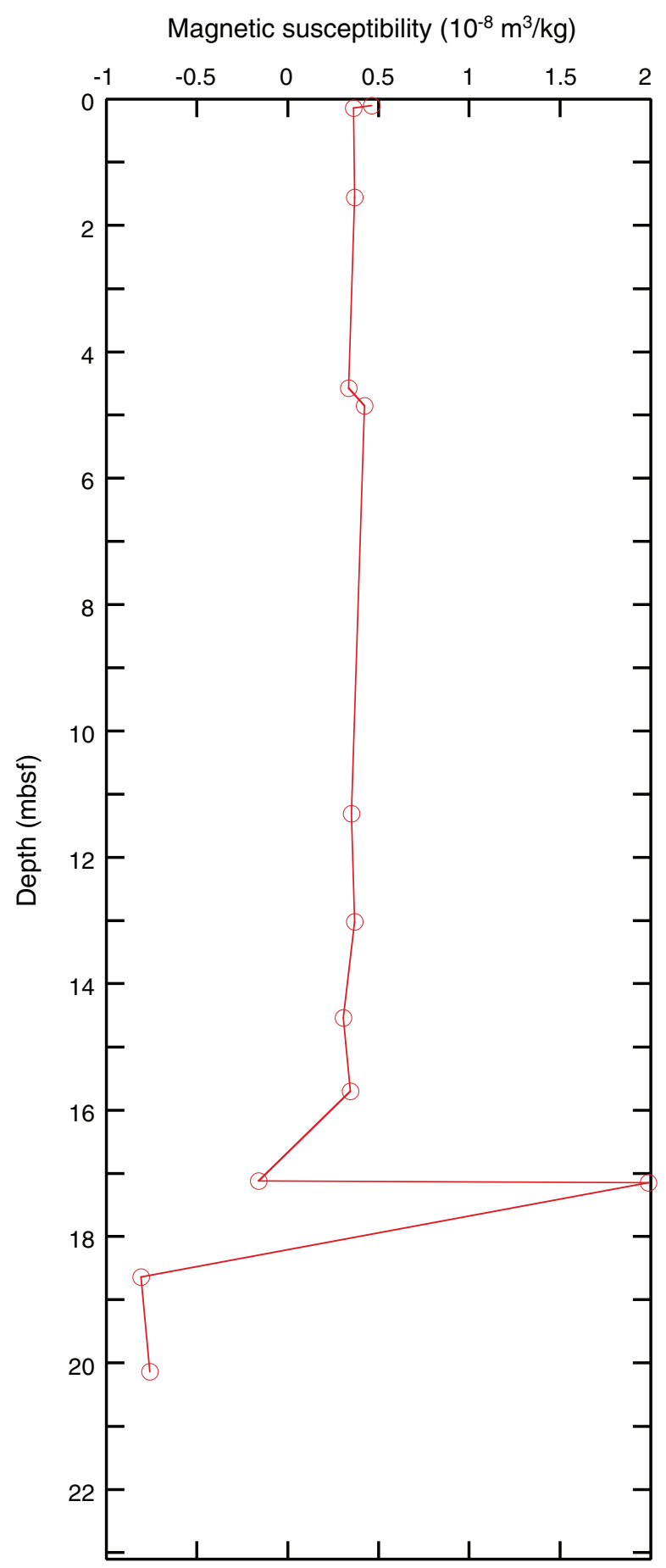


Figure F63. Preliminary chronology for Hole M0034A. Radiocarbon data are presented as graphs with the uncalibrated radiocarbon age and uncertainty shown as the red normal distribution on the ordinate axis and the probability distribution of the calibrated age shown in gray on the abscissa. The marine09 calibration curve is shown in blue. Horizontal bars indicate portions of the age distribution that are significant at the $95.4 \%$ confidence interval and the mean age (white circle \pm 1 standard deviation) used for the purposes of the preliminary dating. All ages are presented as thousands of calendar years BP (1950 AD). See Table T10 in the "Methods" chapter. (See Bronk Ramsey [2009], as well as Bronk Ramsey [2010] at c14.arch.ox.ac.uk/oxcal.html.)
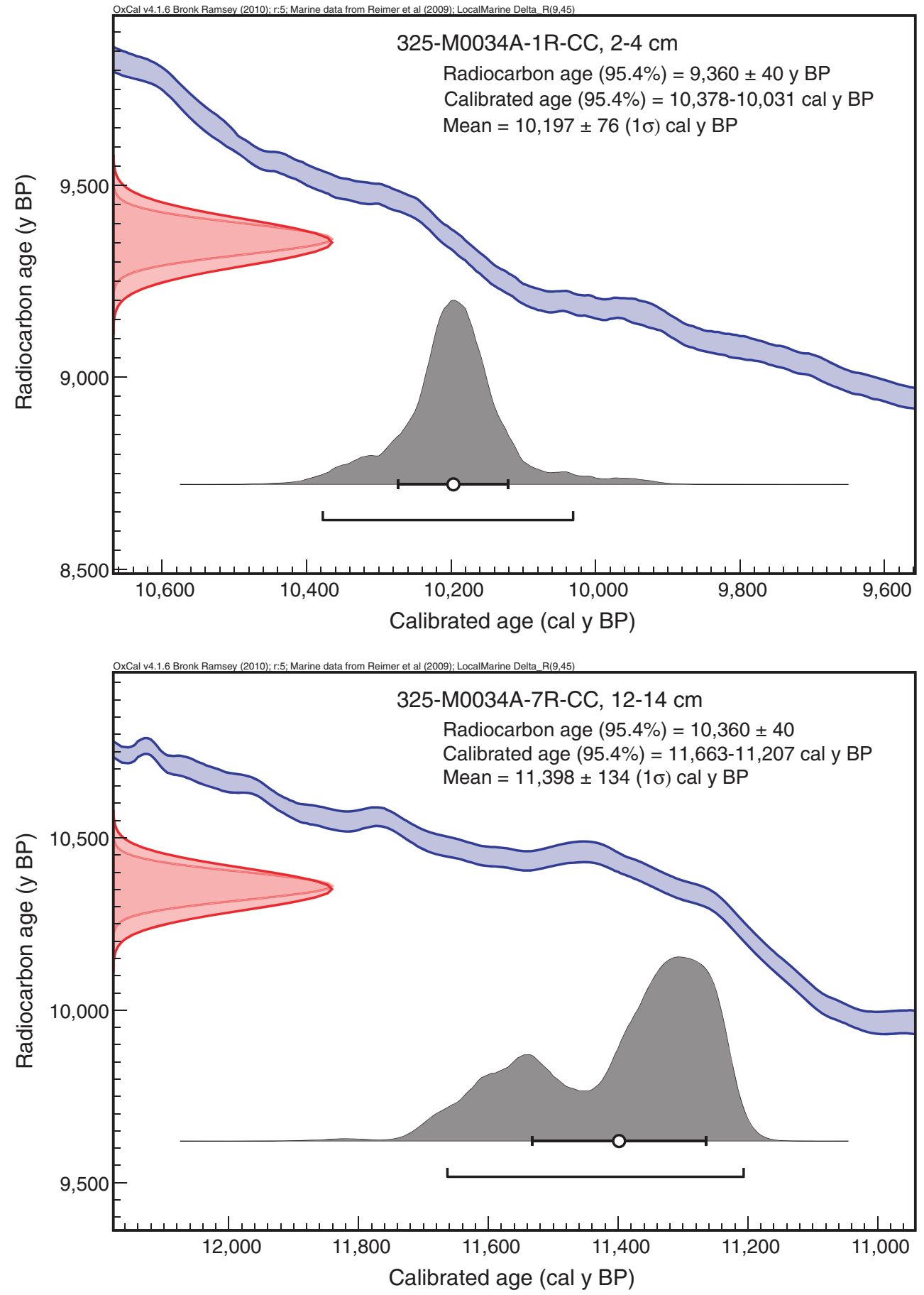
Figure F64. High-resolution line scan image of a massive fragmented Isopora colony (interval 325-M0035A-5R$1,36-70 \mathrm{~cm})$.

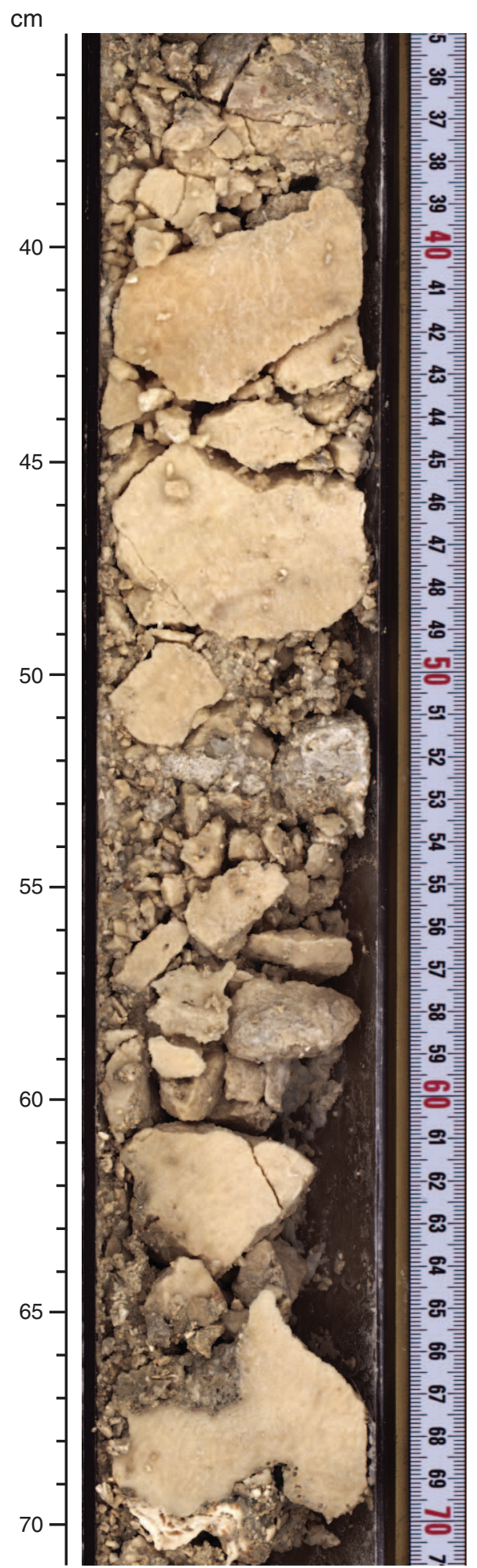


Figure F65. High-resolution line scan image showing a coralgal-microbialite boundstone and Tubipora musica colonies (interval 325-M0035A-8R-1, 32-80 cm).

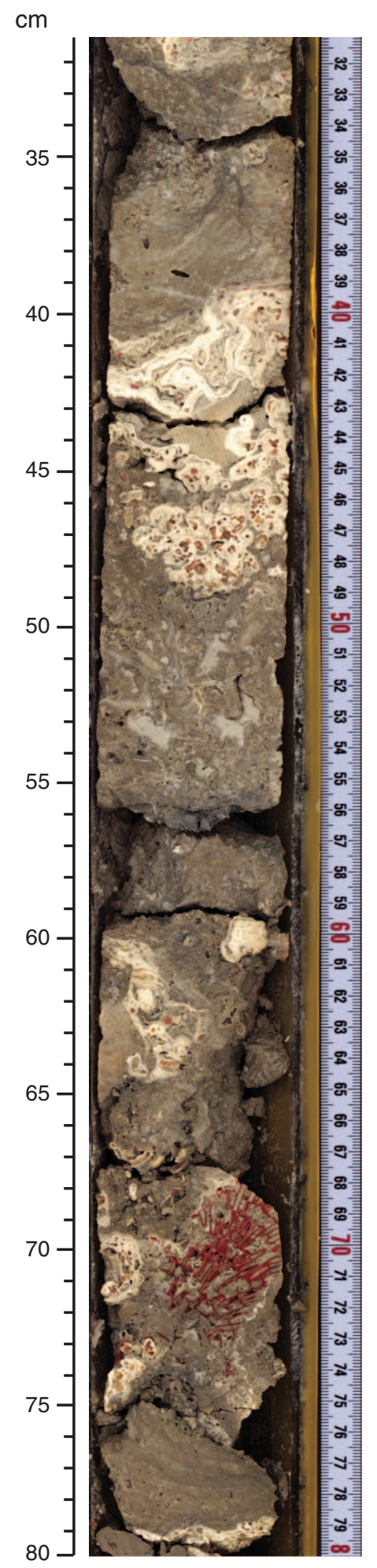


Figure F66. High-resolution line scan image of undetermined bioeroded encrusting corals encrusted by laminated microbialites (interval 325-M0035A-19R-1, 28-45 cm). Halimeda infillings are present between the columns of microbialites.

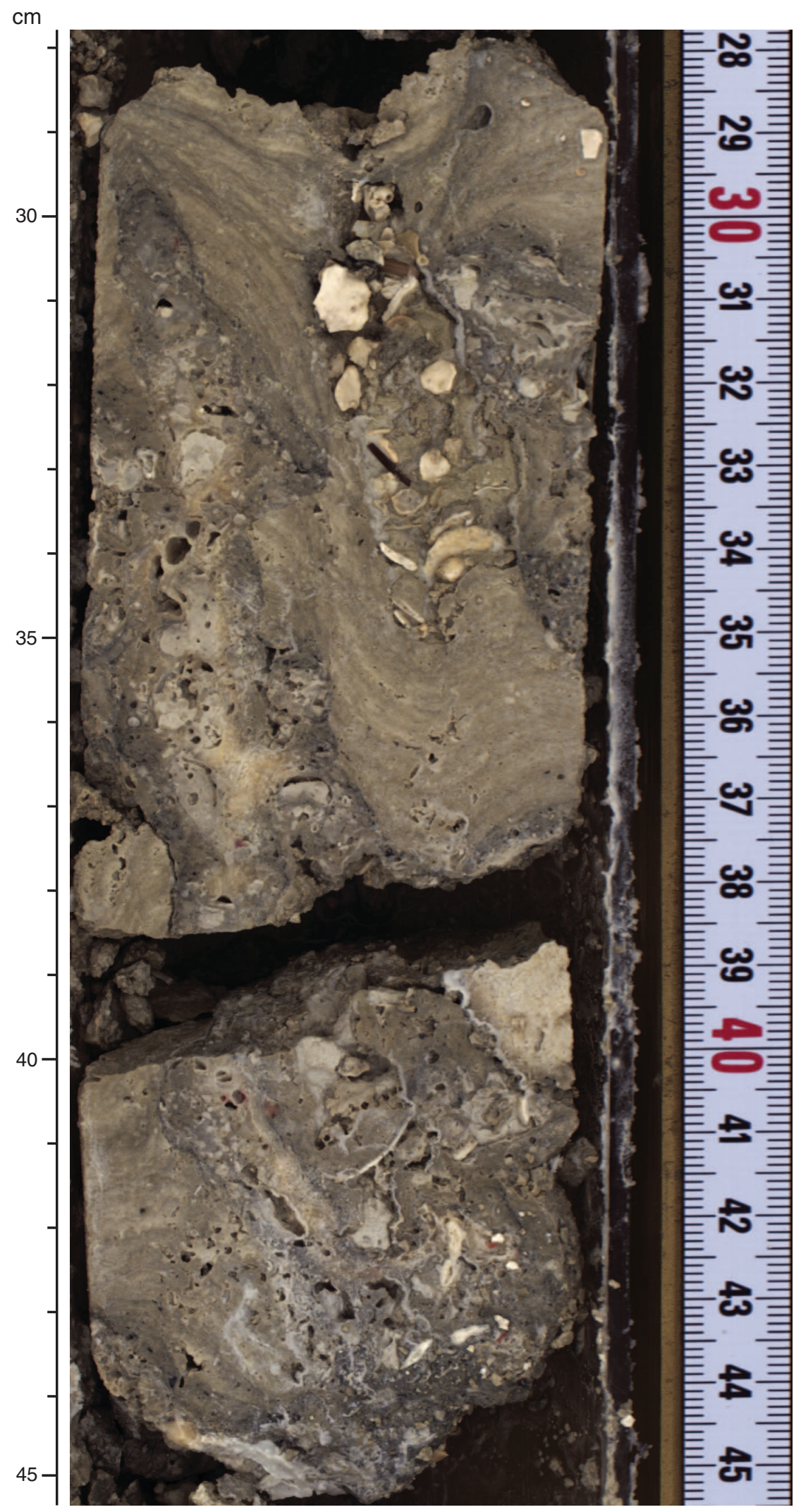


Figure F67. High-resolution line scan image of a massive Isopora colony (interval 325-M0035A-14R-1, 1-9 cm).

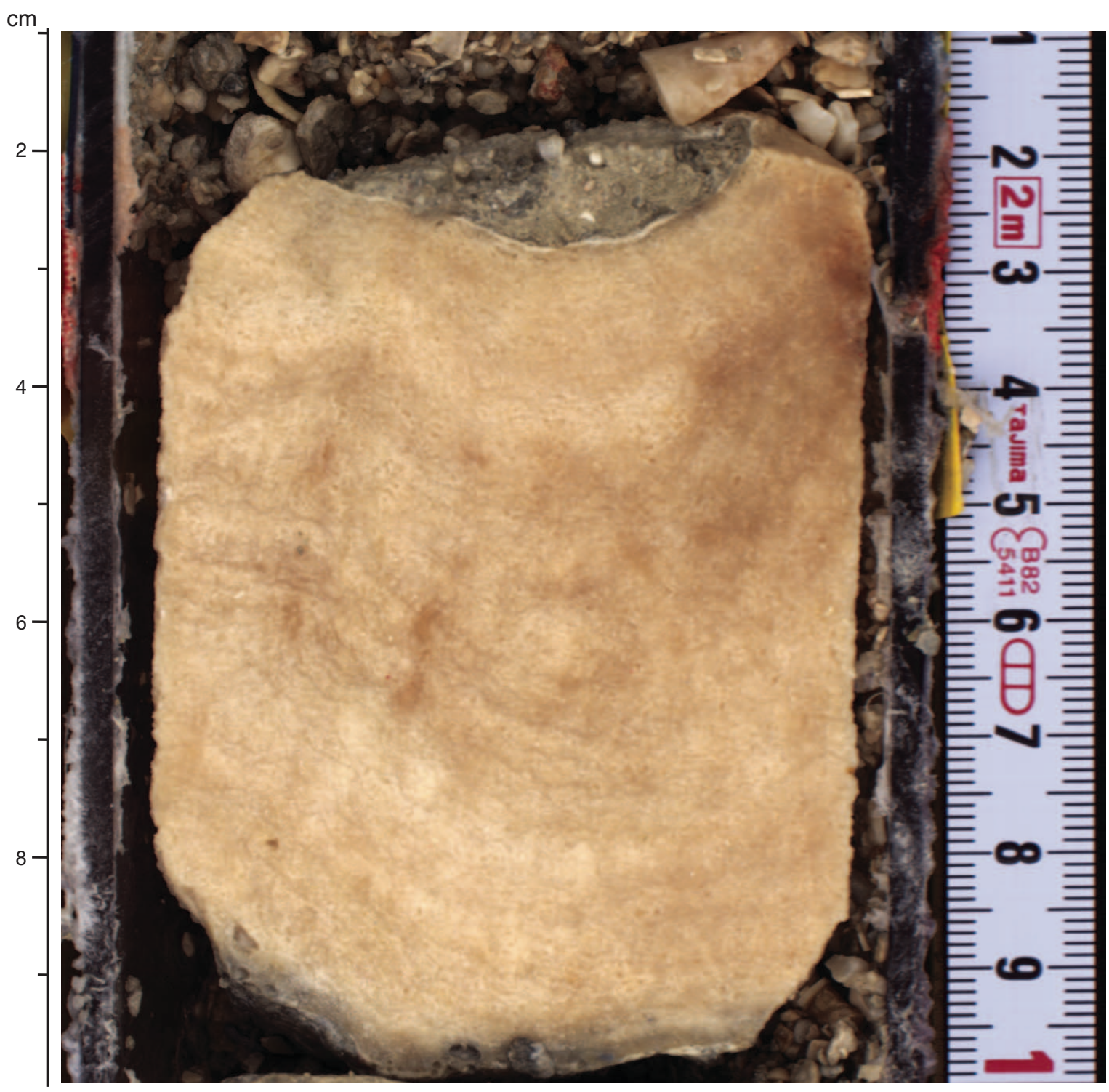


Figure F68. High-resolution line scan image of a fine branching Seriatopora colony (in situ) encrusted by thin coralline algae (interval 325-M0035A-12R-1, 40-54 cm).

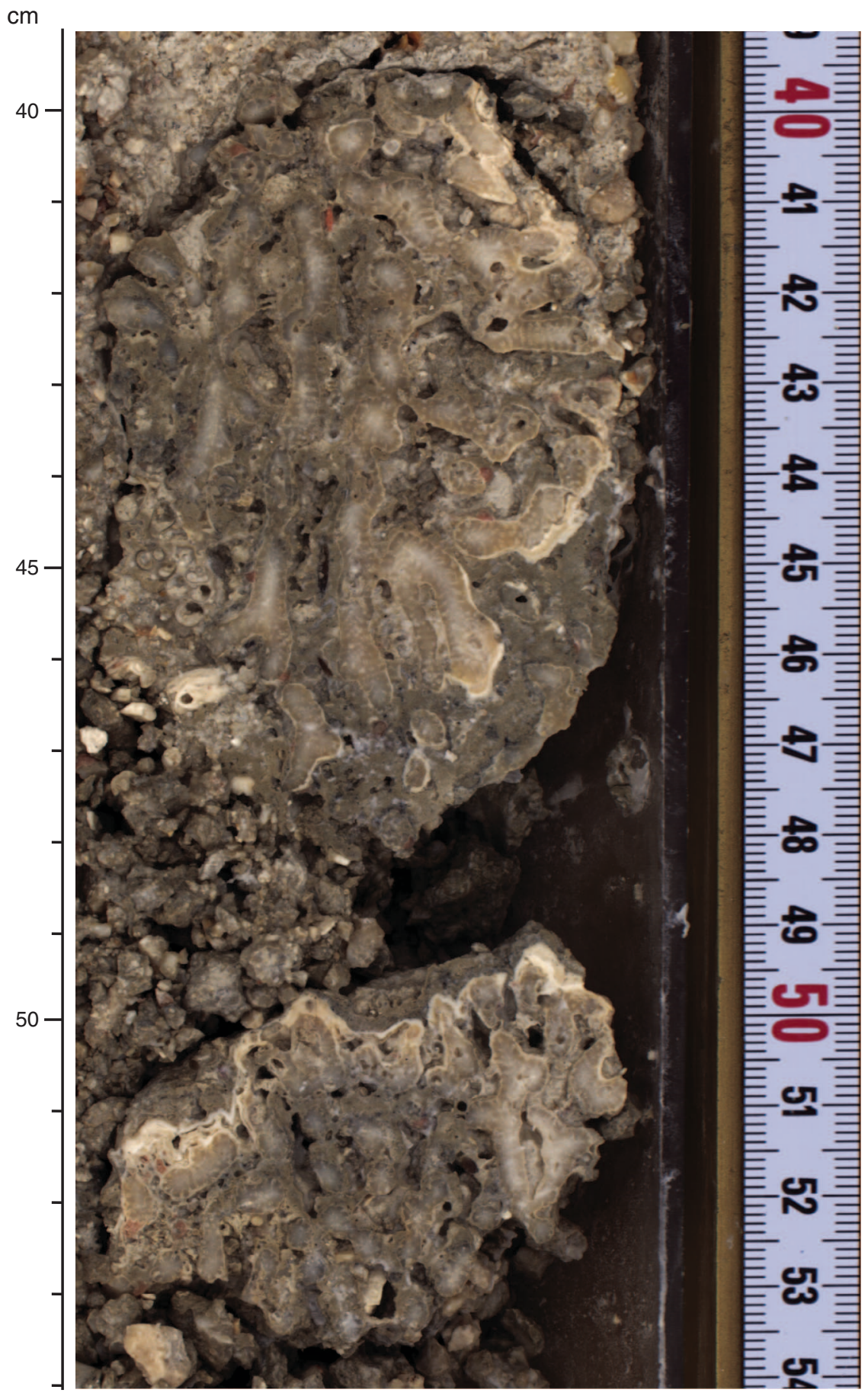


Figure F69. High-resolution line scan image of a medium branching Acropora colony (interval 325-M0035A11R-1, 38-47 cm).

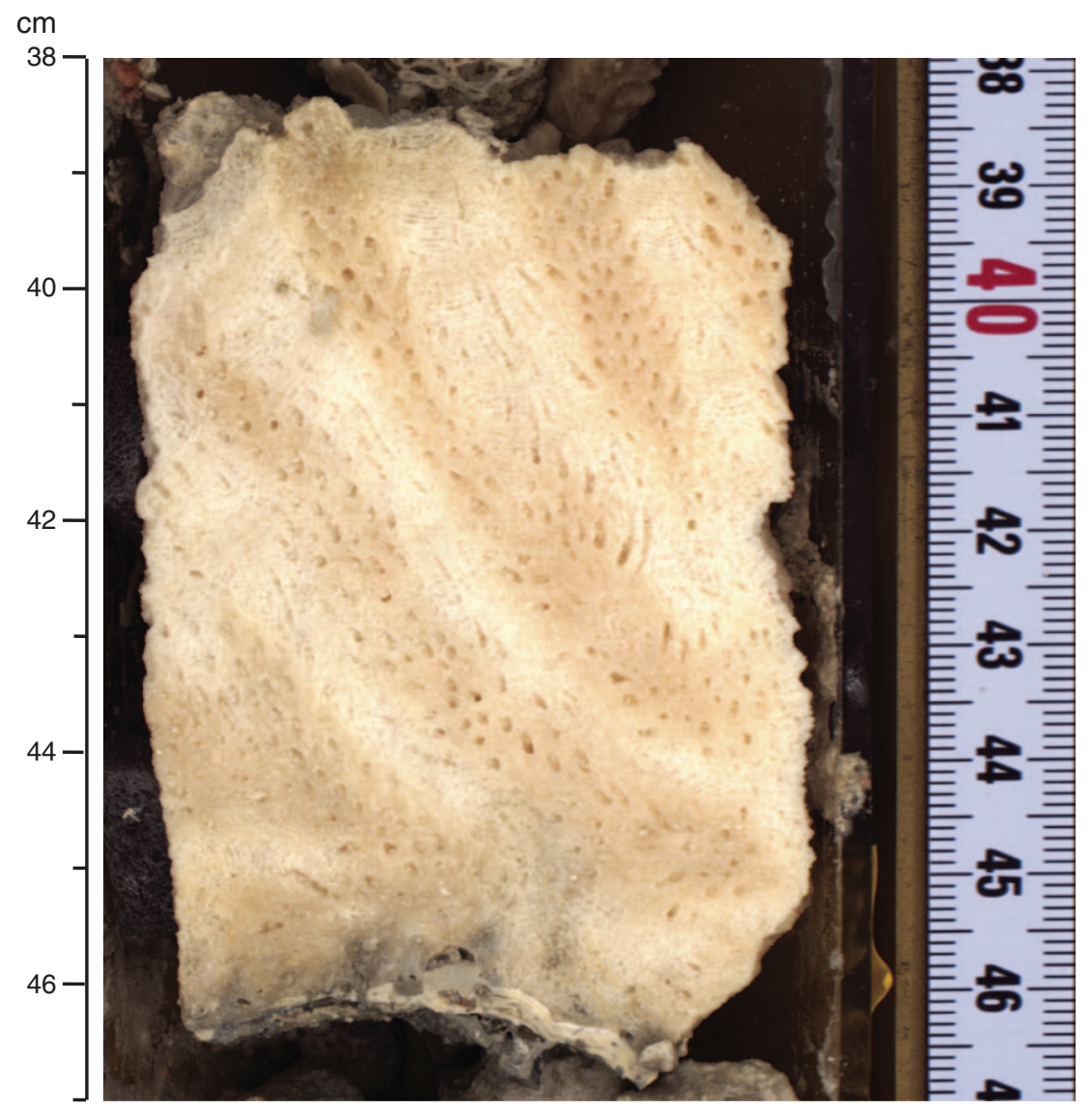


Figure F70. High-resolution line scan image of a massive Favia pallida colony (in situ?) (interval 325-M0035A16R-1, 4-17 cm).

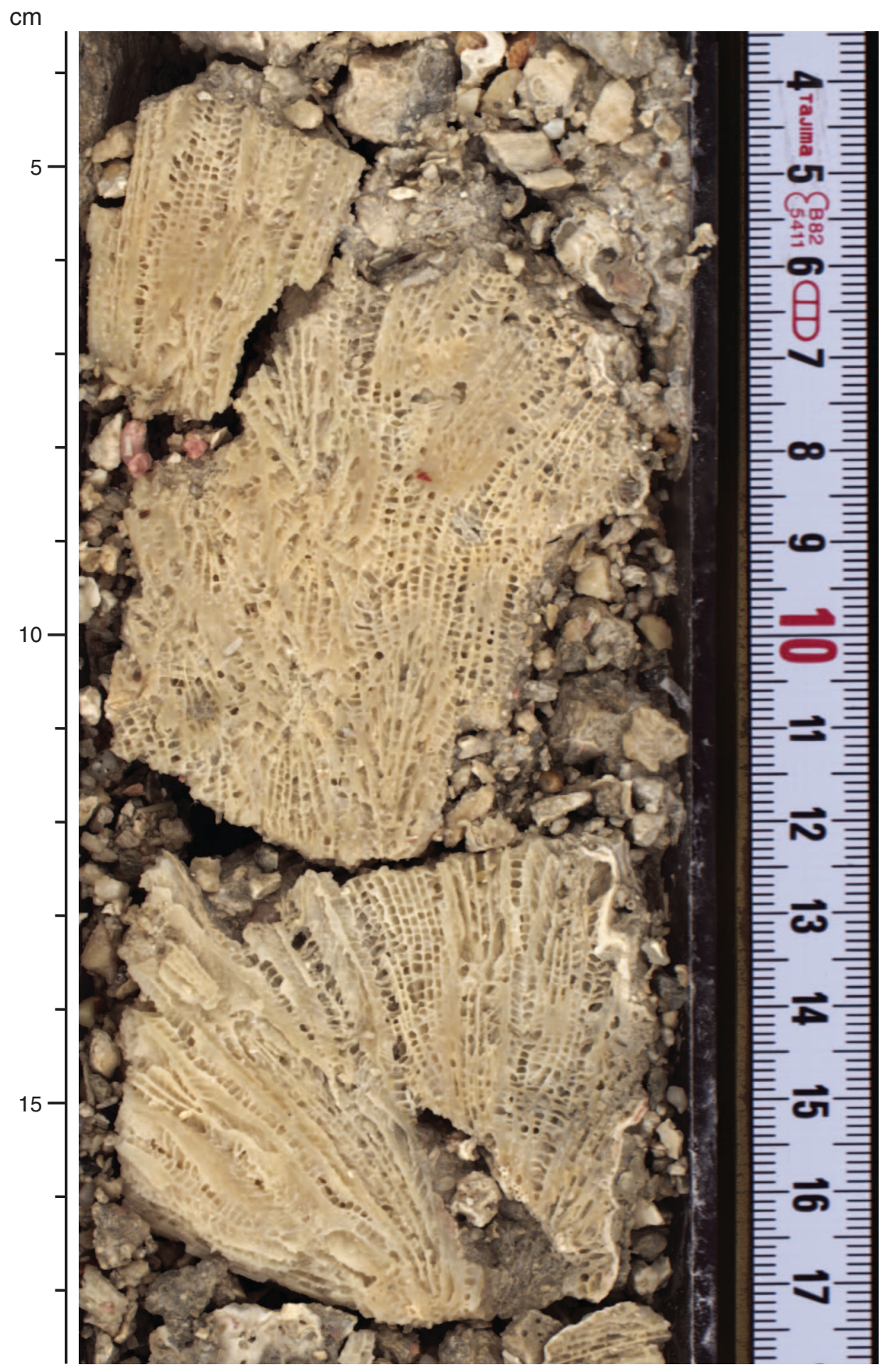


Figure F71. High-resolution line scan image of a massive Tubipora musica colony (in situ?) encrusted by Montipora (interval 325-M0035A-17R-1, 3-15 cm). Thick crusts of coralline algae and laminated microbialites are also present.

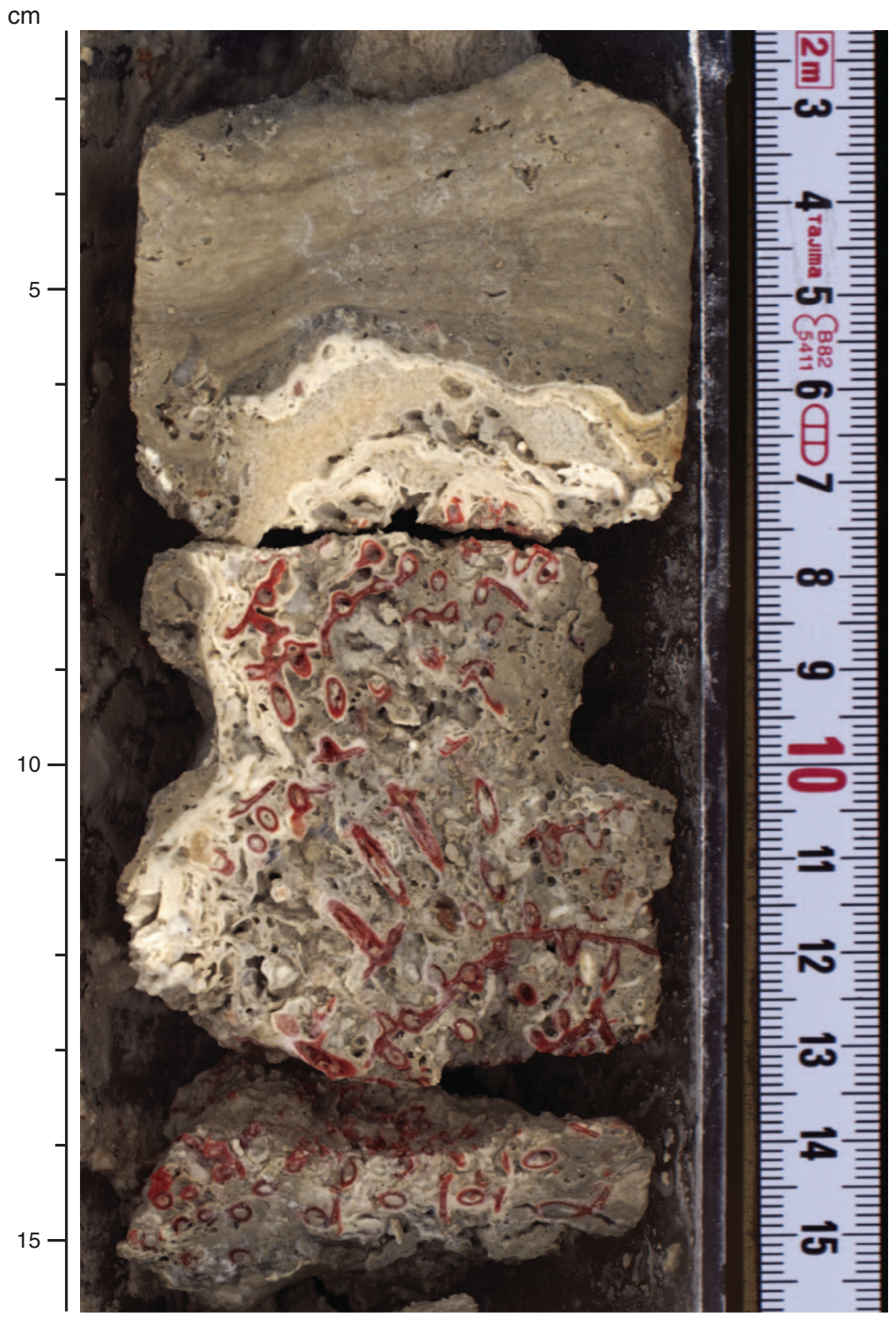


Figure F72. High-resolution line scan image of a tabular Acropora colony encrusted by coralline algae associated with encrusting foraminifera, along with thick laminated microbialite crusts (interval 325-M0035A-18R-1, 20$31 \mathrm{~cm})$.

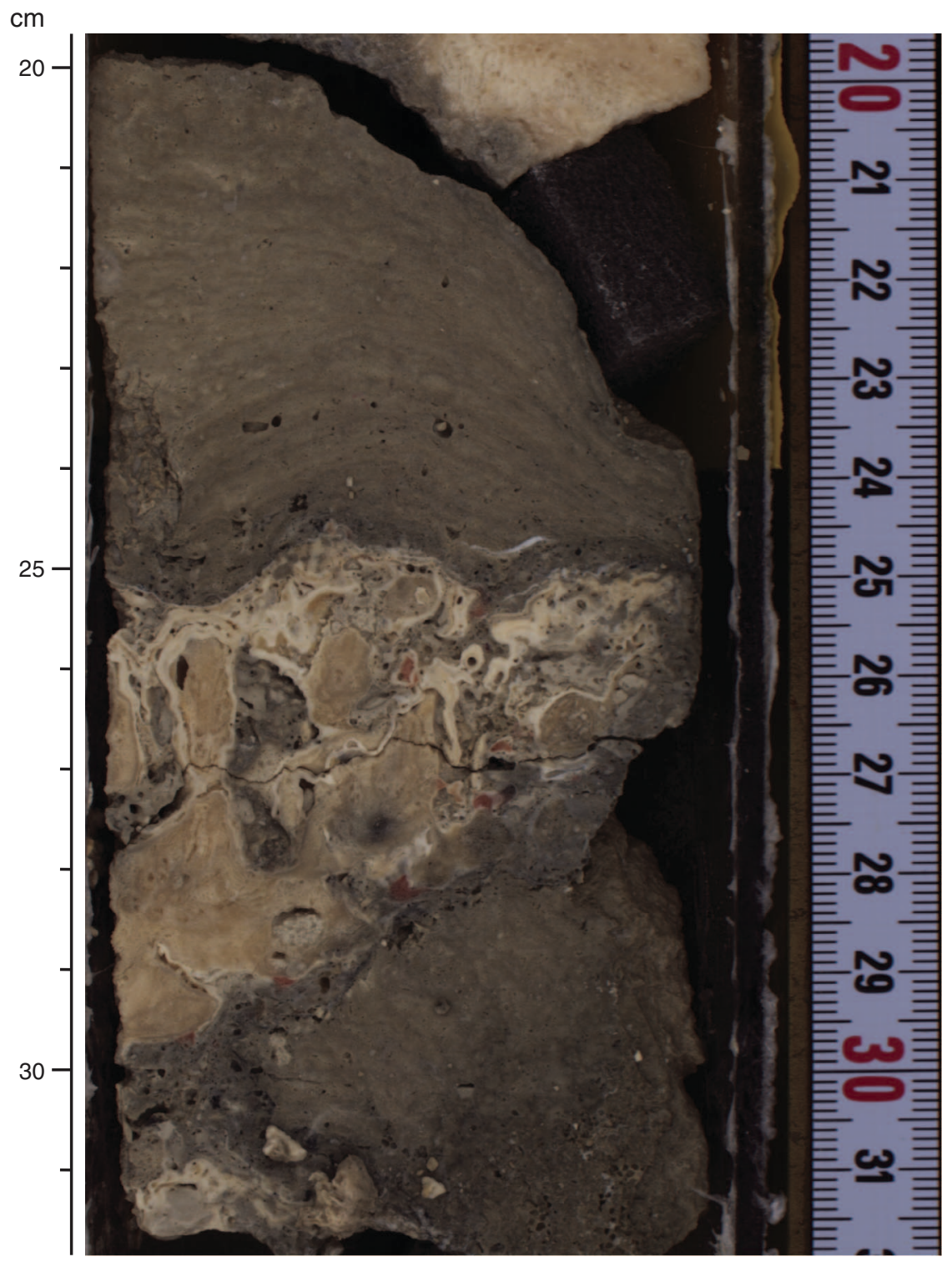


Figure F73. High-resolution line scan image of packstone to grainstone with bioclasts containing corals, foraminifera, mollusks, and Halimeda (interval 325-M0035A-23R-1, 15-24 cm).

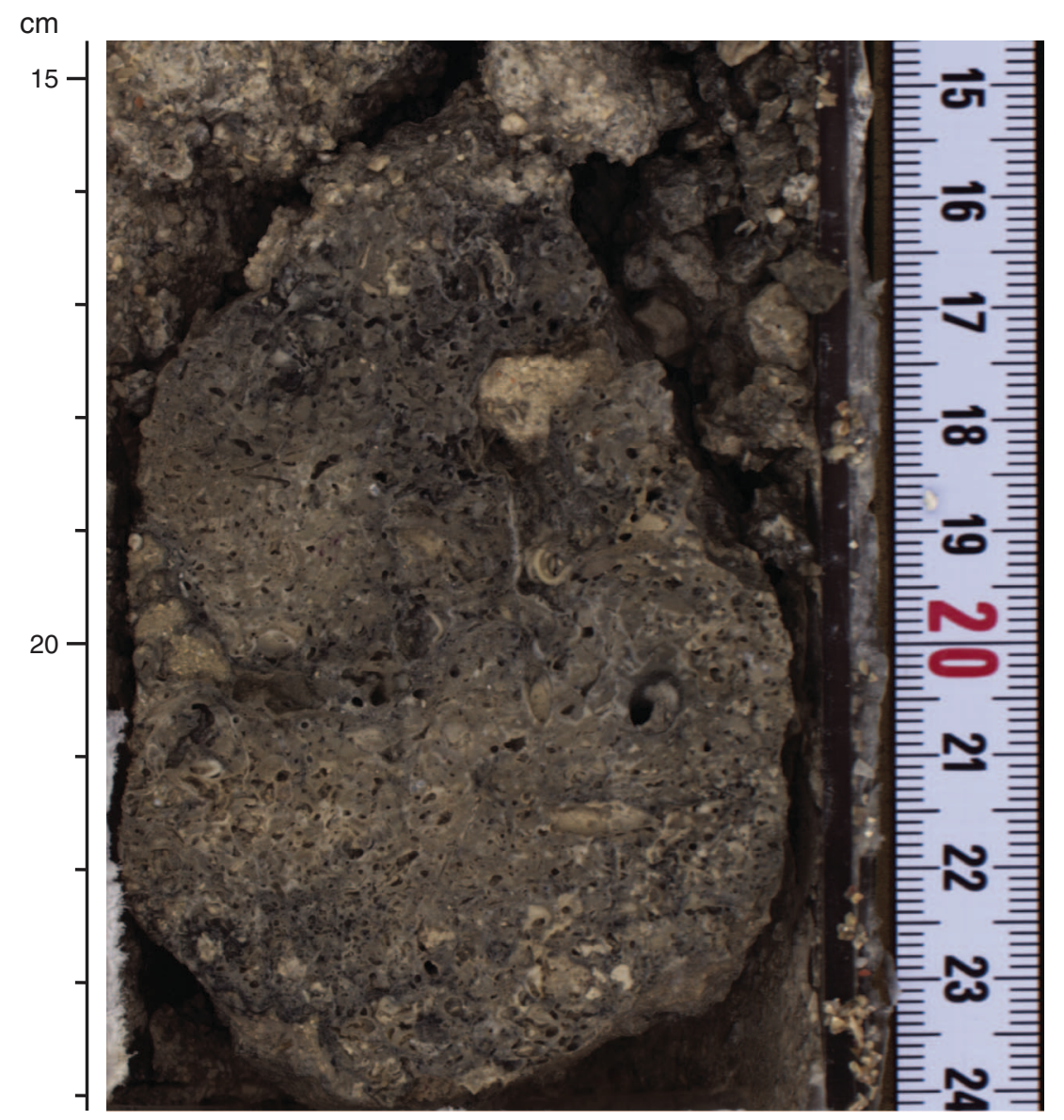


Figure F74. High-resolution line scan image taken from immediately below Figure M0035A-C-F10 showing the continuation of packstone to grainstone with bioclasts containing corals, foraminifera, mollusks, and Halimeda (interval 325-M0035A-23R-CC, 1-4 cm).

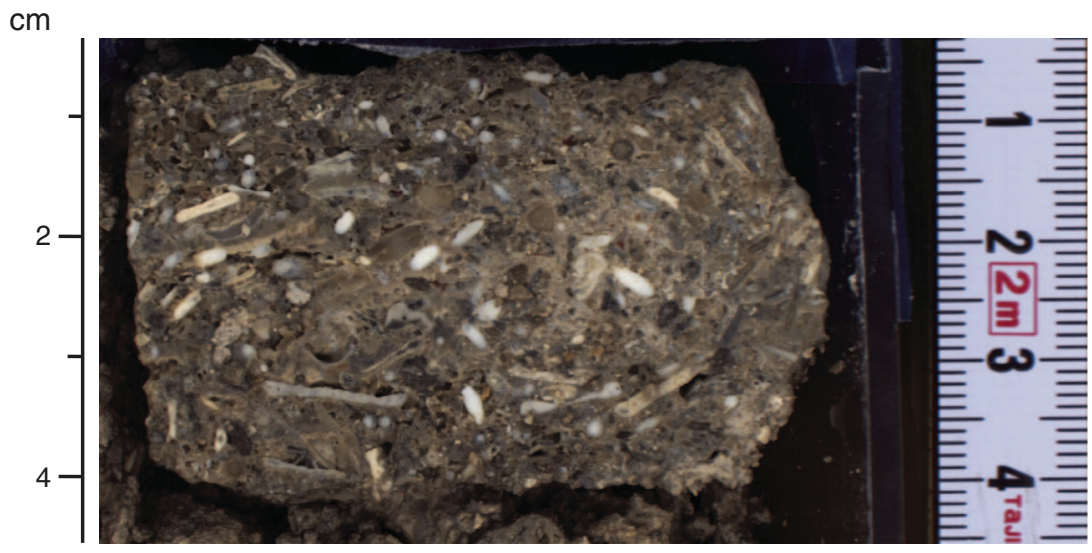


Figure F75. Summary diagram showing data collected on whole cores using the MSCL, Hole M0035A.

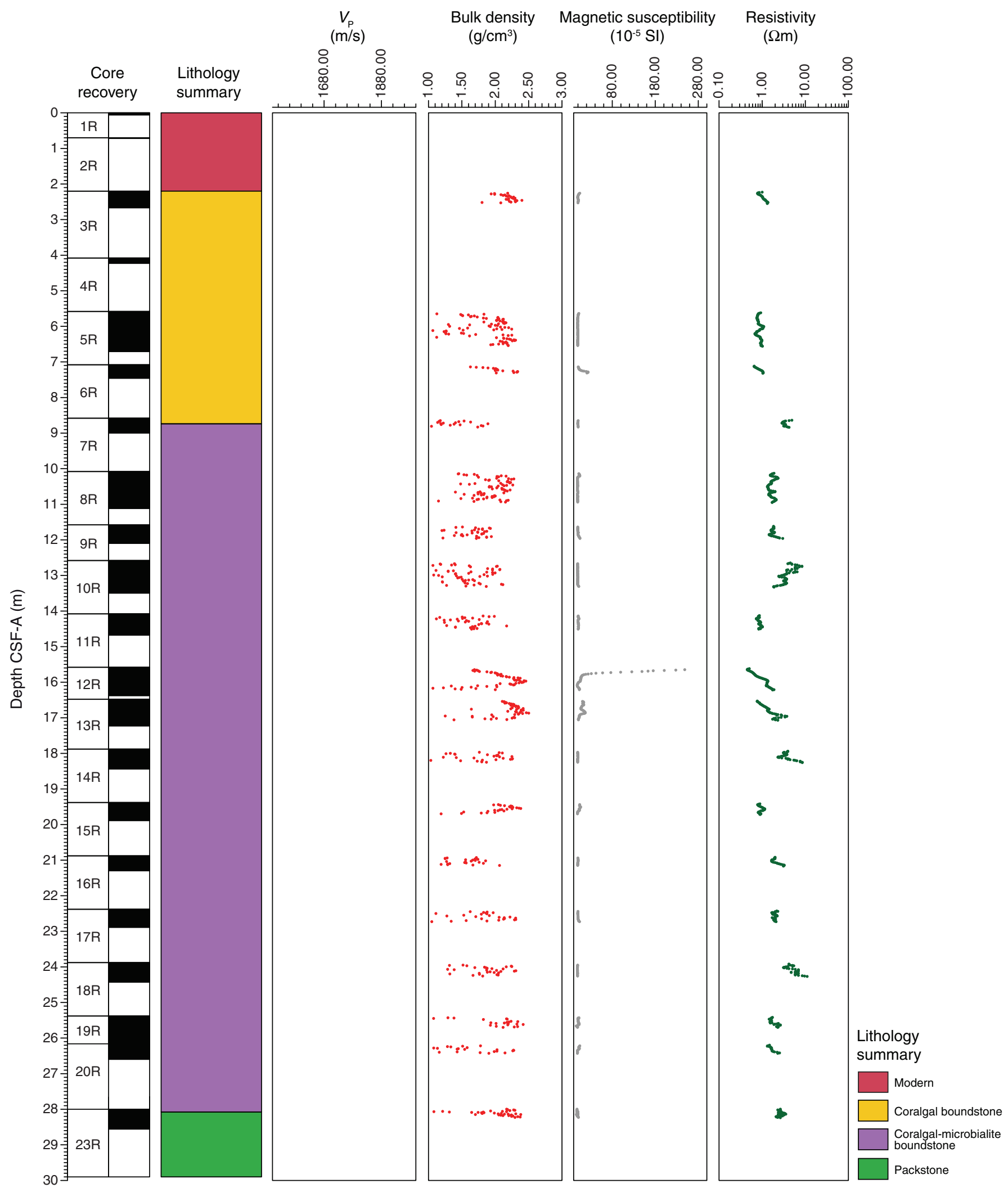


Figure F76. Petrophysical measurements obtained from discrete samples with a pycnometer, Hole M0035A. Bulk density measured on whole cores with the MSCL is shown in red on the bulk density plot.

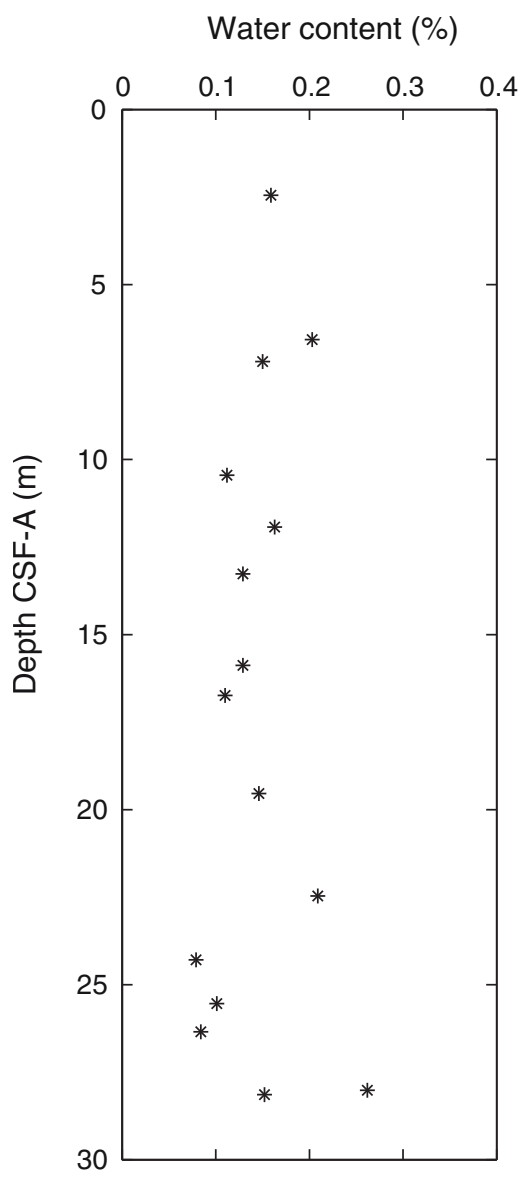

\section{Bulk density $\left(\mathrm{g} / \mathrm{cm}^{3}\right)$}

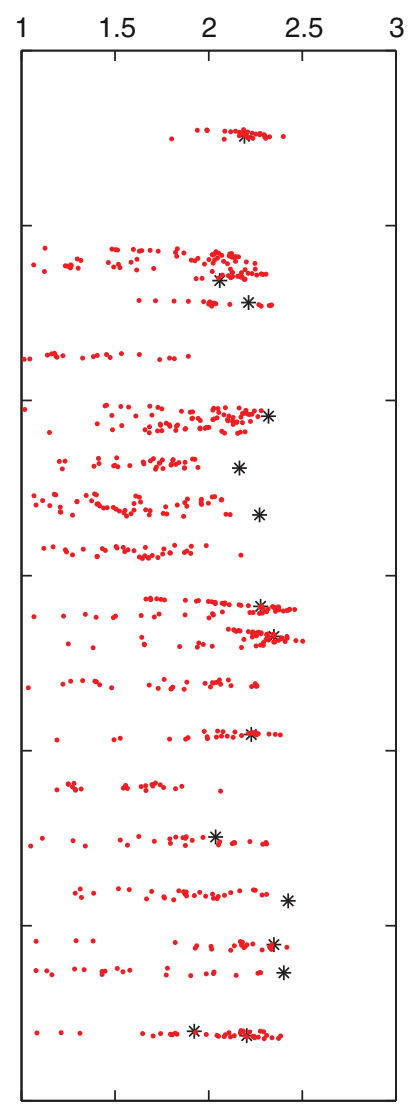

Grain density $\left(\mathrm{g} / \mathrm{cm}^{3}\right)$

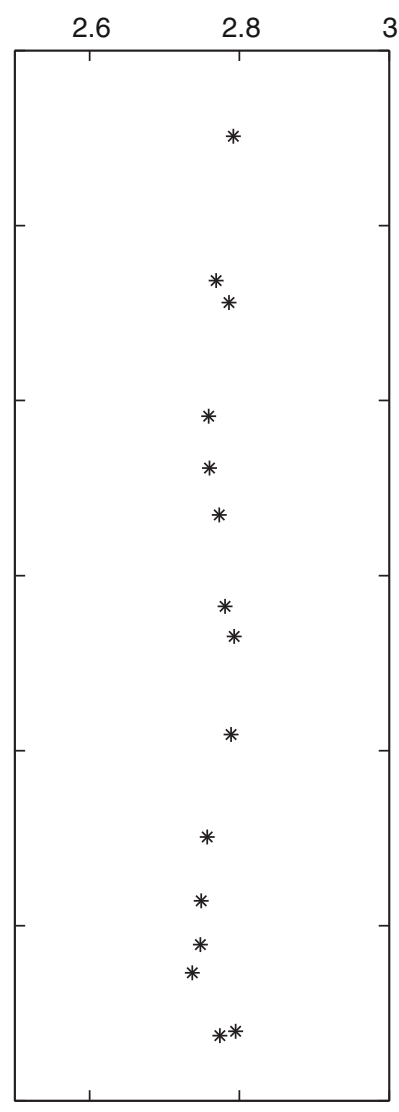

Porosity (\%)

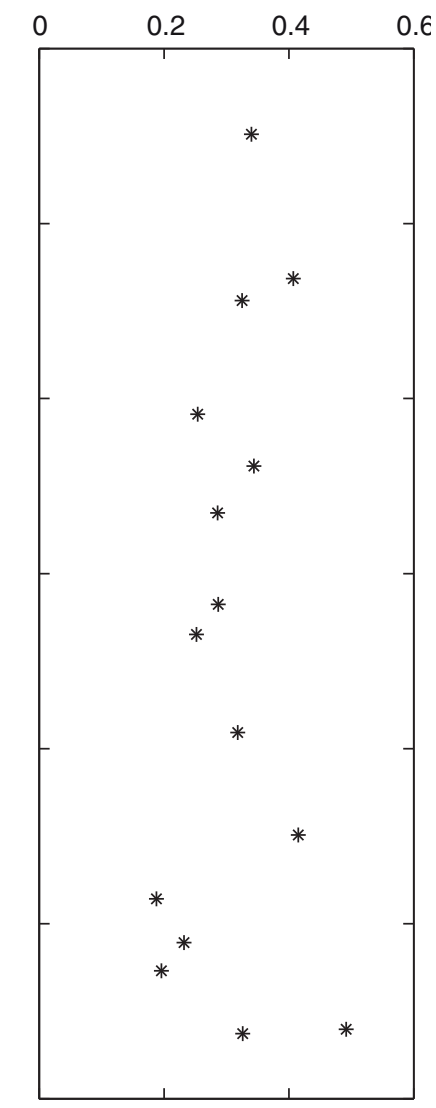


Figure F77. $P$-wave velocity data, Hole M0035A. A. Plot of initial, dry, and resaturated $P$-wave velocity measurements on discrete samples vs. depth. Three measurements were taken at each depth and are denoted by a dot. Average values are plotted as an open triangle. B. Plot showing discrete $P$-wave velocity vs. discrete bulk density.

A

A

Initial velocity $P$-wave velocity $(\mathrm{m} / \mathrm{s})$

Dry velocity
$P$-wave velocity $(\mathrm{m} / \mathrm{s})$

Resaturated velocity

$P$-wave velocity $(\mathrm{m} / \mathrm{s})$
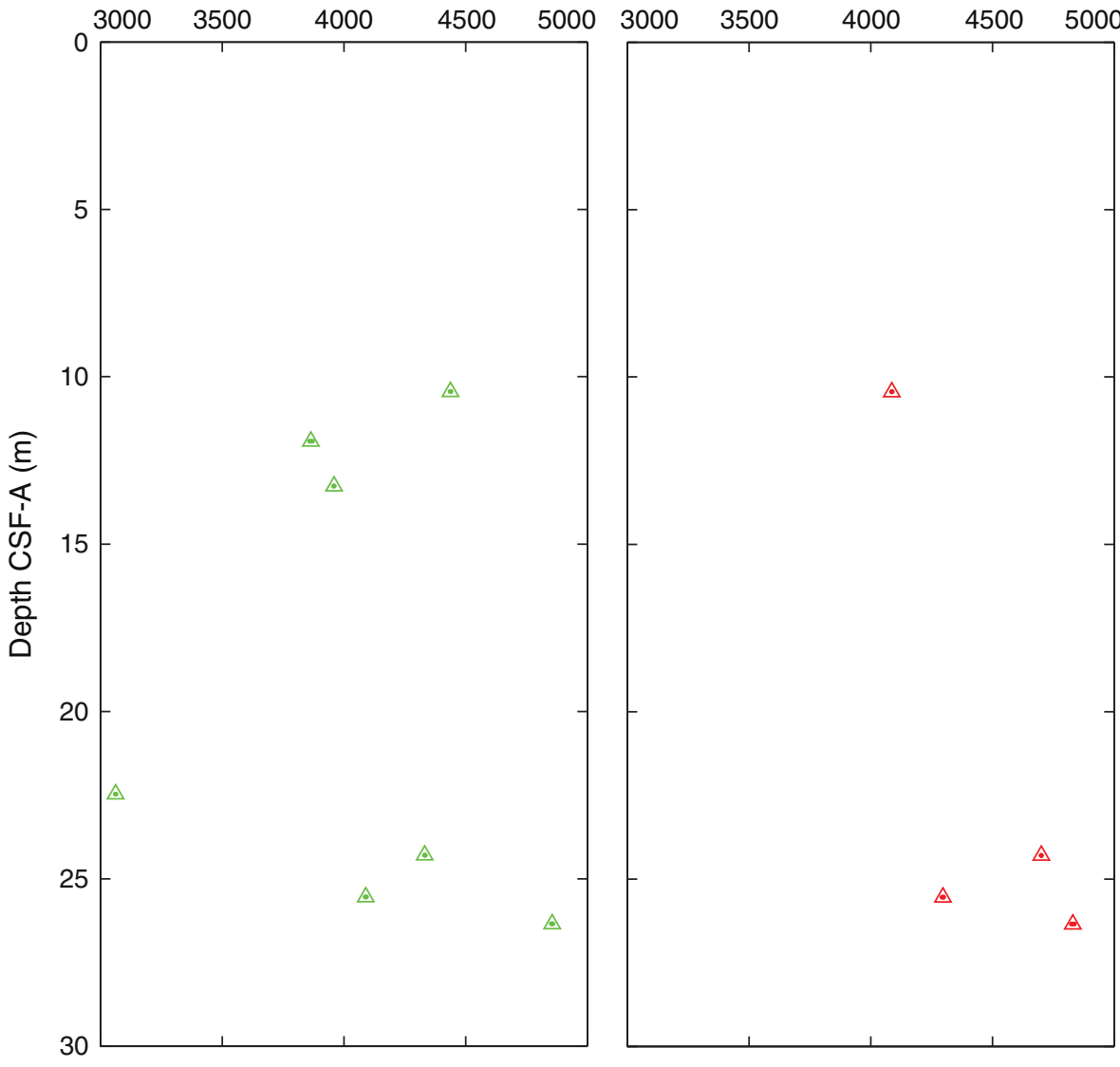

$\begin{array}{lllll}3000 & 3500 & 4000 & 4500 \quad 5000\end{array}$

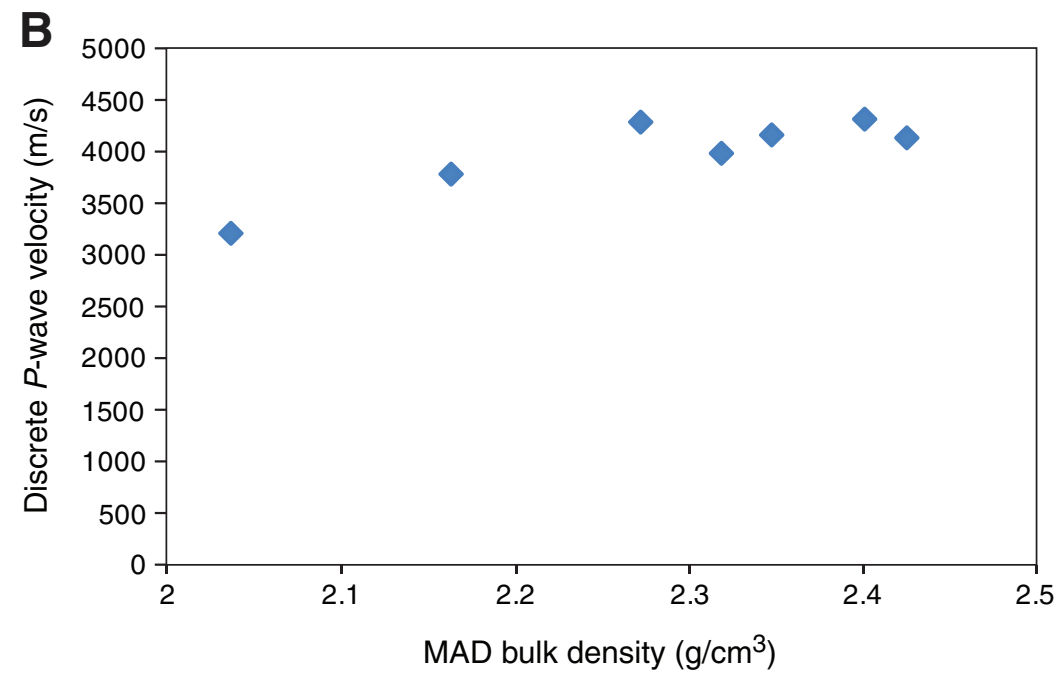


Figure F78. Values of reflectance $\left(\mathrm{L}^{*}\right)$, green to red $\left(\mathrm{a}^{*}\right)$, and blue to yellow $\left(\mathrm{b}^{*}\right)$ indexes, along with ratio $\mathrm{a}^{*} / \mathrm{b}^{*}$ for Hole M0035A.

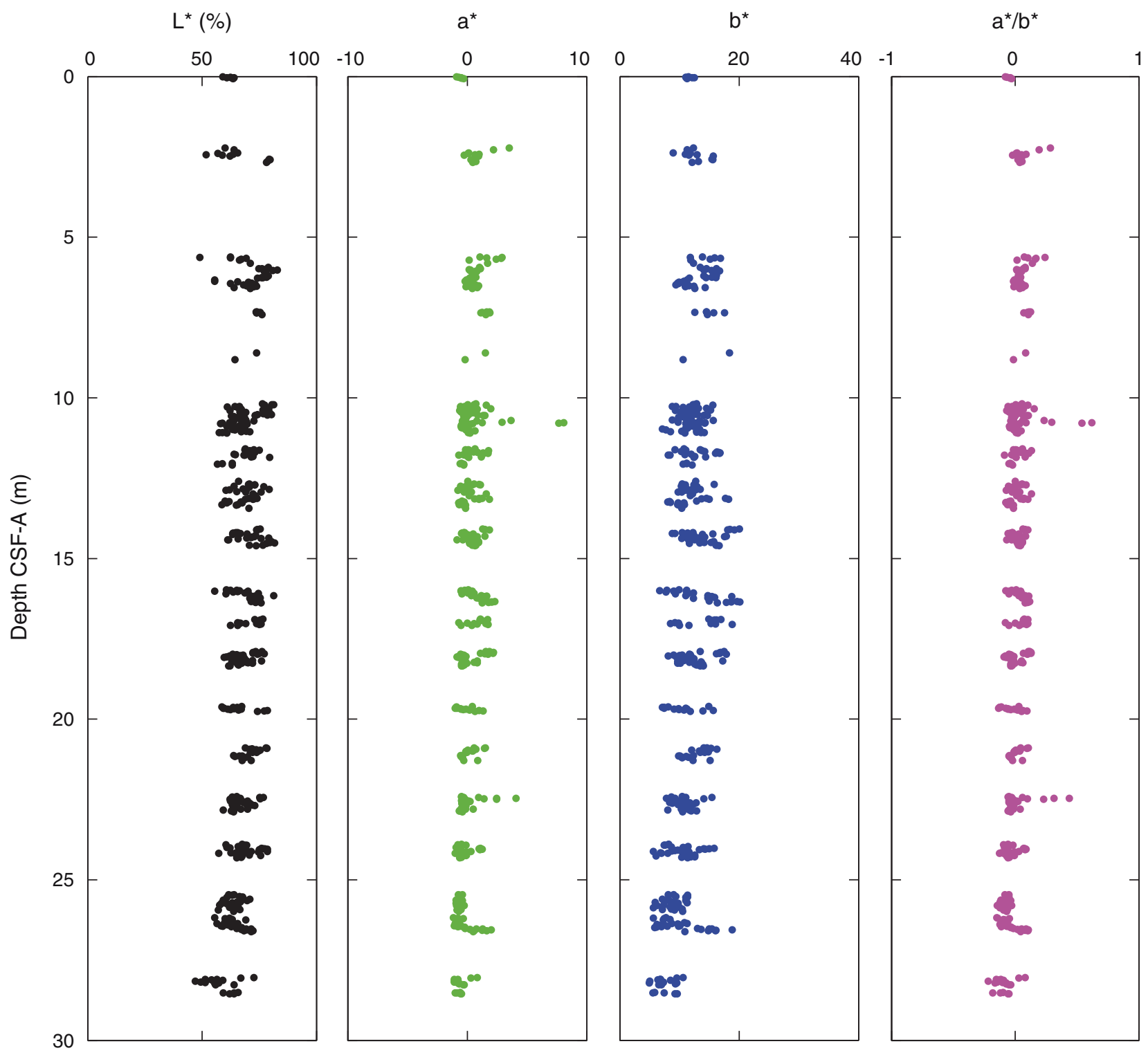


Figure F79. Magnetic susceptibility record for Hole M0035A. Water depth $=100.05 \mathrm{~m}$ (lowest astronomical tide).

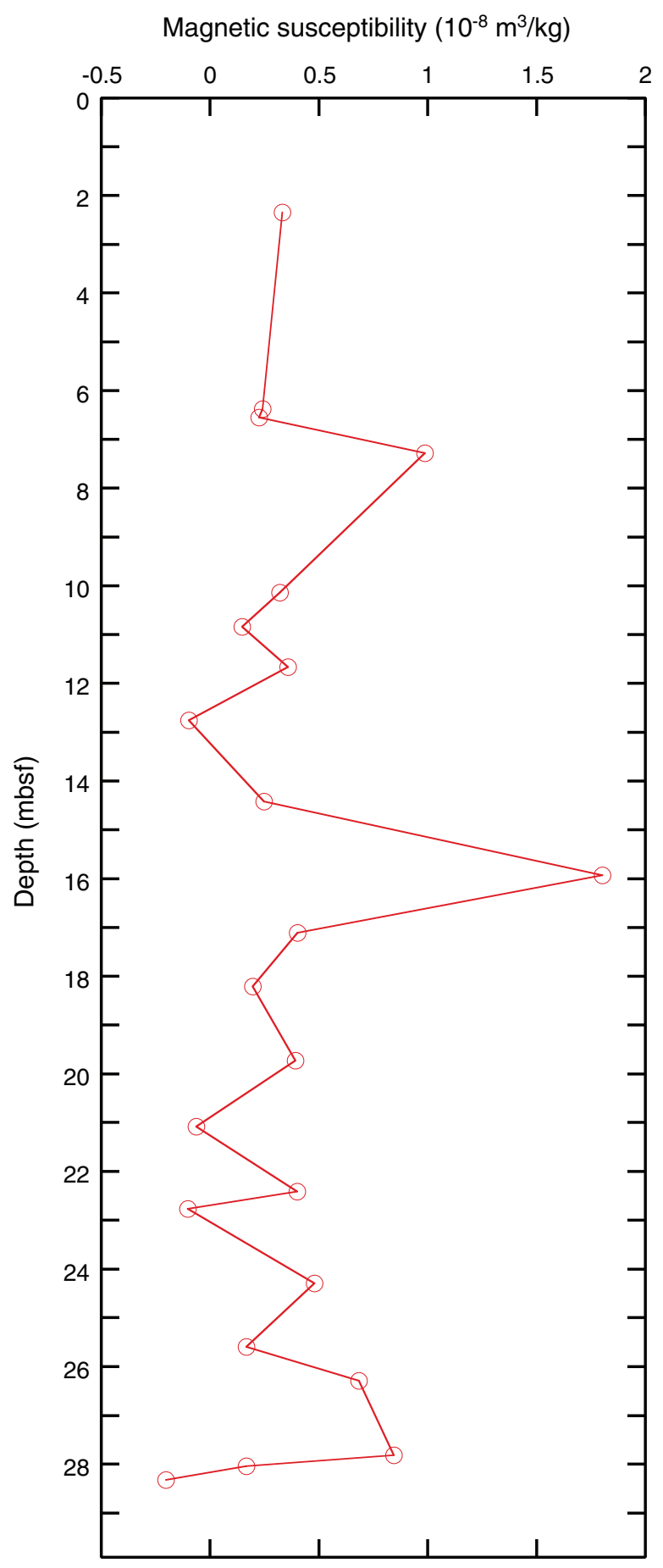


Figure F80. Preliminary chronology for Hole M0035A. Radiocarbon data are presented as graphs with the uncalibrated radiocarbon age and uncertainty shown as the red normal distribution on the ordinate axis and the probability distribution of the calibrated age shown in gray on the abscissa. The marine09 calibration curve is shown in blue. Horizontal bars indicate portions of the age distribution that are significant at the $95.4 \%$ confidence interval and the mean age (white circle \pm 1 standard deviation) used for the purposes of the preliminary dating. All ages are presented as thousands of calendar years BP (1950 AD). See Table T10 in the "Methods" chapter. (See Bronk Ramsey [2009], as well as Bronk Ramsey [2010] at c14.arch.ox.ac.uk/oxcal.html.)
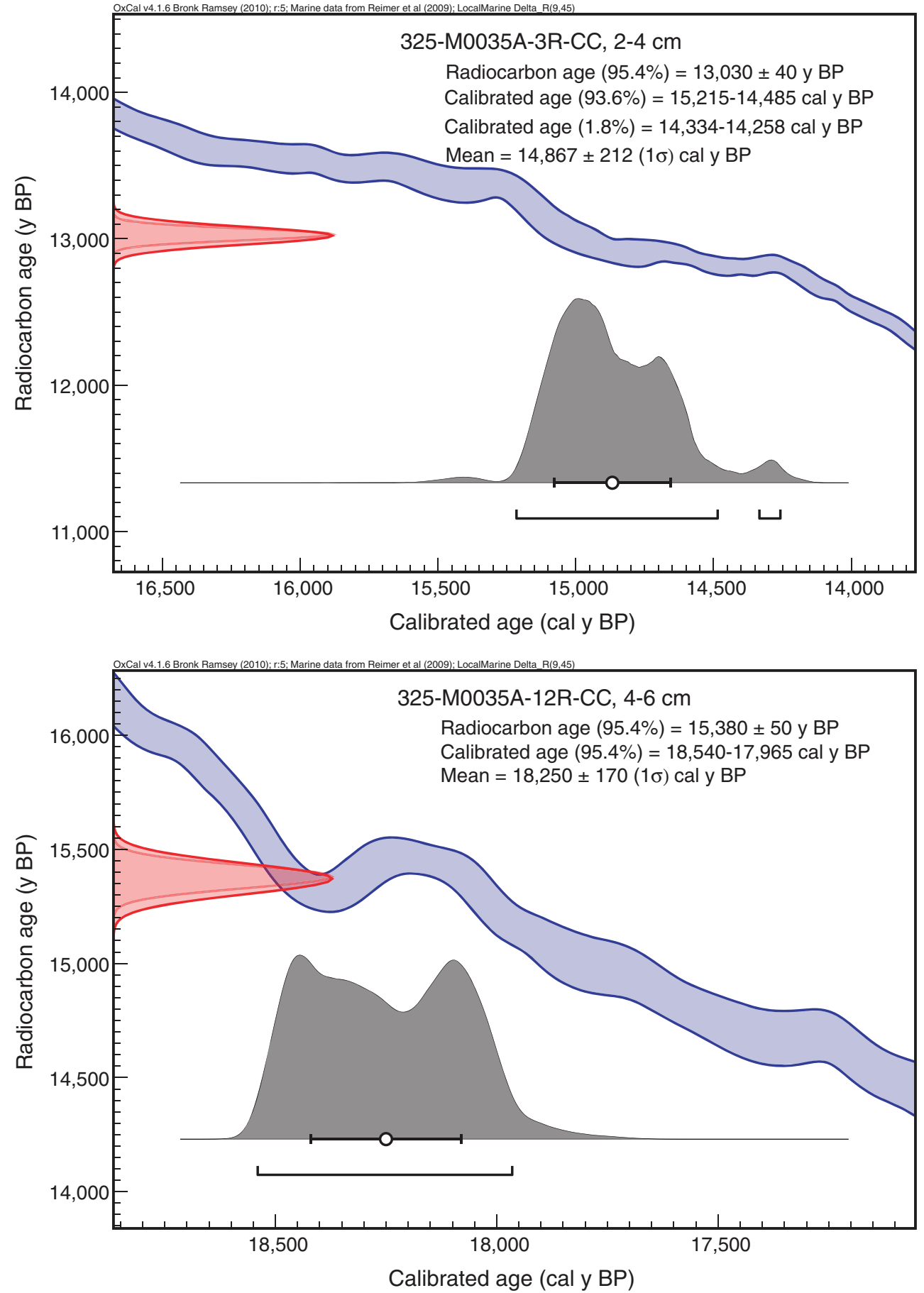
Figure F81. High-resolution line scan image of lime granules and pebbles composed of Halimeda, larger foraminifera, coral fragments, and nodular bryozoans (interval 325-M0036A-3W-1, 76-91 cm).

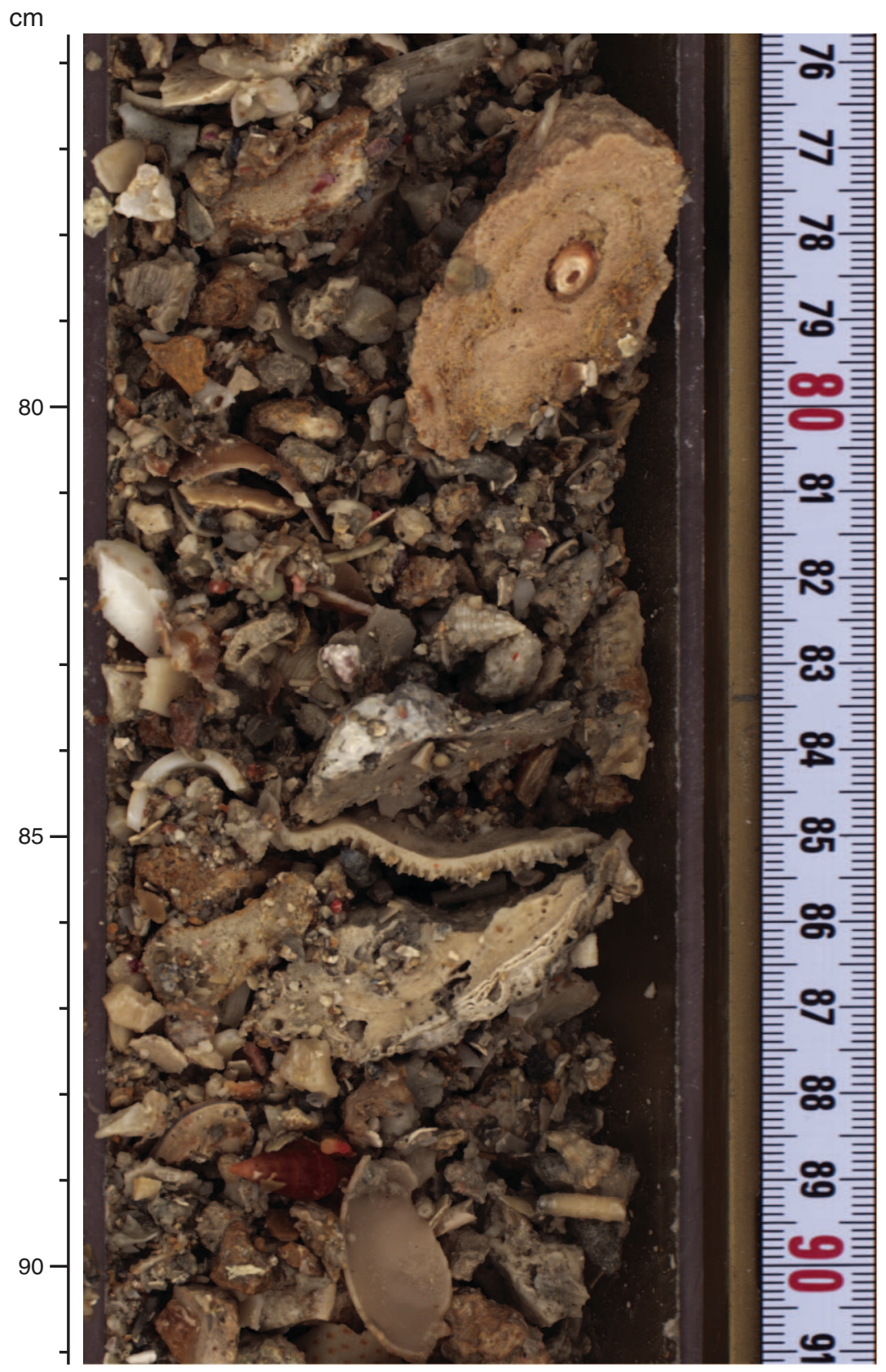


Figure F82. High-resolution line scan image of a massive Isopora colony (interval 325-M0036A-9R-CC, 3-10 $\mathrm{cm})$.

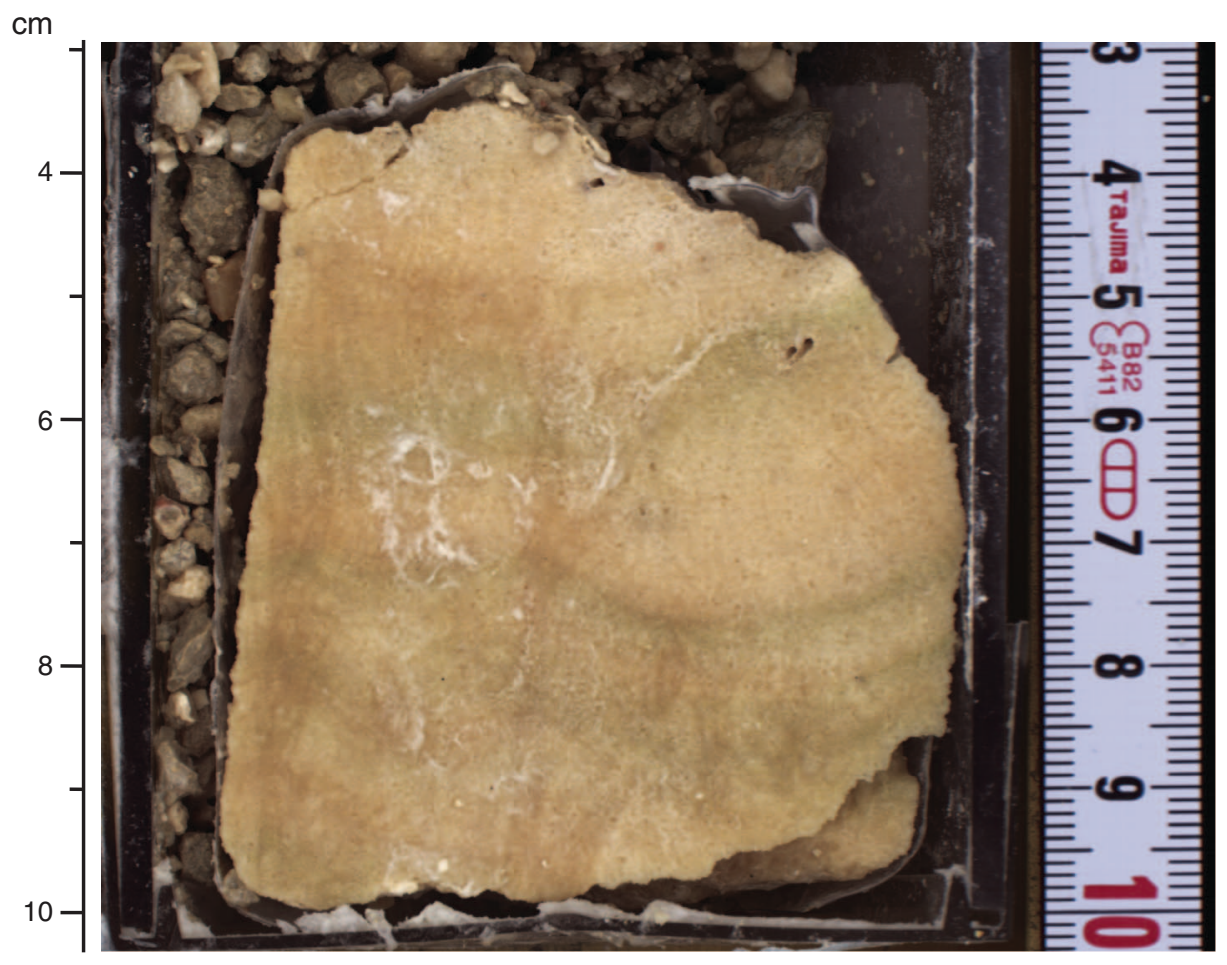


Figure F83. High-resolution line scan image of a fine branching Seriatopora encrusted by thin coralline algae, infilled with sediment rich in Halimeda (interval 325-M0036A-15R-1, 14-23 cm).

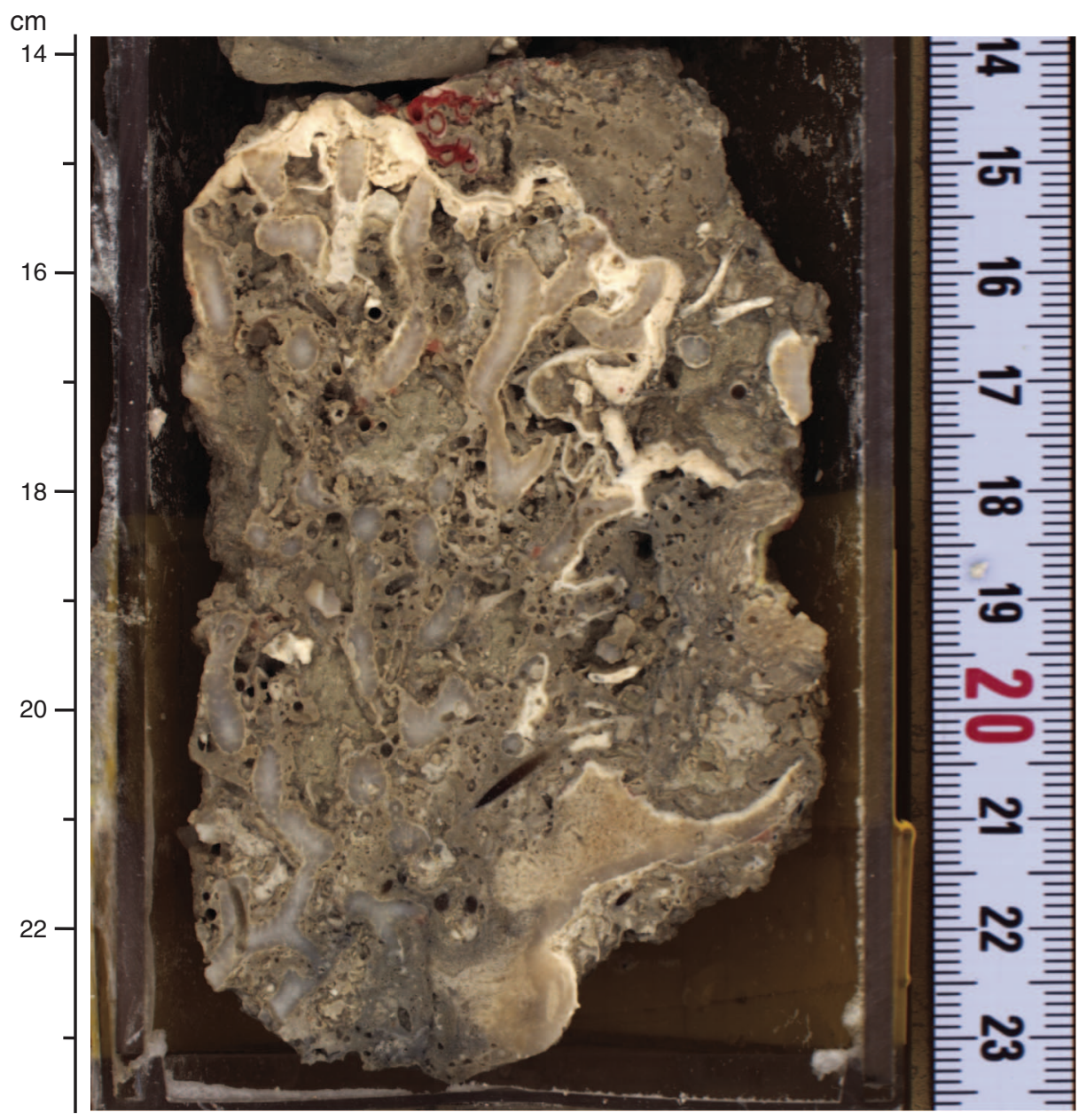


Figure F84. High-resolution line scan image of a medium branching Acropora colony encrusted by coralline algae and microbialites (interval 325-M0036A-17R-1, 21-35 cm). The associated internal sediment is rich in bioclasts (Halimeda, etc.).

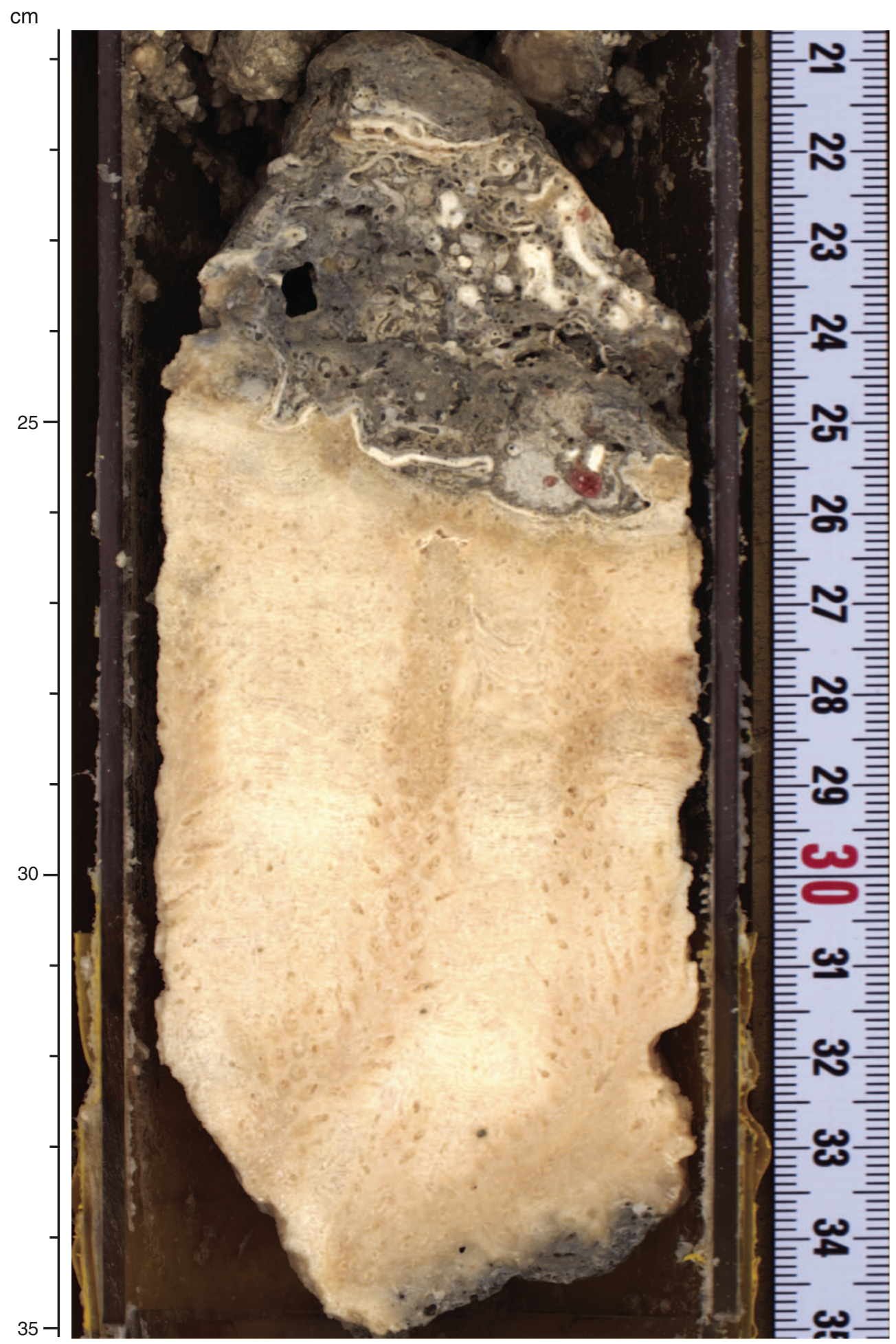


Figure F85. High-resolution line scan image of packstone with larger foraminifera, mollusks, and Halimeda (interval 325-M0036A-20R-2, 0-5 cm).

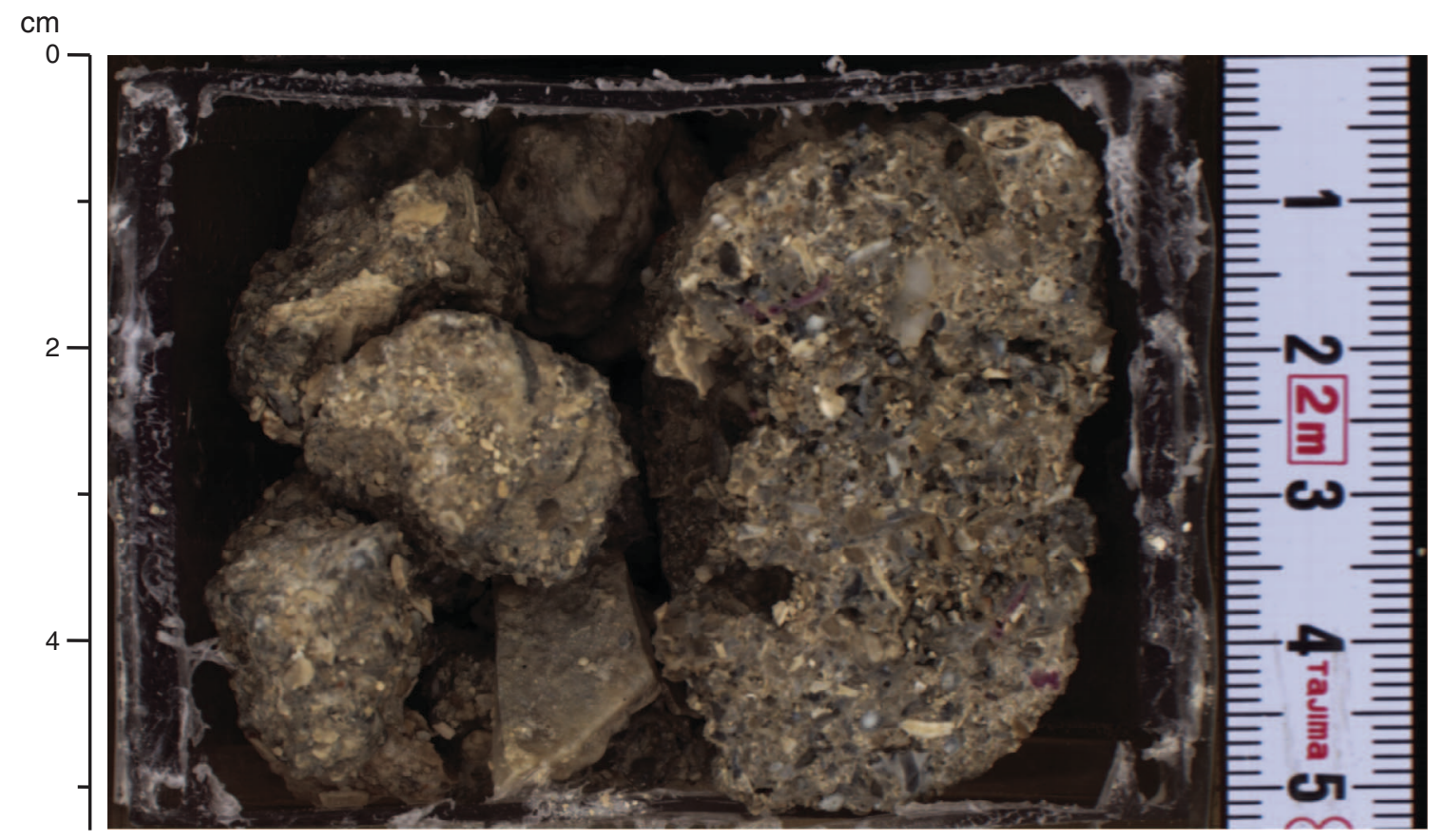


Figure F86. Summary diagram showing data collected on whole cores using the MSCL, Hole M0036A.

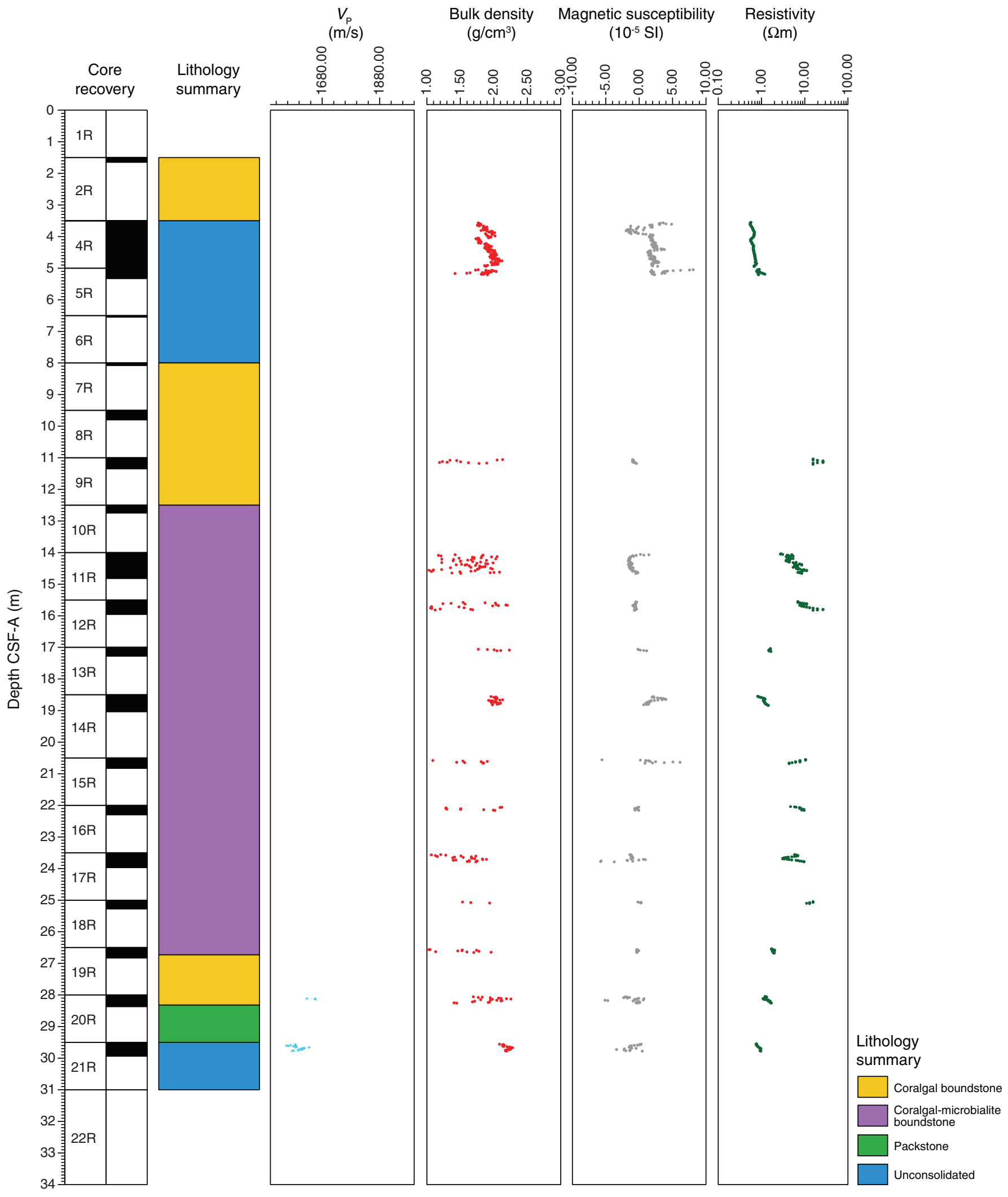


Figure F87. Petrophysical measurements obtained from discrete samples with a pycnometer, Hole M0036A. Bulk density measured on whole cores with the MSCL is shown in red on the bulk density plot.

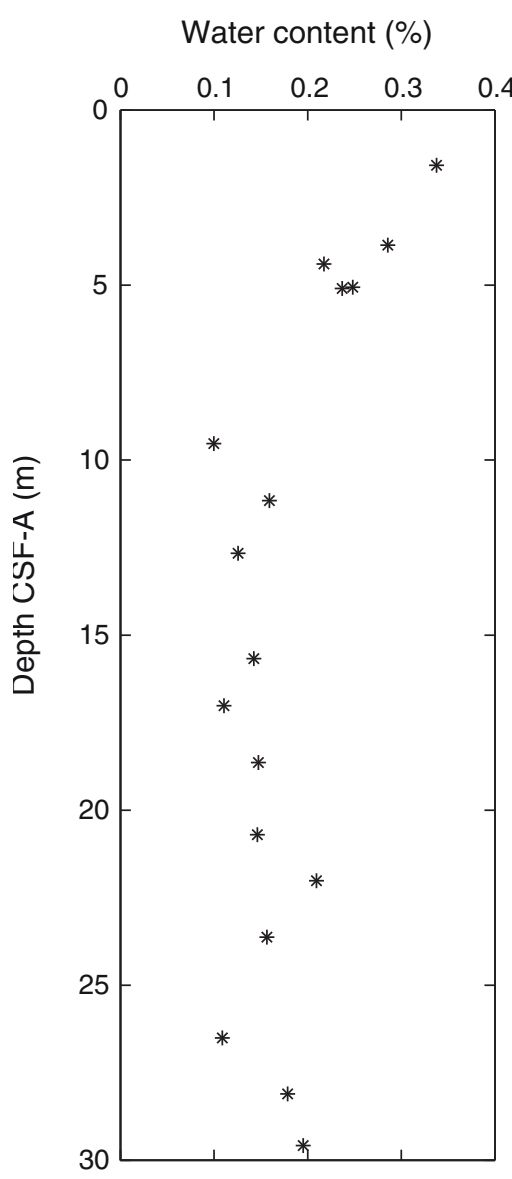

Bulk density $\left(\mathrm{g} / \mathrm{cm}^{3}\right)$

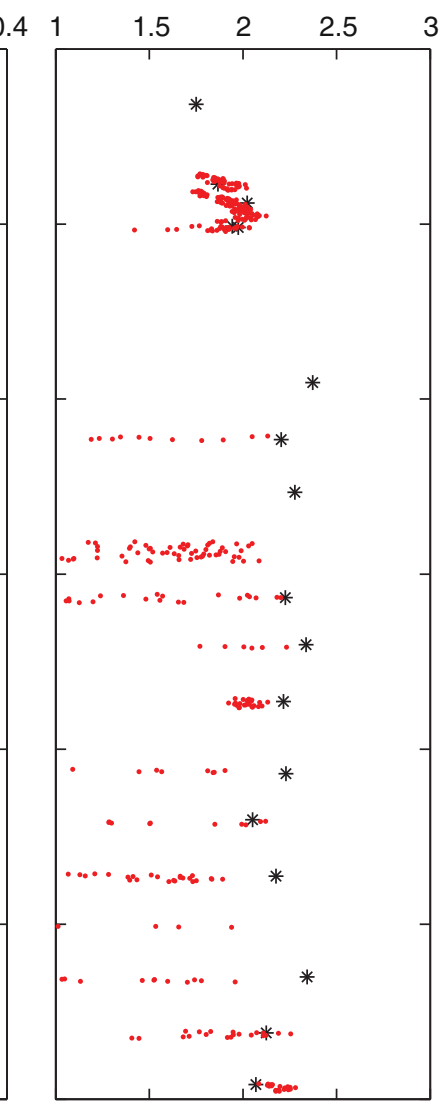

Grain density $\left(\mathrm{g} / \mathrm{cm}^{3}\right)$

Porosity (\%)

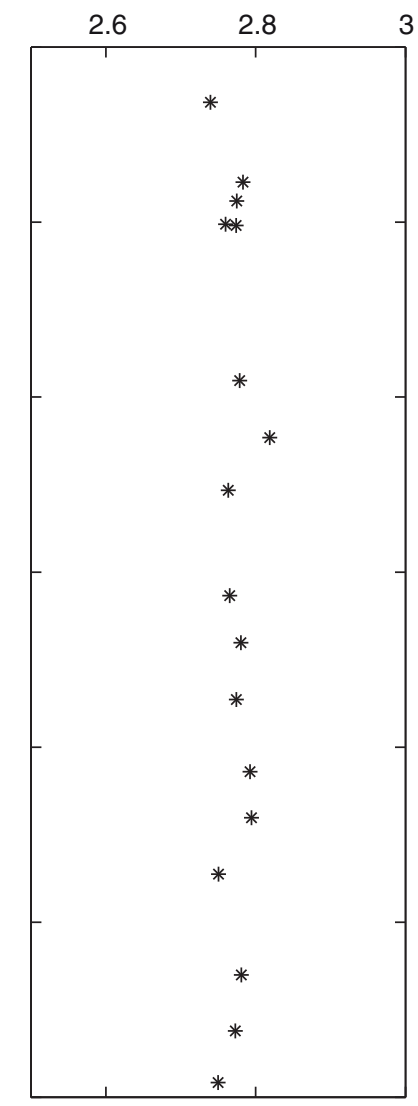

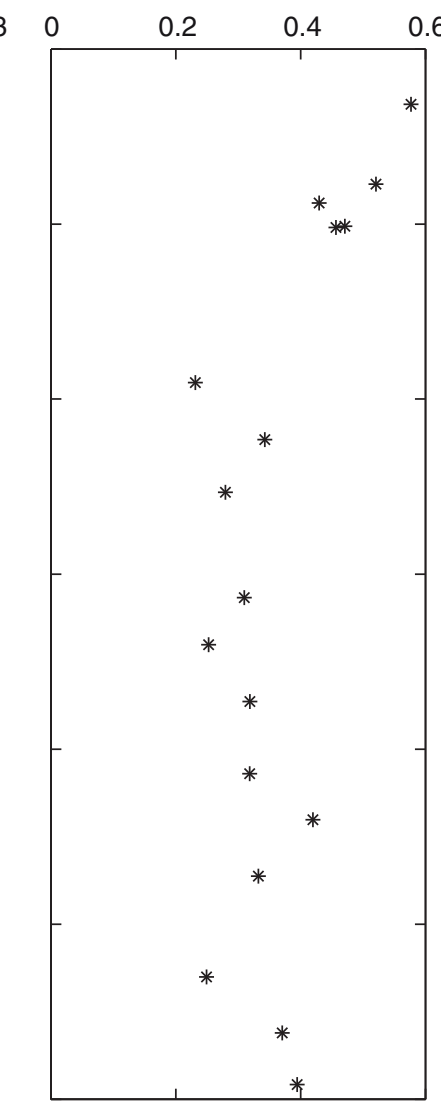


Figure F88. $P$-wave velocity data, Hole M0036A. A. Plot of initial, dry, and resaturated $P$-wave velocity measurements on discrete samples vs. depth. Three measurements were taken at each depth and are denoted by a dot. Average values are plotted as an open triangle. B. Plot showing discrete $P$-wave velocity vs. discrete bulk density.

A

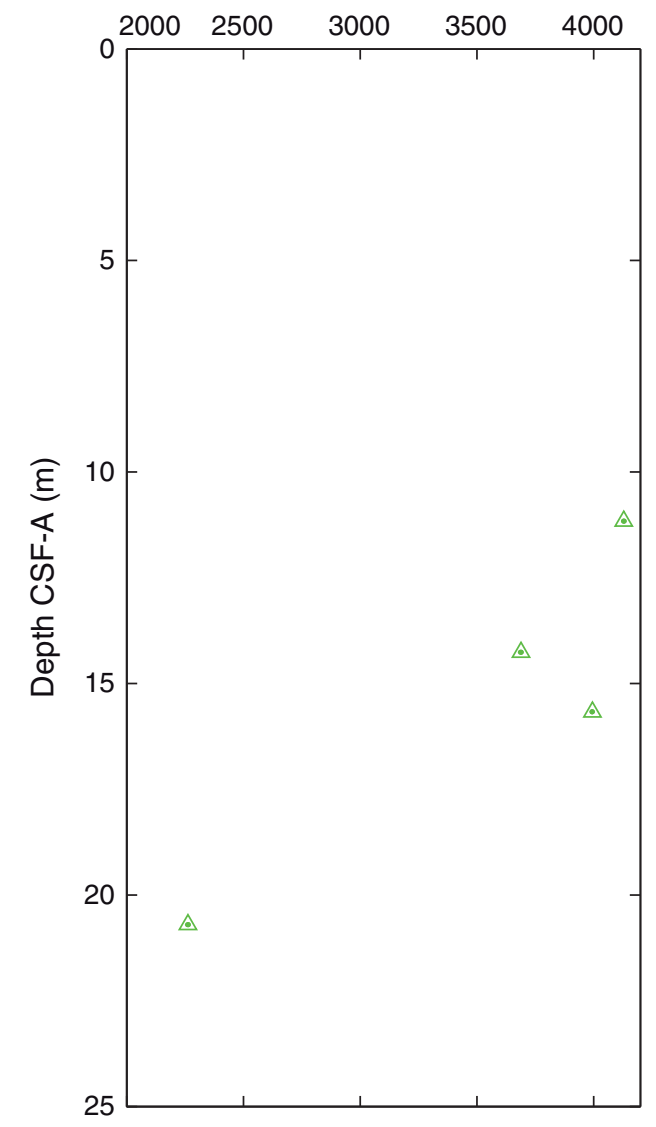

Dry velocity

$P$-wave velocity $(\mathrm{m} / \mathrm{s})$

$\begin{array}{lllll}2000 \quad 2500 \quad 3000 & 3500 \quad 4000\end{array}$

$\Delta$

$\triangle$

$\Delta$

Resaturated velocity

$P$-wave velocity $(\mathrm{m} / \mathrm{s})$
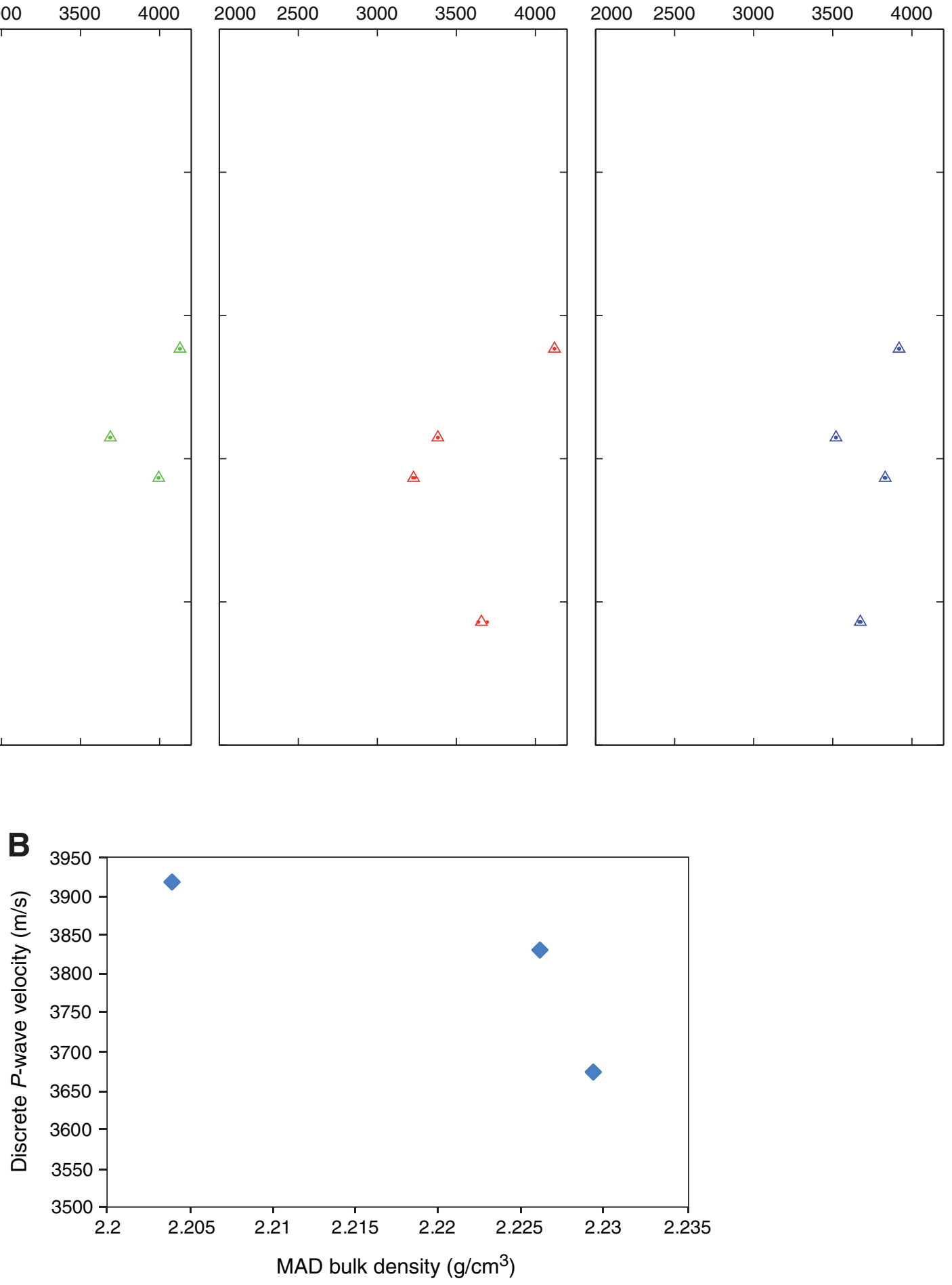
Figure F89. Values of reflectance $\left(\mathrm{L}^{*}\right)$, green to red $\left(\mathrm{a}^{*}\right)$, and blue to yellow $\left(\mathrm{b}^{*}\right)$ indexes, along with ratio $\mathrm{a}^{*} / \mathrm{b}^{*}$ for Hole M0036A.

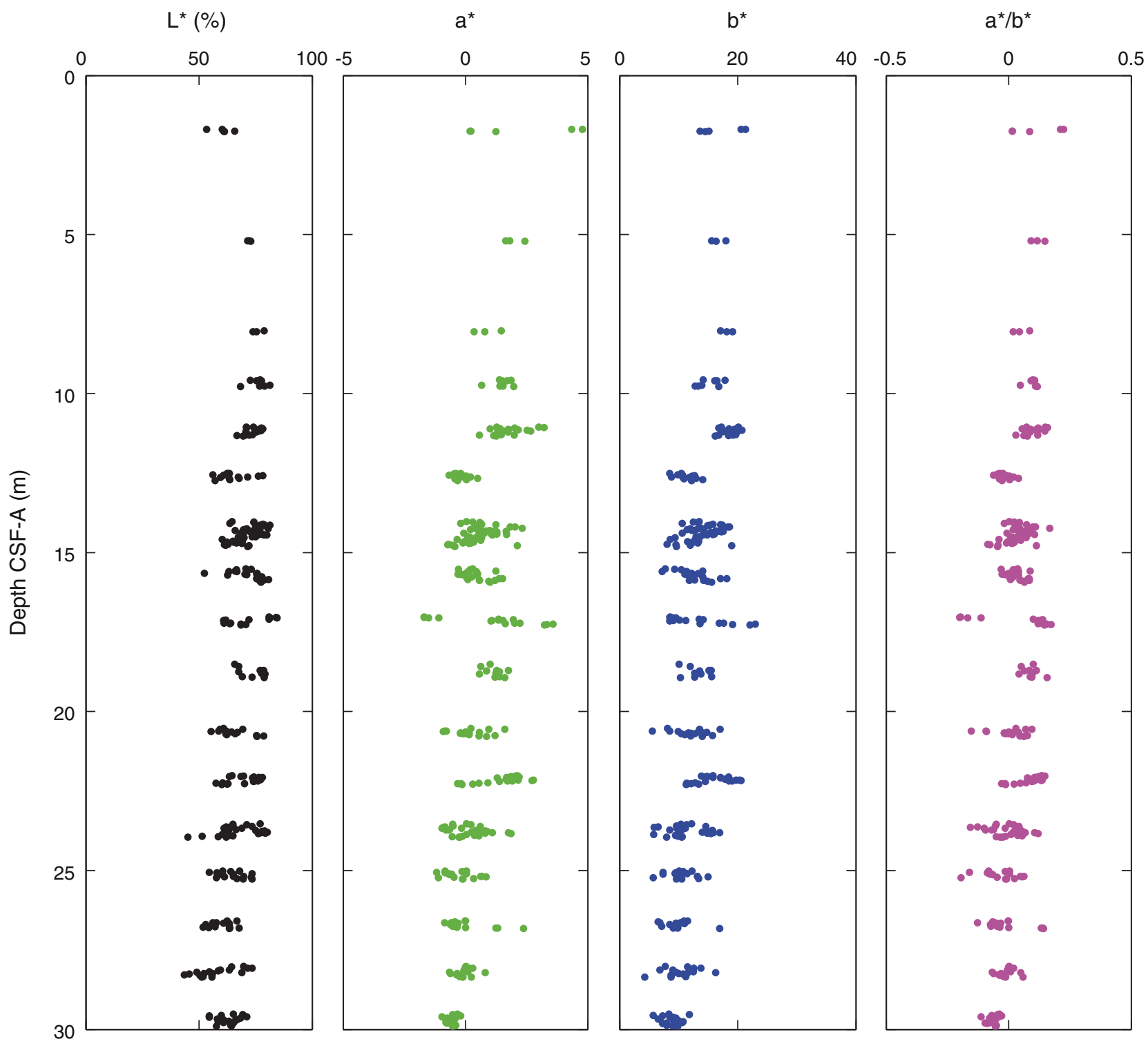


Figure F90. Magnetic susceptibility record for Hole M0036A. Water depth $=103.21 \mathrm{~m}$ (lowest astronomical tide).

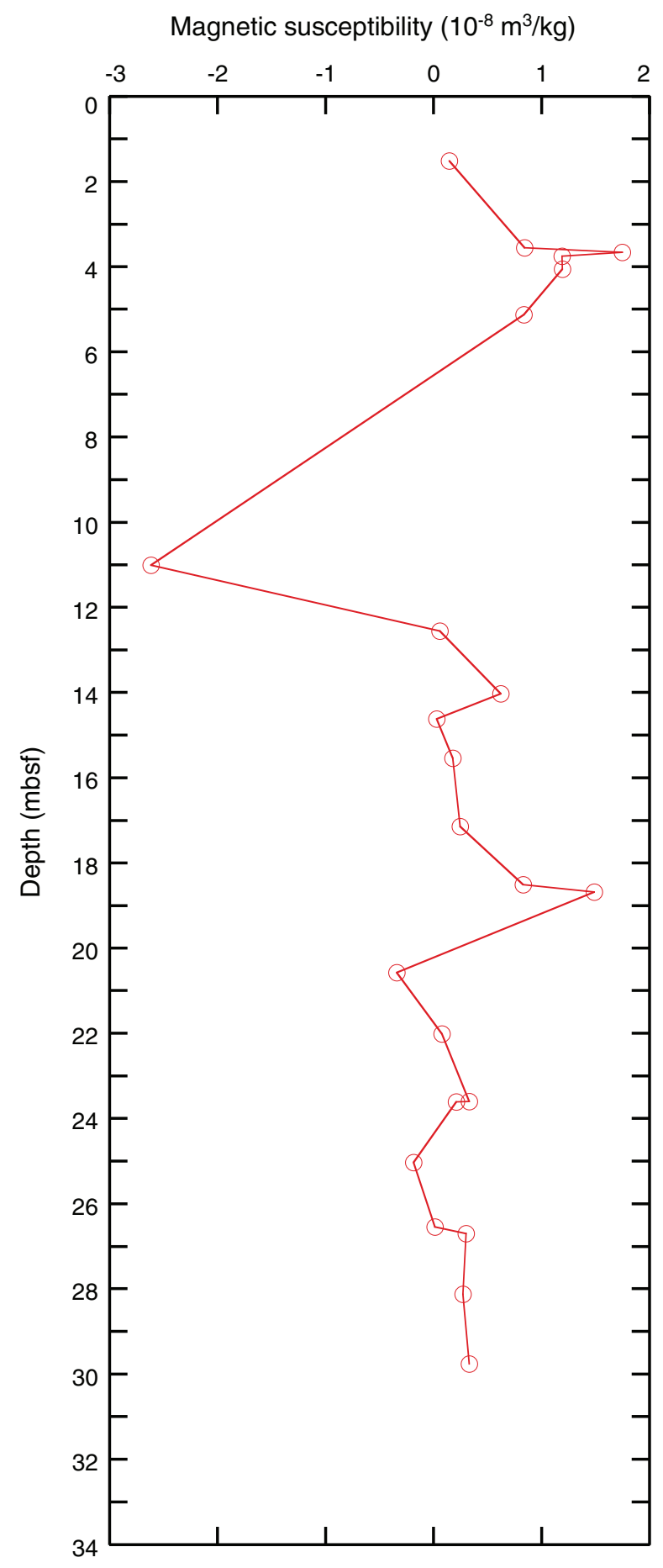


Figure F91. Preliminary chronology for Hole M0036A. Radiocarbon data are presented as graphs with the uncalibrated radiocarbon age and uncertainty shown as the red normal distribution on the ordinate axis and the probability distribution of the calibrated age shown in gray on the abscissa. The marine09 calibration curve is shown in blue. Horizontal bars indicate portions of the age distribution that are significant at the $95.4 \%$ confidence interval and the mean age (white circle \pm 1 standard deviation) used for the purposes of the preliminary dating. All ages are presented as thousands of calendar years BP (1950 AD). See Table T10 in the "Methods" chapter. (See Bronk Ramsey [2009], as well as Bronk Ramsey [2010] at c14.arch.ox.ac.uk/oxcal.html.)
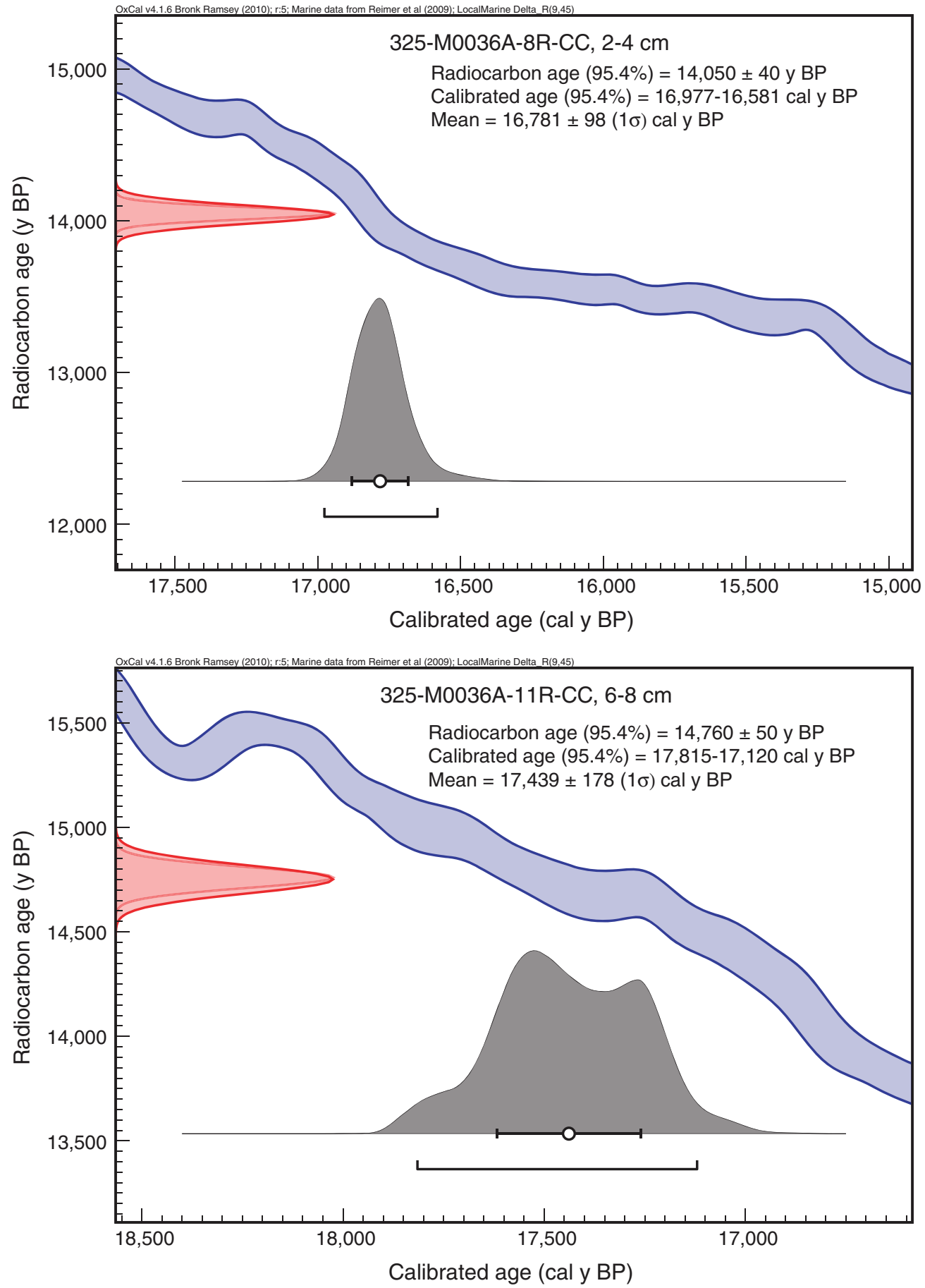
Figure F92. Logging data, Hole M0036A. A. Composite showing all through-pipe logging data collected in Hole M0036A. TGR = total gamma ray (raw), $\mathrm{TP}=$ through pipe. (This figure also available in an oversized format.) (Continued on next two pages.)

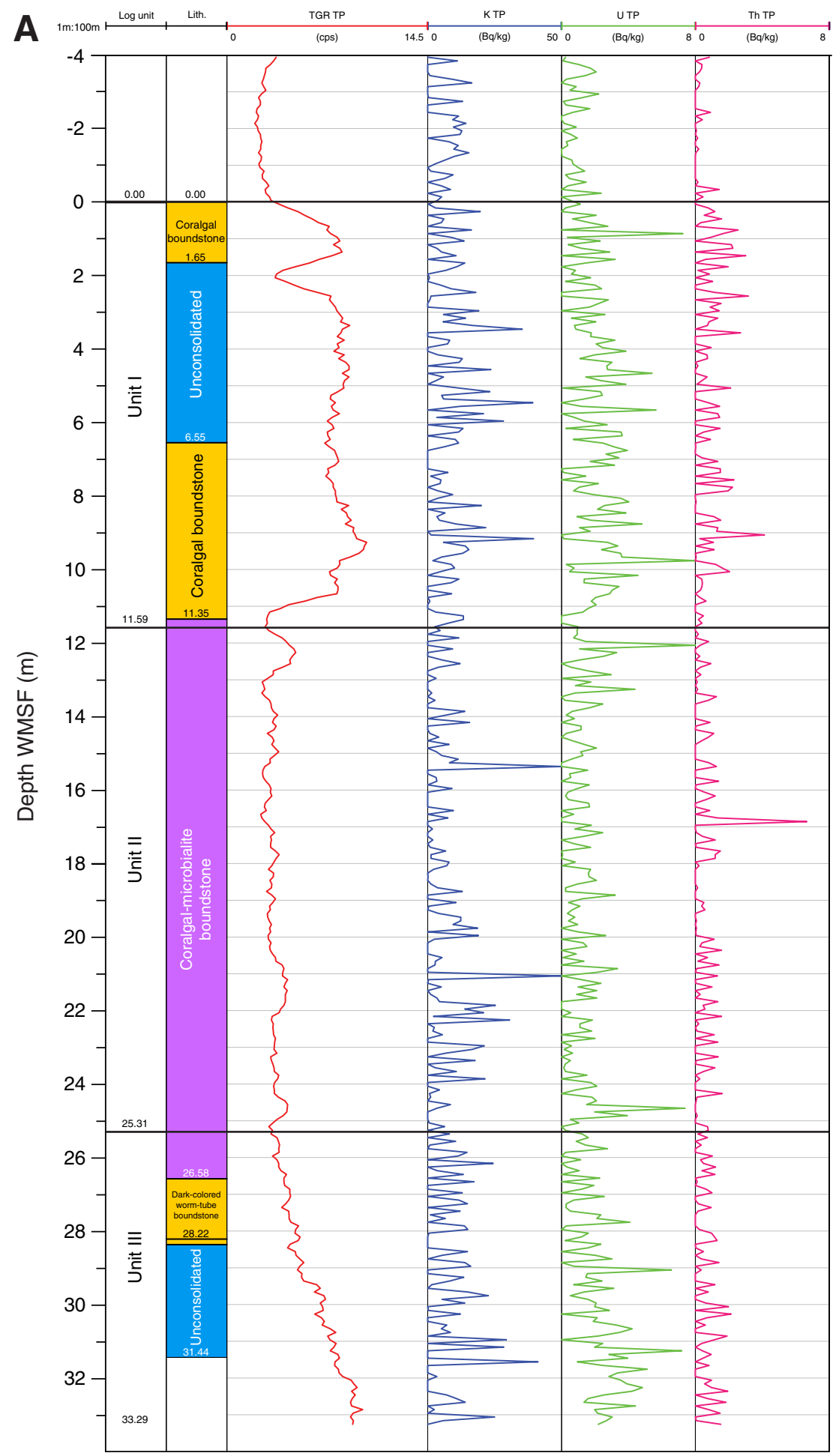


Figure F92 (continued). B. Composite showing conductivity and sonic logging data for Hole M0036A. ILD = deep conductivity, ILM = medium conductivity, RX1 = sonic waveforms for receiver 1 , RX2 = sonic waveforms for receiver 2. (Continued on next page.)

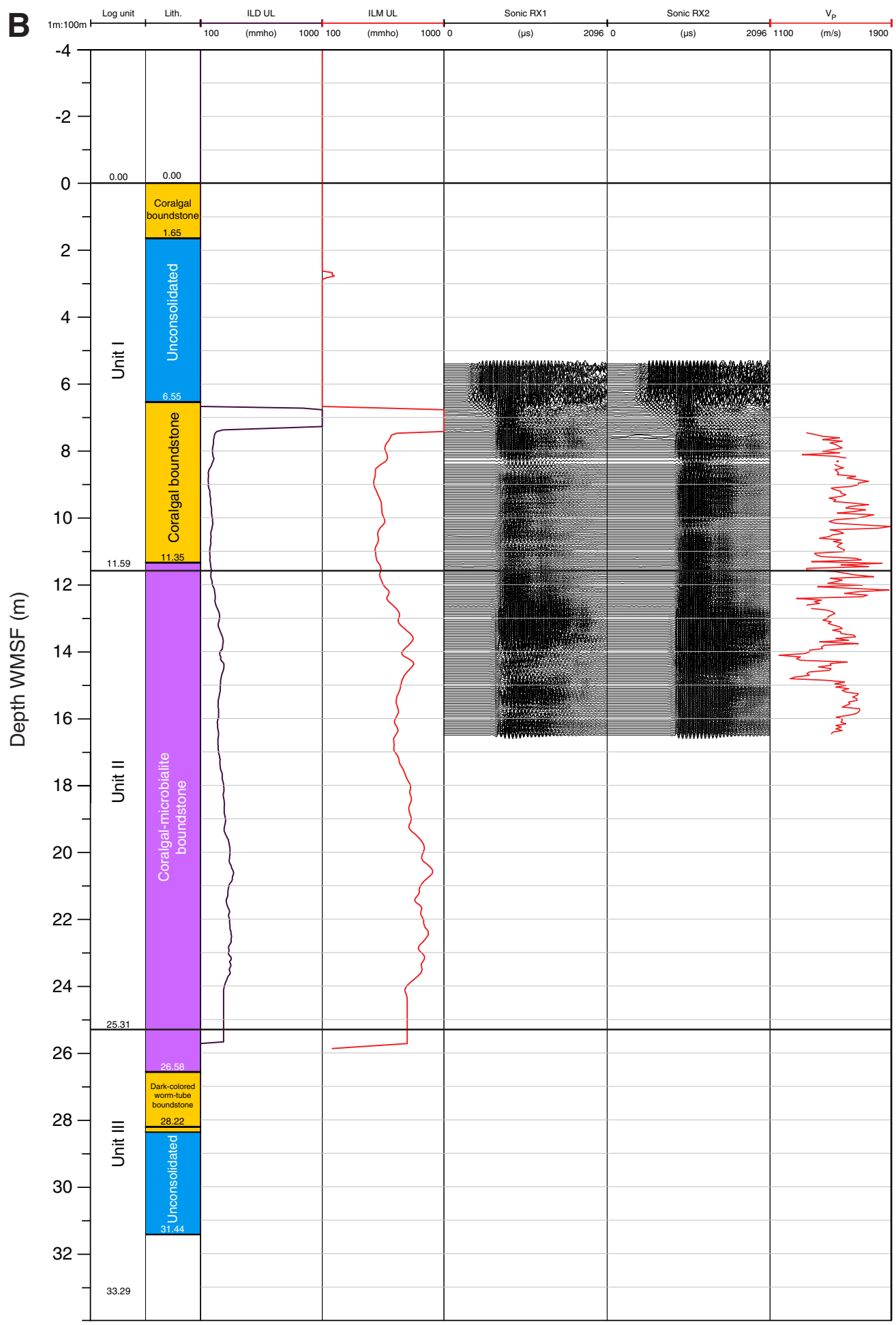


Figure F92 (continued). C. Composite showing open-hole gamma and EM51 logging data for Hole M0036A. $\mathrm{TGR}=$ total gamma ray $(\mathrm{raw}), \mathrm{OH}=$ open hole, $\mathrm{DL}=$ downlog, $\mathrm{MSUS}=$ magnetic susceptibility, $\mathrm{IL}=$ induction $\log$.

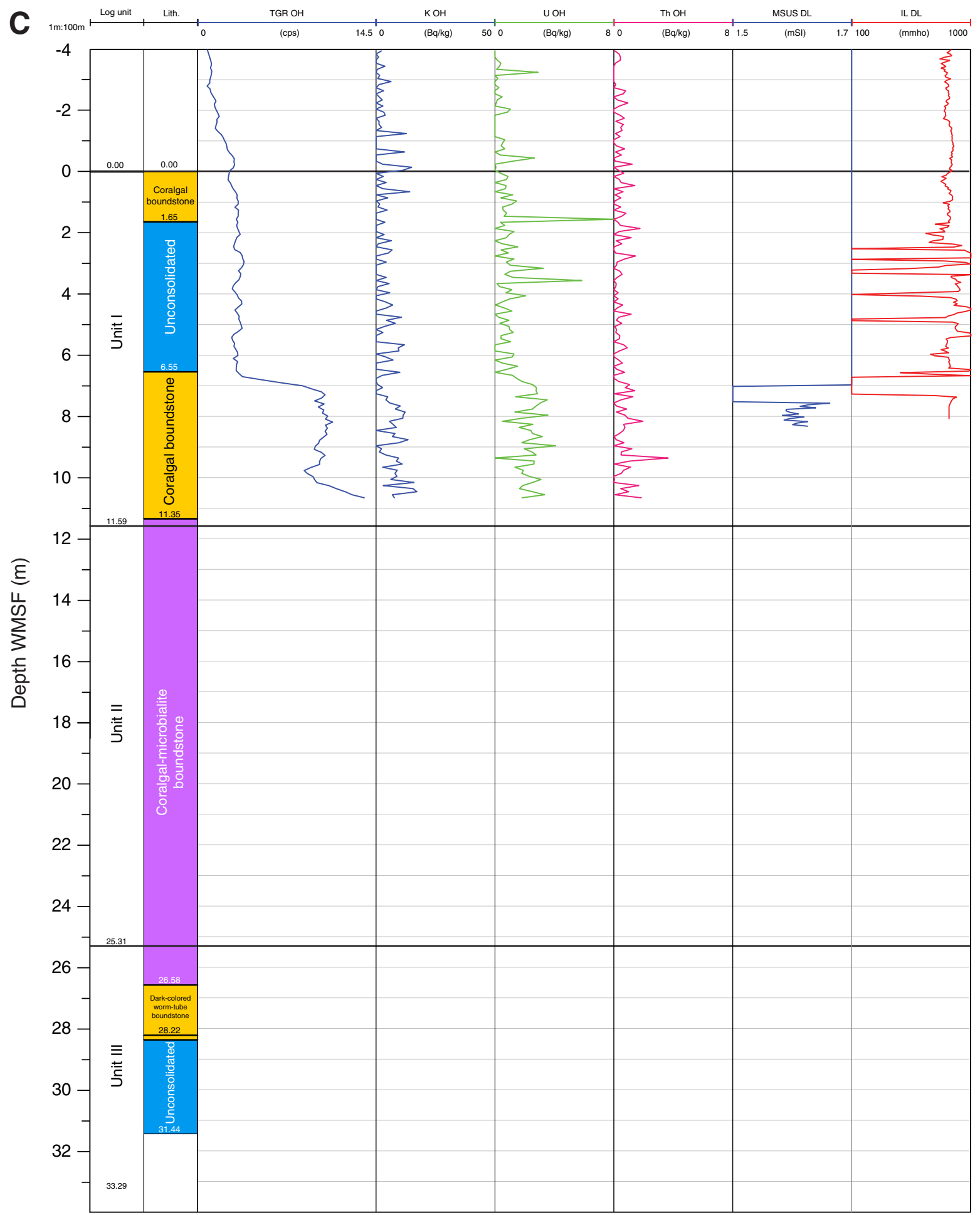


Figure F93. High-resolution line scan image of a grainstone with well-sorted grains and larger foraminifera, mollusks, and corals (interval 325-M0037A-8R-1, 58-68 cm).

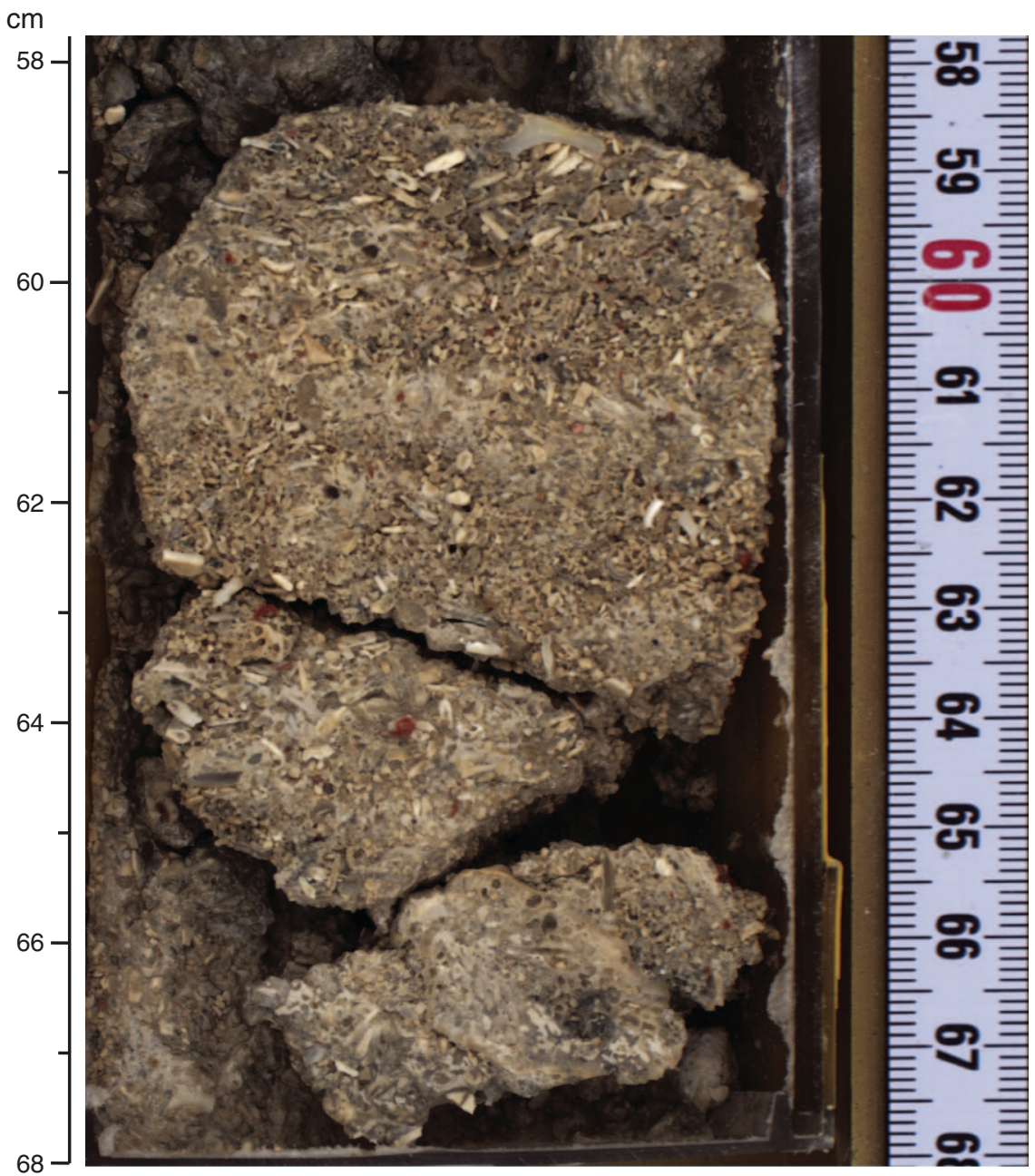


Figure F94. High-resolution line scan image of a mollusk floatstone (interval 325-M0037A-10R-1, 102-140 cm).

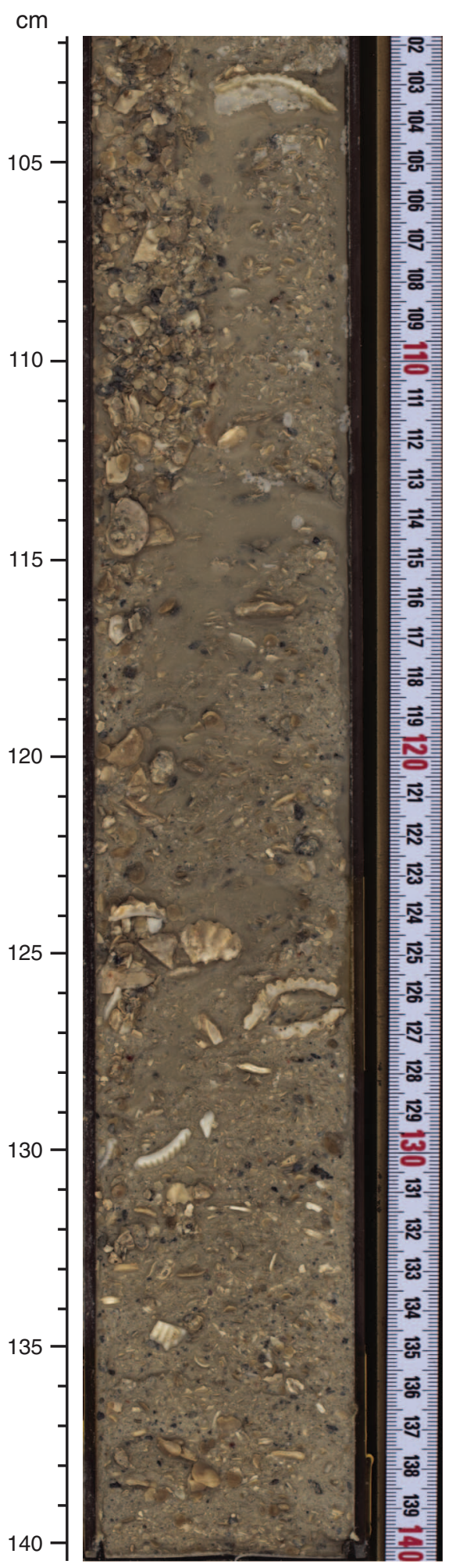


Figure F95. Summary diagram showing data collected on whole cores using the MSCL, Hole M0037A.

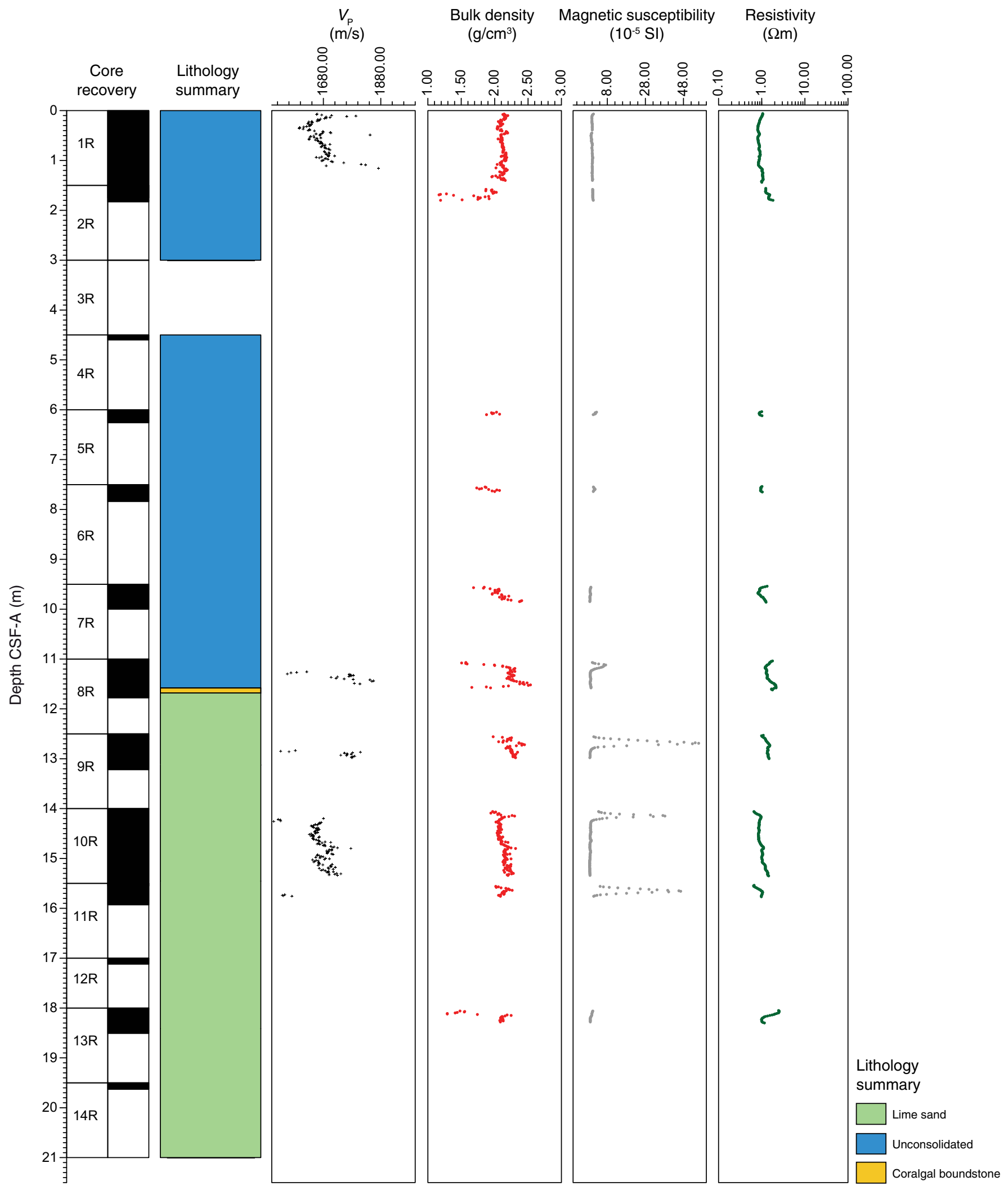


Figure F96. Petrophysical measurements obtained from discrete samples with a pycnometer, Hole M0037A. Bulk density measured on whole cores with the MSCL is shown in red on the bulk density plot.

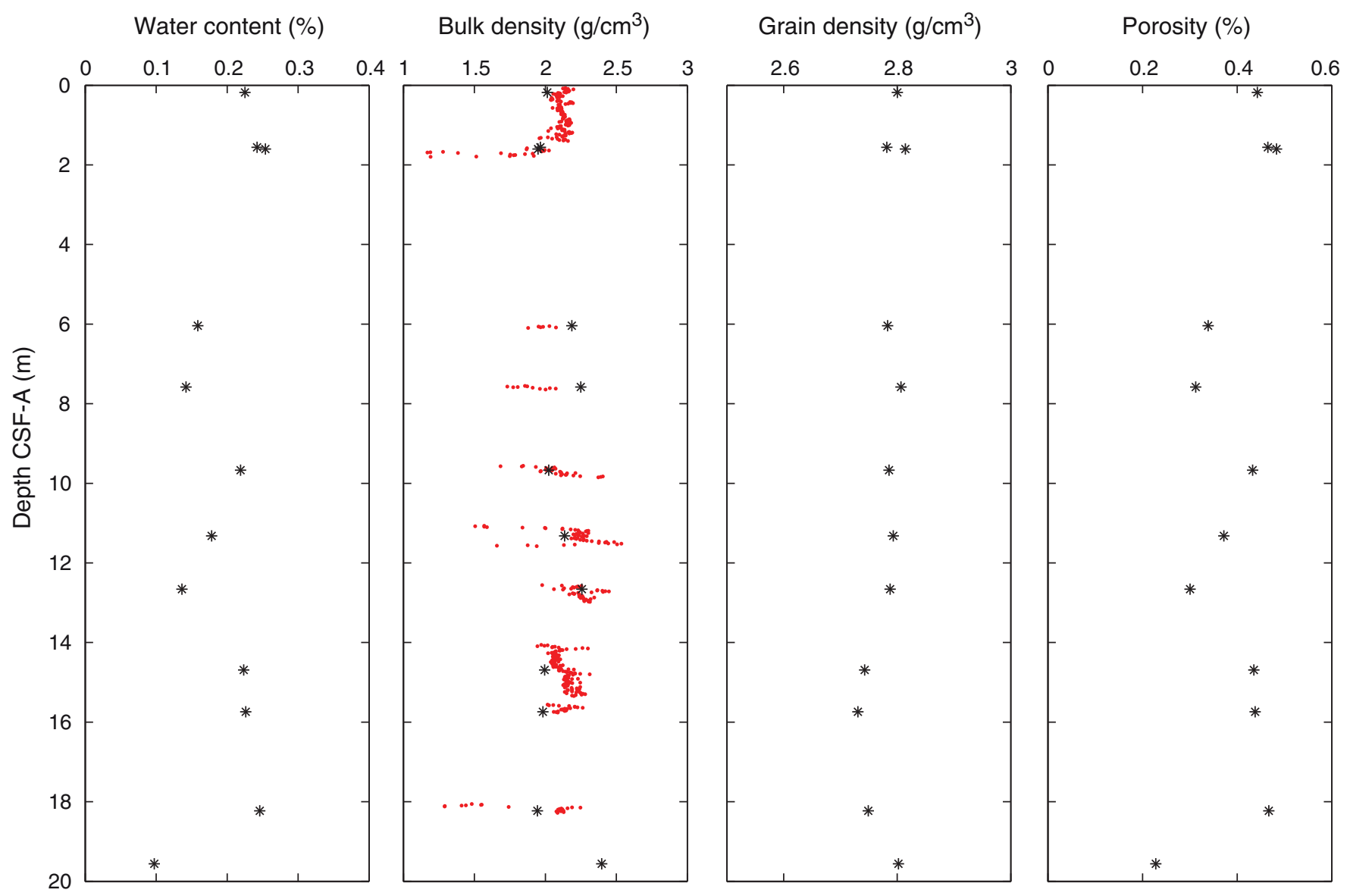


Figure F97. Values of reflectance $\left(\mathrm{L}^{*}\right)$, green to red $\left(\mathrm{a}^{*}\right)$, and blue to yellow $\left(\mathrm{b}^{*}\right)$ indexes, along with ratio $\mathrm{a}^{*} / \mathrm{b}^{*}$ for Hole M0037A.

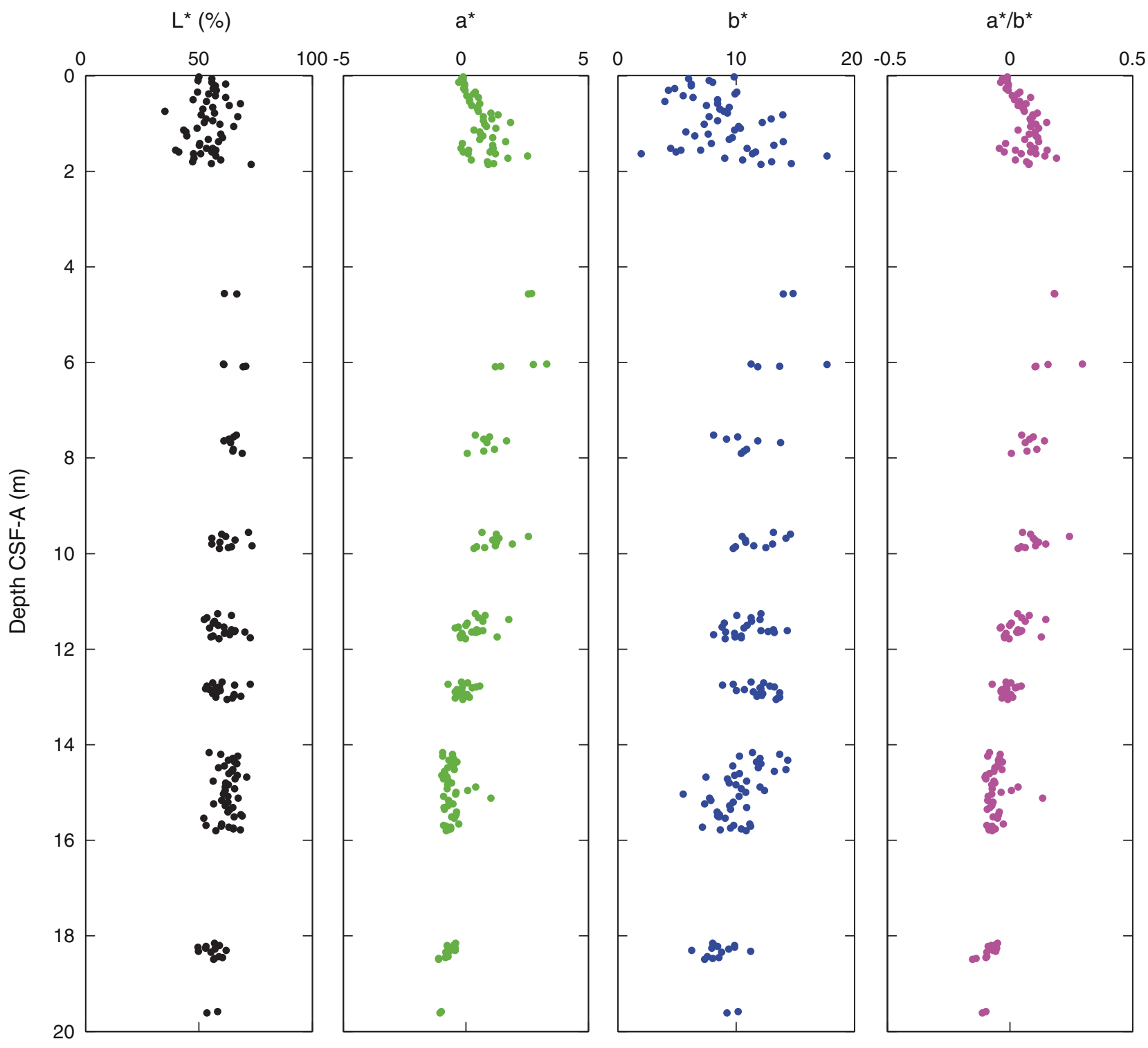


Figure F98. Magnetic susceptibility record for Hole M0037A. Water depth $=122.29 \mathrm{~m}$ (lowest astronomical tide).

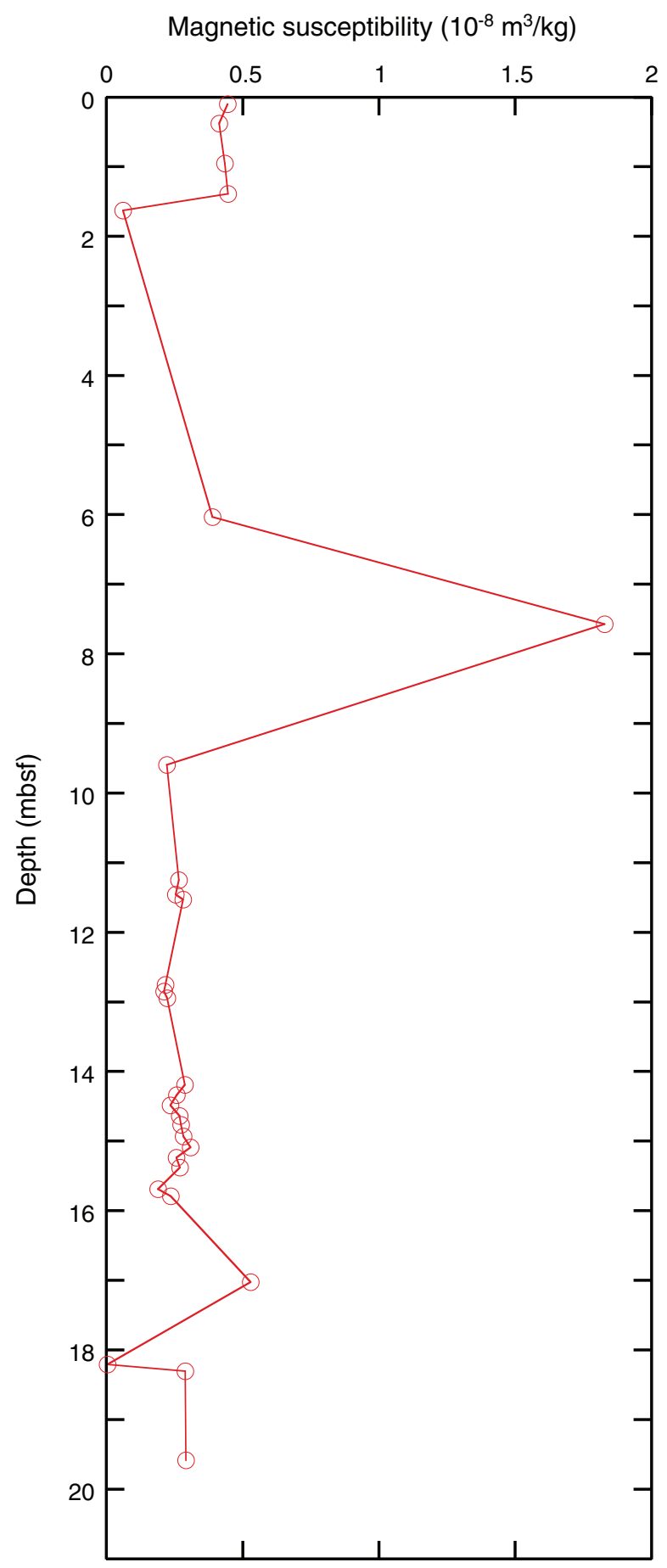


Figure F99. Preliminary chronology for Hole M0037A. Radiocarbon data are presented as graphs with the uncalibrated radiocarbon age and uncertainty shown as the red normal distribution on the ordinate axis and the probability distribution of the calibrated age shown in gray on the abscissa. The marine09 calibration curve is shown in blue. Horizontal bars indicate portions of the age distribution that are significant at the $95.4 \%$ confidence interval and the mean age (white circle \pm 1 standard deviation) used for the purposes of the preliminary dating. All ages are presented as thousands of calendar years BP (1950 AD). See Table T10 in the "Methods" chapter. (See Bronk Ramsey [2009], as well as Bronk Ramsey [2010] at c14.arch.ox.ac.uk/oxcal.html.)
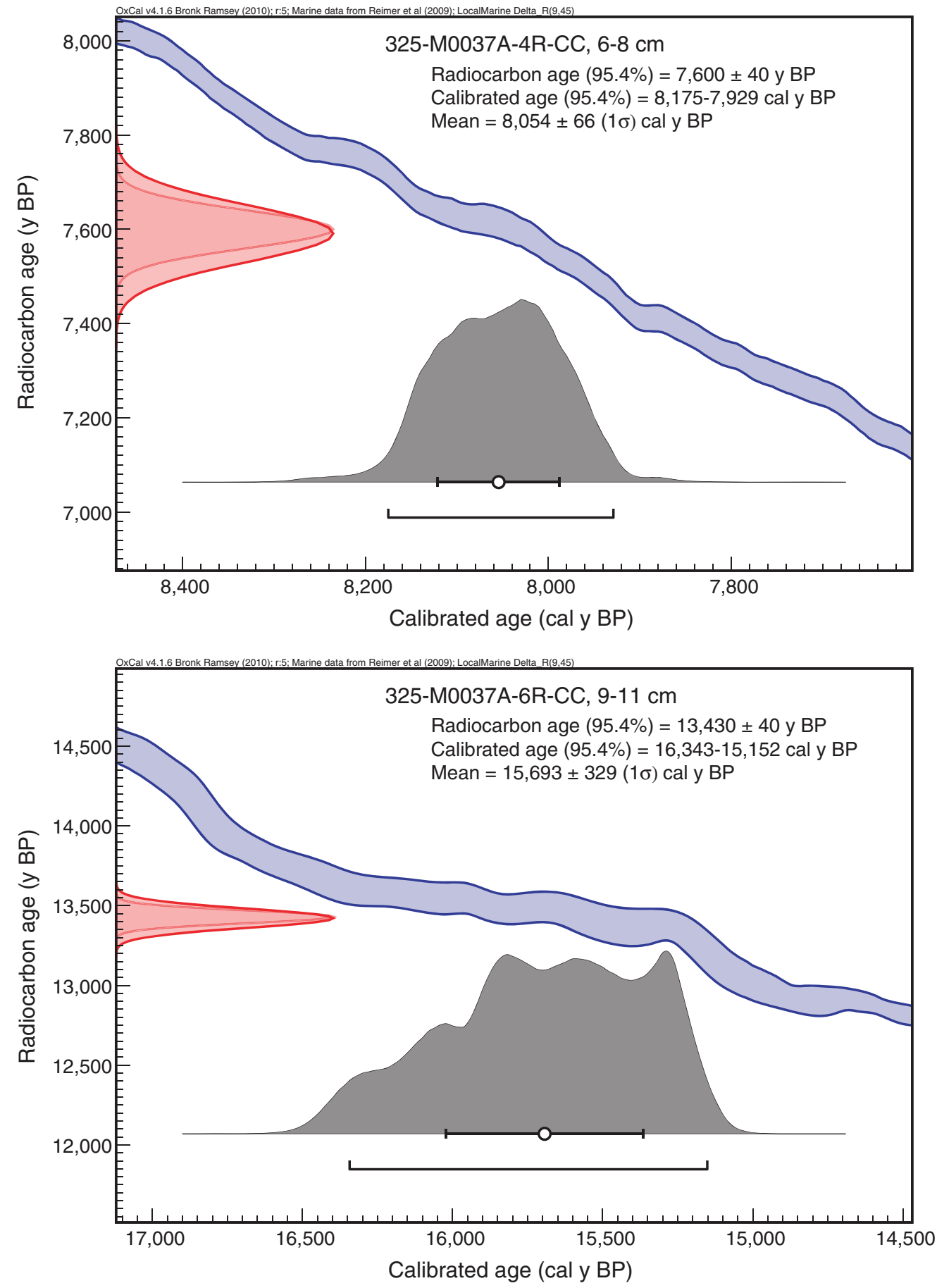
Figure F100. Preliminary chronology for Hole M0038A. Radiocarbon data are presented as graphs with the uncalibrated radiocarbon age and uncertainty shown as the red normal distribution on the ordinate axis and the probability distribution of the calibrated age shown in gray on the abscissa. The marine09 calibration curve is shown in blue. Horizontal bars indicate portions of the age distribution that are significant at the $95.4 \%$ confidence interval and the mean age (white circle \pm 1 standard deviation) used for the purposes of the preliminary dating. All ages are presented as thousands of calendar years BP (1950 AD). See Table T10 in the "Methods" chapter. (See Bronk Ramsey [2009], as well as Bronk Ramsey [2010] at c14.arch.ox.ac.uk/oxcal.html.)

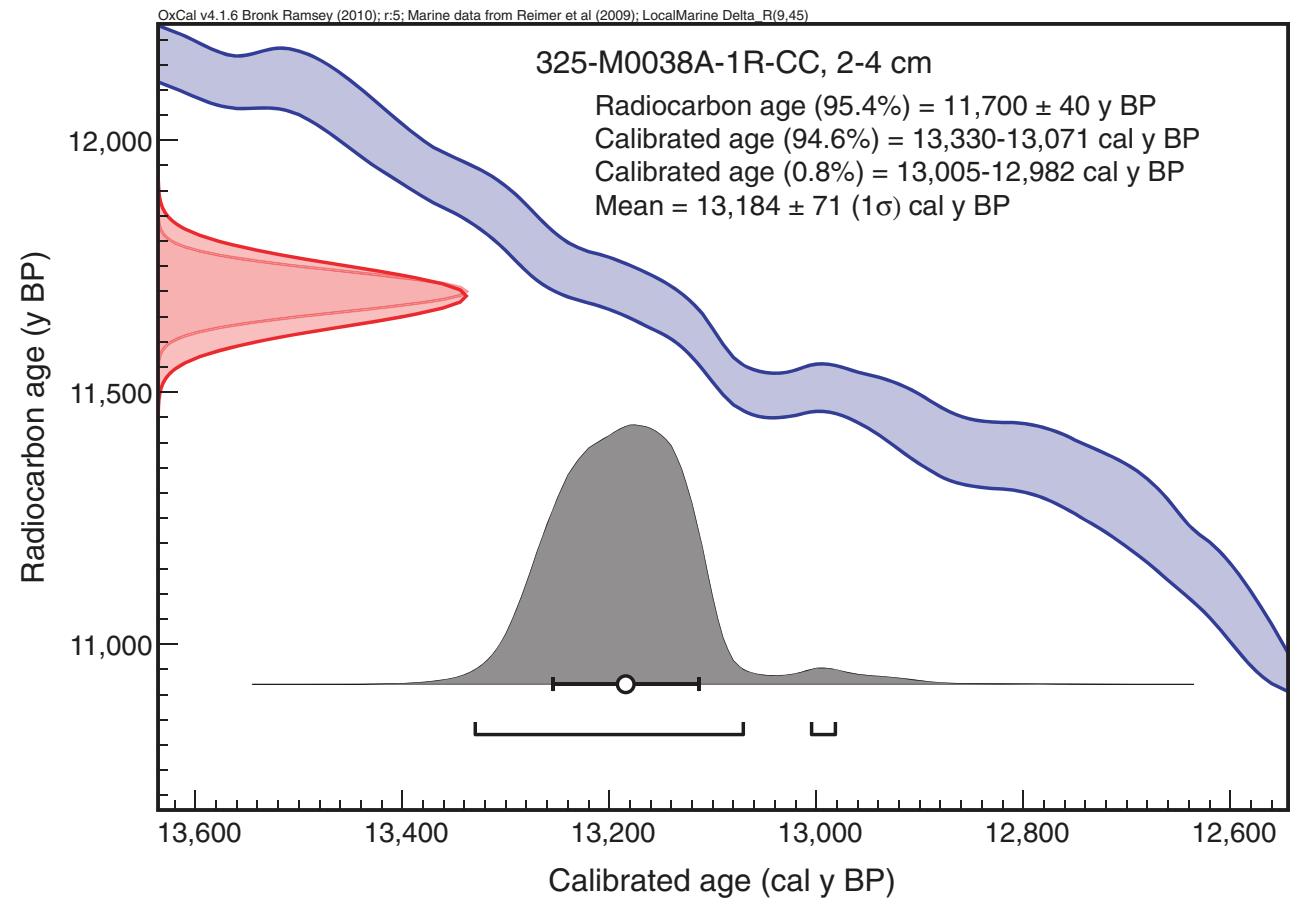


Figure F101. High-resolution line scan image of floatstone with corals, mollusks, foraminifera, and bryozoans overlying a massive Porites boundstone (interval 325-M0039A-1R-1, 16-46 cm).

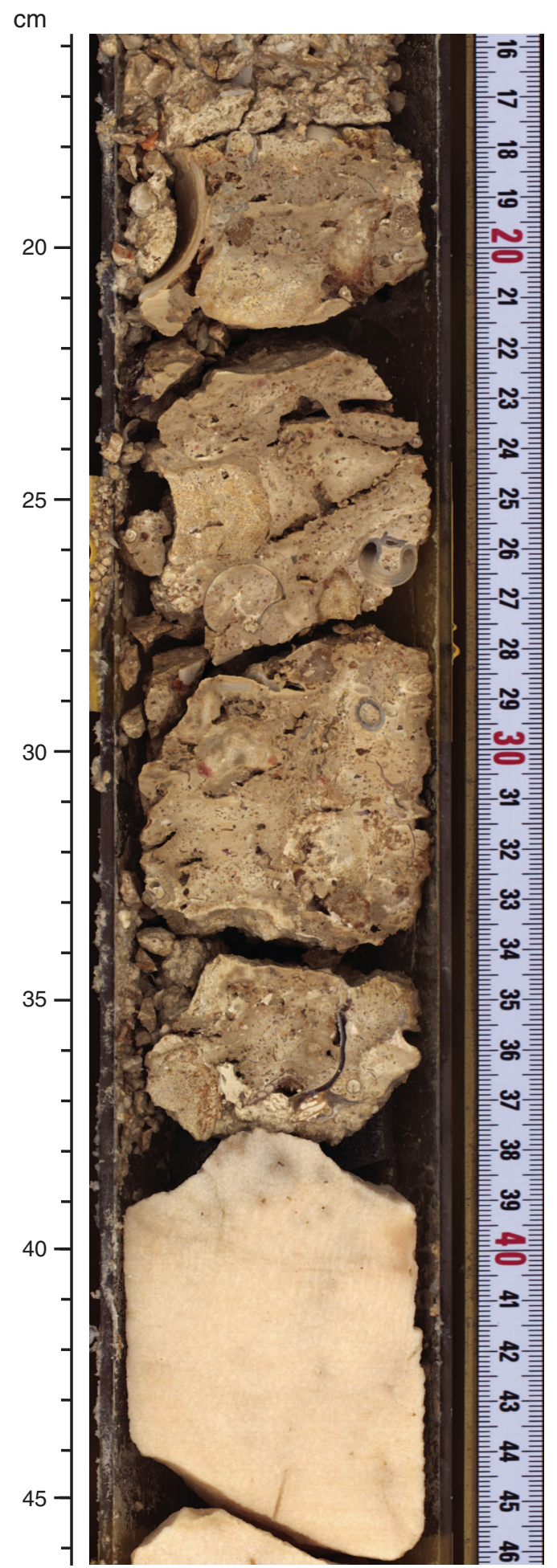


Figure F102. High-resolution line scan image of a medium branching Acropora with thick coralline algal crust, vermetids, boring bivalves, and Homotrema (interval 325-M0039A-3R-1, 25-35 cm).

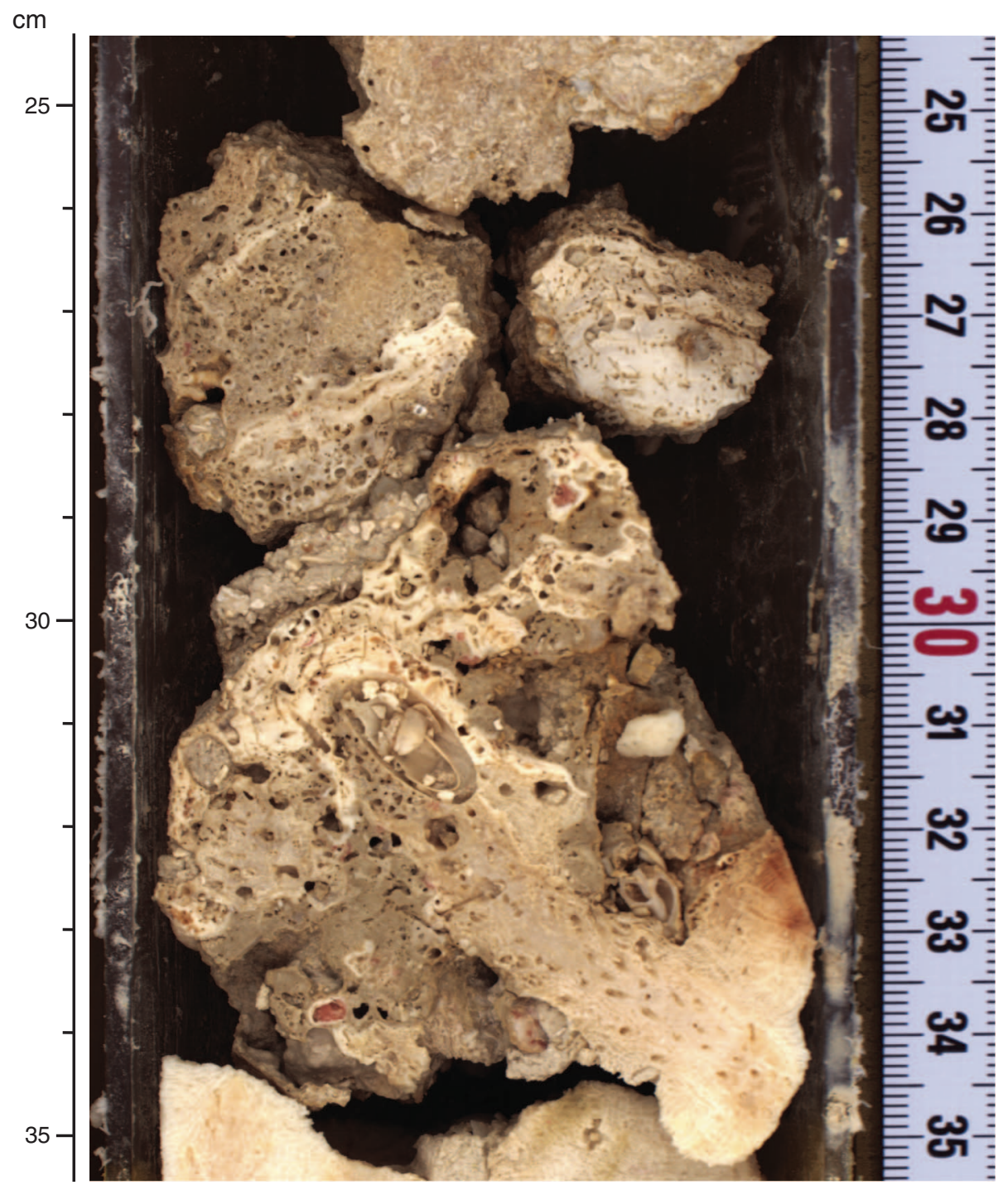


Figure F103. High-resolution line scan image of a coralgal packstone with mollusk shells, Halimeda, and foraminifera overlying a coralgal boundstone made of fine to medium branching Pocilloporidae, thick coralline crusts, and thin microbialite crust (interval 325-M0039A-4R-1, 19-35 cm).

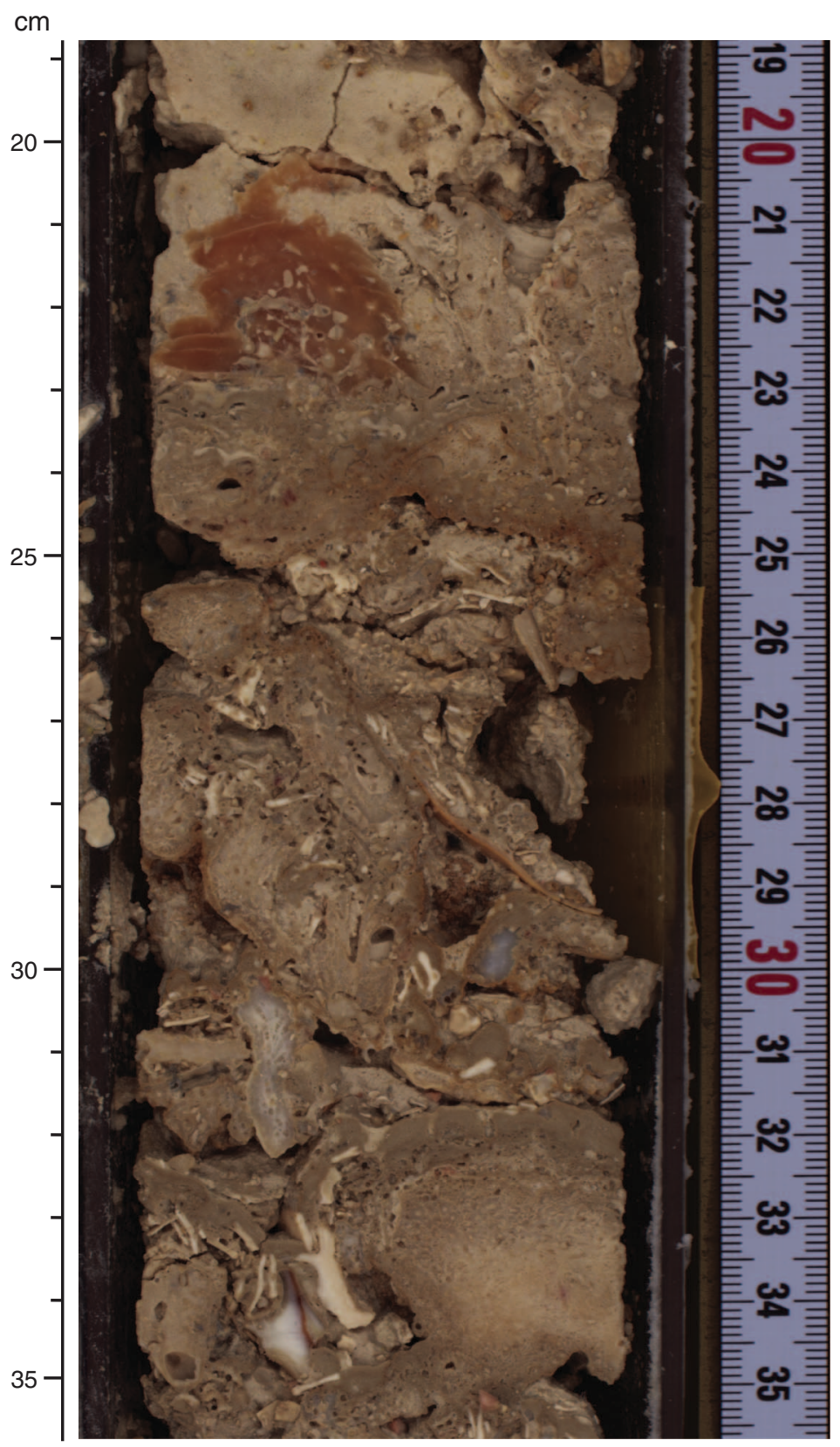


Figure F104. High-resolution line scan image of a massive Porites colony (in situ?) (interval 325-M0039A-1R-1, $37-51 \mathrm{~cm})$.

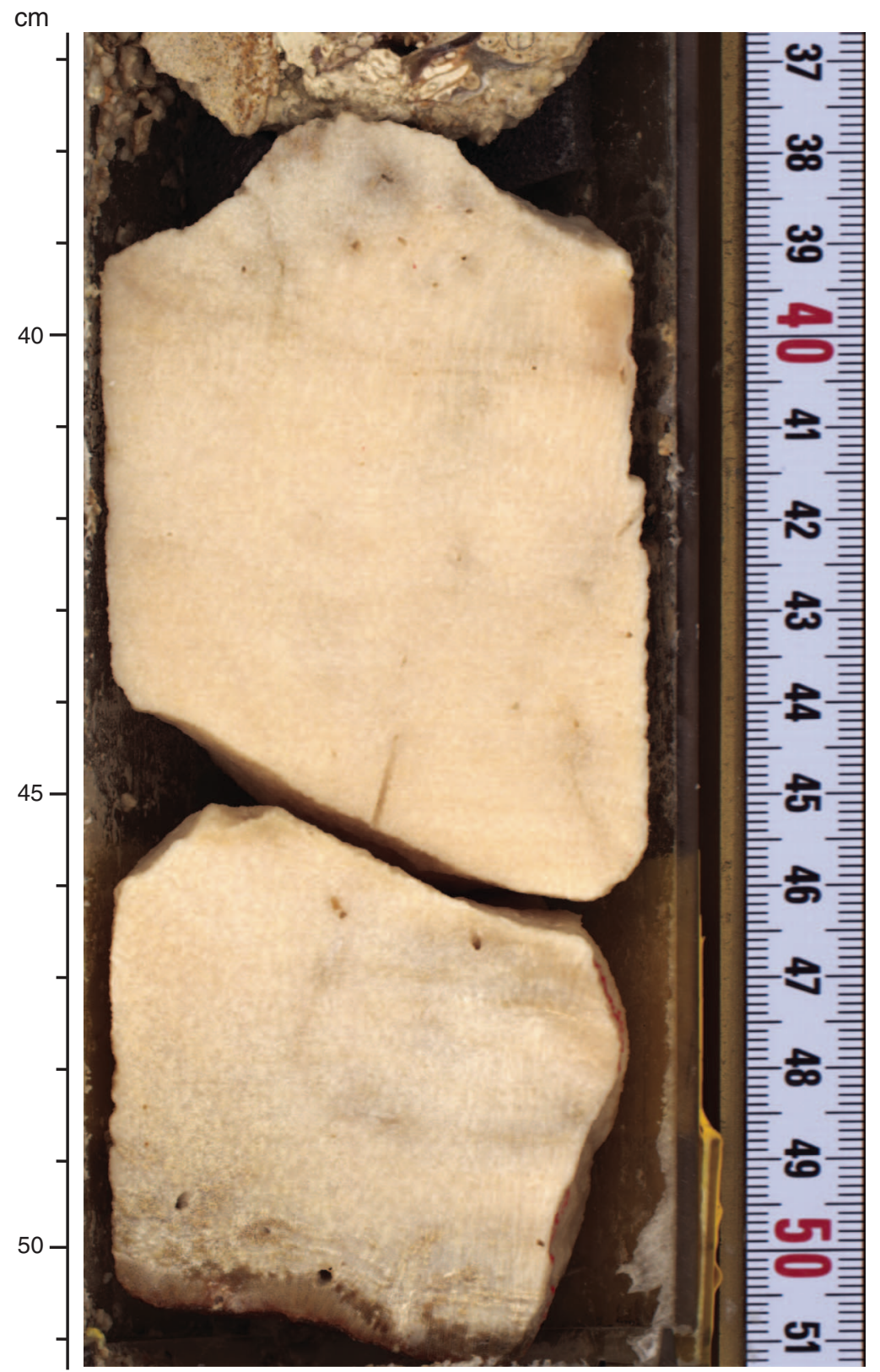


Figure F105. High-resolution line scan image of a massive Isopora colony (interval 325-M0039A-3R-1, 15-26 $\mathrm{cm})$.

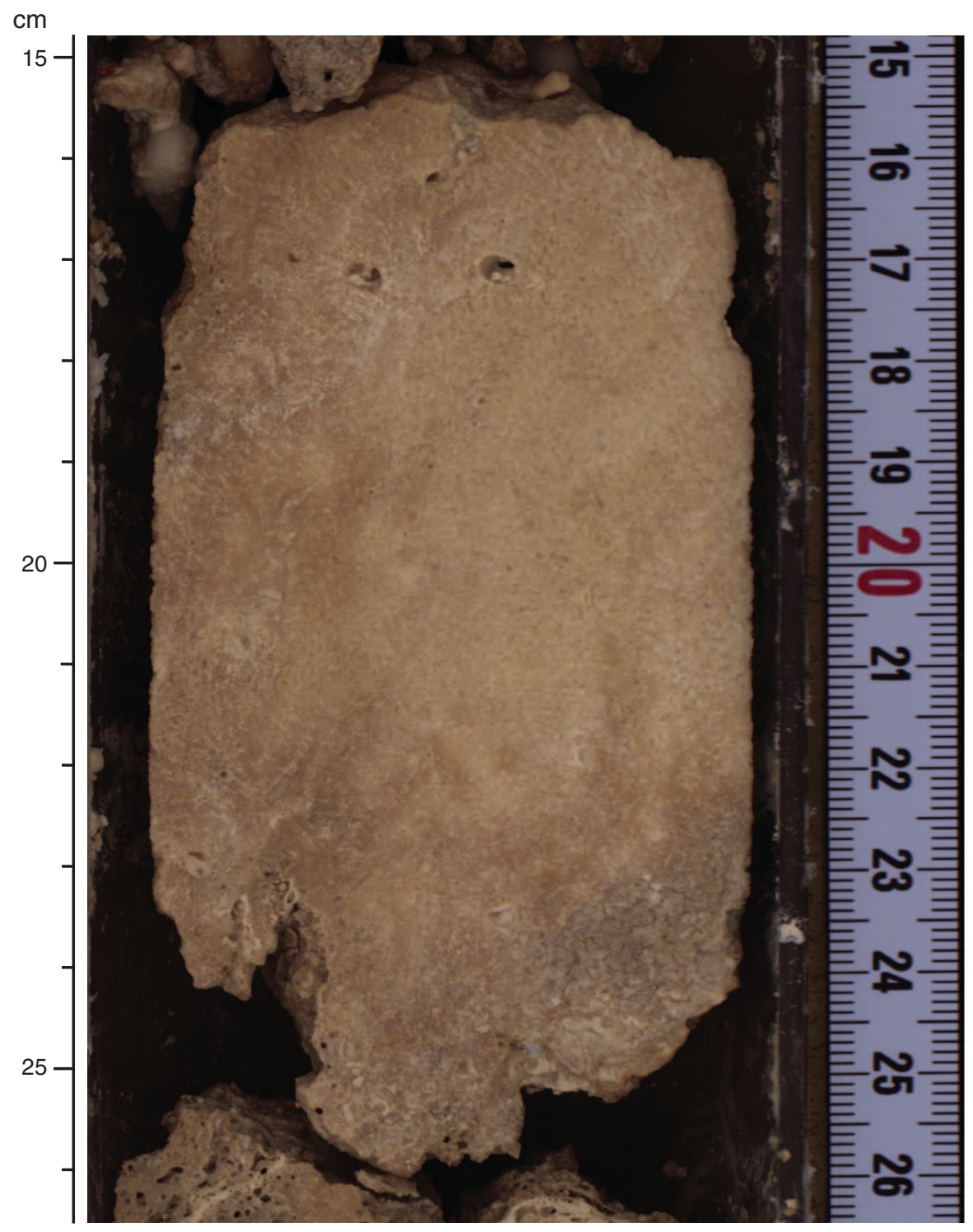


Figure F106. High-resolution line scan image of a medium branching Acropora colony (interval 325-M0039A3R-1, 30-40 cm).

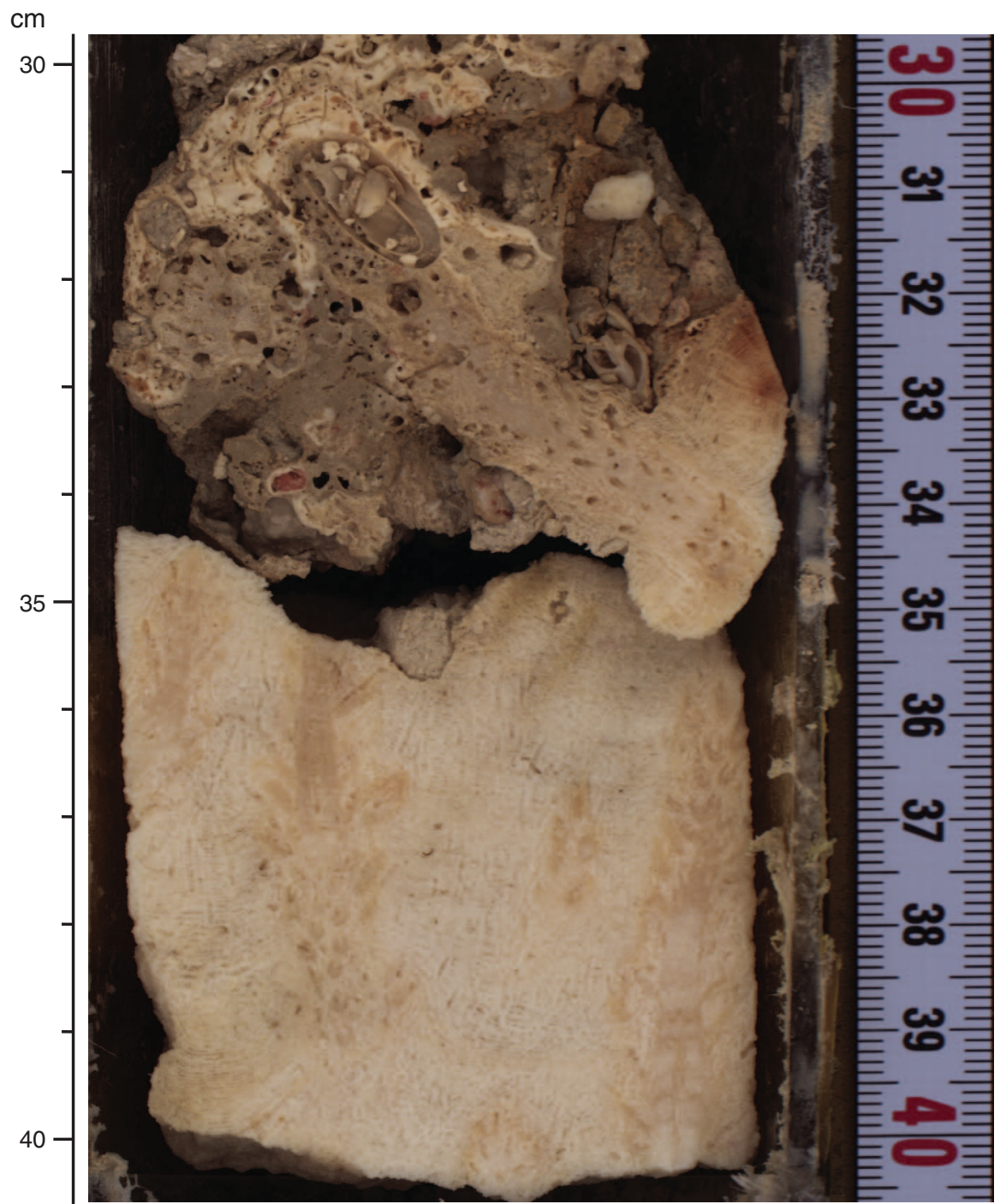


Figure F107. High-resolution line scan image of a fine branching Seriatopora encrusted by a thick coralline algal crust and microbialites (interval 325-M0039A-7R-1, 1-15 cm).

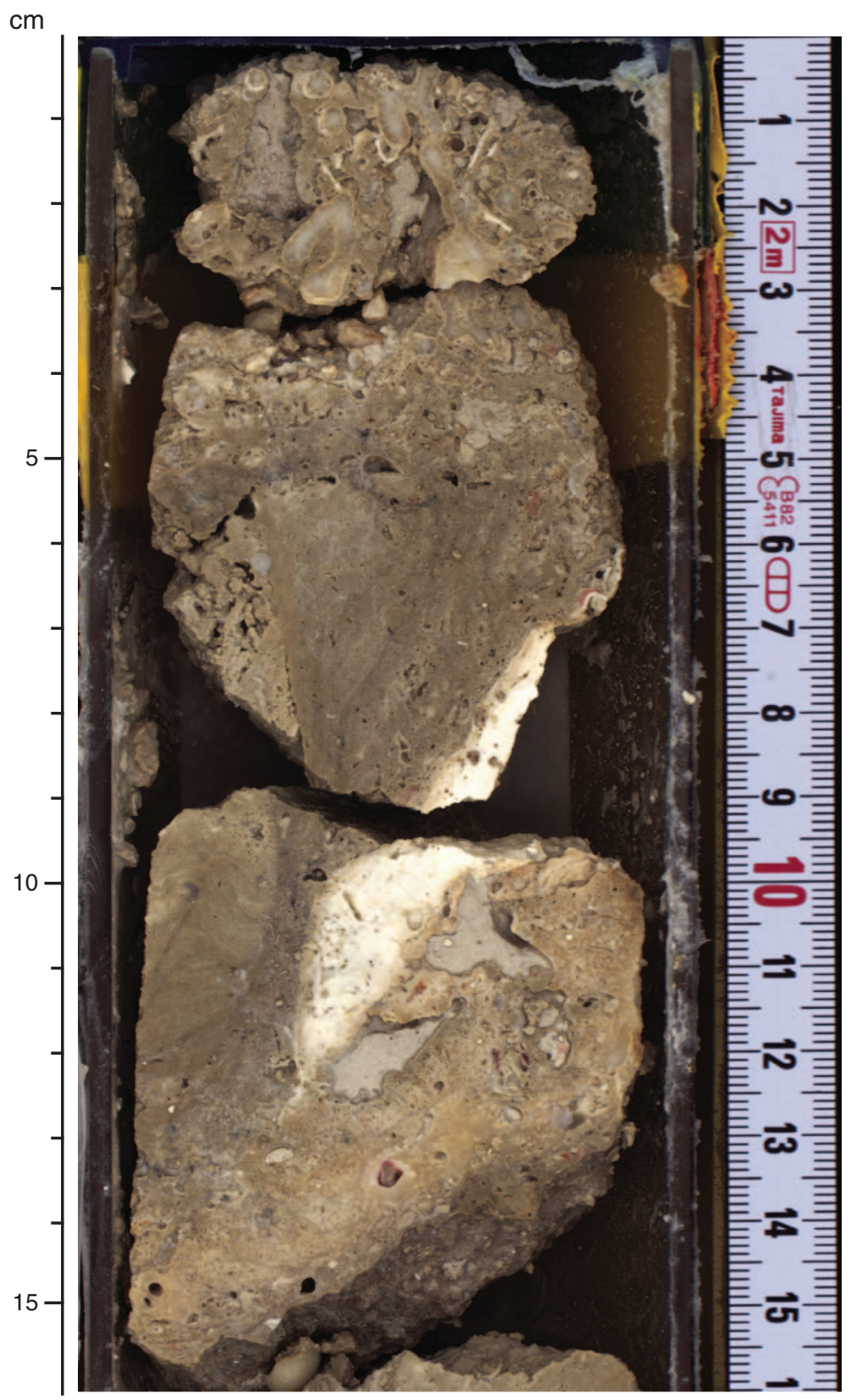


Figure F108. High-resolution line scan image of microbialite encrusting a bioclastic packstone to rudstone with Halimeda, mollusks, echinoderms, corals (fine branching Seriatopora and medium branching Acropora), and thick coralline algal crust (interval 325-M0039A-12R-1, 26-45 cm).

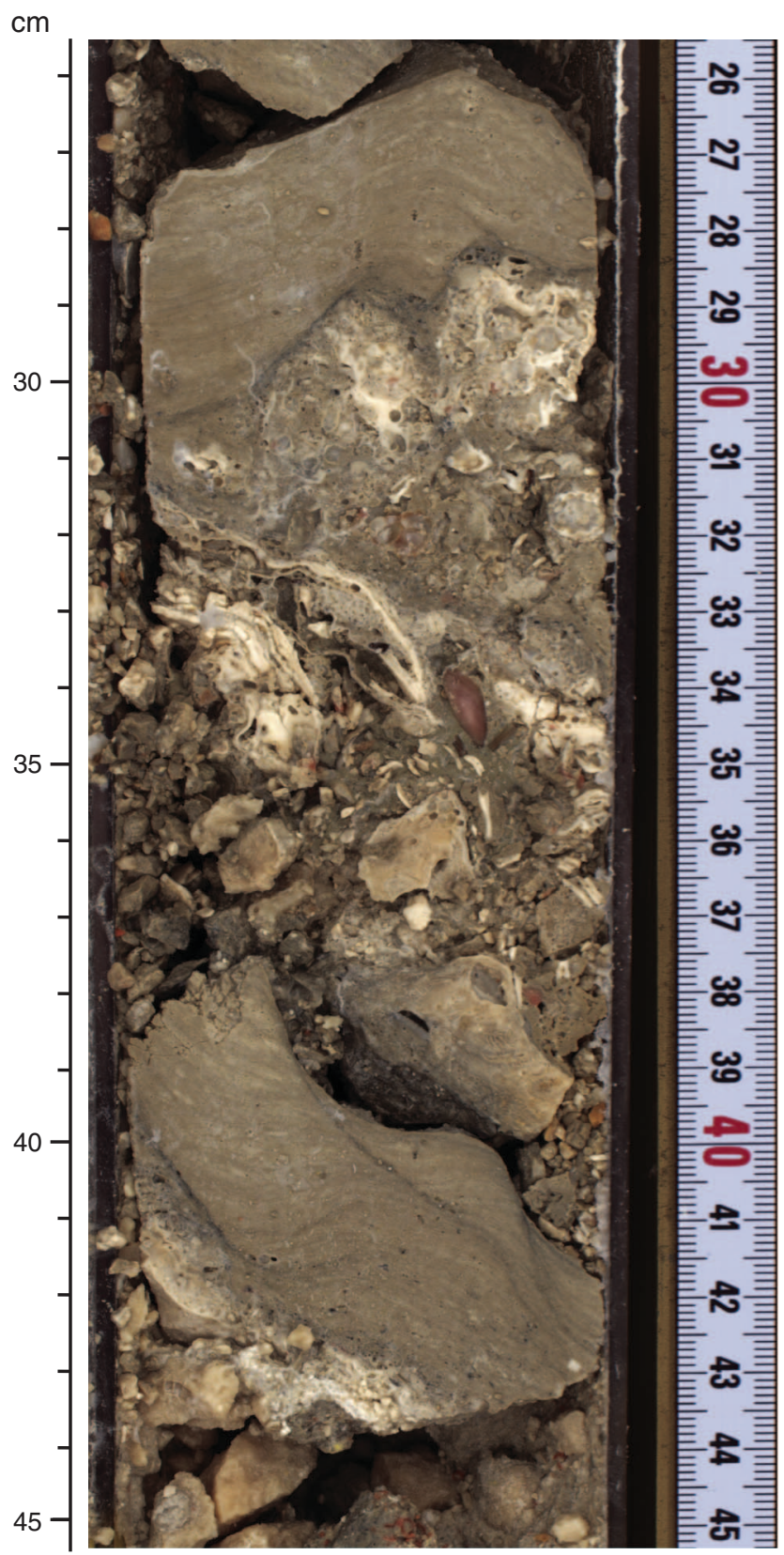


Figure F109. High-resolution line scan image of coralgal-microbialite boundstone, fine branching Seriatopora(?), platy Montipora, and submassive Montipora (in situ?), infilled with a bioclastic rudstone (interval 325M0039A-9R-1, 30-55 cm).

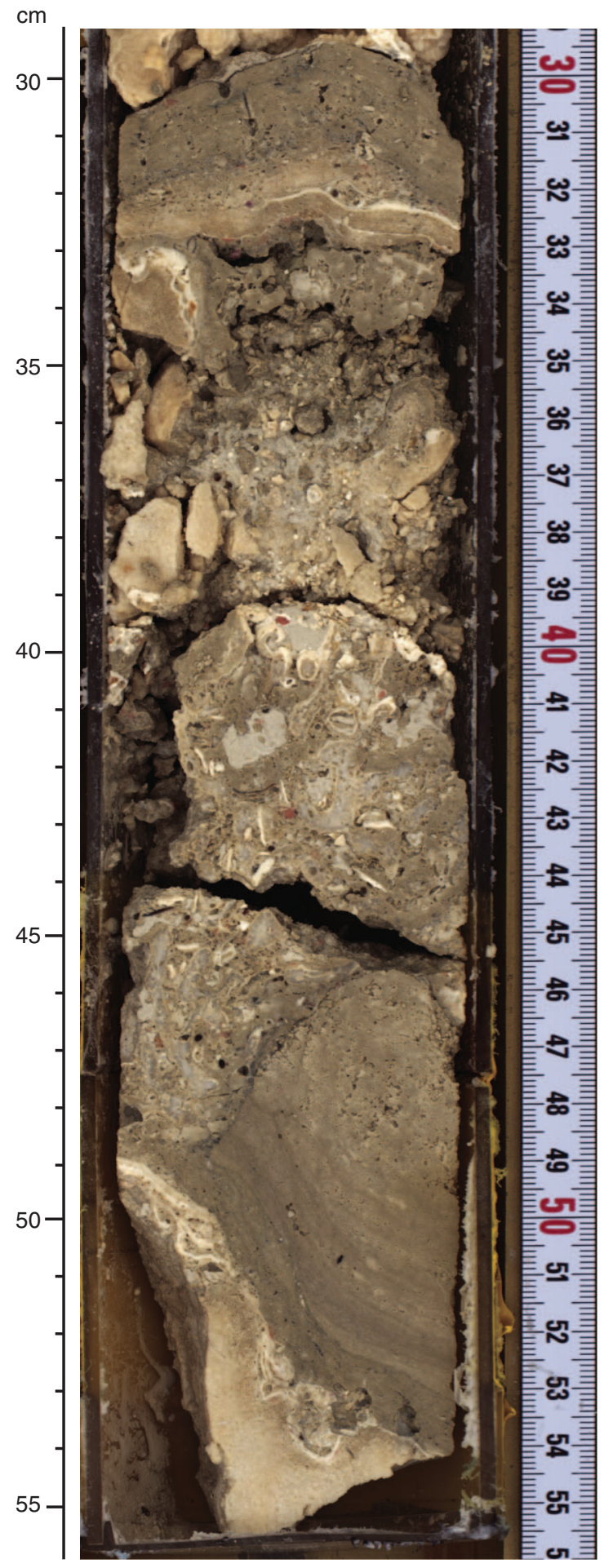


Figure F110. High-resolution line scan image of sand with pebbles, common to abundant bioclasts of Halimeda, benthic foraminifera, and mollusks in addition to corals and limestone clasts (interval 325-M0039A21R-1, 12-22 cm).

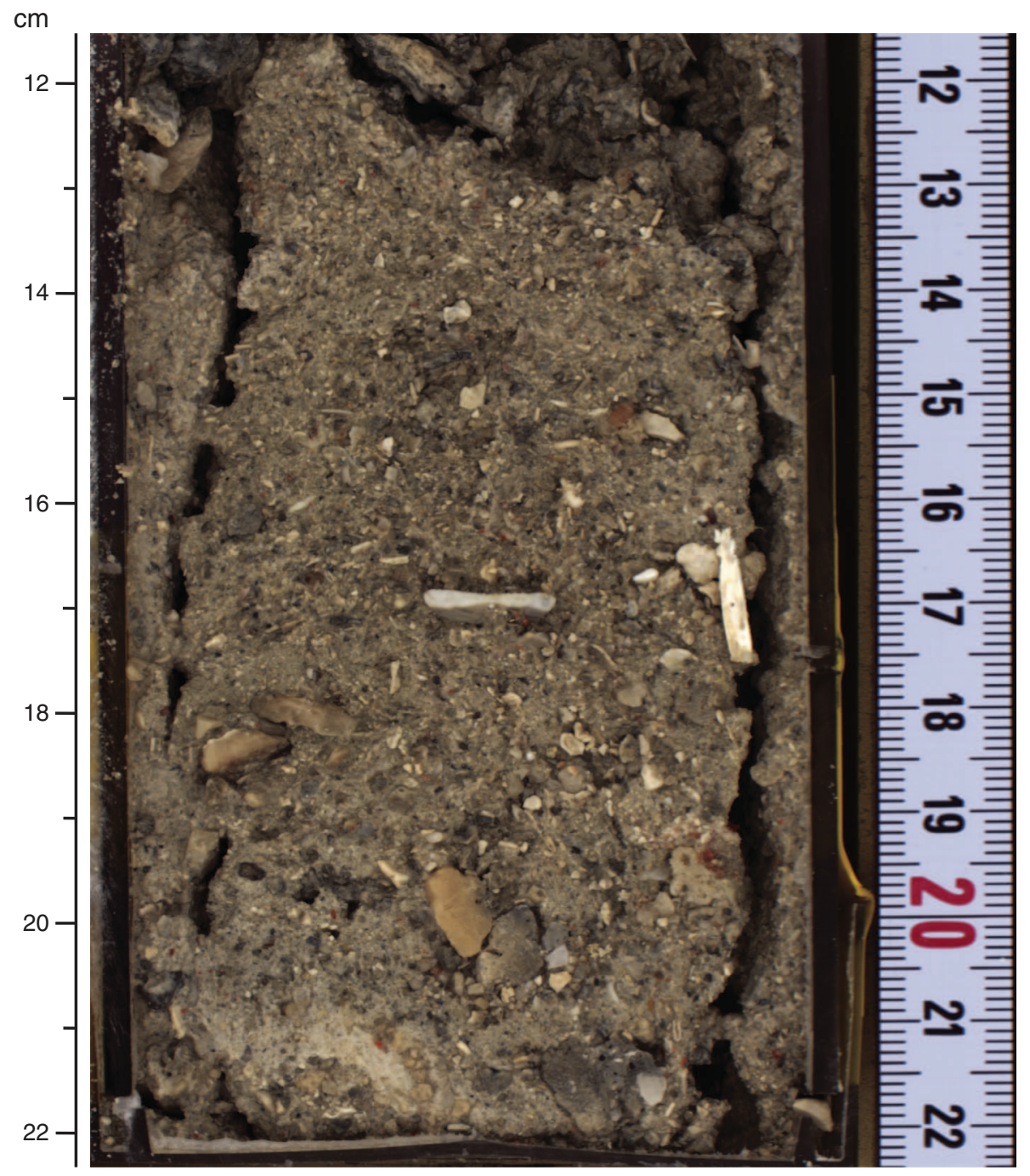


Figure F111. High-resolution line scan image of a massive Acropora colony (interval 325-M0039A-6R-1, 1-23 $\mathrm{cm})$.

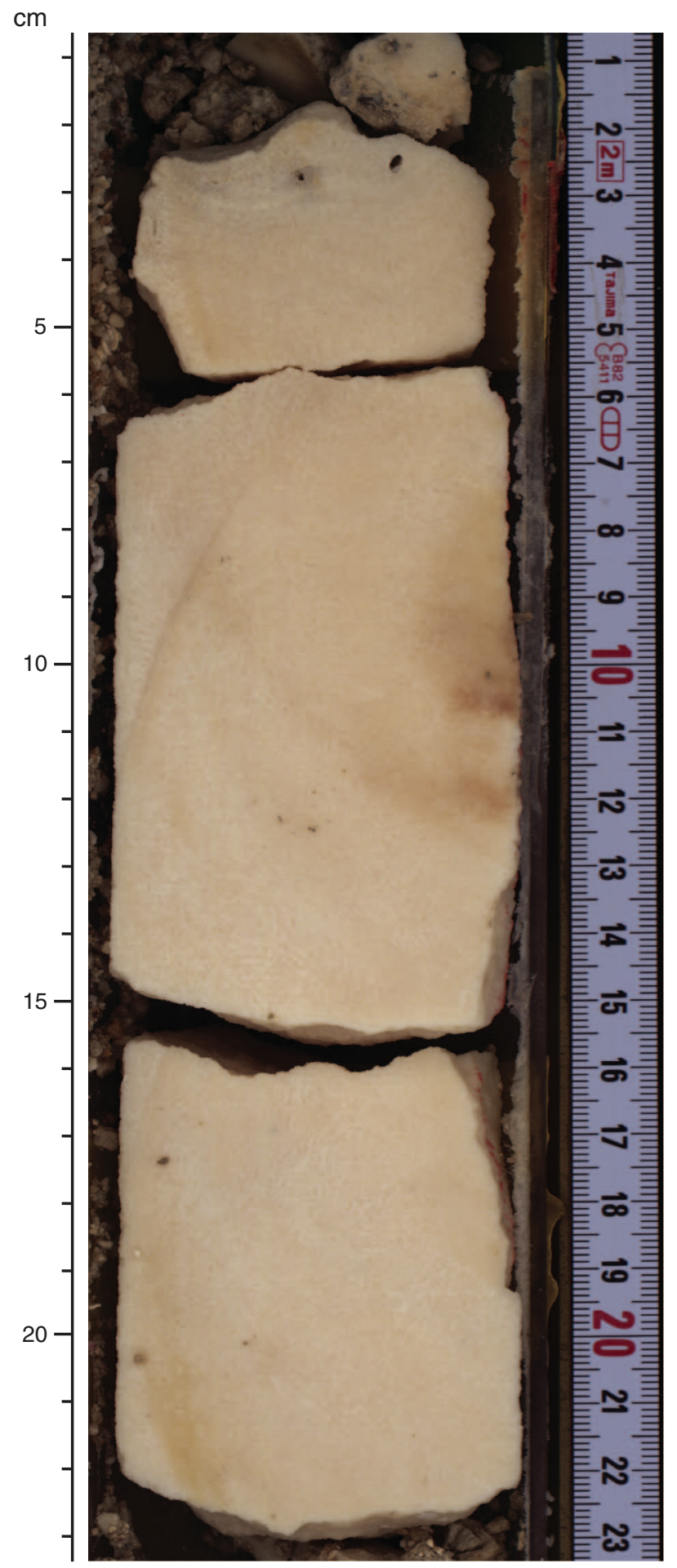


Figure F112. High-resolution line scan image showing a submassive to massive Faviidae (interval 325-M0039A$14 \mathrm{R}-1,41-51 \mathrm{~cm})$.

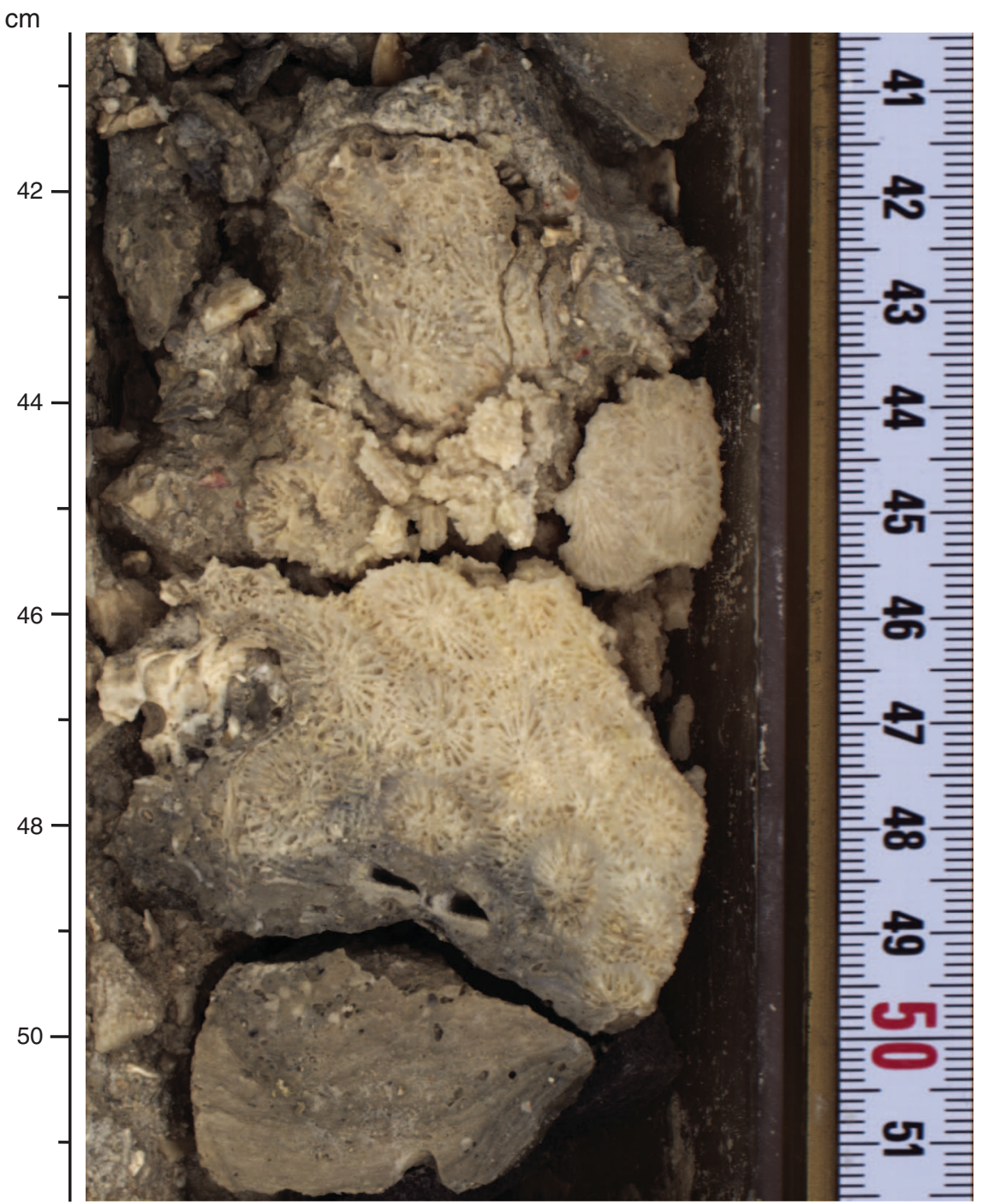


Figure F113. High-resolution line scan image of a massive Isopora colony (interval 325-M0039A-7R-1, 30-45 $\mathrm{cm})$.

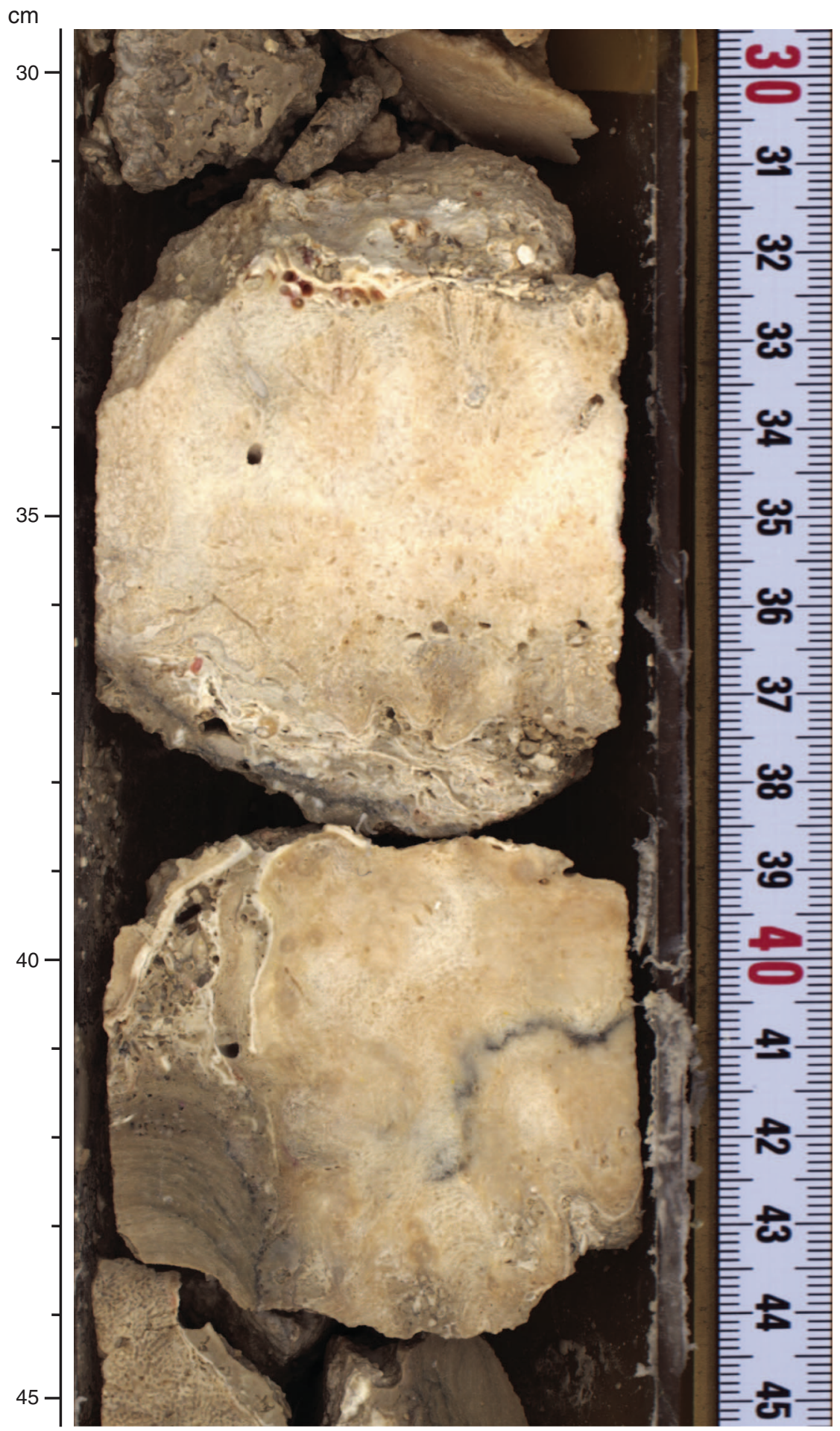


Figure F114. High-resolution line scan image of a tabular Acropora colony encrusted by a thin coralline algal crust (interval 325-M0039A-14R-1, 31-40 cm).

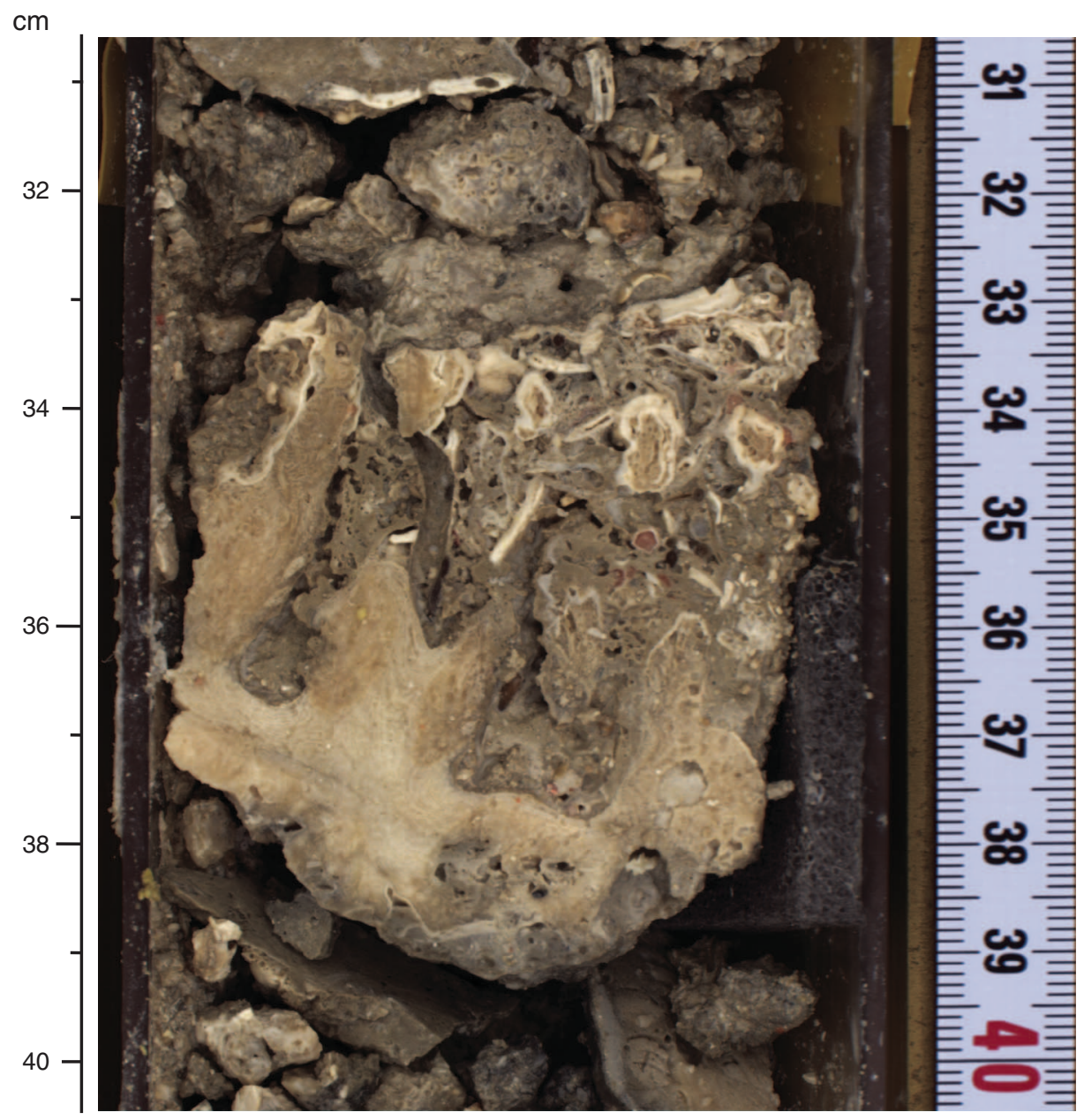


Figure F115. High-resolution line scan image of a massive Astreopora colony (interval 325-M0039A-8R-1, 31$53 \mathrm{~cm})$.

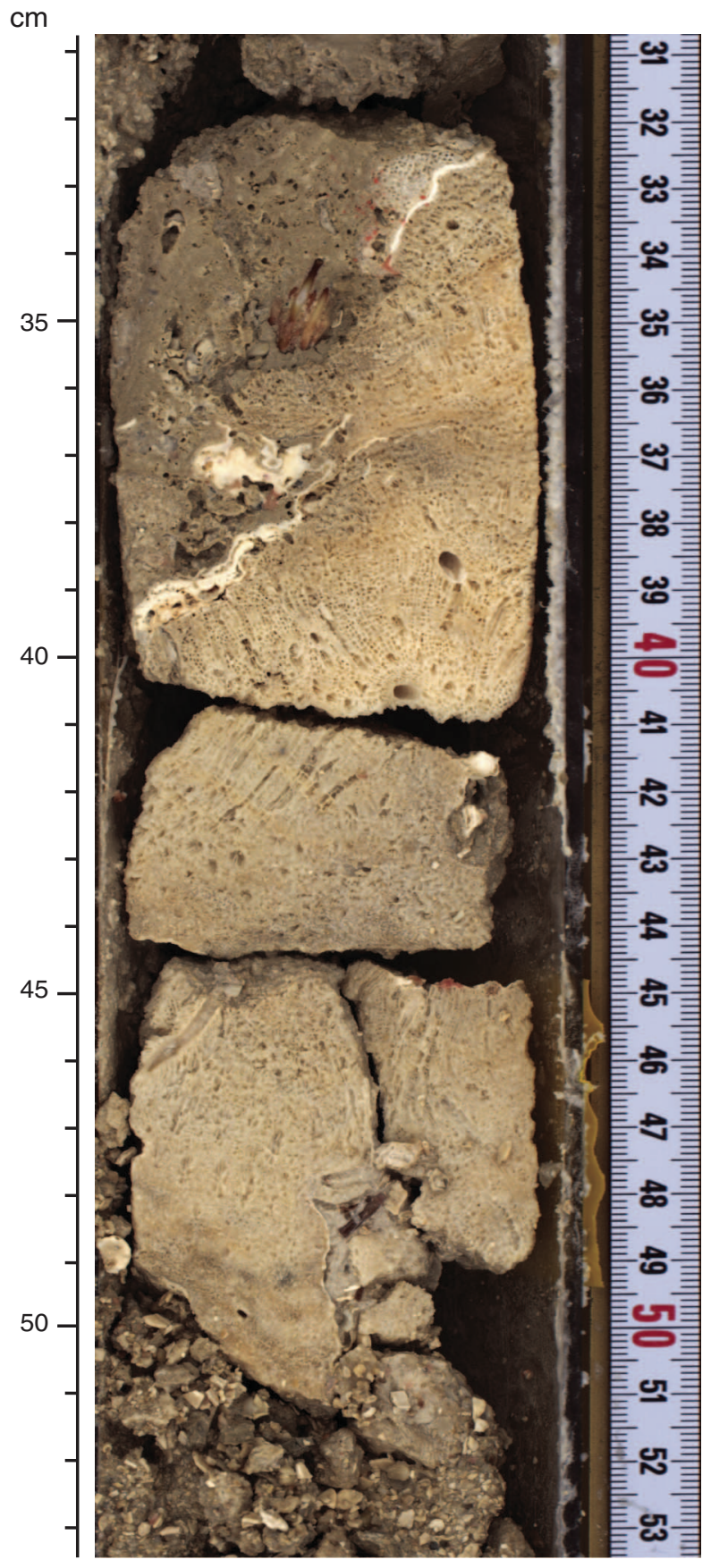


Figure F116. High-resolution line scan image of Echinopora (interval 325-M0039A-10R-1, 18-29 cm).

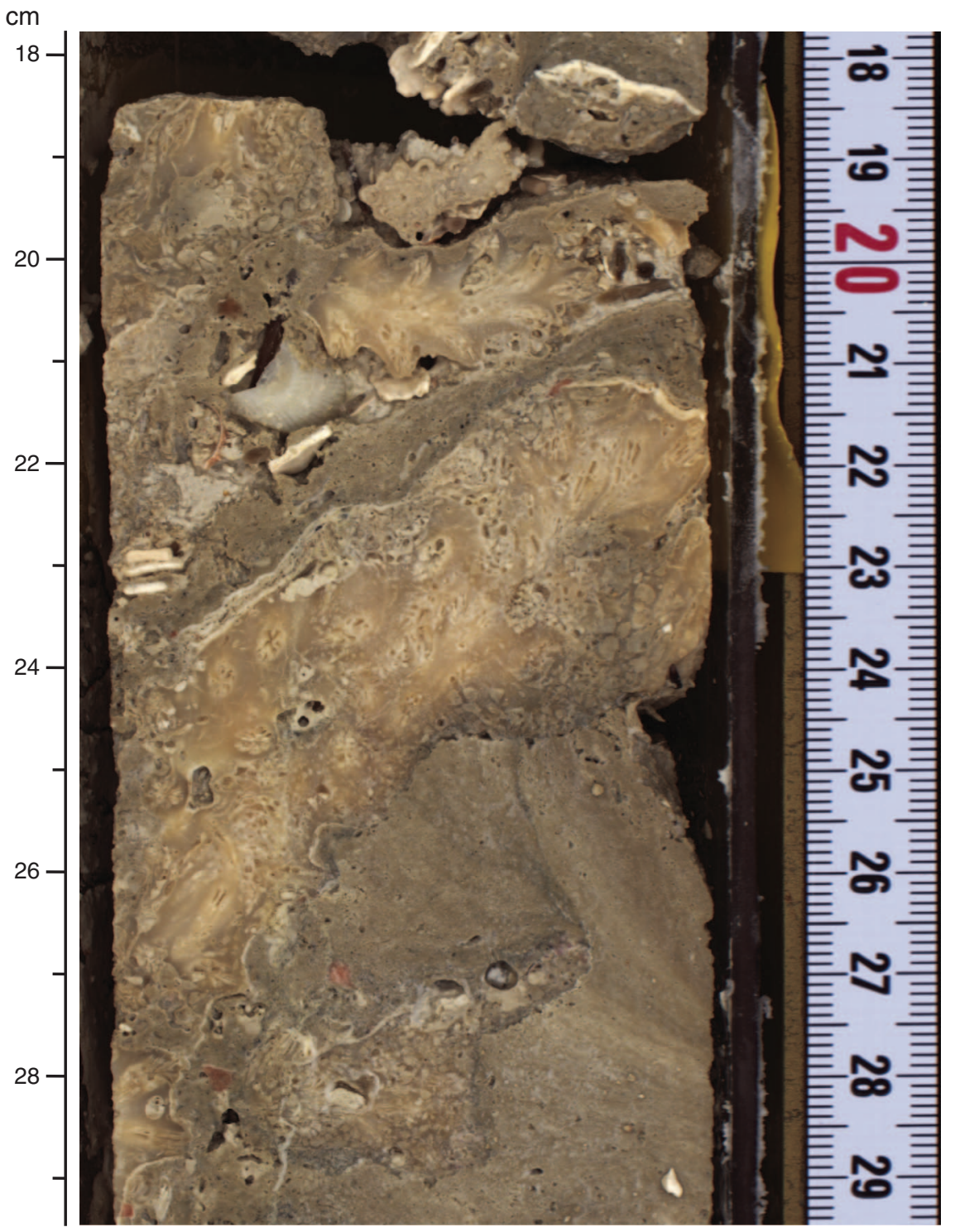


Figure F117. High-resolution line scan image of an apparent alcyonarian spiculite (interval 325-M0039A-10R$1,50-66 \mathrm{~cm})$.

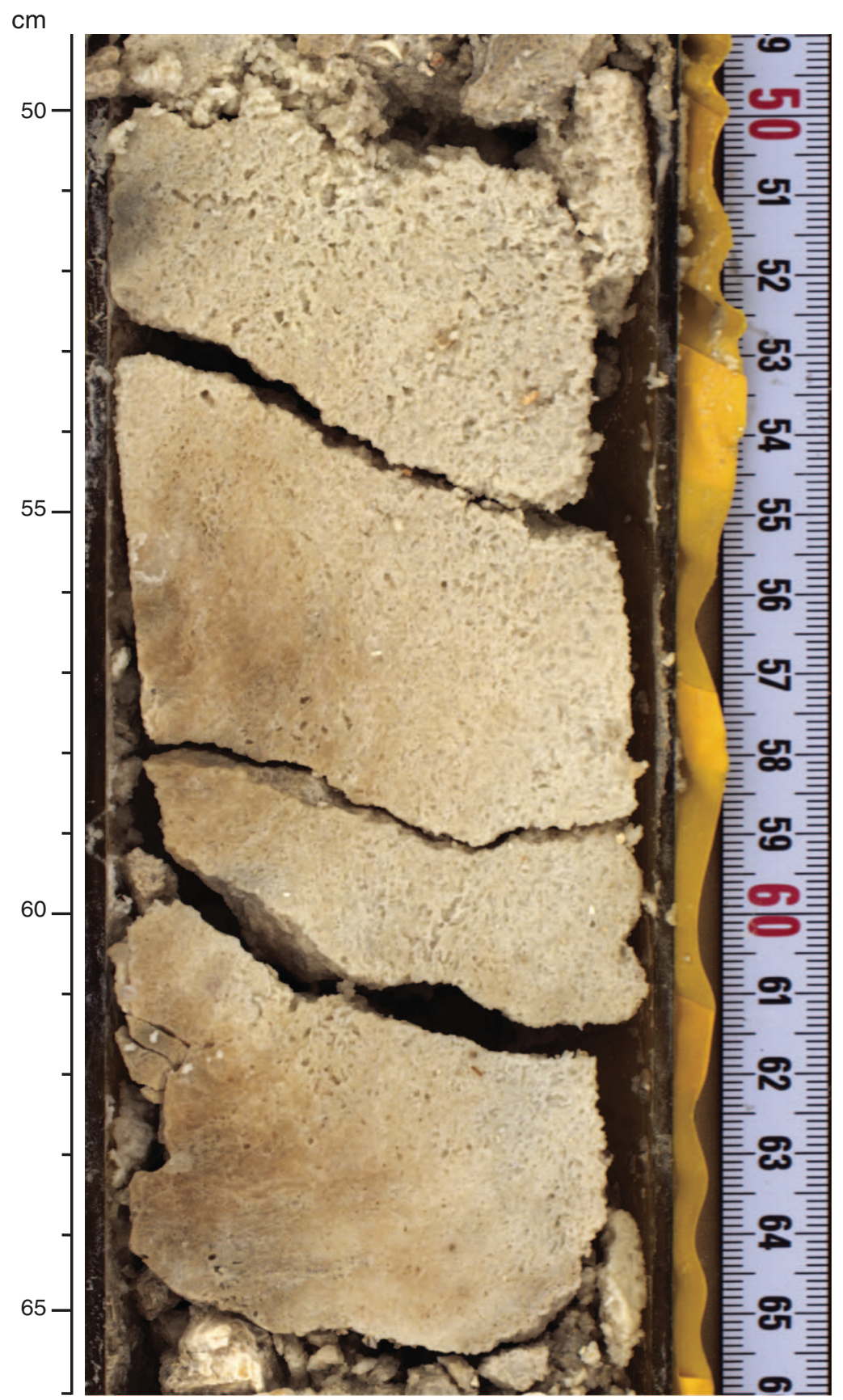


Figure F118. High-resolution line scan image of grainstone with fragments of corals, coralline algae, foraminifers, Halimeda, and mollusk shells (interval 325-M0039A-21R-CC, 5-14 cm).

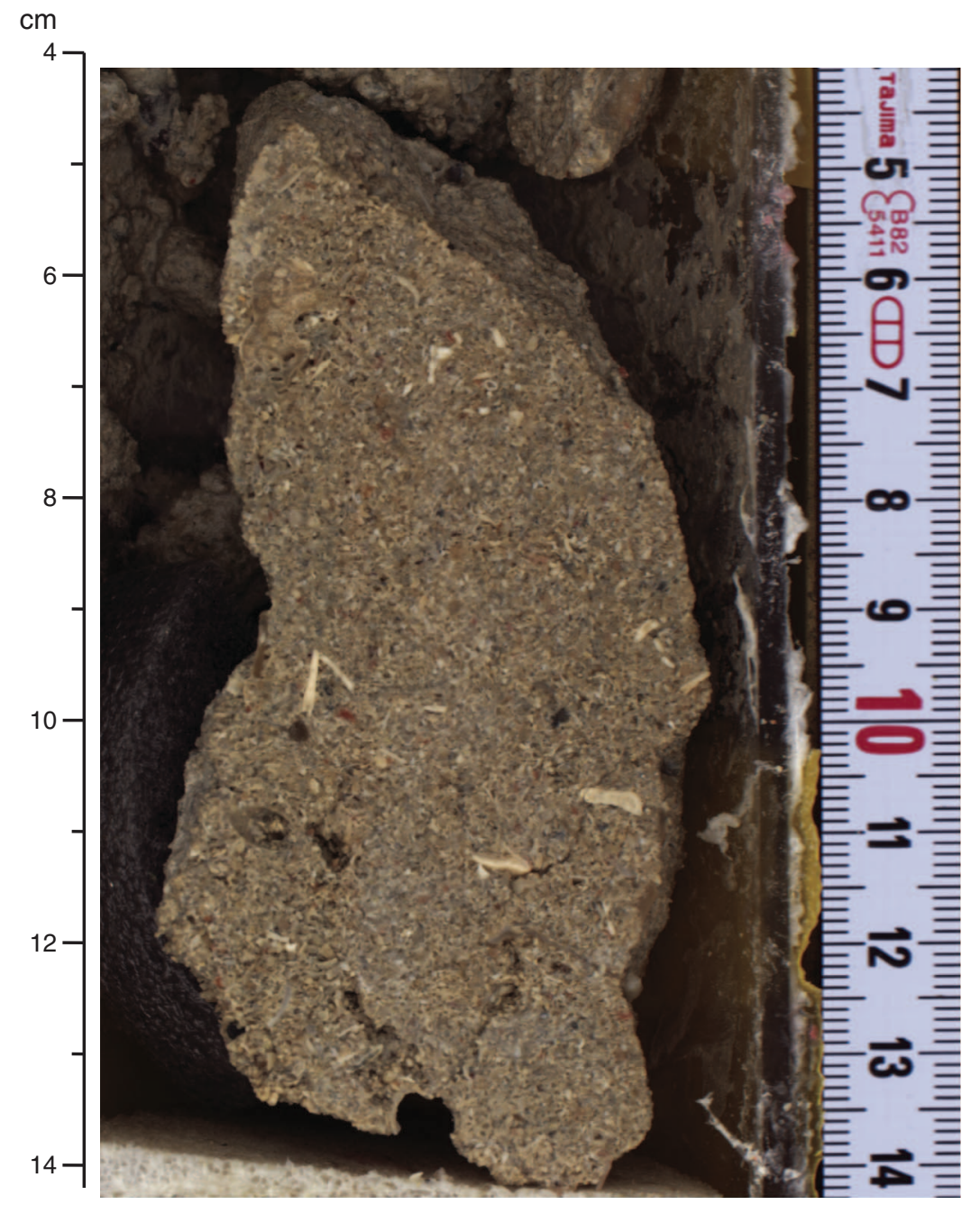


Figure F119. Summary diagram showing data collected on whole cores using the MSCL, Hole M0039A.

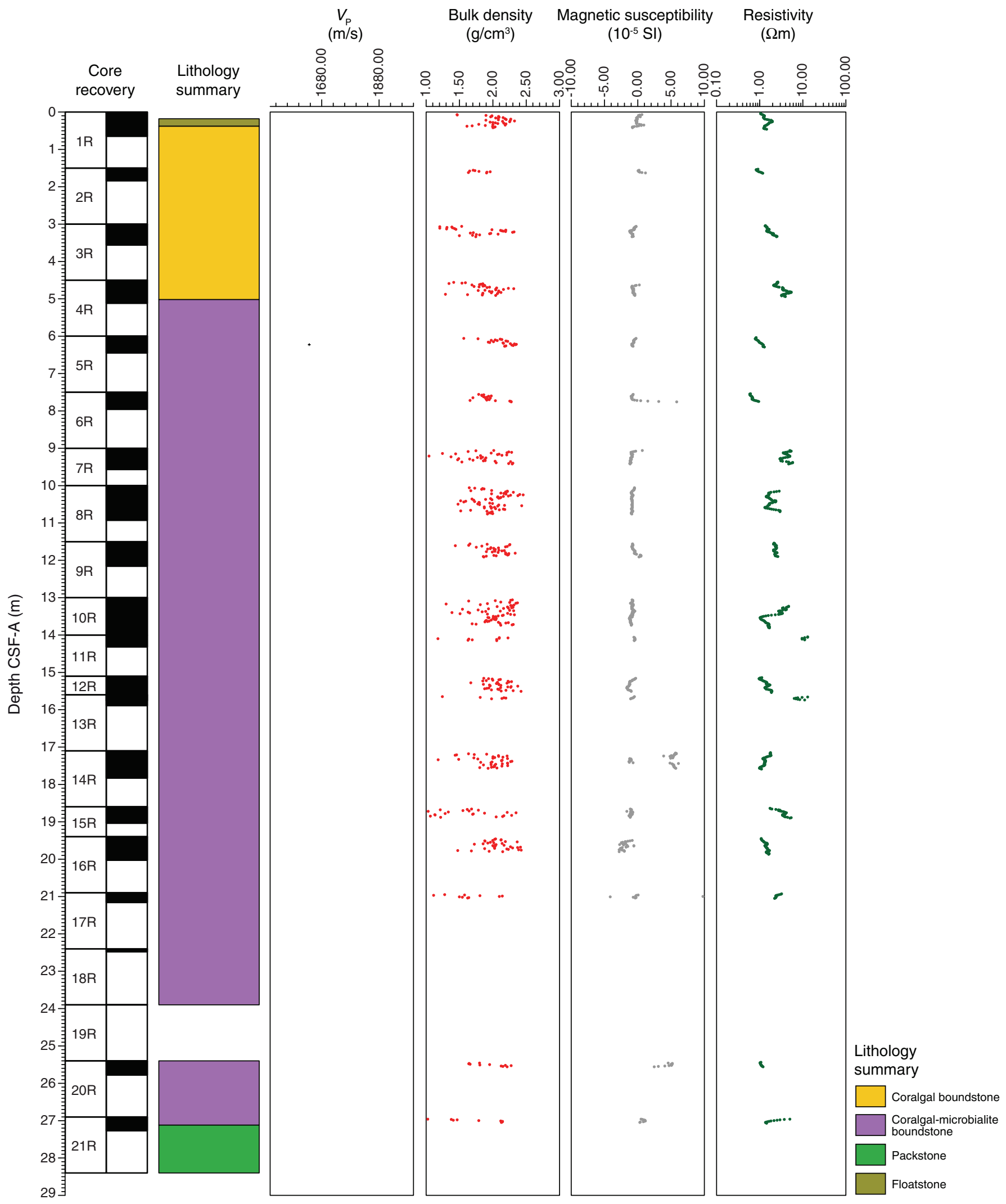


Figure F120. Petrophysical measurements obtained from discrete samples with a pycnometer, Hole M0039A. Bulk density measured on whole cores with the MSCL is shown in red on the bulk density plot.

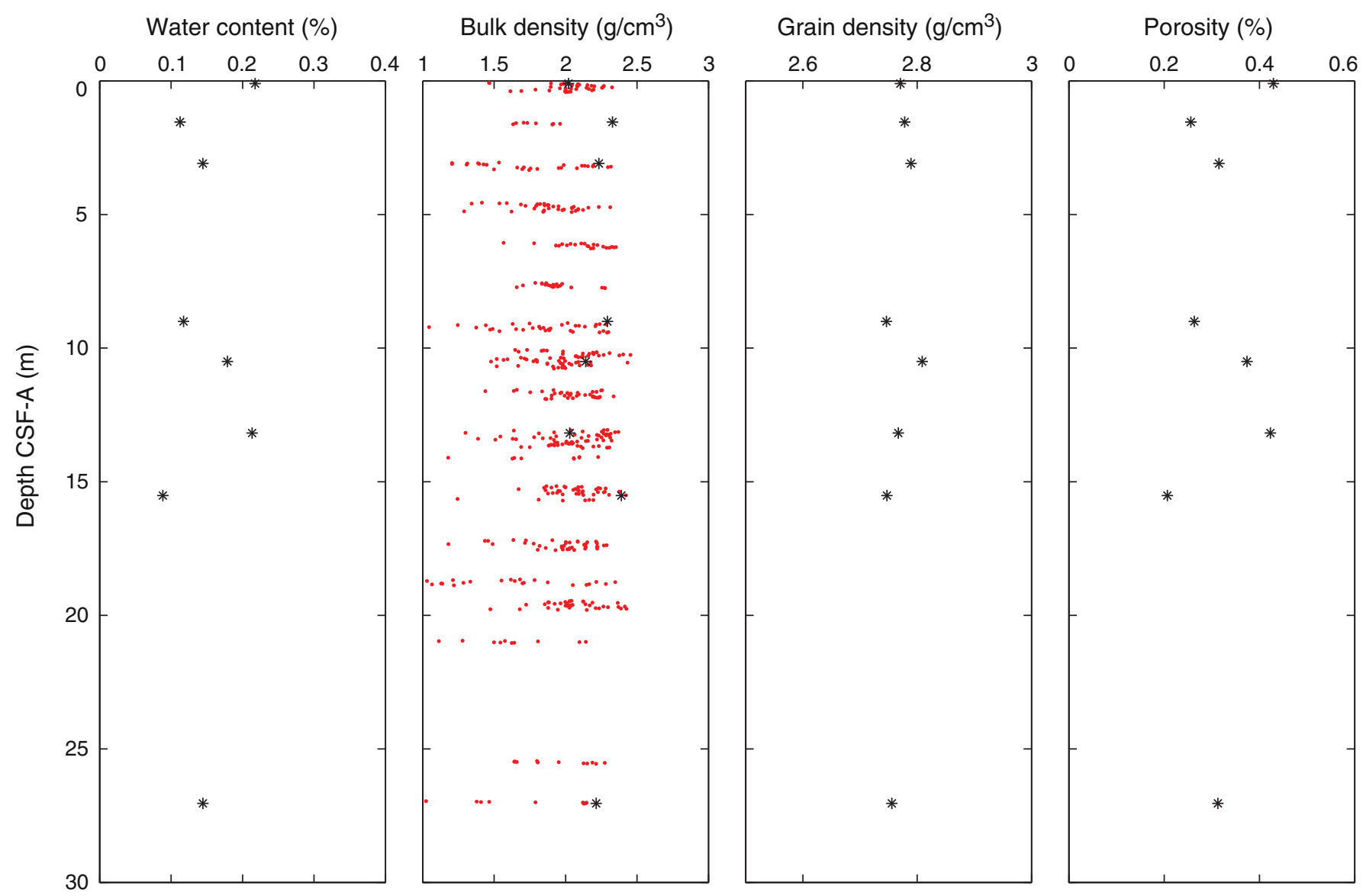


Figure F121. $P$-wave velocity data, Hole M0039A. A. Plot of initial, dry, and resaturated $P$-wave velocity measurements on discrete samples vs. depth. Three measurements were taken at each depth and are denoted by a dot. Average values are plotted as an open triangle. B. Plot showing discrete $P$-wave velocity vs. discrete bulk density.
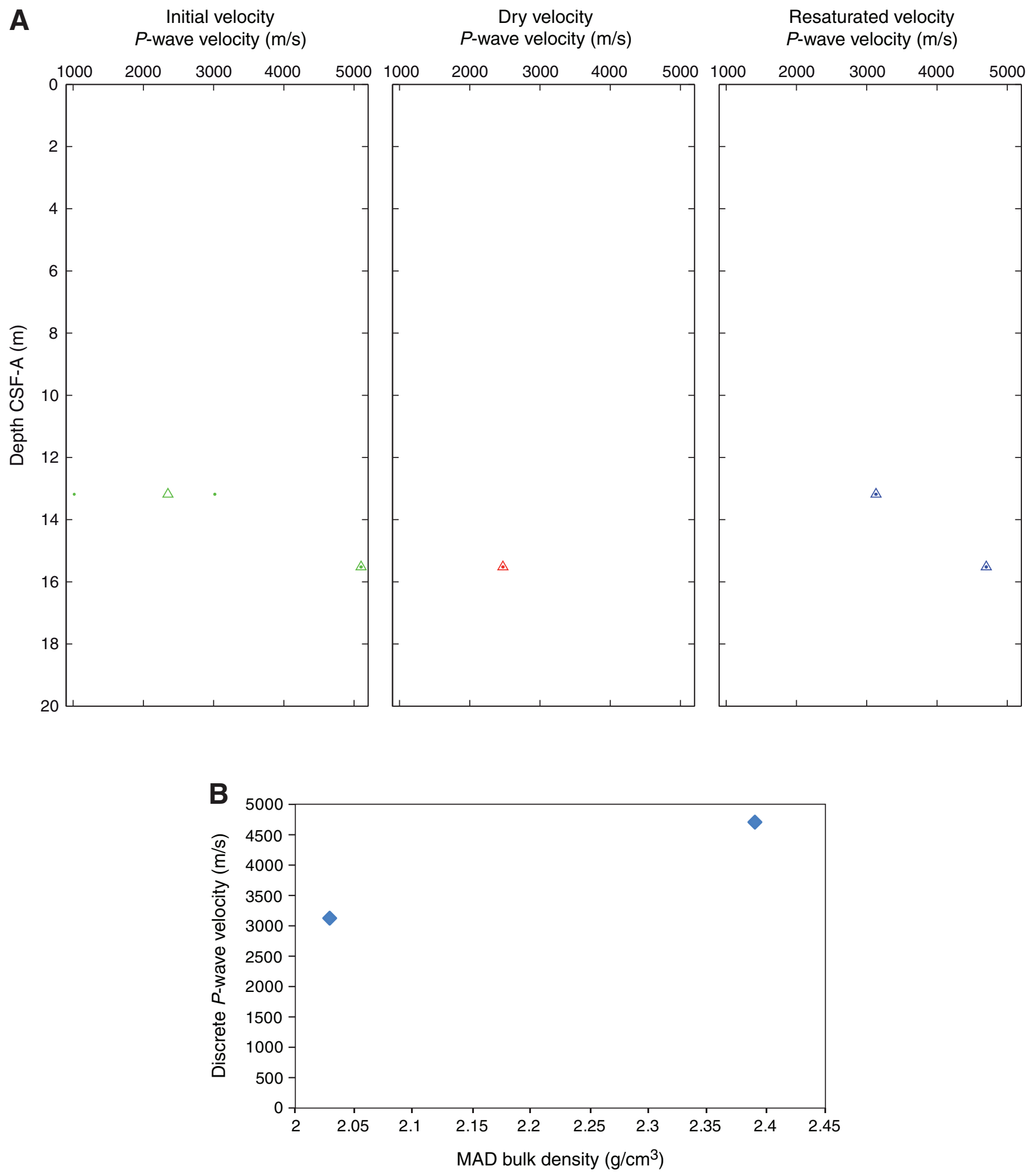
Figure F122. Values of reflectance $\left(\mathrm{L}^{*}\right)$, green to red $\left(\mathrm{a}^{*}\right)$, and blue to yellow $\left(\mathrm{b}^{\star}\right)$ indexes, along with ratio $\mathrm{a}^{*} /$ $\mathrm{b}^{*}$ for Hole M0039A.

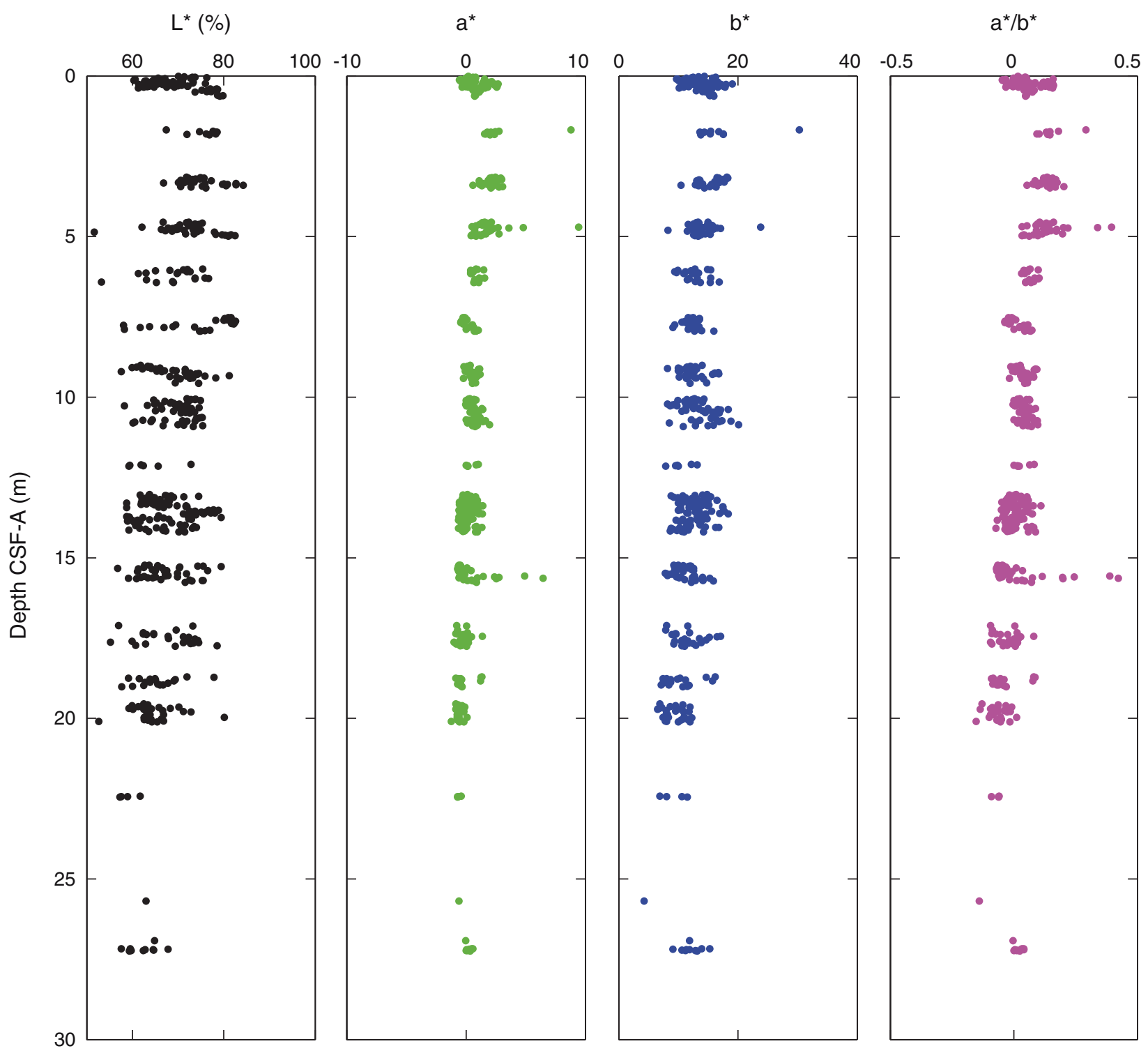


Figure F123. Magnetic susceptibility record for Hole M0039A. Water depth $=107.04 \mathrm{~m}$ (lowest astronomical tide).

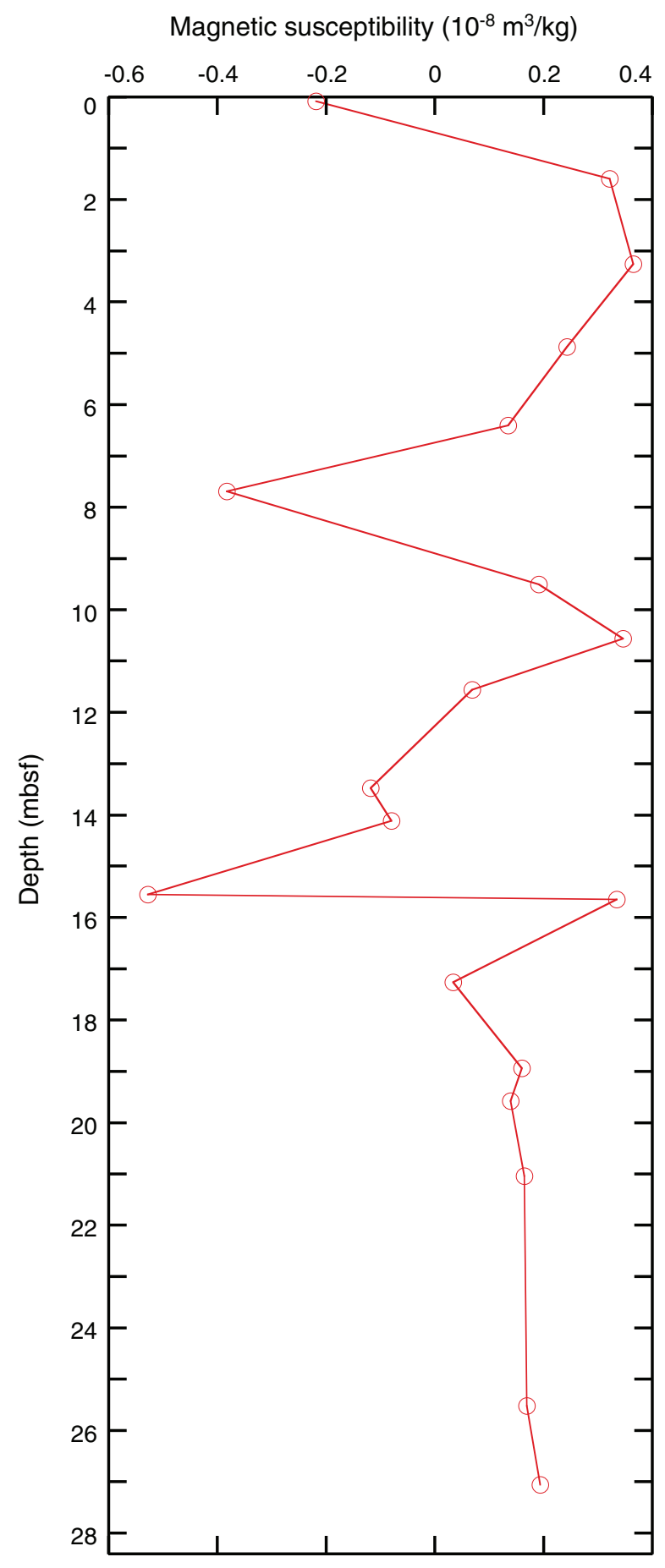


Figure F124. Preliminary chronology for Hole M0039A. Radiocarbon data are presented as graphs with the uncalibrated radiocarbon age and uncertainty shown as the red normal distribution on the ordinate axis and the probability distribution of the calibrated age shown in gray on the abscissa. The marine09 calibration curve is shown in blue. Horizontal bars indicate portions of the age distribution that are significant at the $95.4 \%$ confidence interval and the mean age (white circle \pm 1 standard deviation) used for the purposes of the preliminary dating. All ages are presented as thousands of calendar years BP (1950 AD). See Table T10 in the "Methods" chapter. (See Bronk Ramsey [2009], as well as Bronk Ramsey [2010] at c14.arch.ox.ac.uk/oxcal.html.)
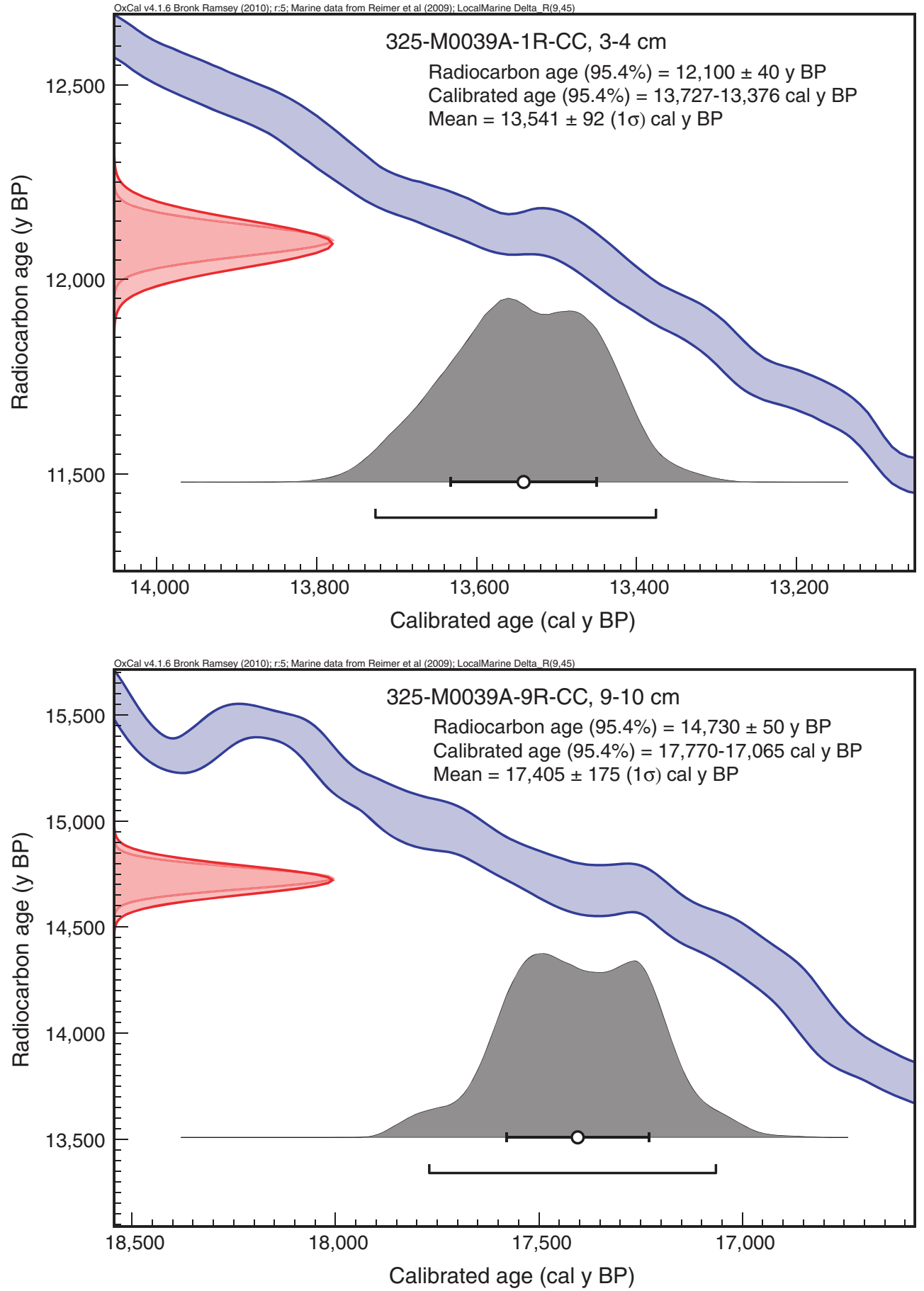


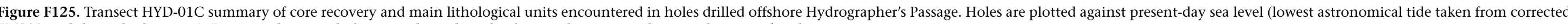
EM300 multibeam bathymetry). Distances between holes are indicated on the diagram but are not drawn to horizontal scale.

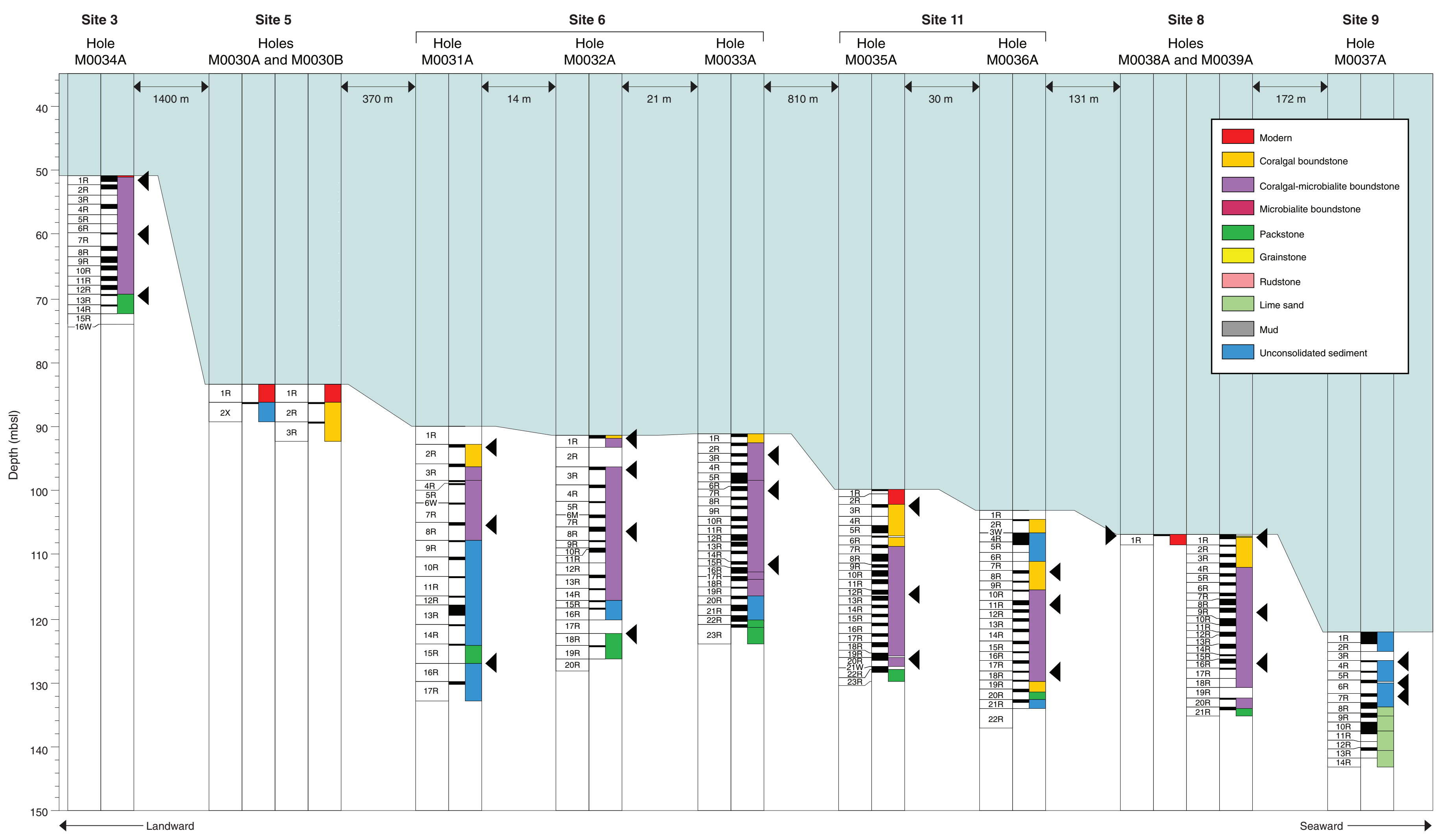


Figure F126. Porosity of discrete samples for all holes measured in transect HYD-01C in order from shallow water to deep water (left to right).

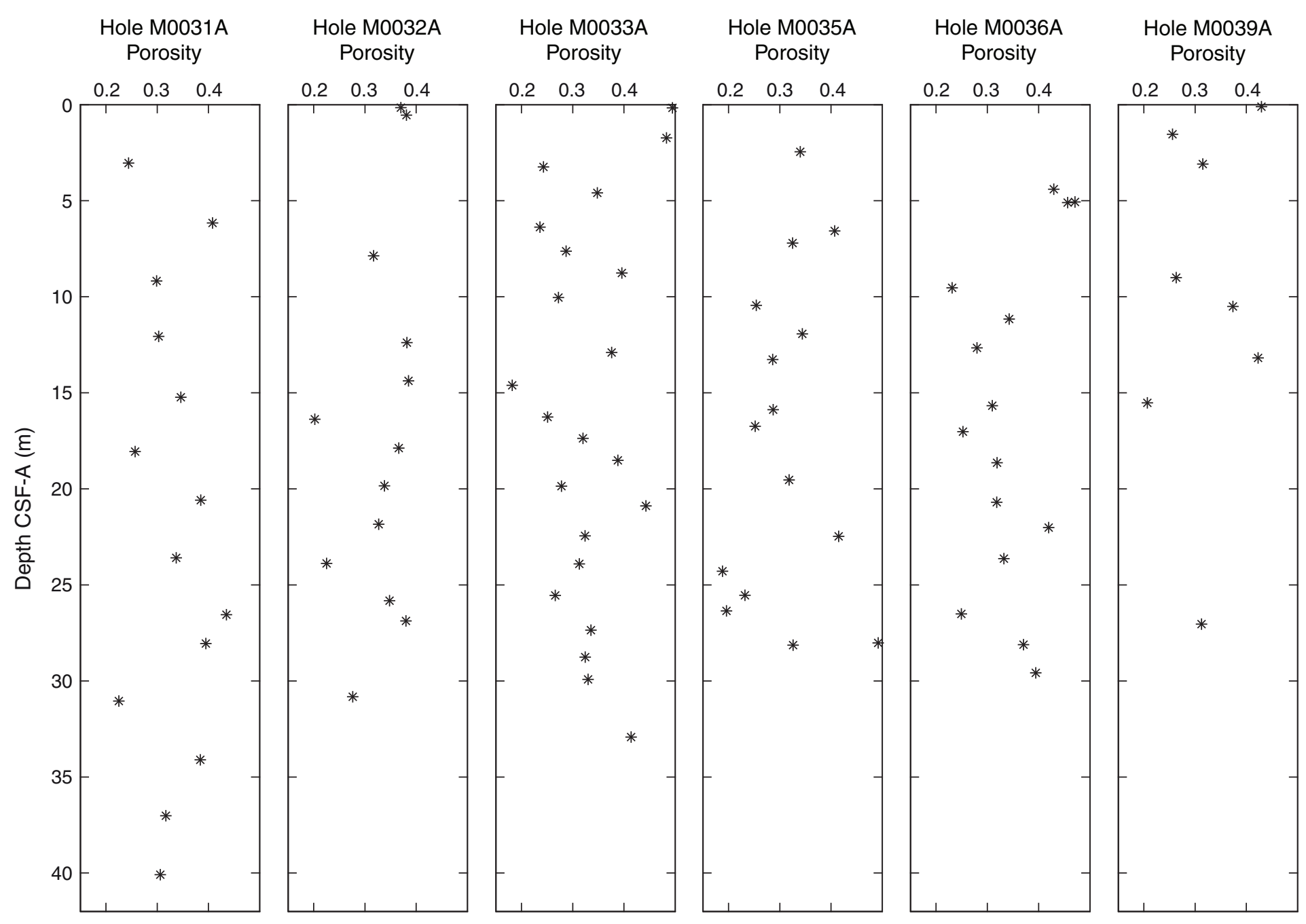


Figure F127. Plot showing porosity vs. bulk density measured in discrete samples from transect HYD-01C.

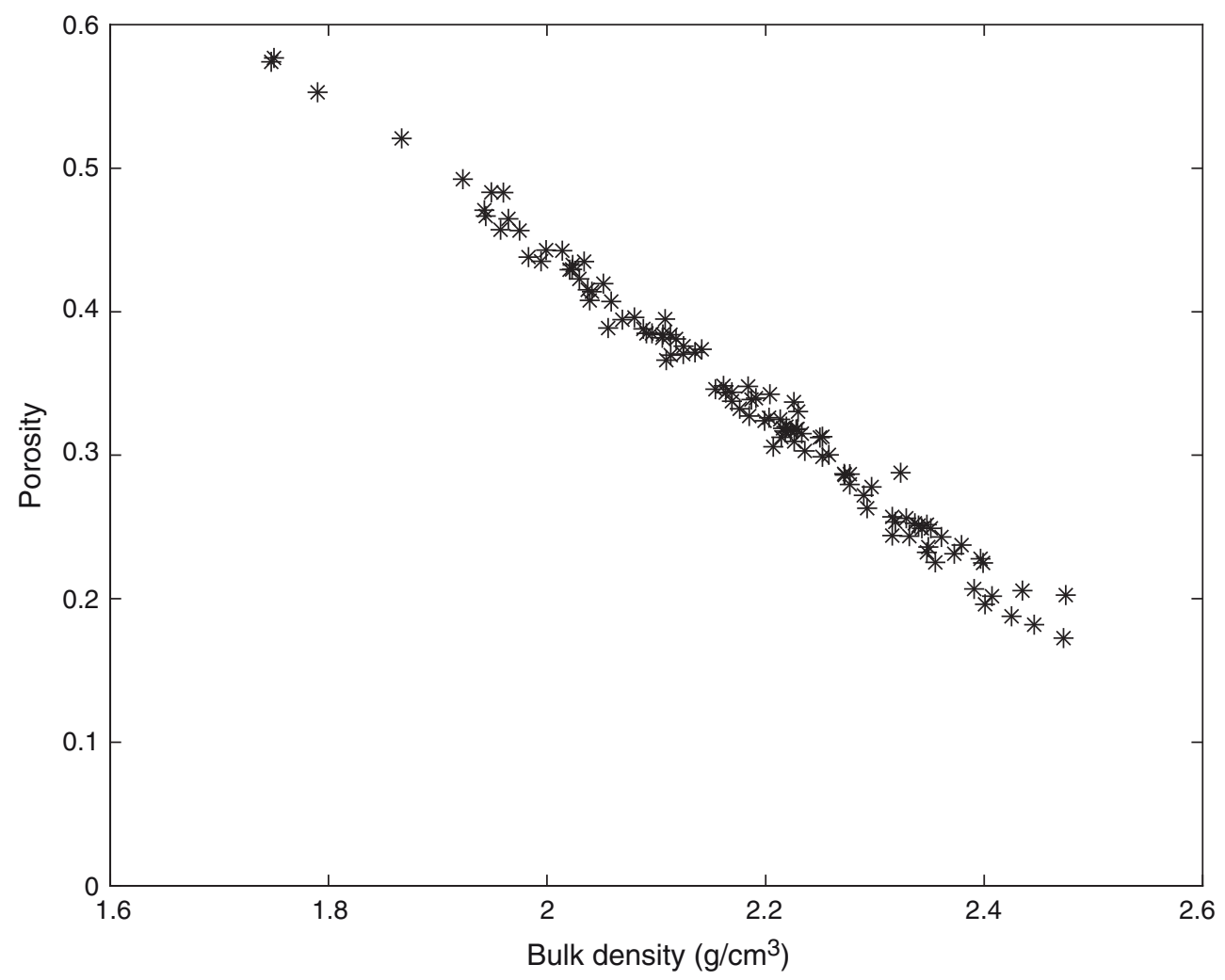


Figure F128. Plot of all porosity and $V_{\mathrm{P}}$ measurements from discrete samples analysis from all transect HYD01C holes.

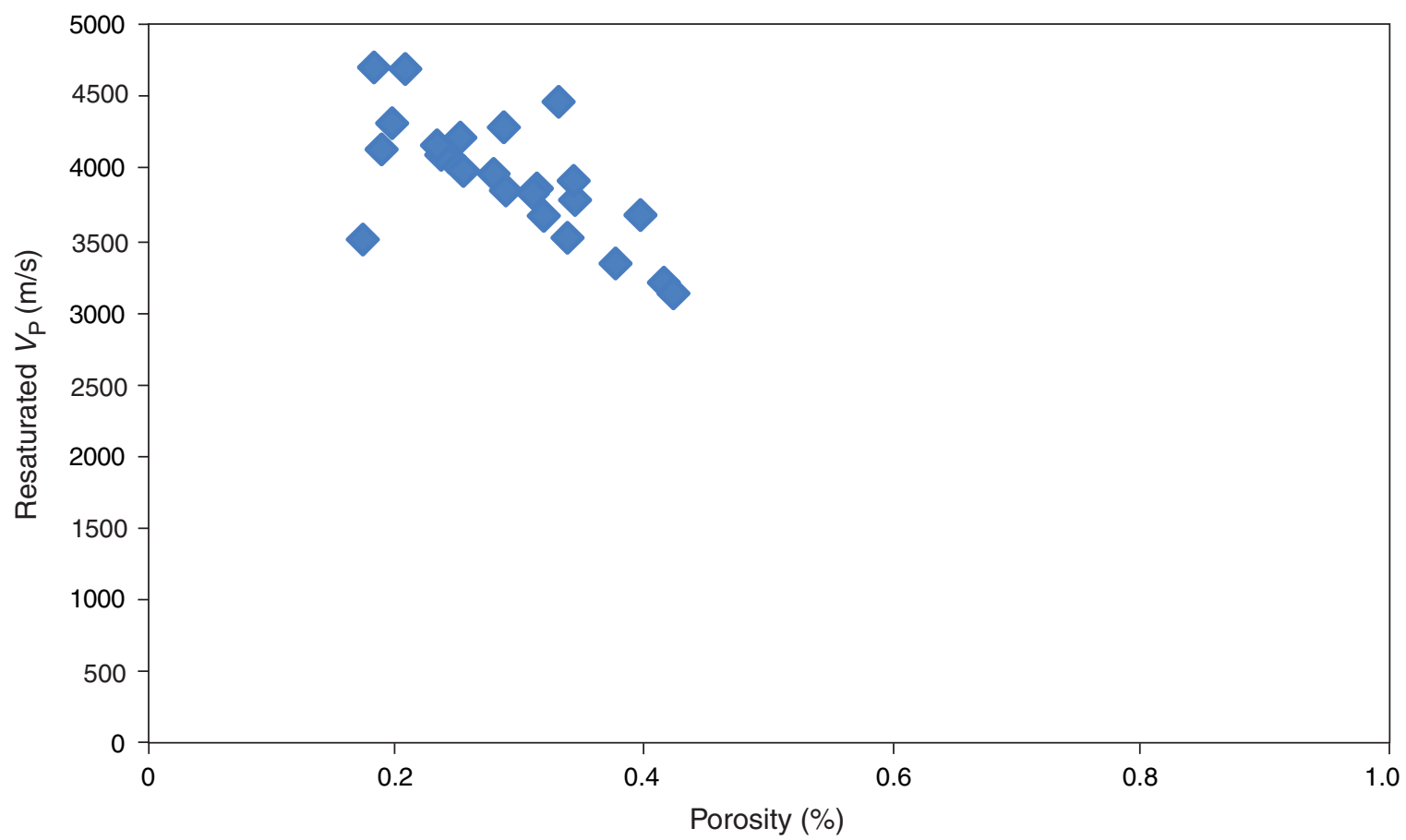


Figure F129. Color reflectance $\left(\mathrm{L}^{*}\right)$ for all transect HYD-01C holes in order from shallow water to deep water (left to right).

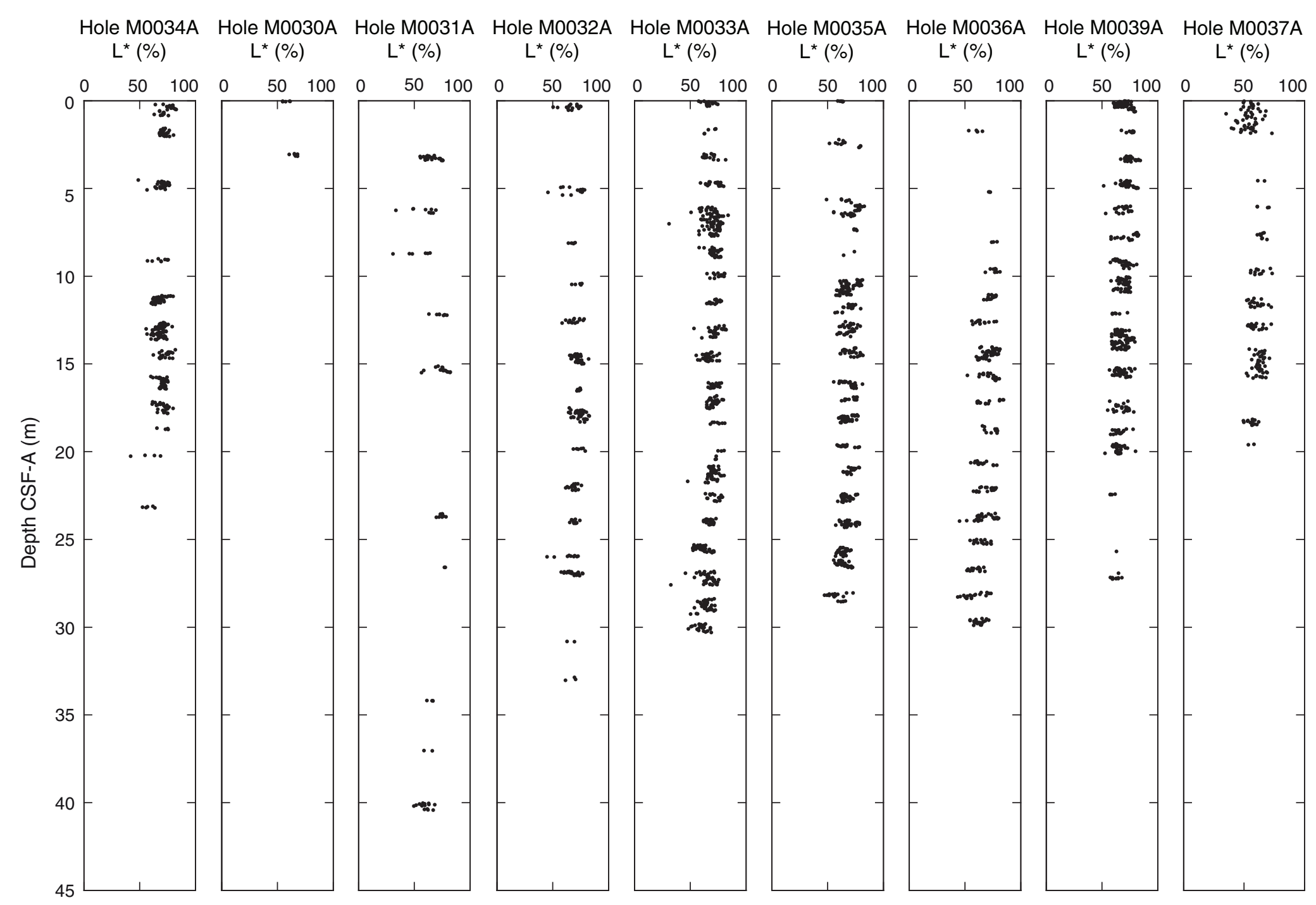


Figure F130. Composite comparing the total gamma ray (TGR) curve measured through pipe (TP) in Hole M0031A to the TGR (TP) log acquired in Hole M0036A. TGR (TP) with negative concentration values removed is overlain by an interpolation line. Dashed gray lines denote possible correlations between the two logs. Please note the two holes are $~ 800 \mathrm{~m}$ apart, and Hole M0031A is situated in shallower water. A. Hole M0031A. (Continued on next page.)

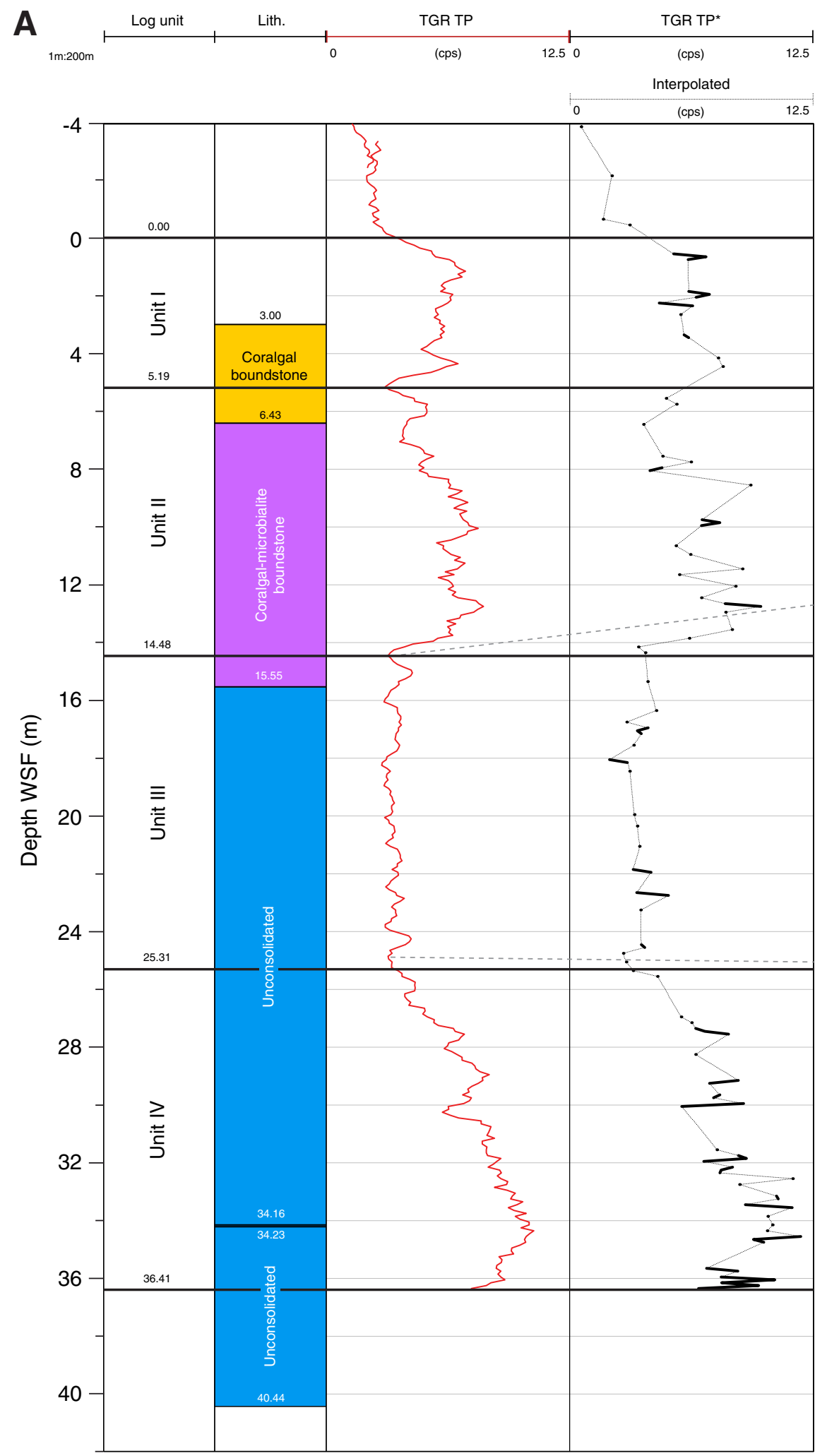


Figure F130 (continued). B. Hole M0036A.

B
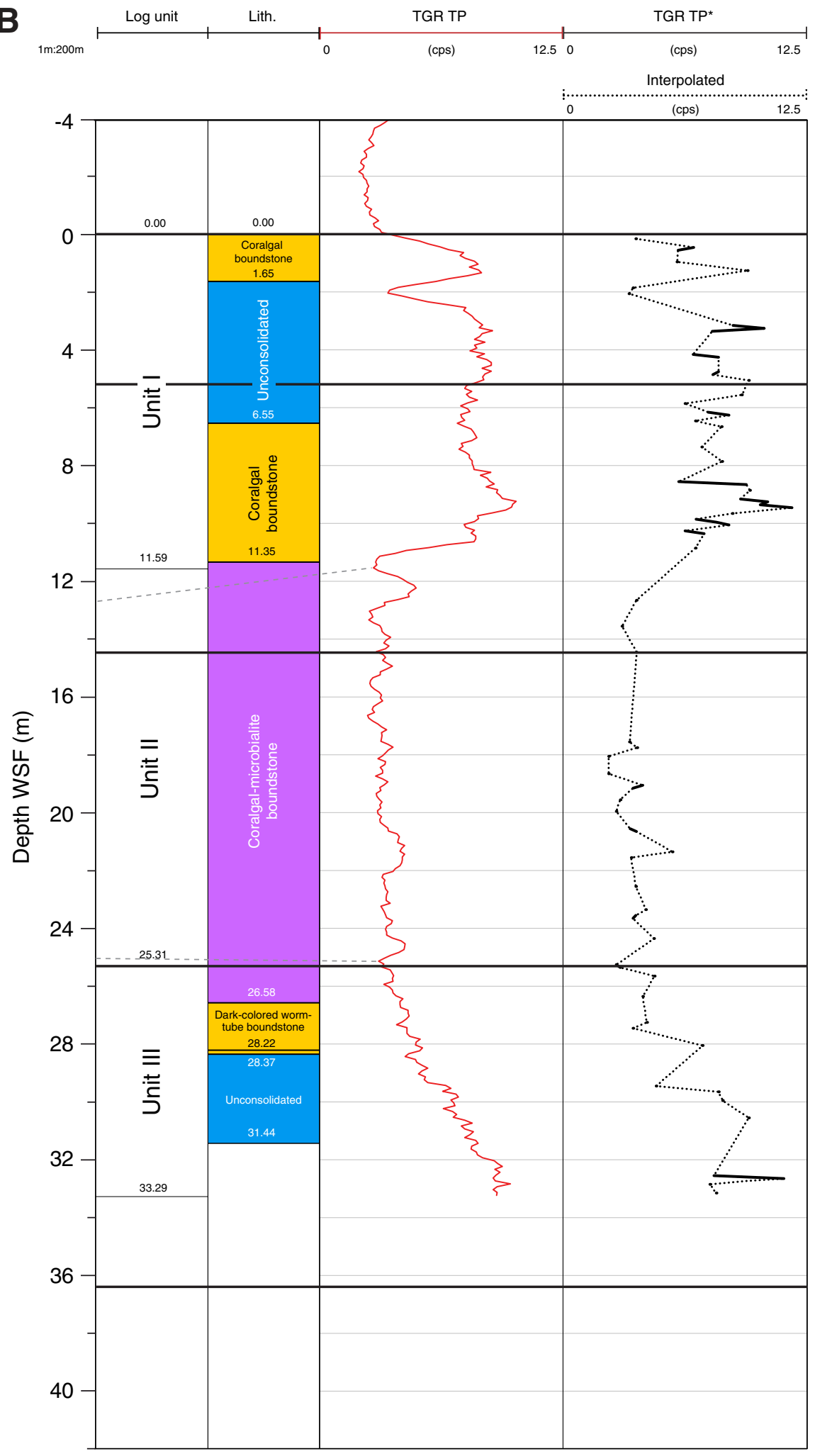
Table T1. Coring summary, transect HYD-01C. (See table note.) (Continued on next two pages.)

\begin{tabular}{|c|c|c|c|c|c|c|c|c|}
\hline \multirow[b]{2}{*}{ Core } & \multirow{2}{*}{$\begin{array}{l}\text { Date } \\
(2010)\end{array}$} & \multirow{2}{*}{$\begin{array}{l}\text { Time } \\
\text { (UTC) }\end{array}$} & \multicolumn{2}{|c|}{ Depth (mbsf) } & \multicolumn{2}{|c|}{ Length (m) } & \multirow{2}{*}{$\begin{array}{l}\text { Recovery } \\
\text { (\%) }\end{array}$} & \multirow[b]{2}{*}{ Comments } \\
\hline & & & Top & Bottom & Cored & Recovered & & \\
\hline \multicolumn{9}{|c|}{ 325-M0030A- } \\
\hline 1R & 13 Feb & 1000 & 0 & 3 & 3 & 0.06 & 2.00 & \\
\hline $2 X$ & 13 Feb & 1145 & 3 & 6 & 3 & 0.18 & 6.00 & $\begin{array}{l}\text { Shoe blocked with loose carbonate sand. Sample wire twisted on } \\
\text { this run-repairs necessitated pulling out of the seabed. }\end{array}$ \\
\hline \multicolumn{9}{|c|}{ 325-М0030B- } \\
\hline 1R & 13 Feb & 2245 & 0 & 3 & 3 & 0.19 & 6.33 & \\
\hline $2 \mathrm{R}$ & 13 Feb & 2340 & 3 & 6 & 3 & 0.18 & 6.00 & \\
\hline $3 R$ & 14 Feb & 600 & 6 & 9 & 3 & 0.18 & 6.00 & $\begin{array}{l}\text { Barrel stuck and winch cable snapped trying to recover it. Hole } \\
\text { aborted. }\end{array}$ \\
\hline \multicolumn{9}{|c|}{ 325-M0031A- } \\
\hline $1 \mathrm{R}$ & 14 Feb & 1825 & 0 & 3 & 3 & 0 & 0.00 & \\
\hline $2 \mathrm{R}$ & 14 Feb & 1945 & 3 & 6 & 3 & 0.42 & 14.00 & \\
\hline $3 R$ & 14 Feb & 2035 & 6 & 9 & 3 & 0.43 & 14.33 & \\
\hline $4 \mathrm{R}$ & 14 Feb & 2335 & 9 & 12 & 3 & 0.24 & 8.00 & \\
\hline $5 R$ & 15 Feb & 0130 & 12 & 12 & 0 & 0 & 0.00 & $\begin{array}{l}\text { High water pressure-flushing with mud. Hole collapsed as barrel } \\
\text { recovered_reaming and further flushing. }\end{array}$ \\
\hline $6 \mathrm{~W}$ & 15 Feb & 0330 & 8.6 & 12 & 3.4 & 0.16 & 4.71 & $\begin{array}{l}\text { Hole collapsed while sending barrel down-infill only drilled. When } \\
\text { recovered, inner barrel jammed in outer with sediments. }\end{array}$ \\
\hline $7 R$ & 15 Feb & 0830 & 12 & 15 & 3 & 0.24 & 8.00 & \\
\hline $8 \mathrm{R}$ & 15 Feb & 0930 & 15 & 18 & 3 & 0.55 & 18.33 & \\
\hline $9 \mathrm{R}$ & 15 Feb & 1200 & 18 & 20.5 & 2.5 & 0.17 & 6.80 & $\begin{array}{l}\text { Barrel stuck. Recover overshot, flush with mud, cut and reterminate } \\
\text { damaged wireline, and finally recover barrel. }\end{array}$ \\
\hline $10 R$ & 15 Feb & 1300 & 20.5 & 23.5 & 3 & 0.4 & 13.33 & Reaming before next run. \\
\hline $11 \mathrm{R}$ & 15 Feb & 1340 & 23.5 & 26.5 & 3 & 0.25 & 8.33 & \\
\hline $12 \mathrm{R}$ & 15 Feb & 1540 & 26.5 & 28 & 1.5 & 0.33 & 22.00 & $\begin{array}{l}\text { Running ALN with splits-string pressurizing immediately. Recover } \\
\text { barrel to adjust length of inner barrel. }\end{array}$ \\
\hline $13 \mathrm{R}$ & 15 Feb & 1830 & 28 & 31 & 3 & 1.56 & 52.00 & \\
\hline $14 \mathrm{R}$ & 15 Feb & 1930 & 31 & 34 & 3 & 0.19 & 6.33 & \\
\hline $15 R$ & 15 Feb & 2020 & 34 & 37 & 3 & 0.25 & 8.33 & $\begin{array}{l}\text { Reaming prior to adding another API pipe. Hole closed again, so } \\
\text { further reaming before coring commenced. }\end{array}$ \\
\hline $16 \mathrm{R}$ & 15 Feb & 2310 & 37 & 40 & 3 & 0.05 & 1.67 & \\
\hline $17 R$ & 16 Feb & 0150 & 40 & 43 & 3 & 0.44 & 14.67 & \\
\hline \multicolumn{9}{|c|}{ 325-M0032A- } \\
\hline $1 \mathrm{R}$ & 16 Feb & 1200 & 0 & 1.8 & 1.8 & 0.55 & 30.56 & $\begin{array}{l}\text { Using basket and metal splits. String overpressurizing and hole } \\
\text { caving. }\end{array}$ \\
\hline $2 \mathrm{R}$ & 16 Feb & 1330 & 1.8 & 4.8 & 3 & 0 & 0.00 & String overpressurizing — trip ALN to free it and flush. \\
\hline $3 R$ & 16 Feb & 1650 & 4.8 & 7.8 & 3 & 0.6 & 20.00 & \\
\hline $4 \mathrm{R}$ & 16 Feb & 1720 & 7.8 & 10.3 & 2.5 & 0.44 & 17.60 & Core barrel free-fell last $70 \mathrm{~cm}$-possible cavity? \\
\hline $5 R$ & 16 Feb & 1820 & 10.3 & 12.3 & 2 & 0.2 & 10.00 & Revert back to liner tube and core spring. \\
\hline $6 \mathrm{M}$ & 16 Feb & 1910 & 12.3 & 12.3 & 0 & 0 & 0.00 & \\
\hline $7 R$ & 16 Feb & 1935 & 12.3 & 14.3 & 2 & 0.45 & 22.50 & \\
\hline $8 \mathrm{R}$ & 16 Feb & 2030 & 14.3 & 16.3 & 2 & 0.75 & 37.50 & \\
\hline $9 \mathrm{R}$ & 16 Feb & 2135 & 16.3 & 17.5 & 1.2 & 0.25 & 20.83 & \\
\hline $10 \mathrm{R}$ & 16 Feb & 2300 & 17.5 & 17.8 & 0.3 & 0.46 & 153.33 & \\
\hline $11 \mathrm{R}$ & 17 Feb & 0015 & 17.8 & 19.8 & 2 & 0.54 & 27.00 & \\
\hline $12 \mathrm{R}$ & 17 Feb & 0100 & 19.8 & 21.8 & 2 & 0.16 & 8.00 & Bit heavily blocked with sediment. \\
\hline $13 R$ & 17 Feb & 0200 & 21.8 & 23.8 & 2 & 0.41 & 20.50 & \\
\hline $14 \mathrm{R}$ & 17 Feb & 0300 & 23.8 & 25.8 & 2 & 0.31 & 15.50 & \\
\hline $15 R$ & 17 Feb & 0335 & 25.8 & 26.8 & 1 & 0.23 & 23.00 & \\
\hline $16 \mathrm{R}$ & 17 Feb & 0530 & 26.8 & 28.8 & 2 & 0.27 & 13.50 & Switch back to splits as liners ovalized in the heat. \\
\hline $17 R$ & 17 Feb & 0645 & 28.8 & 30.8 & 2 & 0 & 0.00 & \\
\hline $18 \mathrm{R}$ & 17 Feb & 0730 & 30.8 & 32.8 & 2 & 0.16 & 8.00 & \\
\hline $19 \mathrm{R}$ & 17 Feb & 0835 & 32.8 & 34.8 & 2 & 0.21 & 10.50 & Switch back to core spring and liner. \\
\hline $20 \mathrm{R}$ & 17 Feb & 0950 & 34.8 & 36.7 & 1.9 & 0 & 0.00 & \\
\hline \multicolumn{9}{|c|}{ 325-M0033A- } \\
\hline $1 \mathrm{R}$ & 17 Feb & 1530 & 0 & 1.5 & 1.5 & 0.37 & 24.67 & Fluorescent microspheres. \\
\hline $2 \mathrm{R}$ & 17 Feb & 1610 & 1.5 & 3 & 1.5 & 0.43 & 28.67 & \\
\hline $3 R$ & 17 Feb & 1655 & 3 & 4.5 & 1.5 & 0.43 & 28.67 & \\
\hline $4 \mathrm{R}$ & 17 Feb & 1725 & 4.5 & 6 & 1.5 & 0.4 & 26.67 & \\
\hline $5 R$ & 17 Feb & 1810 & 6 & 7.5 & 1.5 & 1.43 & 95.33 & \\
\hline $6 \mathrm{R}$ & 17 Feb & 2050 & 7.5 & 8.3 & 0.8 & 0.32 & 40.00 & \\
\hline $7 R$ & 17 Feb & 2150 & 8.3 & 9.8 & 1.5 & 0.64 & 42.67 & \\
\hline $8 \mathrm{R}$ & 17 Feb & 2230 & 9.8 & 11.3 & 1.5 & 0.4 & 26.67 & \\
\hline $9 \mathrm{R}$ & 17 Feb & 2320 & 11.3 & 12.8 & 1.5 & 0.32 & 21.33 & \\
\hline $10 R$ & 18 Feb & 0000 & 12.8 & 14.3 & 1.5 & 0.68 & 45.33 & \\
\hline $11 R$ & 18 Feb & 0050 & 14.3 & 15.8 & 1.5 & 0.56 & 37.33 & \\
\hline $12 \mathrm{R}$ & 18 Feb & 0230 & 15.8 & 16.8 & 1 & 0.81 & 81.00 & Torn core liner. Bit showing signs of fragmenting. \\
\hline $13 R$ & $18 \mathrm{Feb}$ & 0330 & 16.8 & 18.3 & 1.5 & 0.83 & 55.33 & \\
\hline
\end{tabular}


Table T1 (continued). (Continued on next page.)

\begin{tabular}{|c|c|c|c|c|c|c|c|c|}
\hline \multirow[b]{2}{*}{ Core } & \multirow{2}{*}{$\begin{array}{l}\text { Date } \\
(2010)\end{array}$} & \multirow{2}{*}{$\begin{array}{l}\text { Time } \\
\text { (UTC) }\end{array}$} & \multicolumn{2}{|c|}{ Depth (mbsf) } & \multicolumn{2}{|c|}{ Length (m) } & \multirow{2}{*}{$\begin{array}{l}\text { Recovery } \\
\text { (\%) }\end{array}$} & \multirow[b]{2}{*}{ Comments } \\
\hline & & & Top & Bottom & Cored & Recovered & & \\
\hline $14 \mathrm{R}$ & 18 Feb & 0415 & 18.3 & 19.8 & 1.5 & 0.51 & 34.00 & \\
\hline $15 \mathrm{R}$ & 18 Feb & 0525 & 19.8 & 20.8 & 1 & 0.66 & 66.00 & \\
\hline $16 \mathrm{R}$ & 18 Feb & 0700 & 20.8 & 22.3 & 1.5 & 0.98 & 65.33 & Barrel stuck broken latch head dog on recovery. \\
\hline $17 \mathrm{R}$ & 18 Feb & 0800 & 22.3 & 22.3 & 0 & 0 & 0.00 & $\begin{array}{l}\text { Barrel recovered as water pressure excessively high. Liner found to } \\
\text { be crushed to half its original length. }\end{array}$ \\
\hline $18 \mathrm{R}$ & 18 Feb & 0900 & 22.3 & 23.8 & 1.5 & 0.55 & 36.67 & \\
\hline $19 \mathrm{R}$ & 18 Feb & 0945 & 23.8 & 25.3 & 1.5 & 0.39 & 26.00 & \\
\hline $20 \mathrm{R}$ & $18 \mathrm{Feb}$ & 1045 & 25.3 & 26.8 & 1.5 & 0.45 & 30.00 & \\
\hline $21 \mathrm{R}$ & 18 Feb & 1130 & 26.8 & 28.3 & 1.5 & 0.82 & 54.67 & \\
\hline $22 \mathrm{R}$ & 18 Feb & 1220 & 28.3 & 29.8 & 1.5 & 0.96 & 64.00 & \\
\hline $23 R$ & 18 Feb & 1335 & 29.8 & 32.8 & 3 & 0.47 & 15.67 & \\
\hline \multicolumn{9}{|c|}{ 325-M0034A- } \\
\hline $1 \mathrm{R}$ & 19 Feb & 0020 & 0 & 1.5 & 1.5 & 0.94 & 62.67 & Fluorescent microspheres. \\
\hline $2 \mathrm{R}$ & 19 Feb & 0110 & 1.5 & 3 & 1.5 & 0.57 & 38.00 & \\
\hline $3 R$ & 19 Feb & 0155 & 3 & 4.5 & 1.5 & 0 & 0.00 & \\
\hline $4 \mathrm{R}$ & 19 Feb & 0255 & 4.5 & 6 & 1.5 & 0.61 & 40.67 & \\
\hline $5 \mathrm{R}$ & 19 Feb & 0335 & 6 & 7.5 & 1.5 & 0 & 0.00 & \\
\hline $6 \mathrm{R}$ & 19 Feb & 0410 & 7.5 & 9 & 1.5 & 0 & 0.00 & $\begin{array}{l}\text { Reduce shoe to bit air gap to decrease mud flow and limit flushing } \\
\text { of unconsolidated material. }\end{array}$ \\
\hline $7 R$ & 19 Feb & 0520 & 9 & 11.1 & 2.1 & 0.26 & 12.38 & Running $\mathrm{HQ}$ pipe after this run. \\
\hline $8 \mathrm{R}$ & 19 Feb & 1150 & 11.1 & 12.6 & 1.5 & 0.54 & 36.00 & \\
\hline $9 \mathrm{R}$ & $19 \mathrm{Feb}$ & 1315 & 12.6 & 14.1 & 1.5 & 1.02 & 68.00 & \\
\hline $10 \mathrm{R}$ & 19 Feb & 1350 & 14.1 & 15.6 & 1.5 & 0.68 & 45.33 & \\
\hline $11 \mathrm{R}$ & 19 Feb & 1430 & 15.6 & 17.1 & 1.5 & 0.85 & 56.67 & \\
\hline $12 \mathrm{R}$ & 19 Feb & 1500 & 17.1 & 18.6 & 1.5 & 0.74 & 49.33 & Bit blocked. Flushed with mud to clear cuttings after freeing it. \\
\hline $13 R$ & $20 \mathrm{Feb}$ & 1010 & 18.6 & 20.1 & 1.5 & 0.18 & 12.00 & Running ALN instead of $\mathrm{HQ}$. \\
\hline $14 \mathrm{R}$ & 20 Feb & 1100 & 20.1 & 21.6 & 1.5 & 0.22 & 14.67 & \\
\hline $15 R$ & 20 Feb & 1145 & 21.6 & 23.1 & 1.5 & 0 & 0.00 & $\begin{array}{l}\text { Poor recovery-tripping barrel and putting on a new impregnated } \\
\text { bit. }\end{array}$ \\
\hline $16 W$ & 20 Feb & 1500 & 23.1 & 23.1 & 0 & 0.1 & 0.00 & Overpressurizing-recover barrel. \\
\hline \multicolumn{9}{|c|}{ 325-M0035A- } \\
\hline $1 \mathrm{R}$ & $27 \mathrm{Feb}$ & 1200 & 0 & 0.7 & 0.7 & 0.06 & 8.57 & Fluorescent microspheres. \\
\hline $2 \mathrm{R}$ & 27 Feb & 1250 & 0.7 & 2.2 & 1.5 & 0.02 & 1.33 & Hole collapsing after retrieving barrel. \\
\hline $3 R$ & 27 Feb & 1630 & 2.2 & 4.08 & 1.88 & 0.47 & 25.00 & \\
\hline $4 \mathrm{R}$ & 27 Feb & 1735 & 4.08 & 5.58 & 1.5 & 0.15 & 10.00 & $\begin{array}{l}\text { Bit blocked-pumping and reaming to free. Not successful so use } \\
\text { hammer sampler. }\end{array}$ \\
\hline $5 \mathrm{R}$ & 27 Feb & 2250 & 5.58 & 7.08 & 1.5 & 1.13 & 75.33 & \\
\hline $6 \mathrm{R}$ & 27 Feb & 2325 & 7.08 & 8.58 & 1.5 & 0.38 & 25.33 & Problem recovering inner barrel-broken dog on latch head. \\
\hline $7 R$ & $28 \mathrm{Feb}$ & 0550 & 8.58 & 10.08 & 1.5 & 0.42 & 28.00 & \\
\hline $8 \mathrm{R}$ & $28 \mathrm{Feb}$ & 0700 & 10.08 & 11.58 & 1.5 & 1.04 & 69.33 & \\
\hline $9 \mathrm{R}$ & 28 Feb & 0750 & 11.58 & 12.58 & 1 & 0.52 & 52.00 & \\
\hline $10 \mathrm{R}$ & $28 \mathrm{Feb}$ & 1100 & 12.58 & 14.08 & 1.5 & 0.92 & 61.33 & Possibly some infill at BHA. \\
\hline $11 \mathrm{R}$ & $28 \mathrm{Feb}$ & 1240 & 14.08 & 15.58 & 1.5 & 0.6 & 40.00 & \\
\hline $12 \mathrm{R}$ & $28 \mathrm{Feb}$ & 1410 & 15.58 & 16.48 & 0.9 & 0.8 & 88.89 & \\
\hline $13 R$ & $28 \mathrm{Feb}$ & 1520 & 16.48 & 17.88 & 1.4 & 0.75 & 53.57 & \\
\hline $14 \mathrm{R}$ & $28 \mathrm{Feb}$ & 1615 & 17.88 & 19.38 & 1.5 & 0.56 & 37.33 & \\
\hline $15 R$ & 28 Feb & 1815 & 19.38 & 20.88 & 1.5 & 0.51 & 34.00 & \\
\hline $16 \mathrm{R}$ & 28 Feb & 1935 & 20.88 & 22.38 & 1.5 & 0.42 & 28.00 & \\
\hline $17 \mathrm{R}$ & $28 \mathrm{Feb}$ & 2045 & 22.38 & 23.88 & 1.5 & 0.51 & 34.00 & \\
\hline $18 \mathrm{R}$ & 28 Feb & 2245 & 23.88 & 25.38 & 1.5 & 0.55 & 36.67 & \\
\hline $19 \mathrm{R}$ & $01 \mathrm{Mar}$ & 0100 & 25.38 & 26.16 & 0.78 & 0.76 & 97.44 & \\
\hline $20 \mathrm{R}$ & $1 \mathrm{Mar}$ & 0210 & 26.16 & 27.66 & 1.5 & 0.44 & 29.33 & $\begin{array}{l}\text { Broken dog on latch head. Pressure very high on next run attempt- } \\
\text { recover barrel without drilling. Inner and outer barrels jammed by } \\
\text { sand. }\end{array}$ \\
\hline $21 \mathrm{~W}$ & $1 \mathrm{Mar}$ & 0410 & 27.66 & 27.66 & 0 & 0.9 & 0.00 & \\
\hline $22 \mathrm{R}$ & $1 \mathrm{Mar}$ & 0625 & 27.66 & 28 & 0.34 & 0 & 0.00 & Hole collapsed after $0.5 \mathrm{~m}$-reaming with mud. \\
\hline $23 \mathrm{R}$ & 1 Mar & 0745 & 28 & 29.9 & 1.9 & 0.32 & 16.84 & \\
\hline \multicolumn{9}{|c|}{ 325-M0036A- } \\
\hline $1 \mathrm{R}$ & $1 \mathrm{Mar}$ & 1150 & 0 & 1.5 & 1.5 & 0 & 0.00 & Very quick penetration. \\
\hline $2 \mathrm{R}$ & $1 \mathrm{Mar}$ & 1250 & 1.5 & 3.5 & 2 & 0.15 & 7.50 & $\begin{array}{l}\text { Very quick penetration-recovery includes seabed fauna sample } \\
\text { suggesting string is "skipping" down a slope. }\end{array}$ \\
\hline $3 \mathrm{~W}$ & $1 \mathrm{Mar}$ & 1400 & 3.5 & 3.5 & 0 & 1.04 & 0.00 & \\
\hline $4 \mathrm{R}$ & $1 \mathrm{Mar}$ & 1440 & 3.5 & 5 & 1.5 & 1.83 & 122.00 & \\
\hline $5 \mathrm{R}$ & $1 \mathrm{Mar}$ & 1530 & 5 & 6.5 & 1.5 & 0.24 & 16.00 & \\
\hline $6 \mathrm{R}$ & $1 \mathrm{Mar}$ & 1600 & 6.5 & 8 & 1.5 & 0.05 & 3.33 & \\
\hline $7 R$ & $1 \mathrm{Mar}$ & 1650 & 8 & 9.5 & 1.5 & 0.08 & 5.33 & \\
\hline $8 \mathrm{R}$ & $1 \mathrm{Mar}$ & 1730 & 9.5 & 11 & 1.5 & 0.3 & 20.00 & \\
\hline $9 \mathrm{R}$ & $1 \mathrm{Mar}$ & 1830 & 11 & 12.5 & 1.5 & 0.35 & 23.33 & $\begin{array}{l}\text { Combination catcher/core lifter wrecked-possibly stopped core } \\
\text { recovery. Revert to core spring only. }\end{array}$ \\
\hline
\end{tabular}


Table T1 (continued).

\begin{tabular}{|c|c|c|c|c|c|c|c|c|}
\hline \multirow[b]{2}{*}{ Core } & \multirow{2}{*}{$\begin{array}{l}\text { Date } \\
(2010)\end{array}$} & \multirow{2}{*}{$\begin{array}{l}\text { Time } \\
\text { (UTC) }\end{array}$} & \multicolumn{2}{|c|}{ Depth (mbsf) } & \multicolumn{2}{|c|}{ Length (m) } & \multirow{2}{*}{$\begin{array}{l}\text { Recovery } \\
\text { (\%) }\end{array}$} & \multirow[b]{2}{*}{ Comments } \\
\hline & & & Top & Bottom & Cored & Recovered & & \\
\hline $10 \mathrm{R}$ & $1 \mathrm{Mar}$ & 1940 & 12.5 & 14 & 1.5 & 0.25 & 16.67 & \\
\hline $11 \mathrm{R}$ & $1 \mathrm{Mar}$ & 2020 & 14 & 15.5 & 1.5 & 0.82 & 54.67 & \\
\hline $12 \mathrm{R}$ & $1 \mathrm{Mar}$ & 2100 & 15.5 & 17 & 1.5 & 0.46 & 30.67 & \\
\hline $13 R$ & $1 \mathrm{Mar}$ & 2140 & 17 & 18.5 & 1.5 & 0.28 & 18.67 & \\
\hline $14 \mathrm{R}$ & $1 \mathrm{Mar}$ & 2230 & 18.5 & 20.5 & 2 & 0.54 & 27.00 & \\
\hline $15 \mathrm{R}$ & $1 \mathrm{Mar}$ & 2320 & 20.5 & 22 & 1.5 & 0.33 & 22.00 & \\
\hline $16 \mathrm{R}$ & $2 \mathrm{Mar}$ & 0000 & 22 & 23.5 & 1.5 & 0.3 & 20.00 & \\
\hline $17 \mathrm{R}$ & $2 \mathrm{Mar}$ & 0100 & 23.5 & 25 & 1.5 & 0.47 & 31.33 & \\
\hline $18 \mathrm{R}$ & $2 \mathrm{Mar}$ & 0135 & 25 & 26.5 & 1.5 & 0.28 & 18.67 & \\
\hline $19 \mathrm{R}$ & $2 \mathrm{Mar}$ & 0200 & 26.5 & 28 & 1.5 & 0.33 & 22.00 & \\
\hline $20 \mathrm{R}$ & $2 \mathrm{Mar}$ & 0240 & 28 & 29.5 & 1.5 & 0.37 & 24.67 & \\
\hline $21 \mathrm{R}$ & $2 \mathrm{Mar}$ & 0310 & 29.5 & 31 & 1.5 & 0.44 & 29.33 & Barrel downhole_-blocked with sand—use hammer sampler. \\
\hline $22 \mathrm{R}$ & $2 \mathrm{Mar}$ & 0600 & 31 & 34 & 3 & 0 & 0.00 & \\
\hline \multicolumn{9}{|c|}{ 325-M0037A- } \\
\hline $1 \mathrm{R}$ & 3 Mar & 1330 & 0 & 1.5 & 1.5 & 1.83 & 122.00 & Fluorescent microspheres. \\
\hline $2 \mathrm{R}$ & 3 Mar & 1420 & 1.5 & 3 & 1.5 & 0.25 & 16.67 & \\
\hline $3 R$ & 3 Mar & 1520 & 3 & 4.5 & 1.5 & 0 & 0.00 & $\begin{array}{l}\text { While tripping barrel, drill string sank by } 0.5 \mathrm{~m} \text {. On pulling back the } \\
\text { hole partially collapsed-three hammer runs required to clear it. }\end{array}$ \\
\hline $4 \mathrm{R}$ & $3 \mathrm{Mar}$ & 1630 & 4.5 & 6 & 1.5 & 0.1 & 6.67 & \\
\hline $5 \mathrm{R}$ & 3 Mar & 1715 & 6 & 7.5 & 1.5 & 0.26 & 17.33 & \\
\hline $6 \mathrm{R}$ & 3 Mar & 1750 & 7.5 & 9.5 & 2 & 0.34 & 17.00 & $\begin{array}{l}\text { Trap poly bag between the sleeve and basket to try to improve } \\
\text { recovery. }\end{array}$ \\
\hline $7 R$ & $3 \mathrm{Mar}$ & 1845 & 9.5 & 11 & 1.5 & 0.5 & 33.33 & $\begin{array}{l}\text { Trap poly bag between the sleeve and basket to try to improve } \\
\text { recovery. }\end{array}$ \\
\hline $8 \mathrm{R}$ & $3 \mathrm{Mar}$ & 1930 & 11 & 12.5 & 1.5 & 0.78 & 52.00 & $\begin{array}{l}\text { Trap poly bag between the sleeve and basket to try to improve } \\
\text { recovery. }\end{array}$ \\
\hline $9 \mathrm{R}$ & 3 Mar & 2030 & 12.5 & 14 & 1.5 & 0.72 & 48.00 & $\begin{array}{l}\text { Trap poly bag between the sleeve and basket to try to improve } \\
\text { recovery. }\end{array}$ \\
\hline $10 \mathrm{R}$ & $3 \mathrm{Mar}$ & 2120 & 14 & 15.5 & 1.5 & 1.55 & 103.33 & $\begin{array}{l}\text { Trap poly bag between the sleeve and basket to try to improve } \\
\text { recovery. }\end{array}$ \\
\hline $11 \mathrm{R}$ & $3 \mathrm{Mar}$ & 2210 & 15.5 & 17 & 1.5 & 0.43 & 28.67 & \\
\hline $12 \mathrm{R}$ & $3 \mathrm{Mar}$ & 2250 & 17 & 18 & 1 & 0.12 & 12.00 & $\begin{array}{l}\text { Trap poly bag between the sleeve and basket to try to improve } \\
\text { recovery. }\end{array}$ \\
\hline $13 R$ & $3 \mathrm{Mar}$ & 2345 & 18 & 19.5 & 1.5 & 0.51 & 34.00 & \\
\hline $14 \mathrm{R}$ & $4 \mathrm{Mar}$ & 0050 & 19.5 & 21 & 1.5 & 0.13 & 8.67 & \\
\hline \multicolumn{9}{|c|}{ 325-M0038A- } \\
\hline $1 \mathrm{R}$ & $4 \mathrm{Mar}$ & 1545 & 0 & 1.5 & 1.5 & 0.18 & 12.00 & $\begin{array}{l}\text { Fluorescent microspheres. Drill string fell quickly. On recovery bit } \\
\text { found to be destroyed. Decision to bump over } 2 \mathrm{~m} \text { to avoid } \\
\text { broken drill fragments. }\end{array}$ \\
\hline \multicolumn{9}{|c|}{ 325-M0039A- } \\
\hline $1 \mathrm{R}$ & $4 \mathrm{Mar}$ & 1700 & 0 & 1.5 & 1.5 & 0.65 & 43.33 & \\
\hline $2 \mathrm{R}$ & $4 \mathrm{Mar}$ & 1750 & 1.5 & 3 & 1.5 & 0.34 & 22.67 & \\
\hline $3 R$ & $4 \mathrm{Mar}$ & 1850 & 3 & 4.5 & 1.5 & 0.56 & 37.33 & \\
\hline $4 \mathrm{R}$ & $4 \mathrm{Mar}$ & 1940 & 4.5 & 6 & 1.5 & 0.62 & 41.33 & \\
\hline $5 \mathrm{R}$ & $4 \mathrm{Mar}$ & 2020 & 6 & 7.5 & 1.5 & 0.45 & 30.00 & \\
\hline $6 \mathrm{R}$ & $4 \mathrm{Mar}$ & 2110 & 7.5 & 9 & 1.5 & 0.46 & 30.67 & \\
\hline $7 R$ & $4 \mathrm{Mar}$ & 2150 & 9 & 10 & 1 & 0.57 & 57.00 & \\
\hline $8 \mathrm{R}$ & $4 \mathrm{Mar}$ & 2230 & 10 & 11.5 & 1.5 & 0.93 & 62.00 & \\
\hline $9 \mathrm{R}$ & $4 \mathrm{Mar}$ & 2340 & 11.5 & 13 & 1.5 & 0.66 & 44.00 & $\begin{array}{l}\text { After this run, next three attempts to core failed with no advance } \\
\text { made. High pressure caused recovery without drilling-latch head } \\
\text { assembly and inner barrel plunger blocked with sediment on all } \\
\text { occasions. }\end{array}$ \\
\hline $10 \mathrm{R}$ & $5 \mathrm{Mar}$ & 0400 & 13 & 14 & 1 & 0.99 & 99.00 & \\
\hline $11 \mathrm{R}$ & $5 \mathrm{Mar}$ & 0545 & 14 & 15.1 & 1.1 & 0.32 & 29.09 & Core lifter twisted out of shoe and into core causing blockage. \\
\hline $12 \mathrm{R}$ & 5 Mar & 0720 & 15.1 & 15.6 & 0.5 & 0.66 & 132.00 & \\
\hline $13 R$ & 5 Mar & 0810 & 15.6 & 17.1 & 1.5 & 0.29 & 19.33 & \\
\hline $14 \mathrm{R}$ & 5 Mar & 0845 & 17.1 & 18.6 & 1.5 & 0.73 & 48.67 & \\
\hline $15 R$ & 5 Mar & 0920 & 18.6 & 19.4 & 0.8 & 0.44 & 55.00 & \\
\hline $16 \mathrm{R}$ & 5 Mar & 1005 & 19.4 & 20.9 & 1.5 & 0.63 & 42.00 & \\
\hline $17 \mathrm{R}$ & 5 Mar & 1045 & 20.9 & 22.4 & 1.5 & 0.26 & 17.33 & Baked disk of core at leading edge of shoe. \\
\hline $18 \mathrm{R}$ & 5 Mar & 1125 & 22.4 & 23.9 & 1.5 & 0.08 & 5.33 & $\begin{array}{l}\text { Barrel was initially stuck for } 10 \mathrm{~min} \text {. On recovery, it is believed the } \\
\text { core slipped out. }\end{array}$ \\
\hline $19 \mathrm{R}$ & 5 Mar & 1240 & 23.9 & 25.4 & 1.5 & 0 & 0.00 & Bit blocked_-possibly due to slipped core from previous run. \\
\hline $20 \mathrm{R}$ & 5 Mar & 1320 & 25.4 & 26.9 & 1.5 & 0.38 & 25.33 & \\
\hline $21 \mathrm{R}$ & 5 Mar & 1355 & 26.9 & 28.4 & 1.5 & 0.37 & 24.67 & \\
\hline
\end{tabular}

Note: UTC $=$ Universal Time Coordinated, $\mathrm{ALN}=$ alien corer (standard rotary corer), API = American Petroleum Institute, $\mathrm{BHA}=$ bottom-hole assembly. 
Table T2. Physical properties summary, transect HYD-01C. (See table notes.)

\begin{tabular}{|c|c|c|c|c|c|c|c|c|c|c|c|c|c|c|}
\hline Hole & Value & $\begin{array}{l}P \text {-wave } \\
\text { MSCL } \\
(\mathrm{m} / \mathrm{s})\end{array}$ & $\begin{array}{c}P \text {-wave } \\
\text { saturated } \\
\text { discrete } \\
\text { samples } \\
(\mathrm{m} / \mathrm{s})\end{array}$ & $\begin{array}{c}\text { Magnetic } \\
\text { susceptibility } \\
\text { MSCL } \\
\left(\times 10^{-5} \mathrm{SI}\right)\end{array}$ & $\begin{array}{c}\text { Electrical } \\
\text { resistivity } \\
\operatorname{MSCL}(\Omega \mathrm{m})\end{array}$ & $\begin{array}{c}\text { Bulk } \\
\text { density } \\
\mathrm{MSCL} \\
\left(\mathrm{g} / \mathrm{cm}^{3}\right)\end{array}$ & $\begin{array}{c}\text { Bulk } \\
\text { density } \\
\text { discrete } \\
\text { samples } \\
\left(\mathrm{g} / \mathrm{cm}^{3}\right)\end{array}$ & $\begin{array}{l}\text { Porosity } \\
\text { (\%) }\end{array}$ & $\begin{array}{l}\text { Grain } \\
\text { density } \\
\left(\mathrm{g} / \mathrm{cm}^{3}\right)\end{array}$ & $\begin{array}{l}\text { Thermal } \\
\text { conductivity } \\
(\mathrm{W} /[\mathrm{m} \cdot \mathrm{K}])\end{array}$ & $L^{*}(D 65)$ & $a^{*}(D 65)$ & $b^{*}(D 65)$ & $a^{*} / b^{*}$ \\
\hline \multirow[t]{3}{*}{ M0030A } & Min & - & - & - & - & - & - & - & - & - & 54.71 & -0.79 & 10.2 & -0.05 \\
\hline & Max & - & - & - & - & - & - & - & - & - & 68.08 & 5.77 & 26.97 & 0.21 \\
\hline & Mean \pm SD & - & - & - & - & - & - & - & - & - & $62.71 \pm 4.80$ & $2.14 \pm 2.28$ & $18.52 \pm 5.32$ & $0.10 \pm 0.09$ \\
\hline \multirow[t]{3}{*}{ М0030B } & Min & 1607 & 2952 & -11.43 & 0.87 & 1.04 & 1.75 & 39 & 2.71 & - & - & - & - & - \\
\hline & Max & 1613 & 2952 & 2.90 & 18.71 & 1.89 & 2.06 & 57 & 2.72 & - & - & - & - & - \\
\hline & Mean \pm SD & $1611 \pm 3$ & - & $-3.50 \pm 5.40$ & $7.14 \pm 6.24$ & $1.51 \pm 0.28$ & $1.9 \pm 1.22$ & $48 \pm 13$ & $2.71 \pm 0.01$ & - & - & - & - & - \\
\hline \multirow[t]{3}{*}{ M0031A } & Min & 1675 & - & -1.28 & 0.74 & 1.03 & 1.79 & 23 & 2.73 & - & 30.81 & -2.37 & 1.74 & -1.36 \\
\hline & Max & 1736 & - & 49.67 & 37.51 & 2.37 & 2.40 & 55 & 2.83 & - & 82.37 & 7.52 & 22.61 & 0.33 \\
\hline & Mean \pm SD & $1700 \pm 27$ & - & $4.43 \pm 8.11$ & $4.78 \pm 8.07$ & $1.75 \pm 0.32$ & $2.17 \pm 0.15$ & $35 \pm 8$ & $2.77 \pm 0.03$ & - & $66.19 \pm 9.84$ & $1.47 \pm 1.47$ & $13.66 \pm 4.87$ & $0.07 \pm 0.19$ \\
\hline \multirow[t]{3}{*}{ M0032A } & Min & 1781 & 5037 & -1.90 & 0.59 & 1.04 & 2.04 & 20 & 2.74 & - & 45.03 & -0.52 & 4.1 & -0.06 \\
\hline & Max & 1938 & 5037 & 12.07 & 12.10 & 2.54 & 2.41 & 41 & 2.79 & - & 82.69 & 4.08 & 23.15 & 0.25 \\
\hline & Mean \pm SD & $1869 \pm 58$ & - & $-0.31 \pm 1.67$ & $2.99 \pm 2.53$ & $1.83 \pm 0.40$ & $2.18 \pm 0.11$ & $34 \pm 6$ & $2.76 \pm 0.01$ & - & $70.56 \pm 5.93$ & $1.78 \pm 0.70$ & $14.01 \pm 3.25$ & $0.10 \pm 0.04$ \\
\hline \multirow[t]{3}{*}{ M0033A } & Min & - & 3340 & -1.29 & 0.77 & 1.00 & 1.84 & 18 & 2.76 & - & 30.86 & -1.31 & 1.05 & -0.48 \\
\hline & Max & - & 4712 & 7.17 & 28.86 & 2.53 & 2.45 & 54 & 2.84 & - & 83.96 & 5.89 & 22.6 & 0.36 \\
\hline & Mean \pm SD & - & $3996 \pm 402$ & $-0.49 \pm 0.78$ & $4.84 \pm 4.79$ & $1.81 \pm 0.37$ & $2.2 \pm 0.15$ & $33 \pm 9$ & $2.78 \pm 0.02$ & - & $68.39 \pm 6.70$ & $0.98 \pm 0.84$ & $12.77 \pm 3.21$ & $0.07 \pm 0.07$ \\
\hline \multirow[t]{3}{*}{ M0034A } & Min & - & 3508 & -2.23 & 1.50 & 1.01 & 1.96 & 17 & 2.74 & - & 41.82 & -0.59 & 4.12 & -0.07 \\
\hline & Max & - & 4471 & 1.35 & 34.92 & 2.57 & 2.48 & 46 & 2.85 & - & 82.77 & 7.18 & 21.56 & 0.69 \\
\hline & Mean \pm SD & - & $3944 \pm 488$ & $-0.56 \pm 0.78$ & $10.32 \pm 7.97$ & $1.69 \pm 0.35$ & $2.29 \pm 0.17$ & $29 \pm 9$ & $2.80 \pm 0.33$ & - & $70.00 \pm 5.71$ & $0.88 \pm 1.02$ & $13.60 \pm 3.21$ & $0.06 \pm 0.07$ \\
\hline \multirow[t]{3}{*}{ M0035A } & Min & - & 3207 & -3.90 & 0.45 & 1.00 & 1.92 & 19 & 2.74 & - & 47.18 & -1.14 & 4.96 & -0.22 \\
\hline & Max & - & 4321 & 248.66 & 11.06 & 2.50 & 2.43 & 49 & 2.80 & - & 82.84 & 8.08 & 20.1 & 0.62 \\
\hline & Mean \pm SD & - & $3985 \pm 390$ & $3.64 \pm 19.81$ & $2.08 \pm 1.55$ & $1.87 \pm 0.36$ & $2.23 \pm 0.14$ & $31 \pm 8$ & $2.77 \pm 0.02$ & - & $68.06 \pm 6.43$ & $0.19 \pm 1.00$ & $11.79 \pm 2.98$ & $0.00 \pm 0.08$ \\
\hline \multirow[t]{3}{*}{ M0036A } & Min & 1556 & 3520 & -5.78 & 0.55 & 1.01 & 1.75 & 23 & 2.74 & 0.826 & 43.55 & -1.69 & 4.27 & -0.20 \\
\hline & Max & 1657 & 3919 & 8.09 & 26.54 & 2.28 & 2.37 & 58 & 2.82 & 0.826 & 84.54 & 4.78 & 22.93 & 0.22 \\
\hline & Mean \pm SD & $1600 \pm 27$ & $3736 \pm 176$ & $0.54 \pm 1.90$ & $3.97 \pm 5.17$ & $1.82 \pm 0.27$ & $2.13 \pm 0.17$ & $37 \pm 10$ & $2.78 \pm 0.02$ & - & $60.23 \pm 8.16$ & $0.54 \pm 1.05$ & $12.88 \pm 3.73$ & $0.03 \pm 0.08$ \\
\hline \multirow[t]{3}{*}{ M0037A } & Min & 1500 & - & -1.31 & 0.65 & 1.17 & 1.94 & 23 & 2.73 & - & 35.12 & -1.11 & 1.97 & -0.15 \\
\hline & $\operatorname{Max}$ & 1872 & - & 55.97 & 2.54 & 2.54 & 2.40 & 48 & 2.81 & - & 73.35 & 3.31 & 17.69 & 0.29 \\
\hline & Mean $\pm S D$ & $1679 \pm 60$ & - & $2.48 \pm 9.20$ & $1.11 \pm 0.32$ & $2.10 \pm 0.18$ & $2.09 \pm 0.15$ & $39 \pm 8$ & $2.78 \pm 0.03$ & - & $59.32 \pm 6.72$ & $0.18 \pm 0.87$ & $10.18 \pm 2.56$ & $0.01 \pm 0.08$ \\
\hline \multirow[t]{3}{*}{ M0038A } & Min & - & - & - & - & - & 2.33 & 24 & 2.75 & - & 72 & 1.45 & 17.48 & 0.08 \\
\hline & $\operatorname{Max}$ & - & - & - & - & - & 2.33 & 24 & 2.75 & - & 74.69 & 2.69 & 21.53 & 0.13 \\
\hline & Mean \pm SD & - & - & - & - & - & - & - & - & - & $73.08 \pm 1.42$ & $2.20 \pm 0.66$ & $19.48 \pm 2.03$ & $0.11 \pm 0.02$ \\
\hline \multirow[t]{3}{*}{ M0039A } & Min & 1636 & 3131 & -4.13 & 0.59 & 1.02 & 2.02 & 20 & 2.75 & - & 51.59 & -1.21 & 4.27 & -0.15 \\
\hline & $\operatorname{Max}$ & 1636 & 4701 & 9.79 & 12.97 & 2.45 & 2.39 & 43 & 2.81 & - & 84.24 & 9.43 & 30.28 & 0.42 \\
\hline & Mean \pm SD & - & $3916 \pm 1110$ & $-0.28 \pm 1.77$ & $2.28 \pm 1.77$ & $1.95 \pm 0.28$ & $2.21 \pm 0.13$ & $32 \pm 8$ & $2.77 \pm 0.02$ & - & $69.20 \pm 6.28$ & $0.55 \pm 1.12$ & $12.74 \pm 2.78$ & $0.03 \pm 0.07$ \\
\hline
\end{tabular}

Notes: $\mathrm{MSCL}=$ multisensor core logger. $\mathrm{SD}=$ standard deviation. $-=$ no measurement taken. 
Table T3. Magnetic susceptibility record, Holes M0030A and M0030B. (See table note.)

\begin{tabular}{lllc}
\hline $\begin{array}{c}\text { Core, section, } \\
\text { interval }(\mathrm{cm})\end{array}$ & $\begin{array}{c}\text { Depth } \\
\text { DSF-A } \\
(\mathrm{m})\end{array}$ & $\begin{array}{c}\text { Depth } \\
(\mathrm{mbsl})\end{array}$ & $\begin{array}{c}\text { Susc-box and holder } \\
\left(10^{-8} \mathrm{~m}^{3} / \mathrm{kg}\right)\end{array}$ \\
\hline $\begin{array}{l}\text { 325-M0030B- } \\
\text { 1R-1, 2.5 }\end{array}$ & 0.025 & 85.025 & 1.72 \\
2R-1, 16 & 3.16 & 88.16 & 0.59 \\
3R-1, 8 & 6.08 & 91.08 & 0.23 \\
325-M0030A- & & & \\
2X-1, 4 & 3.04 & 86.51 & -0.63 \\
2X-1, 3 & 3.03 & 86.5 & 0.52 \\
\hline
\end{tabular}

Note: Susc-box refers to the magnetic susceptibility measured minus the magnetic susceptibility of the box the sample was measured in.

Table T4. Larger foraminifera observed in cores from transect HYD-01C. (See table note.)

\begin{tabular}{|c|c|c|c|c|c|c|c|c|c|c|c|c|c|c|c|c|c|c|c|c|}
\hline $\begin{array}{l}\text { Core, section, } \\
\text { interval }(\mathrm{cm})\end{array}$ & 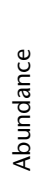 & 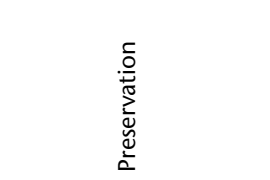 & 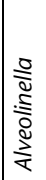 & 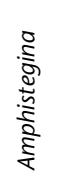 & 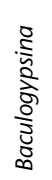 & 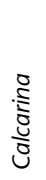 & 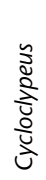 & 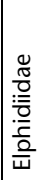 & 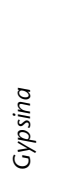 & 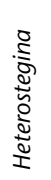 & $\begin{array}{l}\text { ڤे } \\
\text { हેँ } \\
\text { ذे } \\
\text { हे } \\
\text { के }\end{array}$ & 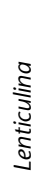 & 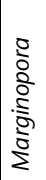 & 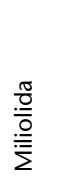 & 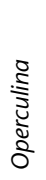 & 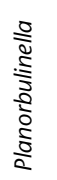 & $\begin{array}{l}\frac{\pi}{0} \\
\frac{\overline{0}}{\sqrt{0}} \\
\stackrel{0}{0} \\
\propto\end{array}$ & 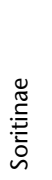 & 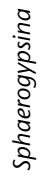 & 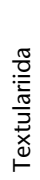 \\
\hline \multicolumn{21}{|l|}{$325-$} \\
\hline M0030A-2X-CC, $0-5$ & A & Good & & & & & $x$ & & & & & & & & $x$ & & & & & \\
\hline M0030B-1R-1, 9-14 & A & Good & & & & & $x$ & $x$ & & & & & & & $x$ & & & & $x$ & \\
\hline M0030B-3R-1, 1-5 & A & Fragmented & & & & & $x$ & & & & & & & & $x$ & & & & & \\
\hline M0031A-4R-1, 5-10 & $\mathrm{R}$ & & $x$ & $x$ & & & & & & & & & & & & & & & & \\
\hline M0031A-13R-1, 45-50 & $\mathrm{R}$ & Good & & $x$ & $x$ & & & & & & & & $x$ & & & & & & & \\
\hline M0031A-13R-1, 115-120 & C & Good & $x$ & $x$ & $x$ & & & & & & & & & & & $x$ & & & $x$ & \\
\hline M0031A-17R-1, 0-5 & & Stained & & & & & & & & & & & & & & & $x$ & & & \\
\hline M0032A-3R-1, 3-8 & $\mathrm{Ab}$ & & & & & & & & & & & & & & & & & & & \\
\hline M0032A-16R-1, 0-5 & C & & & & $x$ & $x$ & & & $x$ & & & & & & & & & & $x$ & \\
\hline M0032A-18R-CC, 0-5 & A & Good & & $x$ & & & & & & & & & & & & & & & & \\
\hline M0032A-19R-1, 12-17 & $\mathrm{R}$ & & & $x$ & & & & & & & & & & & & & & & & \\
\hline M0033A-3R-1, 11-16 & $\mathrm{R}$ & Good & & $x$ & & & & & & & & & & & $x$ & & & & & \\
\hline M0033A-20R-1, 10-15 & $\mathrm{Ab}$ & & & & & & & & & & & & & & & & & & & \\
\hline M0033A-21R-1, 40-45 & $\mathrm{Ab}$ & & & & & & & & & & & & & & & & & & & \\
\hline M0033A-22R-1, 40-45 & C & & $x$ & $x$ & & & & & & & & & & & & & & $x$ & & \\
\hline M0034A-1R-1, 6-11 & C & Good & & $x$ & & & & & & $x$ & $x$ & & & & $x$ & & & & & \\
\hline M0034A-16W-CC, 0-5 & $\mathrm{R}$ & Moderate/fragmented & & & & & & & & $x$ & & & & & & & & & & \\
\hline M0035A-1R-1, 0-5 & A & Stained & $x$ & $x$ & & & $x$ & $x$ & & $x$ & & $x$ & & & & & & & & \\
\hline M0035A-1R-1, 20-25 & $\mathrm{R}$ & Moderate/fragmented & & $x$ & & & & & & & & & & & $x$ & & & & & \\
\hline M0035A-5R-1, 25-30 & $\mathrm{R}$ & Moderate/fragmented & & $x$ & & & & & & $x$ & & & & & & & & & $x$ & \\
\hline M0035A-12R-1, 20-25 & $\mathrm{R}$ & Stained & & $x$ & & & & $x$ & & $x$ & & & & & & & & & & \\
\hline M0035A-13R-1, 20-25 & $\mathrm{R}$ & Moderate/fragmented & & $x$ & & & & $x$ & $x$ & & & & & & & & & & & \\
\hline M0035A-21W-1, 40-45 & A & Good & $x$ & & & & $x$ & & & & $x$ & & & & $x$ & & & & $x$ & $x$ \\
\hline M0035A-23R-CC, 4-8 & $A b$ & & & & & & & & & & & & & & & & & & & \\
\hline M0036A-3W-1, 30-35 & A & Good & $x$ & $x$ & & & $x$ & & & & $x$ & $x$ & & & $x$ & & & & & \\
\hline M0036A-4R-1, 50-55 & A & Good & $x$ & $x$ & & & $x$ & & & & $x$ & $x$ & & & $x$ & & & & & \\
\hline M0036A-4R-1, 140-145 & A & Good & & $x$ & & & $x$ & & & & $x$ & & & & $x$ & & & & & $x$ \\
\hline M0036A-21R-1, 0-5 & C & Good & $x$ & $x$ & & & & $x$ & & & & & & & $x$ & & & & & \\
\hline M0036A-21R-1, 20-25 & C & Moderate/fragmented & & & & & & $x$ & $x$ & & & & & & $x$ & & & & & \\
\hline M0036A-21R-CC, 0-5 & $\mathrm{R}$ & Moderate/fragmented & & $x$ & & & & & & & & & & & $x$ & & & & & \\
\hline M0037A-1R-1, 70-75 & C & Moderate/fragmented & $x$ & $x$ & & & & $x$ & & $x$ & & & & & $x$ & & & $x$ & & \\
\hline M0037A-1R-2, 10-15 & C & Good & $x$ & $x$ & & & & $x$ & & & & & & & & & & $x$ & & \\
\hline M0037A-9R-1, 30-35 & $\mathrm{C}$ & Moderate/fragmented & $x$ & $x$ & $x$ & & & & & & & & & & $x$ & & & & & \\
\hline M0037A-10R-1, 70-75 & C & Good to moderate & $x$ & $x$ & & & & $x$ & & & & & & $x$ & $x$ & & & & & \\
\hline M0037A-13R-1, 25-30 & $\mathrm{R}$ & Moderate & $x$ & & & & & $x$ & & & & & & & $x$ & & & & & \\
\hline M0039A-1R-1, 5-10 & $\mathrm{R}$ & & & & & & & & & & & & & & & & & & & $x$ \\
\hline M0039A-12R-CC, 5-10 & $\mathrm{R}$ & & & & & & & & & & $x$ & & & & & & & & & \\
\hline M0039A-21R-1, 15-20 & C & Good to bad (abraded) & & $x$ & $x$ & $x$ & & & & & & & $x$ & $x$ & & & & & & \\
\hline
\end{tabular}

Note: Abundance: $\mathrm{A}=$ abundant $\mathrm{C}=$ common, $\mathrm{R}=$ rare, $\mathrm{Ab}=$ absent. 
Table T5. Geochemical data relating to the interstitial water collected from transect HYD-01C.

\begin{tabular}{|c|c|c|c|c|c|c|c|c|c|c|c|c|c|c|c|c|c|c|c|}
\hline $\begin{array}{l}\text { Core, section, } \\
\text { interval (cm) }\end{array}$ & $\begin{array}{l}\text { Depth } \\
\text { (mbsf) }\end{array}$ & $\begin{array}{l}\text { Sample } \\
\text { ID }\end{array}$ & $\mathrm{pH}$ & $\begin{array}{l}\text { Alk } \\
(\mathrm{mM})\end{array}$ & $\begin{array}{l}\mathrm{NH}_{4} \\
(\mu \mathrm{M})\end{array}$ & $\begin{array}{c}\mathrm{Ca} \\
(\mathrm{mM})\end{array}$ & $\begin{array}{c}\mathrm{Si} \\
(\mu \mathrm{M})\end{array}$ & $\begin{array}{c}\mathrm{Sr} \\
(\mu \mathrm{M})\end{array}$ & $\begin{array}{c}\mathrm{Mg} \\
(\mathrm{mM})\end{array}$ & $\begin{array}{c}B \\
(\mu M)\end{array}$ & $\underset{(\mathrm{mM})}{\mathrm{K}}$ & $\stackrel{\mathrm{S}}{(\mathrm{mM})}$ & $\begin{array}{c}\mathrm{Na} \\
(\mathrm{mM})\end{array}$ & $\begin{array}{c}\mathrm{Ba} \\
(\mathrm{nM})\end{array}$ & $\begin{array}{c}\mathrm{Li} \\
(\mu \mathrm{M})\end{array}$ & $\begin{array}{c}\mathrm{Al} \\
(\mu \mathrm{M})\end{array}$ & $\begin{array}{c}\text { As } \\
(\mathrm{nM})\end{array}$ & $\begin{array}{c}\mathrm{Be} \\
(\mathrm{nM})\end{array}$ & $\begin{array}{c}\mathrm{Cd} \\
(\mathrm{nM})\end{array}$ \\
\hline \multicolumn{20}{|l|}{$325-$} \\
\hline M0031A-10R-1, 15 & 20.65 & S1 & 7.66 & 6.58 & 114 & 11.3 & 73.2 & 90.6 & 49.7 & 444 & 9.61 & 26.3 & 437 & 132 & 24.5 & 46.2 & 0 & 191 & 25 \\
\hline M0033A-21R-1, 38 & 27.18 & S3 & 7.63 & 3.17 & 30 & 9.8 & 60.4 & 91.9 & 51.7 & 454 & 10.06 & 27.1 & 464 & 71 & 27.7 & 55.4 & 350 & 106 & 0 \\
\hline M0033A-22R-1, 42 & 28.72 & S4 & 7.54 & 2.67 & 13 & 10.5 & 46.4 & 100.6 & 53.3 & 436 & 10.24 & 29.0 & 478 & 93 & 24.2 & 48.4 & 349 & 119 & 0 \\
\hline M0035A-13R-1, 30 & 16.78 & S6 & 7.65 & 4.67 & 28 & & & & & & & & & & & & & & \\
\hline M0036A-4R-1, 76 & 4.26 & S7 & 7.44 & 7.47 & 5 & & & & & & & & & & & & & & \\
\hline M0036A-14R-1, 25 & 18.75 & 58 & 7.60 & 5.99 & 0 & 10.5 & 66.2 & 94.6 & 47.0 & 400 & 9.14 & 25.1 & 436 & 102 & 21.3 & 59.4 & 0 & 125 & 0 \\
\hline M0036A-21R-2, 6 & 29.90 & s9 & 7.89 & 5.48 & 705 & 9.0 & 155.3 & 136.7 & 48.1 & 595 & 9.86 & 24.9 & 452 & 107 & 39.8 & 50.6 & 237 & 102 & 0 \\
\hline M0037A-1R-1, 30 & 0.30 & S10 & 7.61 & 2.33 & 8 & 10.2 & 55.7 & 89.7 & 52.8 & 427 & 10.37 & 28.6 & 476 & 64 & 25.2 & 46.3 & 0 & 84 & 0 \\
\hline M0037A-1R-2, 15 & 1.65 & S11 & 7.77 & 2.30 & 10 & 10.0 & 48.6 & 87.9 & 52.8 & 420 & 10.95 & 28.7 & 472 & 49 & 27.0 & 41.0 & 133 & 144 & 0 \\
\hline M0037A-7R-1, 8 & 9.58 & 12 & 7.59 & 3.11 & 40 & & & & & & & & & & & & & & \\
\hline M0037A-9R-1, 30 & 12.80 & S13 & 7.68 & 3.43 & 38 & 10.3 & 67.4 & 102.7 & 52.5 & 443 & 10.19 & 27.8 & 454 & 57 & 26.6 & 40.5 & 99 & 101 & 0 \\
\hline M0037A-10R-1, 126 & 15.26 & S14 & 7.66 & 3.09 & 63 & 10.3 & 85.8 & 118.0 & 53.0 & 449 & 10.19 & 28.6 & 470 & 76 & 27.2 & 46.8 & 0 & 131 & 1 \\
\hline M0037A-13R-1, 27 & 18.27 & S15 & 7.66 & 3.02 & 112 & 10.4 & 102.6 & 133.1 & 53.0 & 447 & 10.21 & 28.7 & 460 & 69 & 27.5 & 45.6 & 385 & 125 & 4 \\
\hline M0039A-5R-1, 28 & 6.28 & S16 & 7.72 & 3.76 & 17 & 9.1 & 53.3 & 72.2 & 50.3 & 409 & 9.67 & 26.0 & 404 & 92 & 26.4 & 46.9 & 0 & 98 & 0 \\
\hline M0039A-20R-1, 19 & 25.59 & S17 & 7.54 & 5.25 & 17 & 10.0 & 43.7 & 76.6 & 44.3 & 355 & 8.65 & 23.6 & 382 & 113 & 21.8 & 36.0 & 350 & 111 & 0 \\
\hline M0039A-21R-1, 18 & 27.08 & S18 & 7.66 & 3.34 & 14 & 10.5 & 52.5 & 96.3 & 52.9 & 437 & 10.26 & 28.5 & 447 & 100 & 24.2 & 45.8 & 51 & 74 & 0 \\
\hline
\end{tabular}

\begin{tabular}{|c|c|c|c|c|c|c|c|c|c|c|c|c|c|c|c|c|c|c|}
\hline $\begin{array}{l}\text { Core, section, } \\
\text { interval }(\mathrm{cm})\end{array}$ & $\begin{array}{l}\text { Depth } \\
\text { (mbsf) }\end{array}$ & $\begin{array}{c}\text { Sample } \\
\text { ID }\end{array}$ & $\begin{array}{l}\text { Co } \\
(n M)\end{array}$ & $\begin{array}{c}\mathrm{Cr} \\
(\mathrm{nM})\end{array}$ & $\begin{array}{c}\mathrm{Cu} \\
(\mathrm{nM})\end{array}$ & $\begin{array}{c}\mathrm{Fe} \\
(\mu \mathrm{M})\end{array}$ & $\begin{array}{c}\mathrm{Mn} \\
(\mu \mathrm{M})\end{array}$ & $\begin{array}{l}\text { Mo } \\
(n M)\end{array}$ & $\begin{array}{c}\mathrm{Ni} \\
(\mathrm{nM})\end{array}$ & $\begin{array}{c}\mathrm{P} \\
(\mu \mathrm{M})\end{array}$ & $\begin{array}{c}\mathrm{Pb} \\
(\mathrm{nM})\end{array}$ & $\begin{array}{c}\mathrm{Ti} \\
(\mathrm{nM})\end{array}$ & $\begin{array}{c}V \\
(n M)\end{array}$ & $\begin{array}{c}\mathrm{Zn} \\
(\mu \mathrm{M})\end{array}$ & $\begin{array}{c}\mathrm{Zr} \\
(\mathrm{nM})\end{array}$ & $\underset{(\mathrm{mM})}{\mathrm{Cl}}$ & $\begin{array}{c}\mathrm{Br} \\
(\mu \mathrm{M})\end{array}$ & $\begin{array}{l}\mathrm{SO}_{4} \\
(\mathrm{mM})\end{array}$ \\
\hline \multicolumn{19}{|l|}{ 325- } \\
\hline M0031A-10R-1, 15 & 20.65 & S1 & 41 & 32 & 0 & 13.13 & 1.45 & 143 & 443 & 2.97 & 23 & 0 & 210 & 5.60 & 716 & 517 & 802 & 26.9 \\
\hline M0033A-21R-1, 38 & 27.18 & S3 & 0 & 0 & 0 & 1.59 & 0.02 & 0 & 30 & 4.71 & 0 & 0 & 137 & 3.97 & 432 & 557 & 855 & 28.1 \\
\hline M0033A-22R-1, 42 & 28.72 & S4 & 0 & 0 & 0 & 0.93 & 0.00 & 0 & 0 & 2.06 & 0 & 0 & 267 & 3.80 & 343 & 567 & 879 & 29.5 \\
\hline M0035A-13R-1, 30 & 16.78 & S6 & & & & & & & & & & & & & & & & \\
\hline M0036A-4R-1, 76 & 4.26 & S7 & & & & & & & & & & & & & & & & \\
\hline M0036A-14R-1, 25 & 18.75 & 58 & 27 & 0 & 0 & 3.68 & 0.13 & 0 & 45 & 13.97 & 42 & 0 & 123 & 4.12 & 202 & 544 & 845 & 28.3 \\
\hline M0036A-21R-2, 6 & 29.90 & S9 & 0 & 58 & 86 & 0.96 & 0.06 & 0 & 45 & 3.48 & 0 & 0 & 198 & 3.74 & 323 & 554 & 861 & 25.6 \\
\hline M0037A-1R-1, 30 & 0.30 & S10 & 49 & 0 & 0 & 7.95 & 0.36 & 0 & 0 & 1.11 & 0 & 0 & 0 & 3.55 & 245 & 569 & 889 & 29.8 \\
\hline M0037A-1R-2, 15 & 1.65 & S11 & 0 & 0 & 0 & 1.03 & 0.52 & 0 & 61 & 1.89 & 8 & 0 & 140 & 3.58 & 254 & 562 & 878 & 29.4 \\
\hline M0037A-7R-1, 8 & 9.58 & 12 & & & & & & & & & & & & & & & & \\
\hline M0037A-9R-1, 30 & 12.80 & S13 & 0 & 0 & 0 & 1.38 & 0.01 & 0 & 0 & 1.82 & 0 & 0 & 487 & 4.17 & 297 & 553 & 862 & 28.6 \\
\hline M0037A-10R-1, 126 & 15.26 & S14 & 0 & 0 & 0 & 1.10 & 0.01 & 0 & 32 & 2.64 & 0 & 3 & 97 & 4.51 & 282 & 570 & 888 & 29.4 \\
\hline M0037A-13R-1, 27 & 18.27 & S15 & 0 & 0 & 0 & 1.33 & 0.01 & 0 & 0 & 2.05 & 14 & 0 & 408 & 3.67 & 328 & 569 & 892 & 29.6 \\
\hline M0039A-5R-1, 28 & 6.28 & S16 & 37 & 0 & 276 & 0.97 & 0.10 & 0 & 66 & 5.48 & 0 & 0 & 378 & 4.05 & 394 & 518 & 804 & 26.7 \\
\hline M0039A-20R-1, 19 & 25.59 & S17 & 0 & 0 & 206 & 1.31 & 0.45 & 1776 & 133 & 12.32 & 0 & 99 & 128 & 4.14 & 287 & & & \\
\hline M0039A-21R-1, 18 & 27.08 & S18 & 0 & 0 & 0 & 0.88 & 0.04 & 492 & 1 & 3.09 & 0 & 0 & 370 & 3.69 & 291 & 547 & 853 & 28.8 \\
\hline
\end{tabular}

